\title{
Hydroacoustic Evaluation of Fish Passage through Bonneville Dam in 2002
}

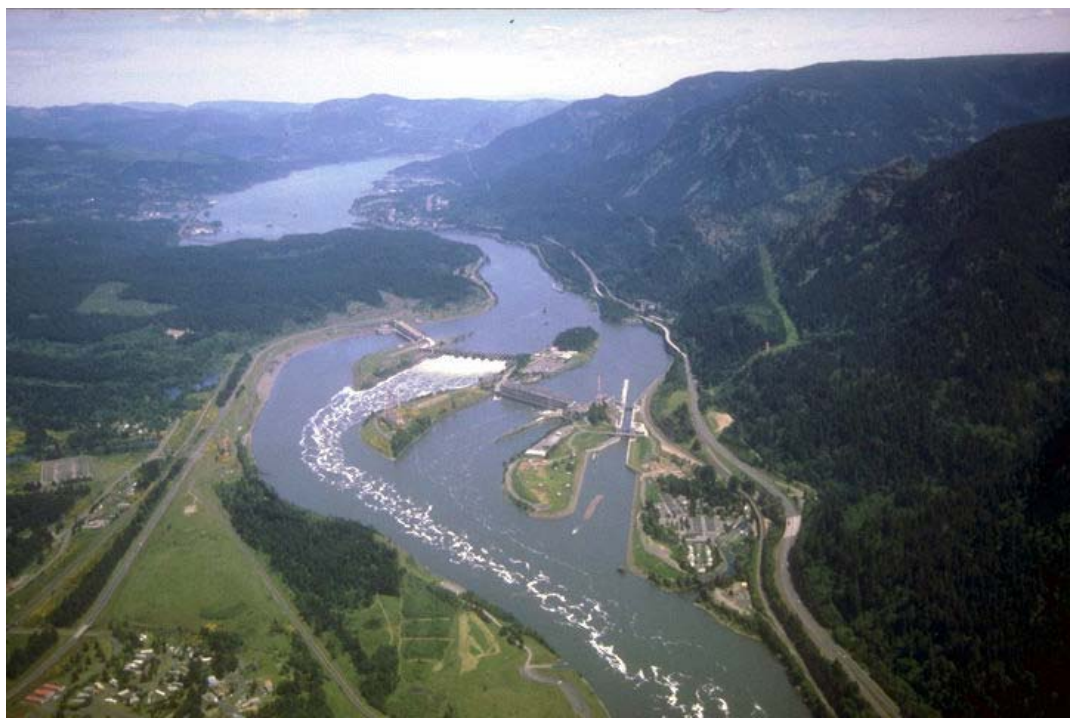
G Ploskey
C. Schilt
J. Kim
C. Escher
J. Skalski

FINAL REPORT

August 2003

Prepared for the

U.S. Army Corps of Engineers

Under a Related Services Agreement

With the U.S. Department of Energy

Contract DE-AC06-76RLO1830

\section{Pacific Northwest National Laboratory}

Operated by Battelle for the U.S. Department of Energy 


\title{
DISCLAIMER
}

This report was prepared as an account of work sponsored by an agency of the United States Government. Neither the United States Government nor any agency thereof, nor Battelle Memorial Institute, nor any of their employees, makes any warranty, express or implied, or assumes any legal liability or responsibility for the accuracy, completeness, or usefulness of any information, apparatus, product, or process disclosed, or represents that its use would not infringe privately owned rights. Reference herein to any specific commercial product, process, or service by trade name, trademark, manufacturer, or otherwise does not necessarily constitute or imply its endorsement, recommendation, or favoring by the United States Government or any agency thereof, or Battelle Memorial Institute. The views and opinions of authors expressed herein do not necessarily state or reflect those of the United States Government or any agency thereof.

\author{
PACIFIC NORTHWEST NATIONAL LABORATORY \\ operated by \\ BATTELLE \\ for the
}

\author{
UNITED STATES DEPARTMENT OF ENERGY \\ under Contract: DE-AC06-76RLO1830 \\ Printed in the United States of America \\ Available to DOE and DOE contractors from the \\ Office of Scientific and Technical Information, \\ P.O. Box 62, Oak Ridge, TN 37831-0062; \\ ph: (865) 576-8401 \\ fax: (865) 576-5728 \\ email: reports@adonis.osti.gov
}

Available to the public from the National Technical Information Service,

U.S. Department of Commerce, 5285 Port Royal Rd., Springfield, VA 22161

ph: (800) 553-6847

fax: (703) 605-6900

email: orders@ntis.fedworld.gov

online ordering: http://www.ntis.gov/ordering.htm 


\title{
Hydroacoustic Evaluation of Fish Passage through Bonneville Dam in 2002
}

\author{
G. R. Ploskey \\ C. R. Schilt ${ }^{(\mathrm{a})}$ \\ J. $\operatorname{Kim}^{(a)}$ \\ C.W. Escher ${ }^{(a)}$ \\ J. R. Skalski ${ }^{(b)}$
}

FINAL REPORT

August 2003

Prepared for

the U.S. Army Corps of Engineers

Portland District, Portland, Oregon

Under a Related Services Agreement

With the U.S. Department of Energy

under Contract DE-AC06 76RLO1830

CENWP MIPR No. W66QKZ20303607

Pacific Northwest National Laboratory

P.O. Box 999

Richland, Washington 99352

(a) Mevatec, Inc. North Bonneville, Washington

(b) School of Aquatic and Fishery Sciences, University of Washington, Seattle, Washington. 


\section{Abstract}

The Portland District of the U.S. Army Corps of Engineers (COE) requested that the Pacific Northwest National Laboratory (PNNL) and the U.S. Army Engineer Research and Development Center (ERDC) conduct fish-passage studies at Bonneville Dam in 2002. The ERDC contracted with MEVATEC Corporation to provide staff ranging from scientists to technicians to help conduct the study. This study supports the Portland District's goal of maximizing fish-passage efficiency (FPE) and obtaining 95\% survival for juvenile salmon passing Bonneville Dam, which has 10 turbines and a sluiceway at Powerhouse 1 (B1), an 18-bay spillway, and eight turbines at Powerhouse 2 (B2).

In this report, we present results of two studies of juvenile salmonid passage at Bonneville Dam that we conducted during the 2002 downstream passage seasons. Both were funded by the U.S. Army Corps of Engineers - Portland District and were conducted at Bonneville Dam from April 20 through July 15, 2002.

The first study of project-wide FPE provides hourly estimates of fish passage and associated variances for all operating turbine units and spill bays, and the two sluiceway entrances at Powerhouse 1 (B1), as well as estimates of a variety of fish-passage efficiency and effectiveness measures. This was the third consecutive year of full-project hydroacoustic sampling and passage estimation. The first was conducted in 2000 (Ploskey et al. 2002a and b) and the second in 2001 (Ploskey et al. 2002c).

The second study was more narrowly focused on B2 turbines and had two goals: 1) to sample the FGE at two modified turbine intakes and compare them with efficiencies of other B2 units that were sampled in the first study, and 2) to evaluate proportions of fish passing up into gatewell slots versus through screen gaps at a few B2 turbine intakes.

The goals of the studies were to:

1. Provide the third consecutive year of route-specific and project-wide estimates of fish passage for run-of-river juvenile salmonids passing Bonneville Dam on their way to the Pacific Ocean.

2. Evaluate effects of screen and gatewell modifications on the fish guidance efficiency (FGE) of B2 units, assess the proportion of screen-guided fish lost to gaps between the top of a submerged traveling screen (STS) and the ceiling at two modified and two unmodified intakes at B2, and assess the feasibility of detecting fish lost to side gaps at an STS.

Sampling with 58 420-kHz hydroacoustic transducers was continuous from April 20 through July 15, 2002, except for about 15 minutes each morning when data were downloaded and archived. One out of three intakes at every operating turbine unit was randomly selected for sampling except at Unit 17, where two out of three intakes were sampled. All 18 spill bays were sampled with one transducer placed randomly (north, middle, or south) in each bay. At least one split-beam transducer was used in each type of deployment to provide deployment-specific data on fish speeds, trajectories, and target strengths for modeling detectability. Deployment types included up-looking and down-looking transducers at B1 and at B2 turbine intakes, side-looking transducers at B1 sluiceway entrances, and down-looking transducers at spill bays. Detectability results were used to adjust spatial expansions to equalize detectability among deployments and by range within each deployment. The two open entrances to the sluiceway at B1 
intakes 7A and 10C were each sampled with a pair of split-beam transducers, and 7A also was sampled with four optical underwater cameras. An acoustic camera was deployed in several B2 gatewell slots to evaluate proportions of fish entering the gatewell and gap at the top of the STS. The acoustic camera also was mounted for $24 \mathrm{~h}$ on the downstream side of the uppermost trash rack in an attempt to detect losses of fish to the side gap between the STS and the intake wall.

A variety of fish-passage metrics, including seasonal estimates of FPE (project-wide and by powerhouse), spill efficiency, spill effectiveness, sluice efficiency, and sluice effectiveness, were calculated (Table A.1). Other metrics, including FGE of in-turbine screens by turbine unit, horizontal distributions of passage, diel distributions, and seasonal trends in fish passage and metrics, as well as operational effects, are described in the extensive Executive Summary and in the report.

Table A1. Estimates of Major Passage Metrics based upon Hydroacoustic Sampling from 4/20 through $6 / 2$ (spring) and from 6/3 through 7/15 (summer). The efficiency and effectiveness estimates for the B1 sluiceway are calculated relative to both the entire Project and to B1.

\begin{tabular}{|lll|}
\hline Major Passage Metric & Spring & Summer \\
\hline \hline Project FPE & $79 \pm 0.1 \%$ & $74 \pm 0.2 \%$ \\
B1 FPE & $58 \pm 0.4 \%$ & $61 \pm 0.3 \%$ \\
B2 FPE & $53 \pm 0.3 \%$ & $46 \pm 0.7 \%$ \\
Spill Efficiency & $52 \pm 0.5 \%$ & $42 \pm 0.5 \%$ \\
Spill Effectiveness & $1.08 \pm 0.01$ & $0.96 \pm 0.01$ \\
Sluiceway Efficiency Project & $6.0 \pm 0.1 \%$ & $11 \pm 0.1 \%$ \\
Sluiceway Effectiveness ${ }_{\text {Project }}$ & $21.9 \pm 0.01$ & $47.9 \pm 0.03$ \\
Sluiceway Efficiency ${ }_{\text {B1 }}$ & $33 \pm 0.9 \%$ & $29 \pm 0.7 \%$ \\
Sluiceway Effectiveness & & $26.9 \pm 0.07$ \\
\hline
\end{tabular}




\section{Executive Summary}

The Portland District of the U.S. Army Corps of Engineers requested that the Pacific Northwest National Laboratory (PNNL) and the U.S. Army Engineer Research and Development Center (ERDC) conduct fish-passage studies at Bonneville Dam in 2002. This study supports the Portland-District goal of maximizing fish-passage efficiency (FPE) and obtaining 95\% survival for juvenile salmon passing Bonneville Dam, which has 10 turbines and a sluiceway at Powerhouse 1 (B1), an 18-bay spillway, and eight turbines at Powerhouse 2 (B2).

\section{Introduction}

\section{General Description}

Bonneville Dam is the most downstream of dams in the Columbia-Snake River System, and therefore more migrating juvenile salmonids must pass Bonneville Dam than any other dam. Unfortunately, Bonneville Dam has had consistently low FGE at turbines and so there is a concerted effort to improve passage conditions for downstream migrants. The work reported here is a part of that effort.

In this report, we present results of two studies of juvenile salmonid passage at Bonneville Dam that we carried out in the 2002 downstream passage seasons. Both were funded by the U.S. Army Engineers Portland District and were conducted at Bonneville Dam from April 20 through July 15, 2002.

The first study of Project-wide FPE provides hourly estimates of fish passage and associated variances for all operating turbine units, spill bays, and the two sluiceway entrances at Powerhouse 1 (B1), as well as estimates of a variety of fish-passage efficiency and effectiveness measures. This was the third consecutive year of full-project hydroacoustic sampling and passage estimation. The first was conducted in 2000 (Ploskey et al. 2002a and b) and the second in 2001 (Ploskey et al. 2002c).

The second study was more narrowly focused on B2 turbines and had two components: 1) to sample the FGE at two modified turbine intakes and compare them with efficiencies of other B2 units that were sampled in the first study, and 2) to evaluate proportions of fish passing up into gatewell slots versus through screen gaps at a few B2 turbine intakes.

\section{Goals}

The goals of the studies were to:

1. Provide the third consecutive year of route-specific and project-wide estimates of fish passage for run-of-river juvenile salmonids passing Bonneville Dam on their way to the Pacific Ocean. A wide variety of metrics such as project FPE, B1 FPE, B2 FPE, spill efficiency, spill effectiveness, sluice efficiency, and sluice effectiveness are calculated from route-specific passage data.

2. Evaluate effects of screen and gatewell modifications on the fish guidance efficiency (FGE) and gap loss of fish at B2 units. Gap loss is the proportion of screen-guided fish lost to gaps between the top of a submerged traveling screen (STS) and the ceiling. Side gaps also exist. 


\section{Objectives}

\section{Project FPE Evaluation}

1. Estimate the proportion of smolt-sized fish that pass the project above and below in-turbine screens, through sluiceway openings, and through spill bays each season.

2. Estimate a variety of fish-passage metrics by hour, day, and season. The metrics include Project FPE, FPE by powerhouse, spill efficiency and effectiveness, B1 sluice efficiency and effectiveness, and FGE by turbine unit.

3. Use estimates of fish passage and associated metrics to evaluate effects of spill percent and rate as well as three spill treatments.

4. Characterize horizontal distributions of smolt-sized fish passing through the Project, B1, B2, B1 sluiceway entrances, and spill bays.

5. Describe diel changes in the passage of smolt-sized fish at B1, B1 sluiceway entrances, B2, and the spillway.

\section{Unit 17 and Gap Loss Evaluations}

1. Hydroacoustically sample fish passage at two intakes of Unit 17 with modified gatewell slots at B2 and estimate FGE, then compare those estimates to FGE estimates of other units with unmodified gatewell slots, as determined in the Project FPE Evaluation described above.

2. Deploy a down-looking acoustic camera in one unmodified and one modified gatewell at B2 and sample for two days each season to record the proportions of juvenile salmonids moving up into the gatewell versus downstream through the gap between the top of the STS and the ceiling of the intake.

3. Deploy an acoustic camera on the downstream side of the trash racks to determine the feasibility of recording the rate of fish loss through a gap between the side of the screen and the wall of the intake.

Common metrics used to describe fish passage at Bonneville Dam are listed below.

- Fish passage efficiency (FPE) - the proportion or percent of fish that pass through non-turbine routes relative to total Project passage or just to B1 or B2 passage. Non-turbine passage includes fish guided by in-turbine screens, passing through sluiceways, or passing through the spillway.

- Spill passage efficiency (SPE) - the proportion or percentage of fish that pass through the spillway relative to total Project passage.

- Spill passage effectiveness (SPN) - SPE divided by the proportion or percentage of Project discharge going through the spillway.

- Sluiceway efficiency - (SLE) the proportion or percentage of all fish that passed through the B1 sluiceway relative to total Project passage or relative to B1 passage. 
- Sluiceway effectiveness (SLN) - SLE divided by the percentage of total discharge going through the sluiceway. SLN may be relative to the entire Project or relative to an adjacent powerhouse.

- Fish guidance efficiency (FGE) - the proportion or percentage of fish that pass a turbine unit above the screen. It is the number guided by the screen divided by the total turbine passage (number guided plus number unguided). FGE may be estimated for single intakes within units or for an entire turbine unit.

\section{Site Description and Conditions in 2002}

From the Oregon shore north toward Washington, the Project is composed of a navigation lock, a 10unit powerhouse (B1), Bradford Island, an 18-gate spillway, Cascades Island, and an 8-unit powerhouse (B2). Principal passage routes include the spillway and two powerhouses, but within a powerhouse, fish passage can be through ice/trash sluiceways, turbines, or the juvenile bypass system (JBS). Smolts enter the JBS after they encounter screens in the upper part of turbine intakes and are diverted to gatewell slots and then pass through orifices opening to a bypass channel.

In 2002, Unit 5 at B1 was off line and the ice and trash sluiceway at B2 was closed all year. Sluiceway intakes at B1 intakes 7A (Unit 7) and 10C (Unit 10) were open and were sampled. In 2002, B2 was the priority powerhouse for generation. There was an attempt to test the effects of three spill treatments including low daytime spill $(<80,000 \mathrm{cfs})$, high daytime spill ( $>85,000 \mathrm{cfs})$, and high nighttime spill ( $>85,000 \mathrm{cfs}$ ). In 2002, Bonneville Dam discharged flows very near the ten-year mean, whereas in the drought year of 2001, discharge was only about $63 \%$ of the ten-year mean (Columbia River Data Access in Real Time [DART] website data).

In an attempt to improve FGE at B2 turbines, the Portland District modified gatewell slots in Unit 15 before the 2001 smolt migration and gatewells at Unit 17 before the 2002 migration. Modifications consisted of removing a lot of concrete, greatly expanding the surface area the of vertical barrier screens (VBS), and adding a turning vane and gap closure device to direct more water up the slot and away from the gap between the top of the STS and the intake ceiling. In a few days of preliminary sampling with an acoustic camera in 2001, we recorded large numbers of fish passing through STS gaps, and those observations prompted the gap-loss investigations reported here. The gap at the top of the STS in unmodified units is about 17 inches high and 20 feet wide. In modified units (B2 units 15 and 17), the gap is about 6 inches high and 20 feet wide.

\section{Materials and Methods}

\section{Equipment}

Each of the three dam structures (B1, spillway, and B2) was sampled with four hydroacoustic systems. Each system consisted of an echosounder, cables, transducers, an oscilloscope, and a computer system. The $420-\mathrm{kHz}$, circular, single- or split-beam Precision Acoustic Systems (PAS) transducers were controlled by PAS 103 echosounders and Hydroacoustic Assessments' HARP software running on Pentium-class computers. 
Sluiceway entrances 7A and 10C at B1 were sampled by one of the hydroacoustic systems described in the previous paragraph, and Entrance 7A also was sampled with four Inuktun FireflEYE (sic) optical cameras. A Leightonics MiniT-Pro programmable video switcher allowed us to sequentially sample the four cameras, and sampling was remotely controlled by the Panasonic AG-DV2000 video tape recorder. The large-format DV tapes were Panasonic model \# AY-DV 186PQ, which hold 3 hours of digital video each.

We deployed a down-looking acoustic camera on a traversing beam in several gatewells of B2 to record proportions of juvenile salmonids moving up into the gatewell and through the gap between the top of the STS and the ceiling of the intake. The Dual-Frequency Identification Sonar (DIDSON) was developed by the Applied Physics Laboratory (APL) at the University of Washington for the Space and Naval Warfare Systems Center harbor surveillance program. The DIDSON was attached to a programmable traversing mount so that samples could be taken from five lateral locations across the gatewell when operators were present to remotely control the DIDSON's position. The traversing part of the 20 -ft wide beam was moved by a stepper motor and controlled by custom designed software on a laptop computer through a serial communication port.

\section{Calibrations}

Before deployment, all hydroacoustic equipment was transported to Seattle, Washington, where PAS electronically checked the echo sounders and transducers and calibrated the transducers using several standard transducers. After calibration, we calculated receiver gains to equalize the output voltages among transducers for on-axis targets ranging in hydroacoustic size from -56 to $-36 \mathrm{~dB} \| 1 \mu P a @ 1 m$. Lengths of fish corresponding to that acoustic size range would be about 1.3 and 12 inches, respectively, for fish insonified within $21^{\circ}$ of dorsal aspect (Love 1977).

\section{Sampling Powerhouse 1}

In turbine units 1-4 and 6-10, we sampled one randomly selected intake slot out of three per unit. Unit 5 did not run in 2002. We mounted one upward- and one downward-angled, $6^{\circ}$ transducer in the selected slots to monitor guided and unguided passage, respectively. The lateral location of both transducers within the same intake was randomly selected to be on the north, center, or south side of the trash rack so that some of the lateral variation in passage within intakes would be captured in the variance estimate for the entire powerhouse.

Transducers deployed in Unit 9 were $6^{\circ}$ split-beams to provide target strength data for detectability modeling. Sampling the 40-ft-long extended submerged bar screen (ESBS) at Unit 8 required a different deployment of transducers. Fish passing above and below the ESBS of Unit 8 were sampled with an upward- and a downward-angled, $6^{\circ}$ single-beam transducer to estimate guided and unguided numbers, respectively, but the down-looking transducer was mounted on the downstream side of the ESBS instead of on trash racks. Paired transducers in every intake were fast multiplexed to acquire 151 -minute samples from each intake per hour on each single-beam system and 20 1-min samples/h on the split-beam system. Fast multiplexing allowed us to estimate covariances for the simultaneous samples of guided and unguided fish. The pulse repetition rate was 13 pings per second for the split-beam transducers in Unit 9 , and 14 pings/s for all others. 
At sluiceway entrances above turbine intakes 7A and 10C, two opposing 6-degree split-beam transducers were aimed across the entrance and sampled throughout the spring and summer seasons. One transducer was aimed toward the south, and the other transducer was aimed toward the north, and only the far half of each beam was used to count fish passing through one half of the entrance. The split-beams provided data on fish speed, trajectory, direction of movement, and target strength. Transducers were fast-multiplexed at 50 pings per second ( $25 \mathrm{pings} / \mathrm{s}$ each) and each sluiceway was sampled for 152 -min intervals every hour.

Four optical cameras provided a second independent estimate of fish passage into Sluice Entrance 7A. The up-looking cameras were equally spaced along the upstream side of the chain gate and lenses were flush with the top of the gate. The four cameras were sequentially switched and sampled a combined 15 minutes per hour ( $3 \mathrm{~min}, 45 \mathrm{~s}$ intervals per camera). Tapes were changed twice a day, and sampling was conducted 24 hours per day. Data collection started on 6 May 2002 and continued through 19 July. Only video recorded during daylight hours was usable due to constraints on infrared lighting methods. Out of all sampled hours, $126(10.5 \%)$ were processed manually to estimate fish passage.

\section{Sampling the Spillway}

Each of the 18 spill bays were sampled with one transducer. Most transducers were $10^{\circ}$ singlebeams, except for $12^{\circ}$ split-beam transducers deployed in Bays 6, 9, and 16. The split-beams provided data on fish speed, trajectory, direction of movement, and target strength. All transducers were mounted $28 \mathrm{ft}$ below the tops of the spill gates. The $10^{\circ}$ beams were aimed $5^{\circ}$ upstream from vertical so that the downstream edges of the beams were adjacent to the spill gates. The $12^{\circ}$ split beams were aimed about $10^{\circ}$ upstream from vertical. The maximum gate opening in 2002 was about $6.25 \mathrm{ft}$, and it provided for about $14,200 \mathrm{cfs}$ of water discharge. The lateral location of each transducer within a bay was randomly selected to be on the north, center, or south side so that some of the lateral variation in passage within bays would be captured in the variance estimate for the entire spillway. All transducers had a pulse repetition rate of 25 pings per second. Single-beam transducers in 15 bays took 121 -min samples each hour, and split-beam transducers in bays 6,9, and 16 took 201 -min samples per hour.

\section{Sampling Powerhouse 2}

At B2, one out of three intakes at every turbine unit was randomly selected for sampling, except at Unit 17, where two of three intakes were randomly selected. Three transceivers and computers were used to control the 18 transducers. In each sampled intake, we mounted a pair of transducers on the downstream side of the trash racks. One transducer of each pair was mounted near the bottom of the uppermost trash rack and aimed downward to sample unguided fish passing below the traveling screen. The second transducer of each pair was mounted near the bottom of the fourth trash rack from the top and aimed upward to sample fish passing above the screen. The lateral location of both transducers within the same intake was randomly selected to be on the north, center, or south side of the trash rack. The two transducers deployed in Unit 12 were split beams to provide data on fish speed, trajectory, direction of movement, and target strength. Each transducer transmitted sound pulses at 14 pings per second, and both transducers of a pair usually were sampled simultaneously. This fast multiplexing allowed us to estimate covariances for the simultaneous samples of guided and unguided fish and to collect 151 -minute samples per hour at all intakes. 
To evaluate gap loss proportions, we deployed a DIDSON acoustic camera on a 20-ft-long beam with a traversing mechanism in the gatewells of modified Intake 17B and unmodified Intake 18A in spring and in modified Intake 17C and unmodified Intake 13B in summer. At each gatewell, we sampled proportions of fish moving up into the gatewell and through the gap for most of two consecutive 24-h periods. We actively sampled five lateral positions across the $20-\mathrm{ft}$ wide gatewell for at least $4 \mathrm{~h}$ from about 2000 until midnight (sometimes as long as $8 \mathrm{~h}$ ) before we moved the DIDSON to the center of the gatewell and let the system acquire data for the rest of the 24-h period.

Movies of fish passing through the gap and up the gatewell were processed manually by recording the range of first detection and the fate of every fish (i.e., gatewell or gap lost). We expanded the count of every fish using the following equation:

$$
E C=\frac{G W}{\left[F R \times T A N\left(\frac{10}{2}\right) \times 2\right]}
$$

where $\mathrm{EC}=$ expanded count, $\mathrm{GW}=$ gatewell width $(6.1 \mathrm{~m}), \mathrm{FR}=$ first range of detection $(\mathrm{m}), \mathrm{TAN}$ is the tangent, and 10 is beam angle relative to GW. The expansion increased the count of fish in the gatewell fraction relative to the gap-lost fraction because gap lost fish were detected at slightly greater range than fish moving up into the gatewell. The frame rate of the DIDSON ranged from 8 to 10 per second depending upon noise conditions.

We also deployed the acoustic camera on the bottom of the uppermost trash rack of Intake 18A for one night in spring to see whether the camera could detect smolts passing through the gap between the side of the STS and the side of the intake.

\section{Hydroacoustic Fish Tracking and Filtering Criteria}

We used autotracking software developed from 1998 through 2002 by COE and PNNL to process raw data into tracked fish observations. Autotracker parameters and the settings used to process the 2002 data are in Appendix C. During most of spring and early summer, we reviewed samples of the autotracker's performance for every deployment on a fish-by-fish basis to evaluate and fine-tune the autotracker and to develop post-processing filters for eliminating false traces from the autotracker's output. We released the autotracker to process data for a given deployment only after we determined that it was missing few of the echo patterns that we would have tracked. In Appendix D, we describe criteria and present Statistical Analysis System (SAS) code used to reject non-fish traces that the autotracker selected. We evaluated its performance and post-processing filters in both seasons by comparing counts of fish by the software and by three trained technicians. Results from the technicians provided an estimate of inter-tracker error and deployment-specific mean hourly estimates for comparison to the autotracker-based estimates. Given the demonstrated wide range of interpersonal variation, we compare our autotracker's results to average human estimates rather than to any one person's estimates. We compared human and autotracked counts for each transducer (channel) because there are important differences in passage characteristics, ranges of interest, trace slopes and lengths, and noise conditions for each deployment site and aiming angle. 


\section{Adjustments to Fish-Passage Estimates}

We adjusted autotracker counts and variances in two ways according to the general methods described in the Materials and Methods section.

First, we regressed average hourly fish counts by technicians on autotracker counts for each transducer and used slopes of regression lines with intercepts forced through zero to convert autotracker counts into mean technician counts.

Second, we examined the direction of travel of fish through all routes and found that the proportion of fish detected moving downstream through routes was significantly less than $100 \%$ for the sluiceway entrances at B1 and for the three spill bays sampled with split-beam transducers. We reduced counts at sluiceway and spillway routes by multiplying passage estimates by the average hourly proportion of fish detected moving downstream toward the openings.

\section{Dam Operations and Fish Passage}

Hourly operations data, including discharge by spill bay and turbine unit, were provided by Bonneville Dam operators, who recorded results in a spreadsheet. Hourly operations data were integrated with fish passage data, and fish passage was set to zero when passage routes were closed for an entire hour. This was important because transducers sampled continuously regardless of operations, and samples from closed turbine units or spill bays will include many traces that may be tracked as passing fish, often multiple times, even when a turbine unit is off or a spill bay is closed. Fortunately, operators recorded exact times that every turbine was started and shut down each day so that we were able to set 1minute samples of fish passage to zero whenever a turbine was off.

\section{Missing Data}

Short equipment failures lasting up to 45 minutes were not a problem because fish counts and associated variances could still be estimated from the remaining within-hour samples. Computer lock-ups usually were fixed within an hour because we had staff monitoring systems 24 hours per day. We had transducer cables fail on units 9 and 11 and both were fixed within a day, as soon as project support or divers became available. The failure at Unit 11 was replaced in March before the fish passage season began. Missing hourly sums and variances that resulted from equipment outages $>45$ minutes were estimated by temporal linear interpolation for periods $<6$ hours and by spatial interpolation or linear regression for periods $>6$ hours. We interpolated fish passage estimates from passage through adjacent bays for Bay 16 in both seasons because of severe structural noise problems there and for Bay 2 after 8 June because of an undetected intermittent signal from that transducer.

\section{Detectability Modeling and Spatial Expansions}

Effective beam angle depends upon the detectability of fish of different sizes in the acoustic beam and is a function of nominal beam width, ping rate, trace criteria, and fish size, aspect, trajectory, velocity, and range. We modeled detectability for every transducer deployment to determine effective beam angle as a function of range from a transducer. We obtained target-strength estimates and fish velocity and trajectory by $1-\mathrm{m}$ range strata from manually tracked split-beam data. These data and other 
hydroacoustic-acquisition data (e.g., ping rate, target-strength threshold, number of echoes, and maximum ping gaps) were entered into a detectability model. Model output consisted of effective beam angle as a function of range from a transducer. Polynomials fitted to those data were substituted for EBA in Equation 1 to correct for differences in detectability by range among transducers and locations.

The count of every fish (1) was spatially expanded based upon the ratio of the opening width to beam diameter at the range of detection:

$$
E X P_{-} N U M=\frac{O W}{\left[M I D_{-} R \times T A N\left(\frac{E B A}{2}\right) \times 2\right]}
$$

where OW is opening width in $\mathrm{m}, \mathrm{MID}$ R is the mid-point range of a trace in $\mathrm{m}$, TAN is the tangent, and EBA is effective beam angle in degrees.

\section{Statistical Methods}

The chapter on Material and Methods contains detailed descriptions of statistical methods used to analyze the hydroacoustic data. Dr. John Skalski developed these methods specifically for this study year.

Our estimates of variation associated with fish passage and efficiency metrics probably are conservative for two reasons. First, we took systematic 1-min samples (usually 12-15) per hour, and treated them as if they were simple random samples. This approach will be unbiased when the passage is random and upwardly biased when there is linear trend, positive autocorrelation, or stratification effect. Negative bias would only occur in unusual situations. Second, we estimated more than just the temporal variation in passage within intakes by post-stratifying adjacent turbine units and estimating the variation in passage between intakes of the multi-unit strata. This approach usually would include more betweenintake variation than we would expect from sampling two or more intakes of individual units because variation among-units usually exceeds the variation among intakes within a unit.

\section{Results and Discussion}

\section{Hydroacoustic Detectability}

Accurate counts estimated by proper expansion of detected fish have the potential to provide estimates with inherent quantitative value as well as providing acceptable relative estimates. Ratio estimators such as fish guidance efficiency only require that the hydroacoustic beams sampling guided and unguided fish have equal detectability so that the ratios of counts, not necessarily the counts themselves, are accurate. Combining counts from different locations such as powerhouses and a spillway also requires equal detectability so that counts from different locations are comparable, although the counts themselves may not be accurate.

We are comfortable that detectability was adequate at all deployment in 2002 because most effective beam angles were near the nominal beam or higher over ranges that fish were counted. Exceptions included guided fish at Unit 8 where sampling had to begin within $2 \mathrm{~m}$ of the up-looking transducer and 
at the sluiceway where sampling began within $2.9 \mathrm{~m}$ of the transducer. Nevertheless, spatial expansions incorporated effective beam angle, so there was appropriate compensation for diminished detectability at short ranges. Apparently, our pulse repetition rate of 25 pings/s was adequate for even the highest spill discharges observed in 2002. Loss of detectability with increased spill-bay discharge could result in the misinterpretation of relations between spill efficiency or effectiveness and spill discharge, but an examination of the mean number of echoes per fish trace and fish counts by discharge range suggested that this was not a problem. Lower detectability may result if fish moved through the beam faster at high than at low discharge and returned fewer than the minimum number of echoes. The average number of echoes per fish trace detected at spill bays fell from 9.9 at 3,000-6000 cfs to 8.7 at 6,000-9,000 cfs to 8.0 at 9,000-12,000 cfs to 7.4 at 12,000-14000 cfs, the highest discharge observed. Nevertheless, 7.4 echoes per trace are well above the 4-echo minimum criterion. An ANOVA and multiple-range test indicated that the average hourly fish count was highest at the highest discharge range in summer when the 2002 hydrograph peaked.

\section{Validation of Autotracking Hydroacoustic Data}

The high coefficients of determination for regressions of human-based counts on autotracker counts for each deployment indicate that the estimates comport very well. Rather than pooling data by deployment type, we adjusted autotracker counts on a channel-specific basis because some of the regression slopes for different channels of a similar deployment were different. Differences likely result from channel-specific differences in noise regimes.

\section{Fish Swimming Direction and Implications for Sluice Management}

Even at high forebay elevations, Sluiceway Entrance 10C does not pass much water (Figure S.1) and smolts congregating and milling there likely are more vulnerable to predation than they would be at other entrances. The low flow into Entrance 10C is the result of limited channel capacity at the most upstream location along the sluiceway channel. We had problems with multiple fish detection at Entrance 10C because as many fish were moving upstream as downstream at that entrance in spring, and the net flux of smolts in a downstream direction was only $18 \%$ in summer. We could not make passage estimates for Entrance 10C. In contrast, flow into Entrance 7A was unimpeded by channel capacity and most detected smolts $(88.4 \%$ in spring and $71 \%$ in summer) were moving downstream into the entrance. The fish moving upstream in summer likely were not sub-yearling smolts but American shad or something else because sub-yearlings could not avoid entrainment by the time they were detected over the weir. We recommend that an alternate entrance located further down the ice and trash sluiceway channel be opened instead of Entrance 10C in the future. Good choices include an entrance at Unit 5 on the south side of the pier between Units 6 and 7 and another entrance at Unit 1 or 2. 


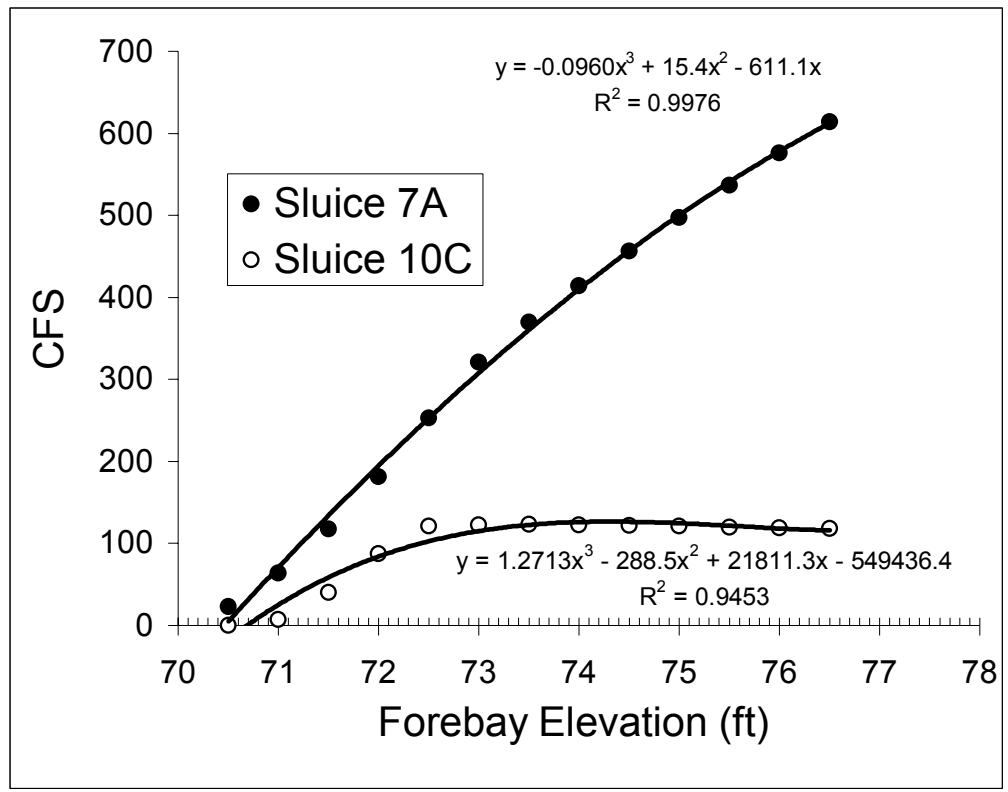

Figure S.1. Relations between Entrance Flow and Forebay Elevations at Sluiceway Entrances 7A and $10 \mathrm{C}$ at B1. Flows estimates were calculated from polynomials derived from model data provided by Kyle McCune (USCOE District, Portland).

\section{Major Passage Metrics and Comparison with Telemetry Estimates}

For two radically different methods of estimating fish-passage metrics, most of the estimates by hydroacoustics and radio telemetry were reasonably similar (Table S.1). Hydroacoustic estimates of major passage metrics in 2002 were made for two sets of days each season, one for the entire time sampled by hydroacoustics and one for dates corresponding to dates of the radio telemetry study. For estimates based on concurrent sample dates, 100 of the 12 pairs of efficiency estimates were within $16 \%$ of each other, $83 \%$ were within $10 \%$, and $42 \%$ were within $5 \%$. The six measures of effectiveness were much less concordant, varying from within $12 \%$ to $59 \%$ of each other (mean difference $=30.5 \%$ ), but as a ratio of ratios, effectiveness tends to amplify differences greatly. Having similar estimates by different sampling methods boosts confidence in results more than having estimates from a single method.

We would not have been surprised by greater differences, given that radio telemetry estimates for two species in spring are averaged for comparison to hydroacoustic estimates, which are calculated from the passage of all species in the run at large. The behavior and passage metrics for these two species often differ, which is the reason for obtaining separate estimates by tagging. However, the run at large includes both radio-tagged species and other species in widely varying proportions over time, and proportions of tagged yearling chinook and steelhead salmon seldom match proportions in the run at large. The species composition of the spring run ranged from $20 \%-84 \%$ for yearling chinook, $0 \%-60 \%$ for coho, and $2 \%$ $25 \%$ for steelhead salmon, and $0 \%-68 \%$ for sub-yearling chinook at different times. According to John Day Bypass data, juvenile sockeye salmon, which supposedly guide poorly at in-turbine screens, made up $25 \%$ of the spring run in 2002. These fish were not sampled in significant numbers at Bonneville Dam. 
Table S.1. Estimates of Major Passage Metrics based upon Hydroacoustic Sampling from 4/20 through $6 / 2$ (spring) and from 6/3 through 7/15 (summer), on Hydroacoustic Sampling during the Radio Telemetry study, and on Radio Telemetry.

\begin{tabular}{|c|c|c|c|}
\hline Major Passage Metric & $\begin{array}{l}\text { Hydroacoustic } \\
\text { Estimate } \\
\text { (Full Seasons) }\end{array}$ & $\begin{array}{l}\text { Hydroacoustic } \\
\text { Estimate for } \\
\text { Telemetry Study } \\
\text { Days }\end{array}$ & $\begin{array}{l}\text { Radio } \\
\text { Telemetry } \\
\text { Estimate }\end{array}$ \\
\hline Spring Project FPE & $79 \pm 0.1 \%$ & $78 \pm 0.1 \%$ & $78 \%$ \\
\hline Spring B1 FPE & $58 \pm 0.4 \%$ & $58 \pm 0.4 \%$ & $74 \%$ \\
\hline Spring B2 FPE & $53 \pm 0.3 \%$ & $53 \pm 0.3 \%$ & $43 \%$ \\
\hline Spring Spill Efficiency & $52 \pm 0.5 \%$ & $50 \pm 0.5 \%$ & $56 \%$ \\
\hline Spring Spill Effectiveness & $1.08 \pm 0.01$ & $1.01 \pm 0.01$ & 1.15 \\
\hline Spring Sluice Efficiency Project & $6 \pm 0.1 \%$ & $8 \pm 0.1 \%$ & $3 \%$ \\
\hline Spring Sluice Effectiveness Project & $21.9 \pm 0.01$ & $29 \pm 0.02$ & 12 \\
\hline Spring Sluice Efficiency в1 & $33 \pm 0.9 \%$ & $33 \pm 0.9 \%$ & $41 \%$ \\
\hline Spring Sluice Effectiveness ${ }_{\mathrm{B} 1}$ & $13.5 \pm 0.06$ & $17 \pm 0.07$ & 21 \\
\hline Summer Project FPE & $74 \pm 0.2 \%$ & $76 \pm 0.2 \%$ & $79 \%$ \\
\hline Summer B1 FPE & $61 \pm 0.3 \%$ & $63 \pm 0.3 \%$ & $70 \%$ \\
\hline Summer B2 FPE & $46 \pm 0.7 \%$ & $50 \pm 0.7 \%$ & $44 \%$ \\
\hline Summer Spill Efficiency & $42 \pm 0.5 \%$ & $40 \pm 0.5 \%$ & $54 \%$ \\
\hline Summer Spill Effectiveness & $0.96 \pm 0.01$ & $0.96 \pm 0.01$ & 1.30 \\
\hline Summer Sluice Efficiency Project & $11 \pm 0.1 \%$ & $11 \pm 0.1 \%$ & $7 \%$ \\
\hline Summer Sluice Effectiveness Project & $47.9 \pm 0.03$ & $48 \pm 0.03$ & 31 \\
\hline Summer Sluice Efficiency в1 & $29 \pm 0.7 \%$ & $29 \pm 0.7 \%$ & $45 \%$ \\
\hline Summer Sluice Effectiveness ${ }_{B 1}$ & $27 \pm 0.08$ & $25 \pm 0.07$ & 37 \\
\hline
\end{tabular}

\section{Project and Powerhouse FPE}

Project-wide FPE was 79\% in spring and $74 \%$ in summer. The B1 estimate, including sluiceway passage, was $58 \%$ in spring and $61 \%$ in summer. The FPE estimate for B2, which had no sluiceway operation in 2002, was 53\% in spring and $46 \%$ in summer. 


\section{Spill Efficiency and Effectiveness}

Spill efficiency for the entire project was $52 \%$ in spring and $42 \%$ in summer. Spill effectiveness for the entire project was 1.08 in spring and 0.96 in summer. Spill effectiveness for just B2 and the spillway was estimated to be 1.17 in spring and 1.20 in summer.

\section{Sluice Efficiency and Effectiveness}

The highly effective B1 sluiceway was a major contributor to B1 FPE, which was higher than B2 FPE in spring and summer, although the FGE for B1 turbine units were considerably lower than those for B2 units in spring. Units at B1 ran only $30 \%$ of all possible unit hours in spring and $65 \%$ in summer. The B1 sluiceway passed a very large proportion of the estimated total project fish passage (just over $6 \%$ in spring and nearly $11 \%$ in summer) with remarkably little water (less than $3 / 10$ s of $1 \%$ of the entire project in each season). Even that discharge is an overestimate of the sluiceway discharge that was actually attracting and passing fish. Since our split-beam data indicated that there was little or no net passage into the overflow weir at Intake 10C, these estimates are only of fish passage at the weir at Intake 7A.

\section{Comparing Estimates for Part of the Project}

For only B2 and the spillway (excluding B1), estimated FPE was 4\% higher in spring (83\%) and 8\% higher in summer $(82 \%)$ than were the corresponding estimates for the entire project. Computing spill efficiency and effectiveness for just one powerhouse and the spillway, regardless of which powerhouse is chosen, also results in substantially higher estimates because the spill passage estimate becomes a greater proportion of total passage. Ignoring B1 raised spill efficiency $12 \%$ in spring and $25 \%$ in summer.

Considering only B2 and the spillway also increased spill effectiveness estimates (1.17 in spring and 1.20 in summer).

We also calculated Project-wide metrics based solely upon data from B2 and the spillway (ignoring fish passage at B1), but we are uncomfortable trying to infer an effect of a B1 shut down from those data because B1 units ran $30 \%$ of all possible unit hours in spring and $65 \%$ of all hours in summer. This is quite different than no B1 operation. If B1 were truly off or most fish traveling down the Oregon side of the river were somehow kept from entering the B1 forebay, Project FPE and spill efficiency might be a lot higher than what we can calculate by ignoring B1 fish passage. Our calculations cannot account for fish densities in the river, the effect of density on fish behavior, or the closer proximity of fish passing down the Oregon side of the river to the spillway than to B2. The density of fish passage at B1 was higher than it was at the spillway or B2, so eliminating or reducing passage at B1 could greatly increase Project FPE and spill efficiency. Our exercise in computing FPE for only the spillway and B2 inevitably produces estimates higher than those that are computed for the entire project, but the same result occurs if only B1 and the spillway are used in calculations. Of course the turbine units at B2 were off only about $18 \%$ of all possible unit hours in spring and $11 \%$ in summer, so it is less logical to ignore B2. Given the narrow entrance to the B1 forebay and the high density of fish passage at B1, we recommend that managers experiment with behavioral ways to shunt fish to the spillway, e.g., turbulence-producing propellers.

There may be reasons for giving generation priority to one powerhouse over the other (e.g., differences in survival), but the decision should not be made solely based upon FPE estimates made from ignoring one or the other powerhouse for reasons described in the previous paragraphs. Of course, 
actually operating the project with only one powerhouse could have important consequences for power production and water quality as well as fish passage.

\section{Effects of Spill Level on Fish Passage}

Results suggest that there may be an optimal spillway discharge rate above which not many more or even fewer fish are spilled, which is consistent with our previous findings, see Ploskey et al. 2001b on The Dalles Dam and 2002b and 2002c on Bonneville Dam). There is often very high variability in spillway fish passage among hours with the same discharge. This is the case even when spillway passage is normalized for fish availability by dividing by total project estimated passage. In spring of 2002, there was a positive association between hourly spillway discharge and hourly estimated spillway passage, but by far the highest estimated spillway passage occurred at around 150,000 cfs. Higher spill events were fairly rare in spring and so sample bias may be important. However, hourly spillway discharge over $160,000 \mathrm{cfs}$ was never associated with estimated spillway passage of more than 15,000 fish. In contrast, there were many hours with spillway discharge of 145,000-160,000 cfs that passed between 20,000 and almost 50,000 fish. In summer, the hourly discharge explained $30 \%$ more of the variation in spillway passage than it did in spring, probably because of inclusion of a much higher range in discharge than in spring. Most of the exceptionally high spillway discharge hours occurred early in the summer and at those levels could include an increased proportion of fallback of American shad as well as juvenile salmonids. High spill does not necessarily result in high estimated spillway passage, and high passage can occur when spill is moderate (e.g. on 23 April).

\section{Effects of Spill Percent and Discharge on Spill Efficiency and Project FPE}

Relations of spill efficiency and FPE as a function of percent spill and spill discharge suggest that percent spill is more important than the amount of spill for achieving benefits. Relations to percent spill are equally well fit by linear or quadratic relations (Figures S.2 and S.3), but relations to spill discharge are often better fit with quadratic equations (Figure S.4). Therefore, the amount of control available to operators is critical, and it is a function of the annual hydrograph.

The regression of hourly spill efficiency and Project FPE against percent spill (Figures S.2 and S.3) reveals close linear relationships in both spring and summer. The spill efficiency relation is always more significant than the FPE relation because FPE depends upon other factors like turbine FGE and sluice efficiency. Spill efficiency is the spillway passage normalized for fish availability for passage and this explains why relations of efficiencies with spill percent or discharge are usually better than relations of fish passage to the same spill variables. The relatively poor fit between hourly spill and spillway passage is to some extent due to high spill discharge hours when relatively few fish were available for passage at the project. Durbin-Watson tests for autocorrelation of errors terms in all regressions on hourly spill percent and spill discharge were not significant, indicating that the assumption of independence of hourly errors was valid. 

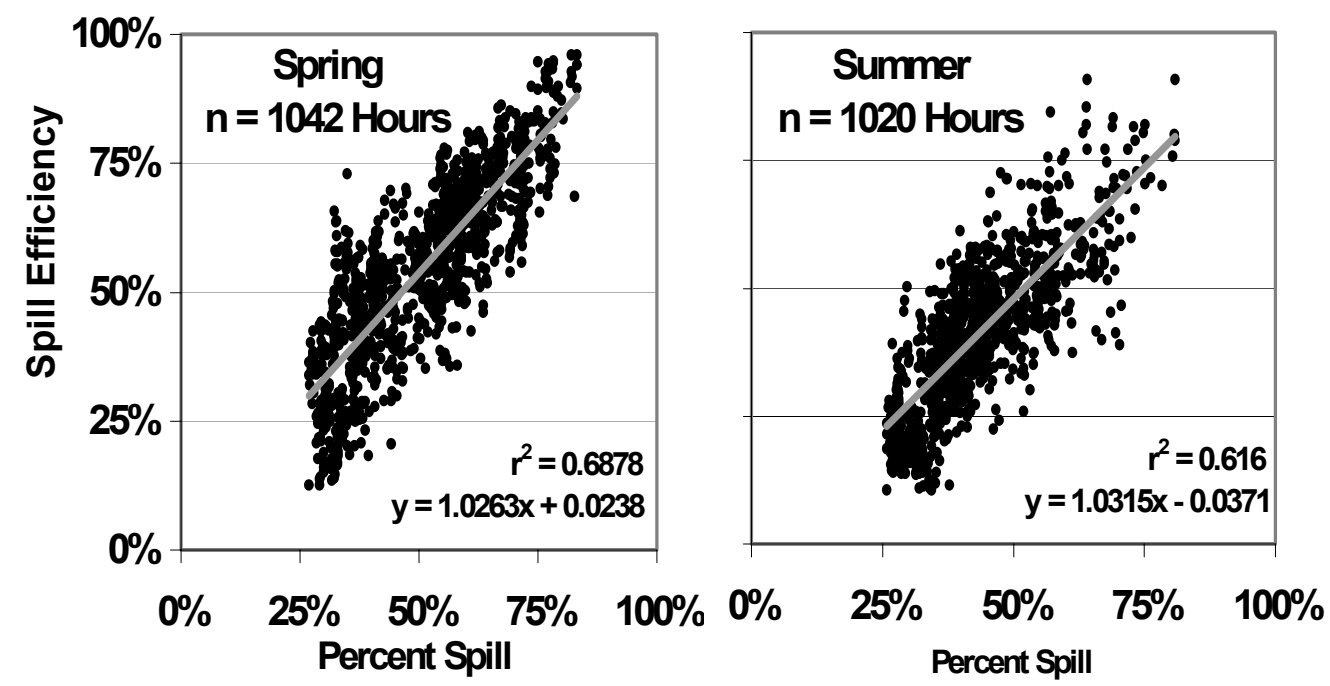

Figure S.2. Linear Regression Plots of Hourly Spill Efficiency on Percent Spill at Bonneville Dam in Spring and Summer of 2002. Data are hourly hydroacoustic estimates of spill efficiency and operational data from the Bonneville Project.
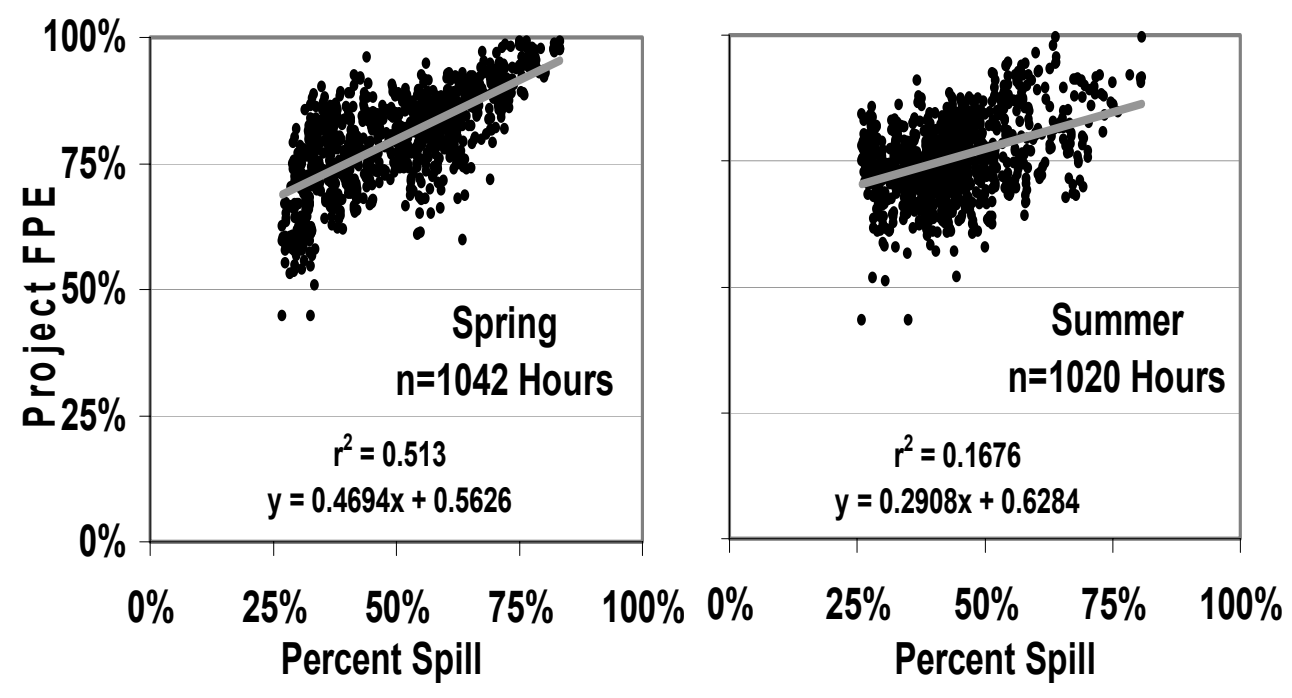

Figure S.3. Linear Regression Plots of Hourly Project FPE on Percent Spill at Bonneville Dam in Spring and Summer of 2002. Data are hourly hydroacoustic estimates of Project FPE and operational data from the Bonneville Project. 

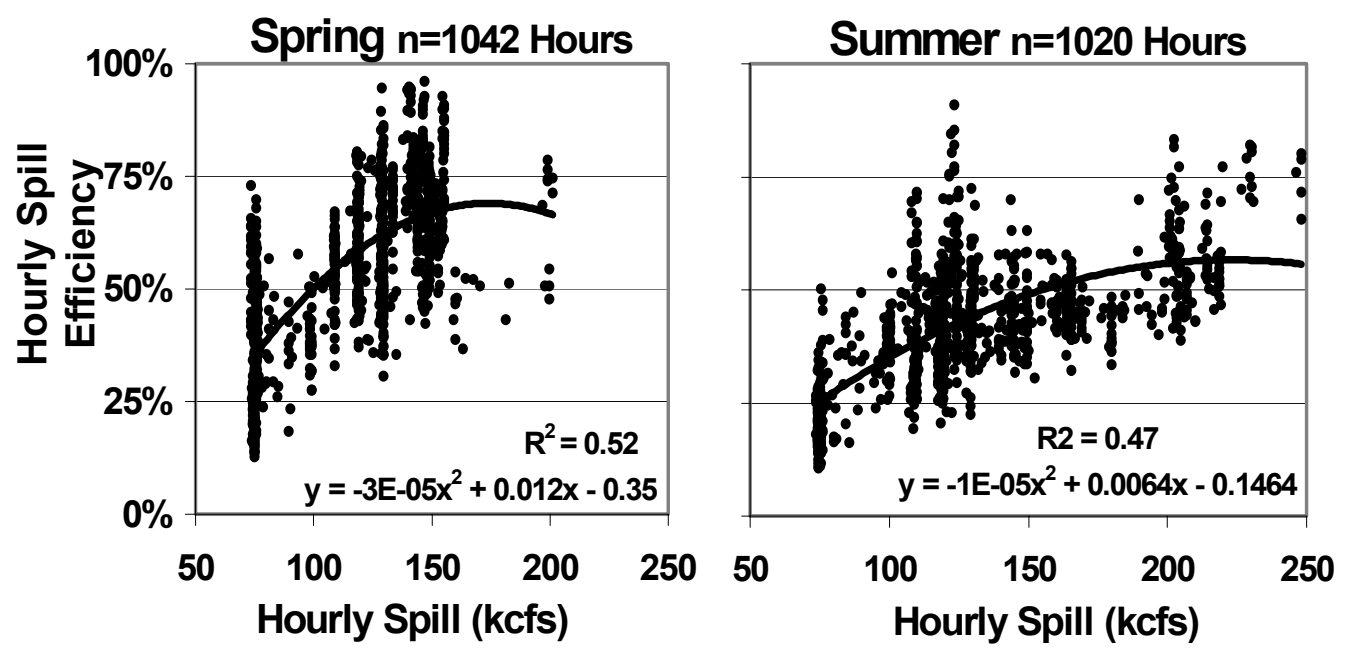

Figure S.4. Regression Plots of Hourly Spill Efficiency on Spillway Discharge at Bonneville Dam in Spring and Summer of 2002.

Reduced operational control and lower turbine FGEs at B2 may explain why the relation between Project FPE and percent spill was more significant in spring than in summer (Figure S.3). In spring, before Columbia River flows peaked in early summer, operators were able to achieve very high spill proportions and FPE by shutting down turbine units. The higher flows in summer reduced the level of control, and flow had to be more evenly distributed among turbines and the spillway (Figure 4.5). Turbine FGEs in summer usually are lower than they are in spring and this was true at B2 in 2002. If operators had been able to exercise more control over the distribution of flow in summer, there would have been more high FPE estimates at high percent spill that would have strengthened the relation for summer.

Although there is a lot of variability in estimated spill efficiency and FPE with discharge, there may be a threshold (perhaps 160,000 cfs in spring and somewhat higher in summer) above which the return for increased spill in improved spill efficiency or FPE may be very small or nonexistent. Of course this interpretation requires equal detectability of fish at all discharge rates, which was true for 2002. Using spill efficiency normalizes spillway passage for fish availability, which is certainly the source of much of the variation in fish passage versus spill rate. Since spill over $200,000 \mathrm{cfs}$ is unusual, we also examined the relations after the 107 hours with over $200,000 \mathrm{cfs}$ discharge had been deleted from the data sets. We found that the quadratic fit of the summer spill efficiency data was improved substantially (over $25 \%, \mathrm{R}^{2}$ $=0.20$ with spill over $200,000 \mathrm{cfs}$ hours; $\mathrm{R}^{2}=0.45$ without). The change in the summer Project FPE vs. spill data was not significant. It is not surprising that FPE data is not as well correlated with spillway discharge as is spill efficiency, since Project FPE includes guided passage at both powerhouses and at the B1 sluiceway. But the regression analysis of spill efficiency vs. spill rate especially, and of Project FPE to a lesser extent, provide support for the view that very high spill discharge, besides potentially harming fish in other ways, may not increase or might even reduce spillway passage. 


\section{Spatial Trends in Fish Passage}

\section{Horizontal Distributions}

Dam operations play an important role in the distribution of fish passage. In 2002, B2 had generation priority, B2 turbine units operated in about $82 \%$ of all possible turbine hours in spring and $89 \%$ in summer, whereas B1 turbine units ran in only about $30 \%$ of the possible turbine hours in spring and $65 \%$ in summer. The spill volume at the spillway was about evenly distributed across all 18 bays in spring and summer.

The proportion of discharge through the primary passage routes was generally a poor indicator of the relative proportion of fish passage among those same routes except on the scale of entire structures. For example, about $12 \%$ of the estimated fish passage and $11 \%$ of the discharge passed through B1 turbines and $52 \%$ of the fish and $49 \%$ of the discharge passed through the spillway in spring. In summer, an estimated $26 \%$ of total Project passage passed through B1 turbines in $26 \%$ of the Project discharge, and an estimated $42 \%$ passed the spillway in $44 \%$ of the discharge. The B1 sluiceway, which was very effective at passing juvenile salmon, was the reason that the percent of fish passage at B1 exceeded the proportion of flow to B1.

The B1 sluiceway entrance over Intake 7A clearly attracted and passed juvenile salmonids more effectively than any other route at the dam. Attraction is indicated by the density of fish passing there (Figures S.5 and S.6). The density of fish passing into Sluice Entrance 7A at B1 was 15,000 fish per million cubic meters $\left(15,000 / \mathrm{M} \mathrm{m}^{3}\right)$ in spring and $21,000 / \mathrm{M} \mathrm{m}^{3}$ in summer, and this would be about 12 and 29 times higher than the density of fish that passed through the most effective spill bay. It also would be about 21 and 27 times higher than the highest density passing into the average turbine.

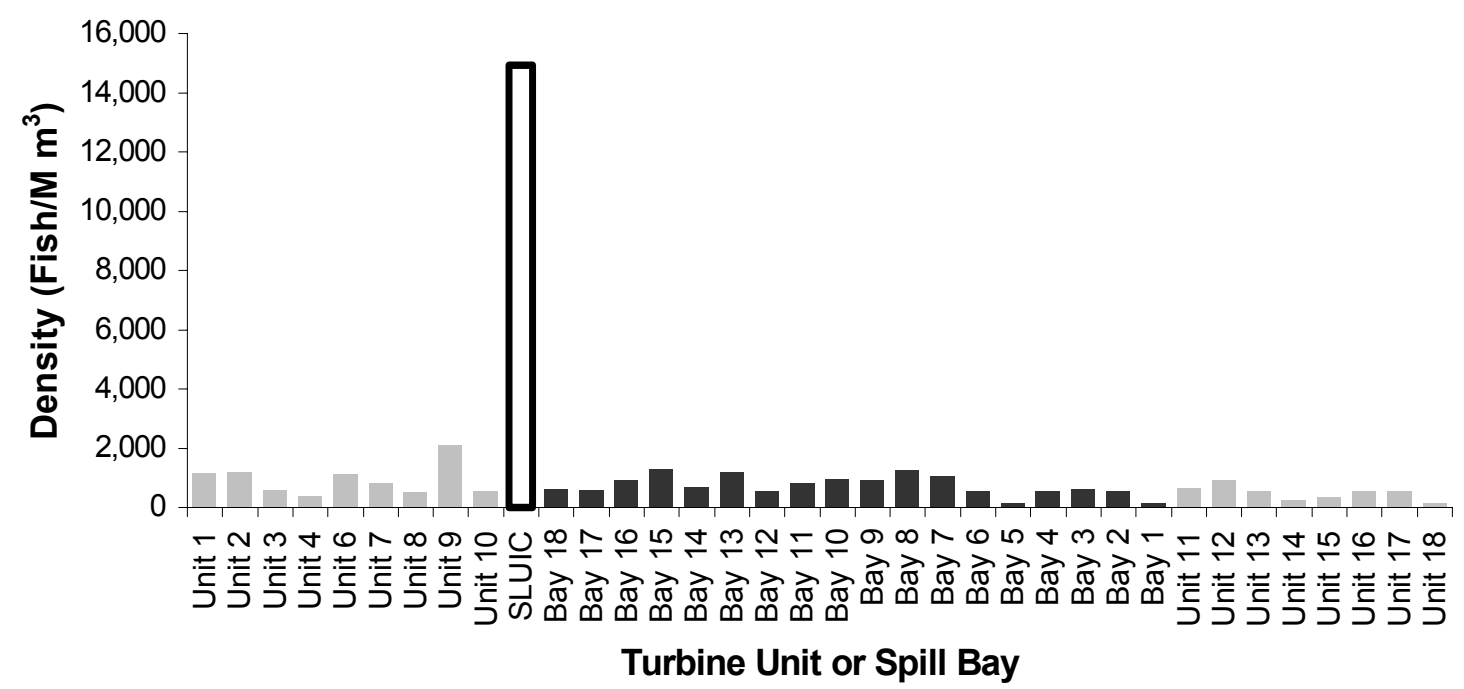

Figure S.5. Horizontal Distribution of Fish Density $\left(\mathrm{Fish} / \mathrm{m}^{3} \times 10^{6}\right)$ through Bonneville Dam in Spring of 2002. Fish density passing through turbines is represented by gray bars, through the B1 sluiceway by the white bar and through spill bays by black bars. Turbine Unit 5 did not operate in 2002. 


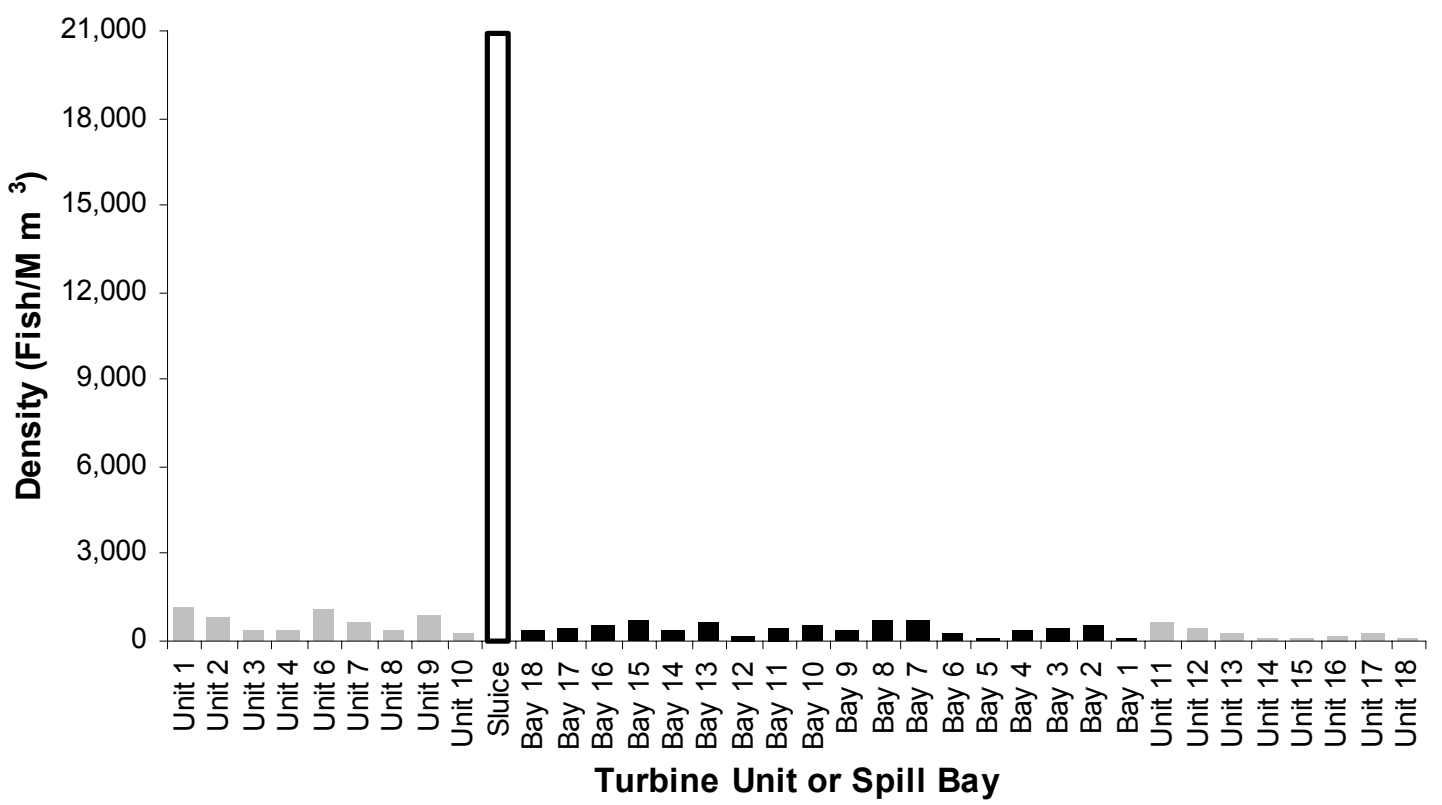

Figure S.6. Horizontal Distribution of Fish Density $\left(\mathrm{Fish} / \mathrm{m}^{3} \times 10^{6}\right)$ through Bonneville Dam in Summer of 2002. Fish density passing through turbines is represented by gray bars, through the B1 sluiceway by the white bar and through spill bays by black bars in spring. Turbine Unit 5 did not operate in 2002.

If the District ever considers testing a removable spillway weir, we recommend locating it somewhere on the south half of the spillway to take advantage of the slight southerly skew in fish passage. The distribution of fish passage at the spillway was slightly skewed toward the south end in both seasons and did not correspond to the distribution of flow, which was fairly evenly distributed among bays, although slightly higher at end bays than at interior bays in both seasons. The southern half of the spillway (spill bays 10 through 18 ) passed $13 \%$ and $14 \%$ more fish in spring and summer, respectively, than did the nine northern bays, largely due to low fish passage at bays 1 and 5. The southerly skew in passage distribution was even more apparent in spring and summer of 2000 (Ploskey et al. 2002b) and spring 2001 (Ploskey et al. 2002c) than it was in 2002 .

A southern skew in the distribution of fish passage at B2 again suggests that the corner surface collector scheduled to come on line in 2004 will be highly successful. Southern units passed about $64 \%$ and $71 \%$ of the fish going through B2 in spring and summer, respectively, and units 11 and 12 accounted for $45.3 \%$ and $49 \%$ of the total each season. Estimated fish passage was especially low at Unit 18 (at the north end of B2), which discharged as much water as any other turbine unit at the project. Both Unit 11 and Unit 18 ran almost $100 \%$ of the sampled hours in spring and summer. A mobile survey in 1996 showed high fish densities in the eddy upstream of the southern end of B2 (Units 11, 12, and 13) in both seasons (Ploskey et al. 1998). In 1998 when the sluice chute ran as a prototype surface collector, the combined FGE of unit 11-13 and the sluice chute was 35\% higher in spring and $60 \%$ higher in summer than the FGE of units 11-13 when the sluice chute was closed (Ploskey et al. 2001). In 2001, we also reported a southern skew in the distribution of fish passage at B2 (Ploskey et al. 2002c). 


\section{Temporal Trends in Fish Passage}

\section{Run Timing}

Run timing estimated by hydroacoustics compared favorably with the smolt passage index by the Pacific States Marine Fisheries Commission, except for a peak around 23 April and two peaks around 3 June that were present in the hydroacoustic count (Figure S.7). Interestingly, of the major peak detected by hydroacoustics on 23 April, $73 \%$ passed at the spillway, $17 \%$ passed as unguided at either powerhouse, and only $10 \%$ were guided by screens, which may explain why it was not apparent in the smolt index. This peak consisted of detections of some of the $3+$ million (M) hatchery fish released into the Bonneville pool a week earlier. The hatchery fish consisted of $1.45 \mathrm{M}$ yearling chinook salmon released from Carson Hatchery on April 16, 1 M yearling chinook salmon released from Little White Salmon Hatchery on April 18, and $0.97 \mathrm{M}$ coho salmon released from the Willard Hatchery on April 18. Other peaks in hydroacoustic and JBS trends either coincided or the hydroacoustic peaks occurred on the day before the JBS peaks, which is plausible given smolt delays in orifice and JBS channels. The peaks in hydroacoustic counts between 2 and 8 June that were absent from the smolt index may be explained by hatchery releases from Prosser (1.7 M on May 20 to June 01, 2002) and Umatilla (0.6 M from May 20 to May 31) adding numbers to the run at large. Of the June 2 peak in hydroacoustic data, $53 \%$ were spilled, $5 \%$ went through Sluice $7 \mathrm{~A}$, and $28 \%$ were unguided, leaving just $14 \%$ guided by screens. If we exclude eight days of data before 29 April and eight days from 1 to 8 June, the hydroacoustic estimates of run timing explain about $52 \%$ of the variation in the smolt index, which averaged about $50 \%$ of hydroacoustic estimates for the entire project (Figure S.8).

\section{Major Fish Passage Metrics}

Sluiceway $7 \mathrm{~A}$ at B1 made a significant contribution to B1 FPE, as the former explained about $84 \%$ of the variation in the latter (Figure S.9), and we observed more day-to-day variability than strong seasonal trends in B1 FPE (including sluiceway passage).

There was a slight downward trend in Project FPE and spill efficiency and spill effectiveness from spring through summer, but all metrics varied nearly as much among days as over the seasons in 2002, as did percent spill through the project (Figure S.10).

The daily estimates of FPE and spill efficiency were highly correlated with daily estimates of percent spill although the slope was less pronounced for Project FPE than for spill efficiency (Figure S.10). The slope for Project FPE was less than that for spill efficiency because Project FPE includes other non-spill guided routes which decrease in efficiency as percent spill increases, i.e., B1 sluiceway efficiency and B2 FPE. According to the regression line for Project FPE vs. percent spill, Project FPE would be about $60 \%$ if there was no spill, and this estimate is similar to an estimate of about 55\% in spring 2001 when there was no spill. 

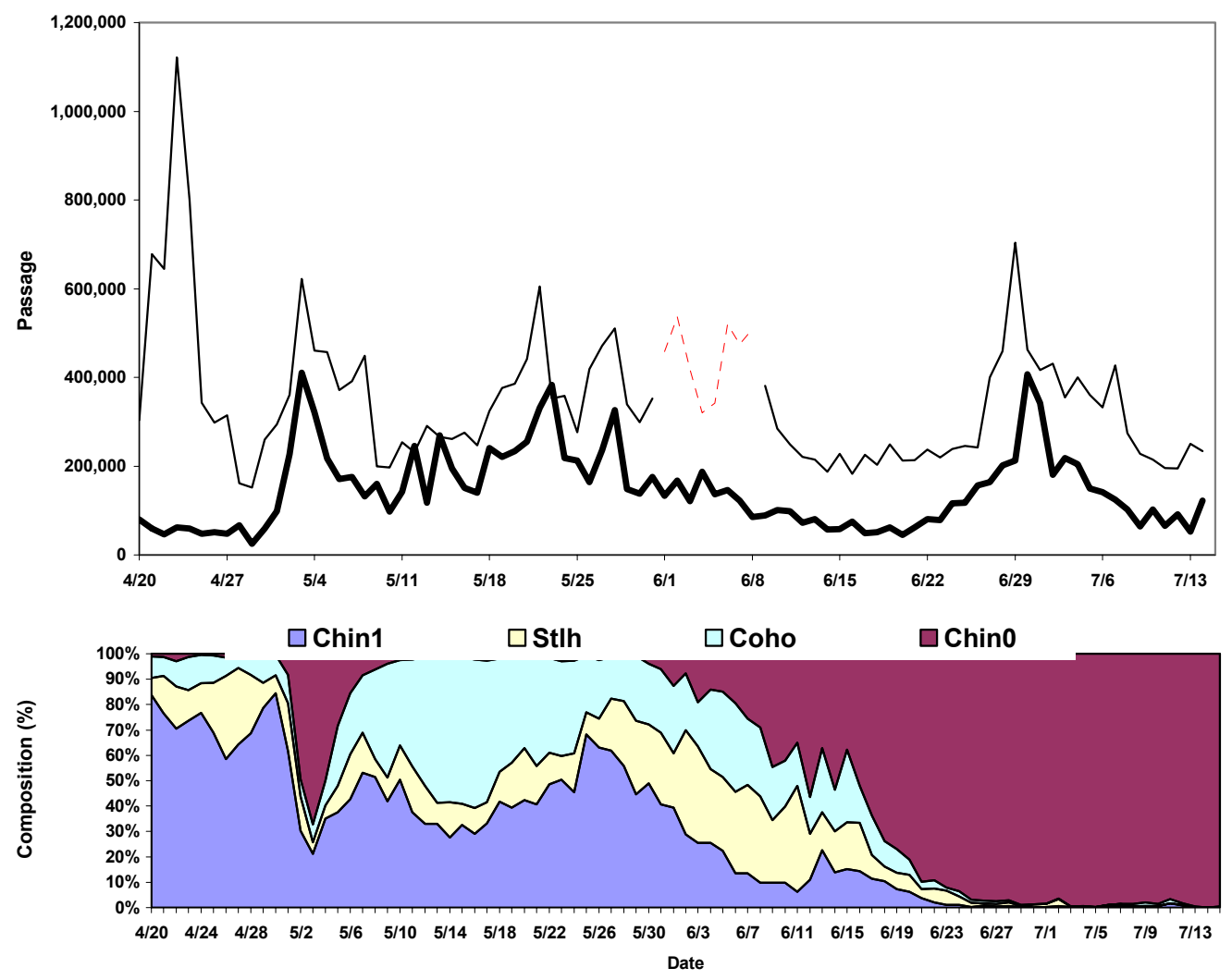

Figure S.7. Patterns of Run Timing (top) Estimated by Hydroacoustics (light black and red dotted lines) and by the JBS smolt index (heavy black line) at Bonneville Dam in 2002. The bottom plot shows the Species Composition through time.

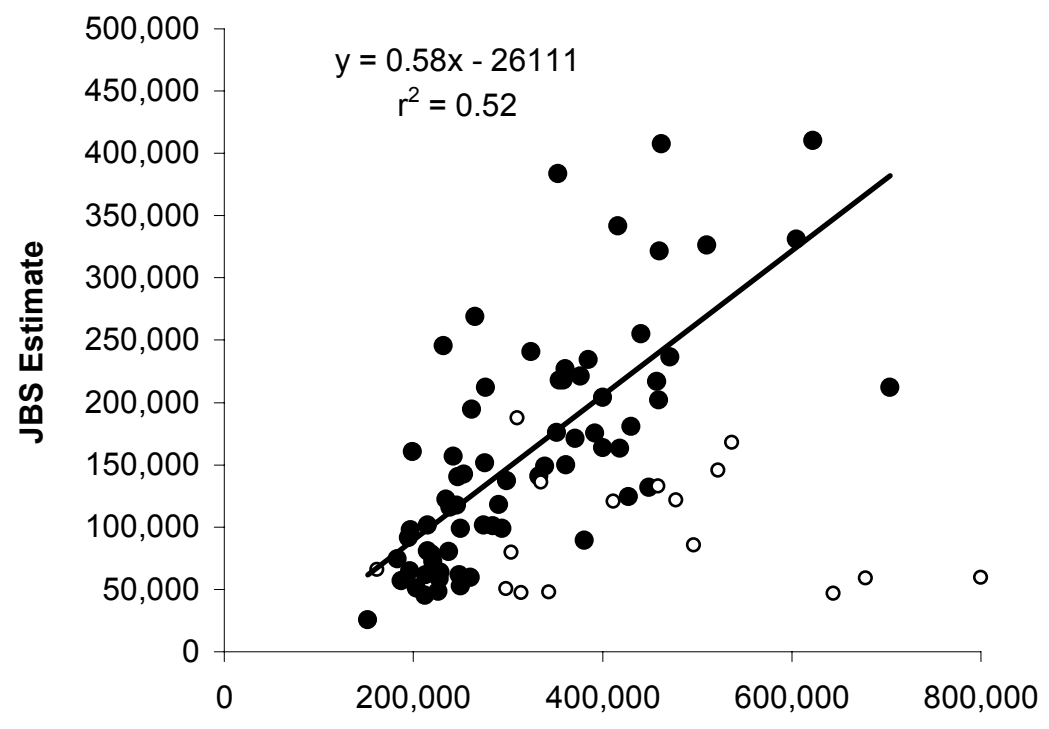

Hydroacoustic Estimate

Figure S.8. Correlation of the Smolt Index from the Juvenile Bypass System with Hydroacoustic Estimates of Fish Passage (solid points). Circles show points for eight days before April 29, 2003, and eight days between June 1 and 8, 2003, that were excluded from the regression equation because most fish from large hatchery releases passed through the spillway on those days. 


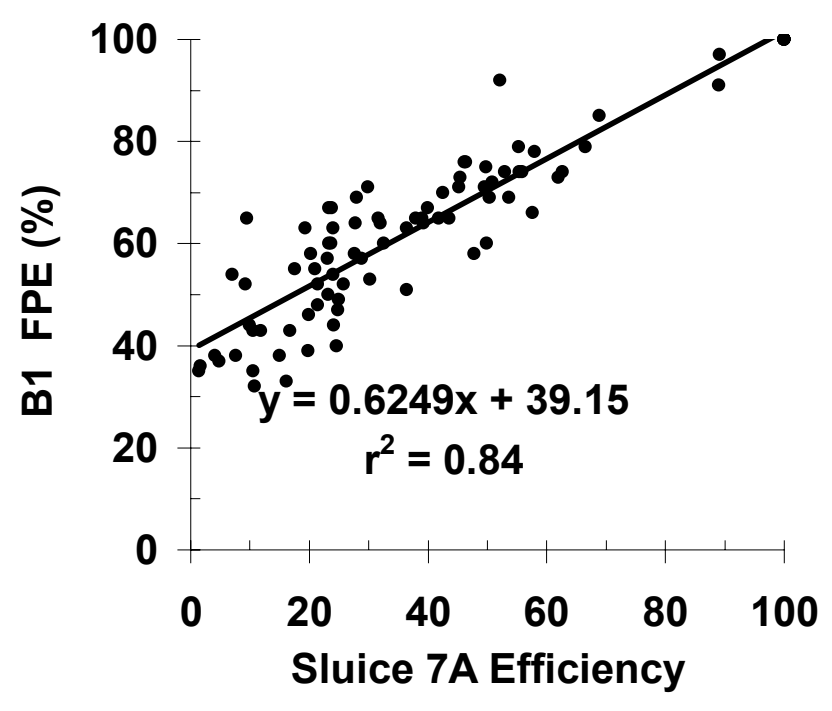

Figure S.9. Regression of Daily Fish Passage Efficiency Estimates for B1 on Sluice 7A Efficiency Relative to B1

\section{Guidance Efficiency at Modified Unit 17}

The FGE of modified Intake 17B had a typical spring-to-summer decline that we expect for most intakes at B2, but the decreasing trend at adjacent Intake 17C was not as steep, for some unknown reason. Given that Intake 15B in 2001 (Figure 3.28 in Ploskey et al. 2002c) showed a spring-to-summer decrease similar to $17 \mathrm{~B}$ in 2002, we suspected that the trends may be more abrupt for Intakes between turbine intake extensions (TIES) than for those behind TIES. However, plotting seasonal trends in Intake FGE for every intake that ran all spring and summer suggests that the trends are more related to location along B2 than to the presence or absence of TIES (Figure 4.6). What might be contamination of late summer samples by American shad is most apparent at units 11-13, just downstream of the large eddy in the south part of the forebay. Most fish passed B2 at units 11 and 12 in both seasons, and this may explain why the seasonal pattern observed at those units was also apparent in the plot of B2 FPE by date. 

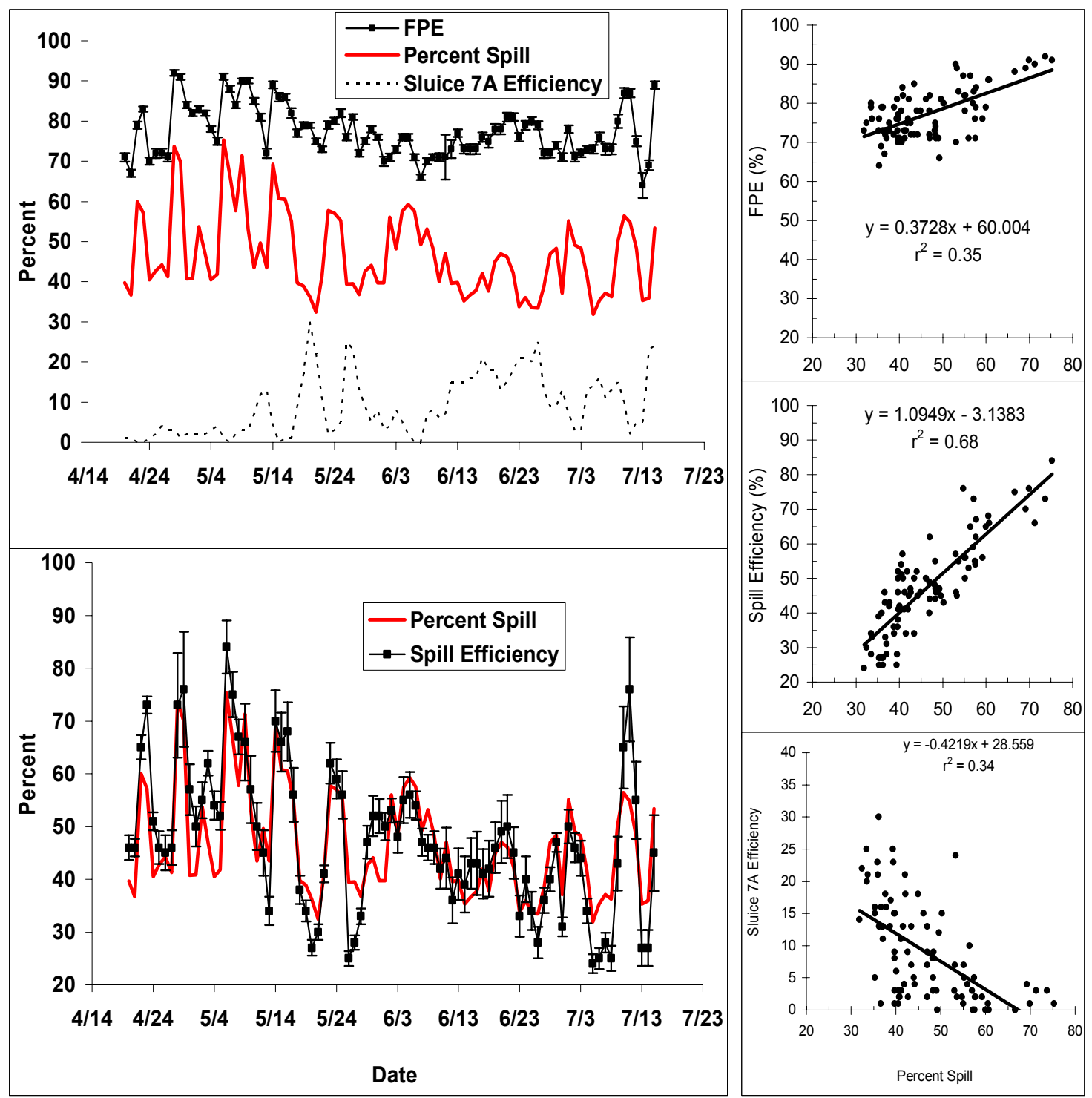

Figure S.10. Estimated Project FPE and Spill Efficiency, and the Proportion of Water Spilled at Bonneville in 2002 . Error bars represent $95 \%$ confidence limits on daily estimates.

\section{Diel Trends}

Project FPE and spill efficiency estimates were both highest in the evenings and through the night, and this typical diel pattern is driven partly by fish behavior and partly by many nights having high spill and most days having low spill (Figure S.11). In 2001, we saw a similar pattern for FPE in spring and summer and for spill efficiency in spring even though spill was nearly constant $24 \mathrm{~h}$ per day, so we know that part of the pattern is the result of fish behavior. The day-night difference was less in summer than in spring 2002, and summer estimated FPE, although always lower than in the same hour in spring, remained relatively higher after daylight (until about $0800 \mathrm{~h}$ ) and dropped relatively lower in the late afternoon and early evening. We suspect that sub-yearling smolts may have more difficulty holding in forebay areas during the day than yearling smolts. The straightforward diel trends were much simpler than the diel Project FPE data in 2000, when estimated Project FPE went up and down throughout the diel 
cycle in both seasons without a clear difference between day and night. High daytime guided passage by the prototype surface collector (PSC) and high night passage at the spillway may have moderated the daynight differences in 2000 .
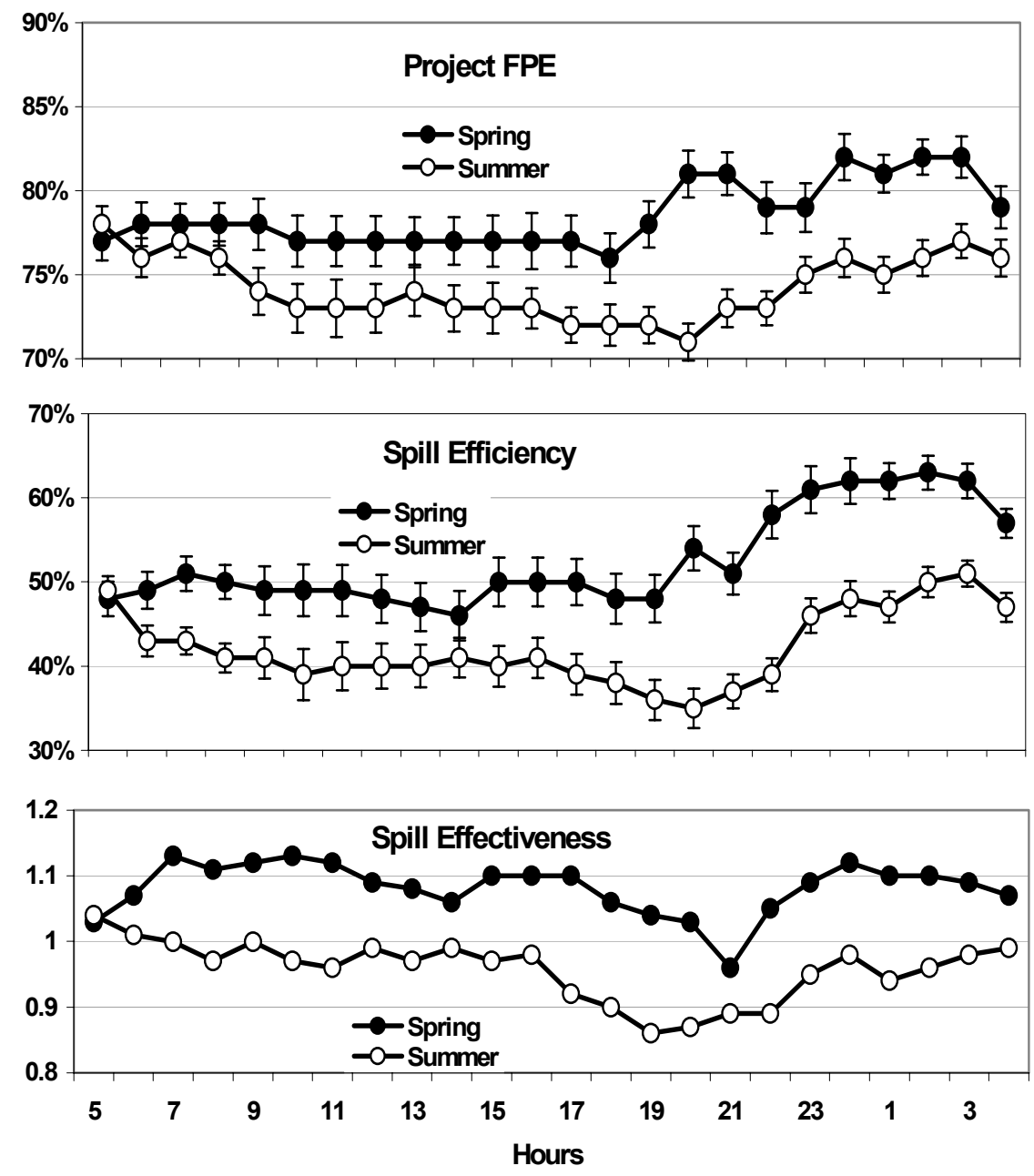

Figure S.11. Diel Patterns of Fish Passage Efficiency, Spill Efficiency, and Spill Effectiveness during the Spring and Summer at Bonneville Dam in Spring and Summer of 2002. Vertical bars for each hour are standard errors among days sampled each season.

The 2002 diel trends are most representative for a year of normal water availability and generation demand without confounding effects of PSC testing at B1 (see Ploskey et al. 2002b and d), although conditions and operations always vary between seasons and among years. The diel trend in estimated Project FPE in 2001 was less consistent than in 2002. The drought and very high power demand in 2001 constrained the duration and level of spill in both seasons and spill, when it occurred at all, varied little day to night. Sampling of the spillway also was much more complete in 2002 than in either of the other years. 
The diel peak in total fish passage in spring and summer is probably due to fish behavior and daytime delay of some individuals in the forebay areas until they lose visual cues and pass at twilight. For the whole project, there was an evening peak in estimated project passage that coincided with twilight and with the hour of highest Project discharge (the 2100 hour in spring and the 2200 hour in summer). This has long been known to be typical of juvenile salmonid passage at northwestern dams. In general, surface passage routes, such as sluiceways and surface collectors, have higher passage during daylight hours whereas turbine units and deep-passage spillways have higher passage at night (Thorne and Johnson 1993; Johnson and Giorgi 1999; Johnson and Carlson 1998; Ploskey et al. 2001a, 2001b; Ploskey et al. 2002a, 2002b, and 2002c). In the 2001 drought season, we found a strong diel trend in spillway passage (with higher passage at night) even with very nearly constant spillway discharge (Ploskey et al. 2002c).

Estimated spill passage peaked within an hour after sunset coincidental with the usual ramping up of spill discharge, but then began to decline through 0400 hours, although discharge remained high until 0400 hours, and this pattern may have implications for effective spill management. The pattern may be because the preponderance of fish available in the spillway forebay passes during the twilight peak and only fish that are newly arrived are available for passage thereafter. If the combination of higher spill and fish behavior predictably result in a reduction in spillway passage later in the night, then under low water availability or dissolved gas constraints, the spillway operations might be modified to mitigate either problem. The night could start with high spillway discharge in the evening followed by lower spillway discharge later in the night to either conserve water or reduce gas entrainment, thereby rapidly passing the juvenile fish that have just descended in the spillway forebay. After midnight in spring and after 0200 in summer the spill discharge level might be somewhat reduced. These operations could be tested with a series of controlled experiments.

The diel pattern in B1 fish passage is largely influenced by sluiceway passage which is higher during the day than at night. The FPE of B1 is relatively constant throughout the diel cycle in both passage seasons, while fish passage undergoes rather large diel excursions with generally higher passage during the day than at night in both seasons. Without the sluiceway's contribution, the diel record of spring estimated passage for turbines is much lower (never over 200,000) and much less varying throughout the day-night cycle than is the record for the turbines and the sluiceway. That is reasonable since our estimates of sluiceway passage in spring were about half of our estimates for B1 turbines only. The summer diel for B1 FPE was flat across the diel cycle both with and without the sluiceway, although it is much higher with the sluiceway (from about 60\%-65\%) than without (from about 40\%-50\%).

The relatively flat diel pattern of sluiceway passage in summer, which differed from the daytimedominated spring pattern by having slightly higher hourly rates at night, probably resulted from underestimates of sub-yearling fish passage when densities were highest during the day. Regression data comparing video and hydroacoustic estimates for the same daytime hours in spring and summer indicated that hydroacoustic counts kept up with camera counts in spring but fell very short in summer when camera densities were highest during the day. The spring data fit reasonably well $\left(\mathrm{r}^{2}=0.56\right)$ to a straight line, whereas the summer data was best described by a quadratic equation $\left(\mathrm{R}^{2}=0.52\right)$. Sub-yearling smolts passing over the weir in summer were often more tightly schooled than spring fish, which often passed as individuals. The hydroacoustic equipment and settings, especially the $200-\mu \mathrm{sec}$ pulse duration, were unable to resolve individual fish less than about 6 inches apart. Inter-fish distances in fish schools are typically a function of the length of individuals (Parris and Turchin 1997). 
The 10\%-15\% drop in B2 FPE at night from daytime was consistent with what we observed in 1998 for units 11-13 (Ploskey et al. 2001) but different than what we observed in 2001, for unknown reasons. The patterns in 1998 and 2002 are easier to explain because more fish tend to be deep in the water column at night than they are during the day, as we observed during B2 forebay sampling in 2000 (Ploskey et al. 2002b). In 2001, the diel trend at B2 FPE was weak in spring when FPE was slightly lower from 1200 to 1500 than during other hours including the night, and summer FPE was higher from about 1800 through 0400 hours than from 0500 through 1700 hours. We could not explain the difference among years, except that B2 operations were more sporadic in 2001 during the drought than they were in 1998 or 2002, when the powerhouse was more evenly loaded. If the lower nighttime FGE were the norm, that would be yet another reason to avoid using end units with the lowest FGEs at night. At least the trend of higher nighttime passage of fish at B2 was consistent with what we observed in 2000 (Ploskey et al. 2002b) and 2001 (Ploskey et al. 2002c).

\section{Comparing the Performance of Fish-Guidance Structures}

In 2002, the most important factors affecting FGE appeared to be related to modifications of units, including the presence of an ESBS instead of an STS at Unit 8, modified gatewells to increase flow up the slots of units 15 and 17, and unit location at B2 (Figure S.12). Factors that may result in differences in FGE among intakes include intake dimensions and depth, screen type, gatewell dimensions and flow, and the location of an intake among powerhouses, units, and within units (slot A, B, or C). Location at a powerhouse can determine proximity to structure (forebay sides, walls, or TIEs) or to forebay eddies. Unit 8 at B1 had the highest FGE of any unit at the project in both spring and summer. It was followed by two units with modified gatewell slots and STSs (Unit 15 and 17) and one unmodified unit (14) near the center of B2 in spring and two unmodified units (10 and 14) in summer. It is important to note that FGE estimates for different units were not always computed for exactly the same days because units ran at different times. Therefore, time of day and day-to-day variation in FGE are a part of these estimates and comparisons.

Unlike results in 2000 and 2001, the FGE of the ESBS in Unit 8 in 2002 was as high in summer as it was in spring. In 2000 and 2001, Unit 8 FGE was significantly higher in spring than in summer, although the estimate in 2001 was based upon only 5 hours of operation for the entire summer season. A plot of Unit 8 FGE by sample date in 2002 indicates that FGE did fall off in summer, just not until early July instead of early June as it did in 2000 (Figure S.13). In 2002, the late falloff in Unit 8 FGE, which began in the beginning of July, coincides with the major peak in run timing for sub-yearling chinook salmon on 30 June (Figure S.7). 


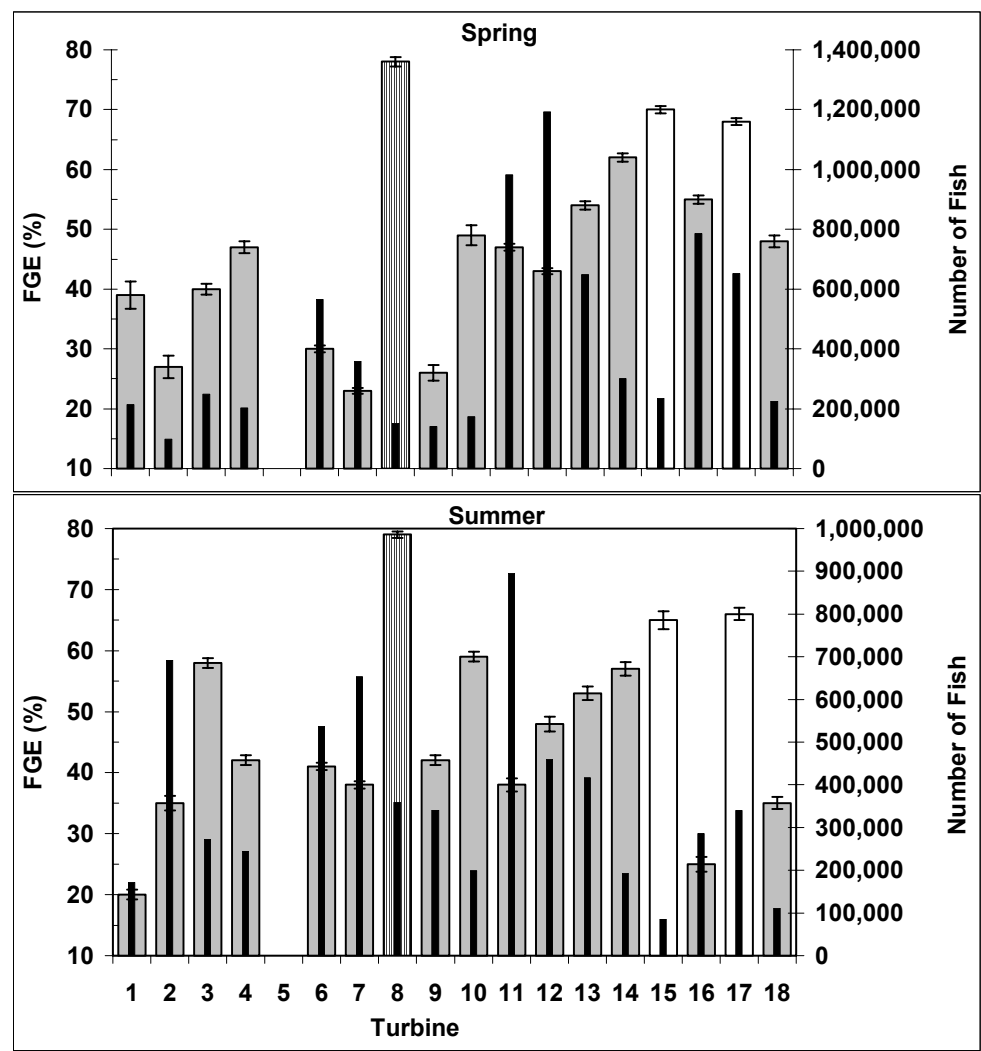

Figure S.12. Comparison of FGE (wide bars) and Fish Passage (narrow black bars) among Turbines at Bonneville Dam in Spring and Summer 2002. Turbines 1-10 are located at B1 and turbines 11-18 are at B2. All turbine intakes have submerged traveling screens except for intakes at Unit 8 (lined bar), which had extended submerged bar screens. The gatewells at units 15 and 17 (white bars) were modified to increase flow up the slot relative to gatewells at other units $(11-14,16$, and 18). Error bars are $95 \%$ confidence limits.

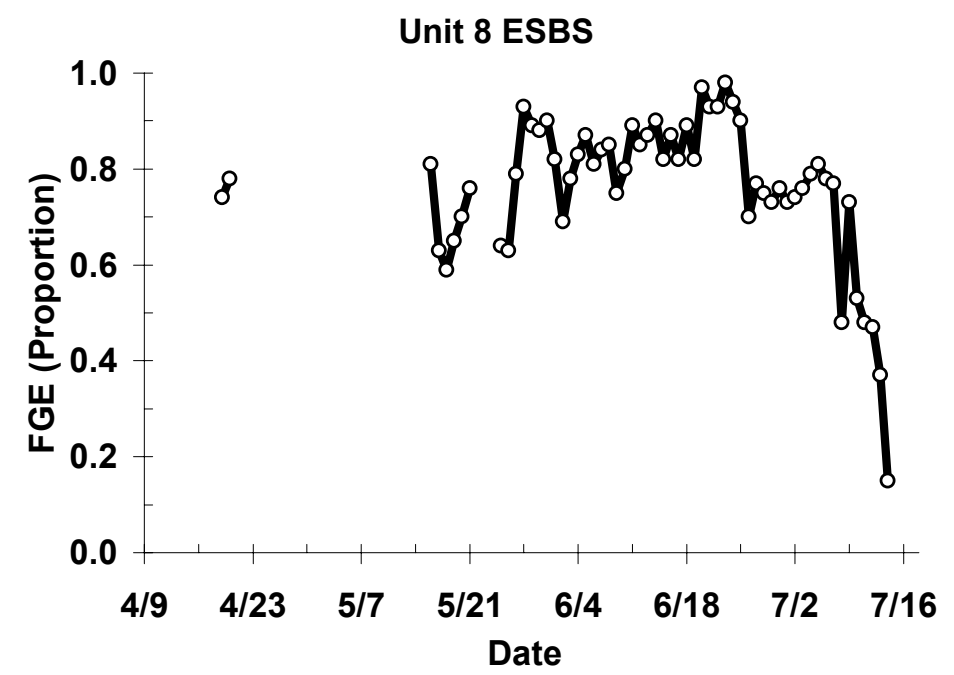

Figure S.13. Seasonal Trend in the FGE of Unit 8 with an Extended Submerged Bar Screen 
The $\mathrm{B}$ and $\mathrm{C}$ slots of $\mathrm{B} 2$ units and those intakes between TIES at B2 had significantly higher FGEs than did A slots or intakes behind TIES, respectively, probably because A slots have the highest flow, and TIEs create vortices that funnel fish down the face of the dam where they enter high in the intake and are easily guided. The significance of an interaction term between slot and TIE treatments in a two-way ANOVA suggests that the relations are complex. In 2002, the B slot of Unit 17 had a higher FGE than did the $\mathrm{C}$ slot, and this likely was because the B slot was between two TIES.

The operational priority of units at B2 results in a decrease in B2 FPE when percent spill increases because the end units, which have among the lowest FGEs at B2, keep running while center units with lower FGEs are shut down. Giving operational priority to end units makes sense for attracting adult salmonids to fish ladders during the day, but we recommend giving priority to units 13-16 at night when adult passage is minimal and juvenile passage is high. Our data suggest that B2 FPE could be increased by as much as $20 \%$ by shutting down the end units first at night. The management tactic is only needed when operational control is possible and required high spill levels dictate that some units must be taken off line. For example, operational control was good in spring 2002, and operators were able to achieve very high spill treatments by shunting water from the powerhouses, but in early summer when river flow peaked, operators had less control over proportions of water in spill and turbines.

Provision of a B2 priority in spring was a good management tactic because B2 units tended to provide higher FGE than STS-equipped units at B1, and the sluiceway at B1 was more efficient than it would have been if B1 had been fully loaded. Unit 8 with the ESBS ran more in 2002 than in 2001 and that also was good because of its high FGE. Unit 8 should be given a high priority in the future.

\section{Comparing FGE Estimates by Different Sampling Methods}

\section{Hydroacoustic and Camera Estimates of Sluice Passage}

Sampling Sluice Entrance 7A with optical cameras provided an independent estimate of fish passage which was correlated with estimates from a new, side-looking hydroacoustic deployment (Figure S.14), and both methods revealed similar horizontal distributions in fish passage (Figure S.15). Comparison of results also provided valuable feedback about fish spacing and resolution limitations of the hydroacoustic gear used in 2002. The 200- $\mu$ s pulse duration of the transducers provided a range resolution of about 6 inches, and this apparently was adequate to resolve most yearling fish at densities up to 8,000 fish/h in spring but not to resolve all sub-yearling chinook salmon in summer when densities in video camera counts exceeded about 4,000 fish/h (Figure S.14). Cameras revealed that the subyearling fish were more closely packed in schools than were the yearling fish. The side-looking deployment looks promising for sampling shallow, wide sluiceway entrances like those at B1, but clearly the resolution needs to be increased by increasing the bandwidth and shortening the pulse width. 

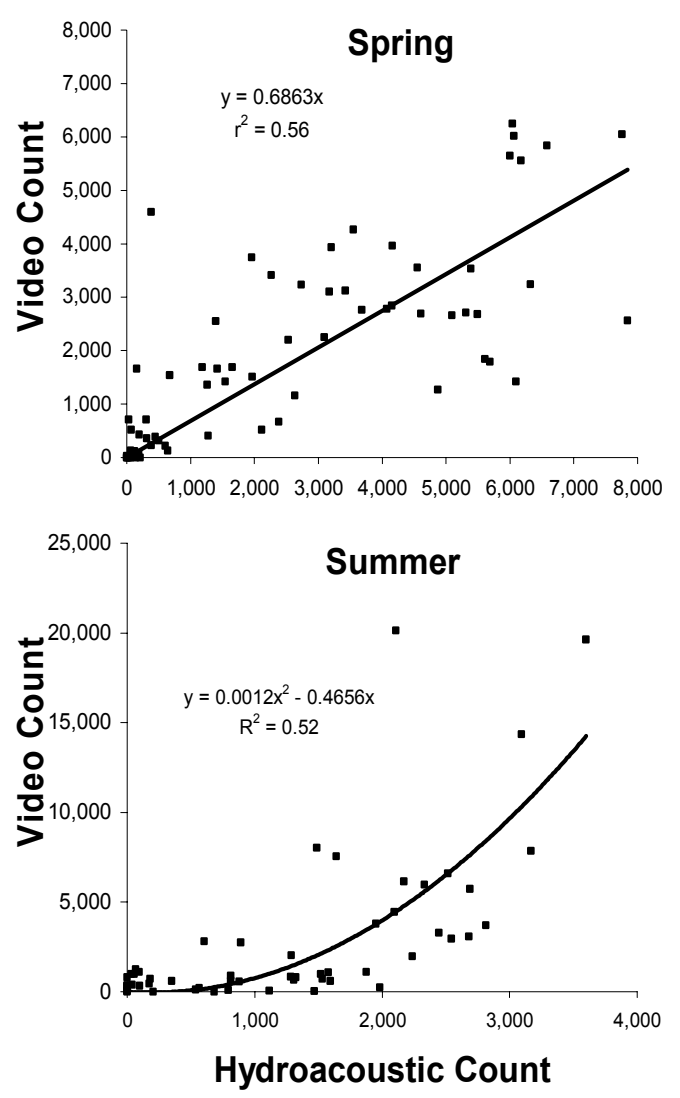

Figure S.14. Scatter Plots of Video-Camera and Hydroacoustic-Sampling Counts of Juvenile Salmonids Passing into Sluice Entrance 7A at B1.

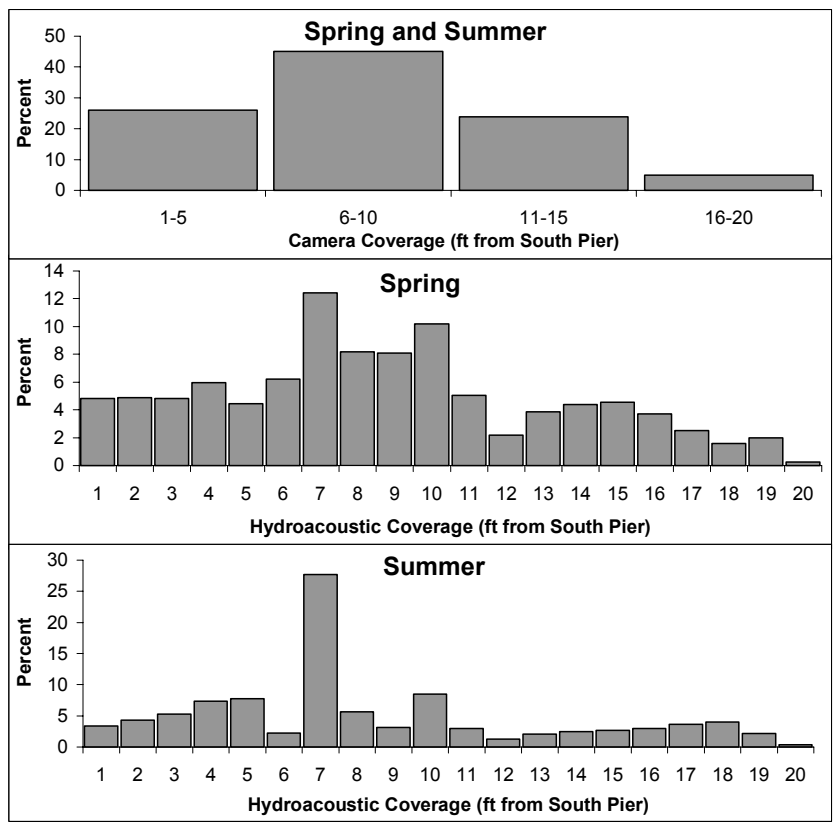

Figure S.15. Plots of the Horizontal Distribution of Fish Passage Based Upon Video-Camera Sampling (Top) and Hydroacoustic Sampling (Middle and Bottom) of Juvenile Salmonids Passing into Sluice Entrance $7 \mathrm{~A}$ at B1. 


\section{Hydroacoustic versus Netting and Radio Telemetry Estimates and Implications of Gap Losses}

Our estimates of FGE compared favorably with netting estimates by NOAA Fisheries in both seasons, particularly when we estimated FGE from all nighttime hours sampled (Figure S.16) instead of just hours of concurrent sampling or all day and night hours. Hydroacoustic estimates of FGE require longer sampling durations than the 1 to 2 hours that are commonly used to estimate FGE by netting. Hydroacoustic beams sample only about $5 \%$ of the cross-sectional area of an intake compared to near $100 \%$ coverage by netting. For example, Ploskey and Carlson (1999) observed that the precision of hydroacoustic estimates of FGE at John Day Dam increased by $50 \%$, and the $r^{2}$ of a correlation line between hydroacoustic and netting estimates increased by $19 \%$, when the hydroacoustic sampling duration was extended from the typical netting duration of 1-2 h to $4 \mathrm{~h}$. In 2002, we were able to sample throughout the night after the NMFS finished netting because the unit was not left idle as it often was in 2001.

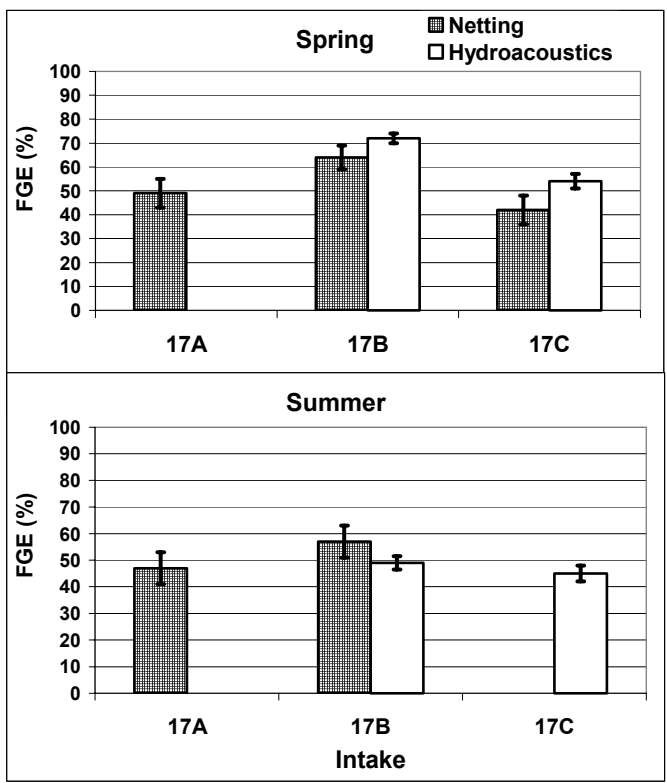

Figure S.16. Plot of FGE Estimates Based Upon Hydroacoustic Sampling in this Study and Net Sampling by NOAA Fisheries During the Same Nights in 2002. Netting was done for 1-2 hours beginning about 2000 hours and hydroacoustic sampling was from 2000 through 0500 hours. Vertical bars depict $95 \%$ confidence limits on the estimates.

In 2002, we were able to assign zero counts to 1-minute samples collected when turbines were off because dam operators provided exact on and off times for every turbine, and these data undoubtedly improved the accuracy of the FGE estimates by eliminating counts of un-entrained fish. Hydroacoustic equipment samples continuously, so it is important to know exactly when units are off. We recommend that future operations data include exact on and off times for turbines sampled by hydroacoustic methods.

There appears to be a disparity between gap loss estimates by netting and those made by imaging devices. According to gap sampling by NOAA Fisheries using a gap net, losses of fish typically range from $1-2 \%$, and the highest reported netting estimate was about $12 \%$ for a STS lowered $1.2 \mathrm{~m}$ below the normal position (Gessel et al. 1991). In 2002, the STSs in unmodified units of B2 had a gap of about 0.76 $\mathrm{m}$, and the gap should have been narrower in modified units with gap-closure devices. Our estimates of 
gap loss ranged from 13 to $15 \%$ of all guided and unguided fish, and this estimate is higher than that reported in netting studies, including the study by Bruce Monk (NOAA Fisheries) at Unit 17 (gap loss < $2 \%$ ) this year. Using optical video cameras, Nestler et al. (1995), reported that 12 to $37 \%$ of the smolts initially guided by an ESBS at McNary Dam were lost to the gap between the VBS and the ESBS. We recommend additional evaluations of gap loss using the acoustic camera and optical cameras (for verification) in future years.

Table S.2. Percent of Smolt-sized Fish Lost through the Gap between the Top of the Submerged Traveling Screen and the Intake Ceiling in Modified and Un-modified Gatewells in Spring and Summer 2002.

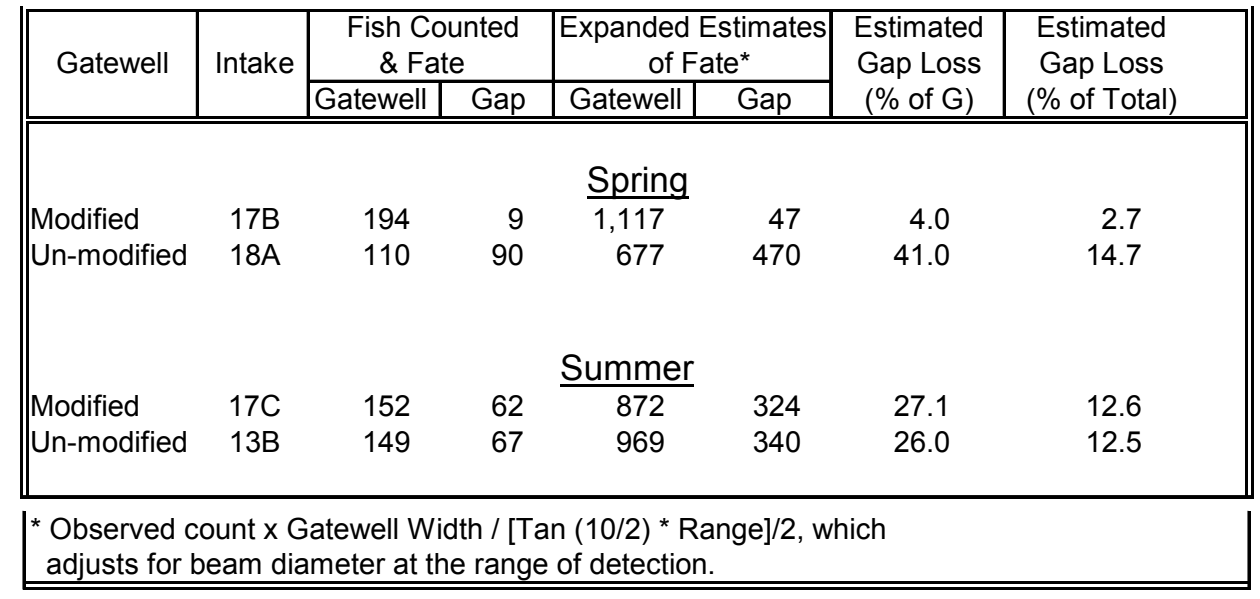

Losses of fish between the top of the STS and the bottom of the intake ceiling may explain some of the difference between FGE estimates by hydroacoustics, netting, and radio telemetry, provided that some gap-lost fish are detected by radio telemetry antennas mounted on the downstream side of the STS. If gap losses are included in estimates by radio telemetry, partially included in netting estimates, and not included in hydroacoustic estimates, managers can view hydroacoustic and netting estimates as the potential FGE that could be achieved and telemetry estimates as the worst case including gap loss. We recommend an assessment of the potential for telemetry antennas to detect gap lost fish. Hydroacoustic estimates of guided fish in this report and other previous reports have no correction for gap loss, but this year we estimated gap losses ranging from $26 \%$ to $41 \%$ of guided fish and $13 \%$ to $15 \%$ of all guided and unguided fish in intakes 13B, 17C, and 18A. The high gap loss at Intake 17C was a surprise, because we expected it to be like that of Intake 17B (4\% of guided and $2.7 \%$ of the total). Both 17B and 17C had gap closure devices and turning vanes designed to increase flow up the slots, and these modifications presumably would reduce gap losses but did not reduce it in Intake 17C. There may be differences among slots in a unit based upon differences in the amount and direction of flow, and this potential needs to be investigated further.

Our effort to detect losses of fish through the side gap between the intake wall and the side of the STS with the acoustic camera were inconclusive because even the best aiming angle only allowed us to see about $3 \mathrm{ft}$ of the gap near the tip of the STS. An expanded estimate of side gap loss would only yield 13 to 20 fish lost over a 24 -h period, which is $<3 \%$ of the expanded estimates of numbers in the gatewell. Although the field of view of the acoustic camera was not ideal, and our expansion assumes that side-gap loss is uniform along the length of the STS, this preliminary estimate of side-gap loss does not seem to be 
significant, which agrees with previous netting studies (John Ferguson, NOAA Fisheries, personal communication).

Acoustic camera estimates of gap losses of $13 \%$ to $15 \%$ of all guided and unguided fish cannot account for FGE differences of $33 \%$ to $39 \%$ in spring or $30 \%$ to $44 \%$ in summer between telemetry and netting or hydroacoustic estimates at Unit 17 . We noticed that differences in hydroacoustic and radio telemetry estimates tended to be smaller when the number of fish detected by radio telemetry was higher, so we plotted differences as a function of the number of tagged fish detected at each unit in spring and summer and fit an exponential-decay curve to the data (Figure S.17). The fitted equation explained about $45 \%$ of the variation in observed differences, and the greatest differences occurred when detections were $<30$ tagged fish per unit. The data suggest that with $>30$ detections differences of $\pm 15 \%$ can be expected. Eighty percent of the 16 seasonal estimates of FGE for individual B2 units by telemetry and hydroacoustics were within $\pm 10 \%$ of each other.

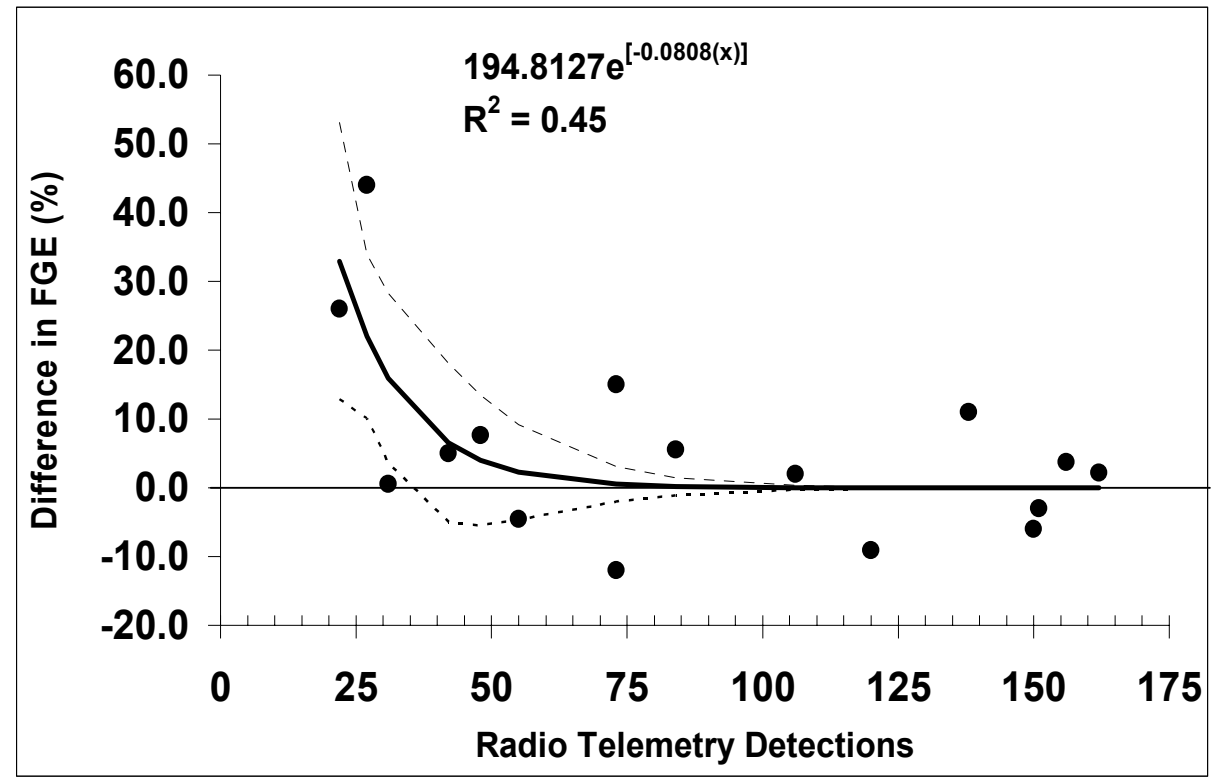

Figure S.17. Plot of the Difference (Hydroacoustic - Radio Telemetry) in Estimates of FGE as a Function of the Total Number of Radio-Tagged Fish Detected at a Turbine Unit. Dotted lines represent upper and lower $95 \%$ confidence limits on the regression line.

Horizontal distributions of fish passage by radio telemetry and hydroacoustic sampling in spring were similar, and those data and the hydroacoustic distribution of fish in summer suggest that the corner collector scheduled for operation in 2004 will pass a lot of fish. Both hydroacoustic sampling and radio telemetry detections indicated that the distribution of fish passage at B2 was strongly skewed to the south end of the powerhouse in spring, and hydroacoustic sampling also showed a similar southerly skew in summer.

Similarities in the horizontal distribution of fish passage at B2 in spring and differences in summer might be explained by a relatively greater effect of tagging on sub-yearling fish than on yearlings. If tagged sub-yearlings were more fatigued than their untagged counterparts in summer they might be more likely to pass at whatever unit they first contacted. Water entering the B2 forebay approaches center units 
first because large eddies occur on the north and south sides. The southerly skew in the hydroacoustic distribution in summer would require fish to avoid passing through center units and to move laterally toward the south. The probability of avoiding entrainment and moving south may be higher for untagged than for tagged sub-yearling fish, and tagged and untagged yearlings may behave similarly because they are less affected by tagging.

\section{Comparison of Major Metrics from 2000 through 2003}

The three years of full Project FPE studies conducted in 2000-2003 yielded a baseline of metrics with a great deal of variability (Table S.3) because operational strategies and river flow varied greatly among years. A goal of the multi-year effort was to establish a baseline for evaluating future management improvements. We found significant differences in most metrics in two or three of the years studied. For example, Project FPE and spill efficiency were lower in 2001 than in 2000 or 2002, because of drought that limited the duration and amount of spill. Spill effectiveness was lower in spring 2001 than it was in spring of 2000 or 2002, but it was higher in summer 2001 than it was in summer of 2000 or 2002 . The FPE of B1 was higher in 2000 than it was in 2001 or 2002 because the B1 PSC was tested and it was highly efficient in both seasons.

About the only metric than did not vary a lot among years was B2 FPE, where estimates for all three years were within $4 \%$ of each other in spring and within $11 \%$ of each other in summer. The B2 FPE probably would have been lower in 2000 if that had been a low-water year, because generation priority was given to B1 to facilitate PSC testing, and unit outages at B2 would have been the more efficient center units. However, 2000 was a normal water year and unit outages at B2 were not excessive. Unit outages at B2 certainly were nothing like those observed at B1 in 2001 and 2002, when managers switched the generation priority to B2 because fish survival through B1 was poor. We sampled shallow sluiceway entrances at B1 as part of the full-Project FPE study for the first time in 2002, and results clearly indicate that the contribution of even small surface bypass routes can be very significant and should not be ignored. Not sampling B1 sluice entrances in 2000 and 2001 was an oversight, but did not diminish the usefulness of comparisons of route-specific metrics among years.

\section{Effects of Spill Treatments on Major Metrics}

High spill (day or night) increased spill efficiency $>20 \%$ over low-day spill each season, but effects on Project FPE were modest in spring $(+7.6 \%$ to $10 \%)$ and were not significant in summer. Modest gains in Project FPE likely result from significantly lower B1-sluice efficiency and B2 FPE during high day or night spill than during low-day spill. During high spill, many fish that might have otherwise passed through the B1 sluiceway or the JBS at either powerhouse were spilled instead, so the major increase in spill efficiency by spilling more may not directly translate into a meaningful benefit unless passage by spill is preferable to passage by other routes. In two-way ANOVAs examining effects of spill-treatment, 4-day treatment blocks, and the interaction between block and treatment in spring (Appendix G-2), 4-day treatment block usually was significant, indicating that metrics changed significantly during the season. The interaction of treatment block and spill treatment also was significant or nearly significant for many metrics, indicating that spill-treatment effects depend upon time-related variables, perhaps run-timing of various juvenile salmonids, hydrology, or water temperature. 
Table S.3. Comparison of Major Fish-Passage Metrics among the Three Years of Hydroacoustic Studies

\begin{tabular}{|c|c|c|c|}
\hline Major Passage Metric & $\begin{array}{l}2000 \\
\text { (PSC) } \\
\text { (B1 Priority) }\end{array}$ & $\begin{array}{l}2001 \\
\text { (Drought) } \\
\text { (B2 Priority) }\end{array}$ & $\begin{array}{l}2002 \\
\text { (B2 Priority) }\end{array}$ \\
\hline Spring Project FPE & $79 \pm 0.2 \%$ & $63 \pm 0.3 \%$ & $79 \pm 0.1 \%$ \\
\hline Spring B1 FPE (without Sluiceway) & $67 \pm 0.4 \%$ & $49 \pm 2.3 \%$ & $37 \pm 0.4 \%$ \\
\hline Spring B2 FPE & $54 \pm 0.8 \%$ & $57 \pm 0.3 \%$ & $53 \pm 0.3 \%$ \\
\hline Spring B2 + Spillway FPE (without B1) & N/A (B1 Priority) & $64 \pm 0.3 \%$ & $83 \pm 0.4 \%$ \\
\hline Spring Spill Efficiency & $44 \pm 0.4 \%$ & $14 \pm 0.2 \%$ & $52 \pm 0.5 \%$ \\
\hline Spring Spill Effectiveness & $1.36 \pm 0.010$ & $0.84 \pm 0.004$ & $1.08 \pm 0.010$ \\
\hline Summer Project FPE & $79 \pm 0.2 \%$ & $53 \pm 0.4 \%$ & $74 \pm 0.2 \%$ \\
\hline Summer B1 FPE (without Sluiceway) & $61 \pm 0.2 \%$ & $40 \pm 1.8 \%$ & $45 \pm 1.2 \%$ \\
\hline Summer B2 FPE & $35 \pm 2.2 \%$ & $42 \pm 0.4 \%$ & $46 \pm 0.7 \%$ \\
\hline Summer B2 + Spillway FPE (without B1) & N/A (B1 Priority) & $54 \pm 0.4 \%$ & $82 \pm 0.5 \%$ \\
\hline Summer Spill Efficiency & $49 \pm 0.4 \%$ & $20 \pm 0.3 \%$ & $42 \pm 0.5 \%$ \\
\hline Summer Spill Effectiveness & $1.03 \pm 0.01$ & $1.83 \pm 0.01$ & $0.96 \pm 0.01$ \\
\hline
\end{tabular}

There were eight days and nine nights of high spill in spring requiring shutdown of all B1 turbines and this unusual condition produced $100 \% \mathrm{FPE}$ at B1 as all fish passed through the sluiceway. The analysis of variance that showed a major increase in B1 FPE during high spill treatments is spurious because of the inclusion of these data. We would have expected no effect, as observed when those data were excluded (Figure 3.42) or even a decrease in B1 FPE with increased spill, as observed in summer. The annual hydrograph peaked in summer, and many B1 turbines ran even during the days and nights of highest spill so there were observations with $100 \%$ B1 FPE.

In spring, Project FPE and spill efficiency, and spill effectiveness were all higher during high spill treatments (day or night) than during low daytime treatments (Figure S.18), although the difference was greater for Project spill efficiency (at least 30.4\%) and effectiveness (13.4\%) than it was for Project FPE (7.5\%). In contrast, B1 FPE, B1 sluice efficiency and effectiveness, and B2 FPE were all higher during low spill treatments than during high spill during the day or night. Project FPE and spill efficiency did not differ between the day and night treatments with high spill.

In summer, high spill during the day or night also resulted in higher Project FPE, spill efficiency, and spill effectiveness than low spill during the day (Figure S.18), although the difference was again greater for Project spill efficiency (at least 23.2\%) and effectiveness (21.7\%) than it was for Project FPE (5\%). As in spring, B2 FPE was significantly lower under high spill than it was during low spill, but for B1 FPE the effect was not as clear as it was in spring primarily because spill level had no discernable effect on B1 sluiceway efficiency or effectiveness in summer. Estimated B1 FPE did not differ between high spill treatments (day or night) and the low spill treatment during the day. The lack of effect in summer may be related to the inability of hydroacoustic sampling to resolve and count all sub-yearling fish that passed into the B1 sluiceway, so daytime counts during low-spill treatments were greatly underestimated. 

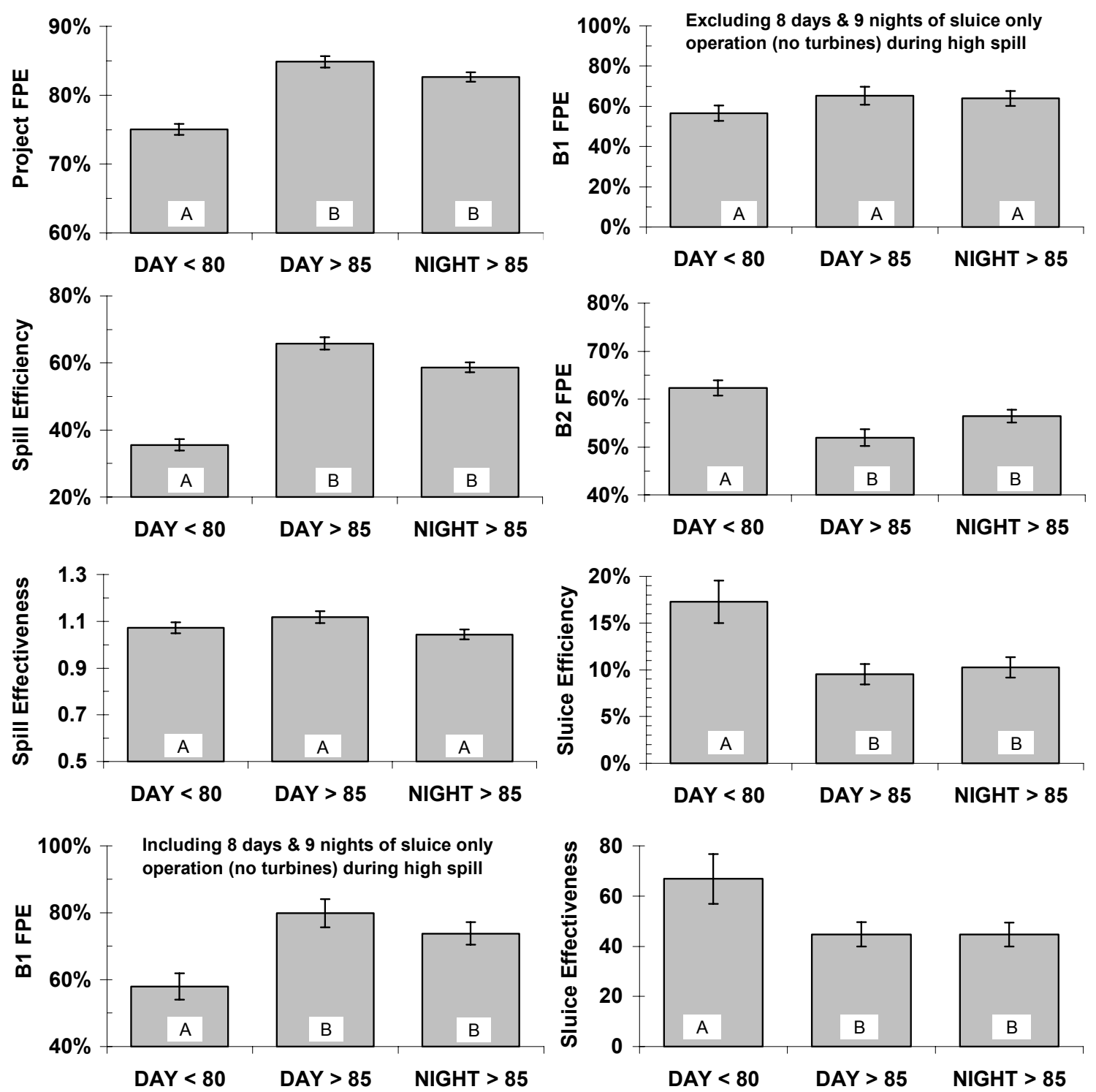

\section{SPILL TREATMENT}

Figure S.18. Plots of Major Passage Metrics by Spill Treatment in Spring. Bars with the same letter did not differ significantly. 

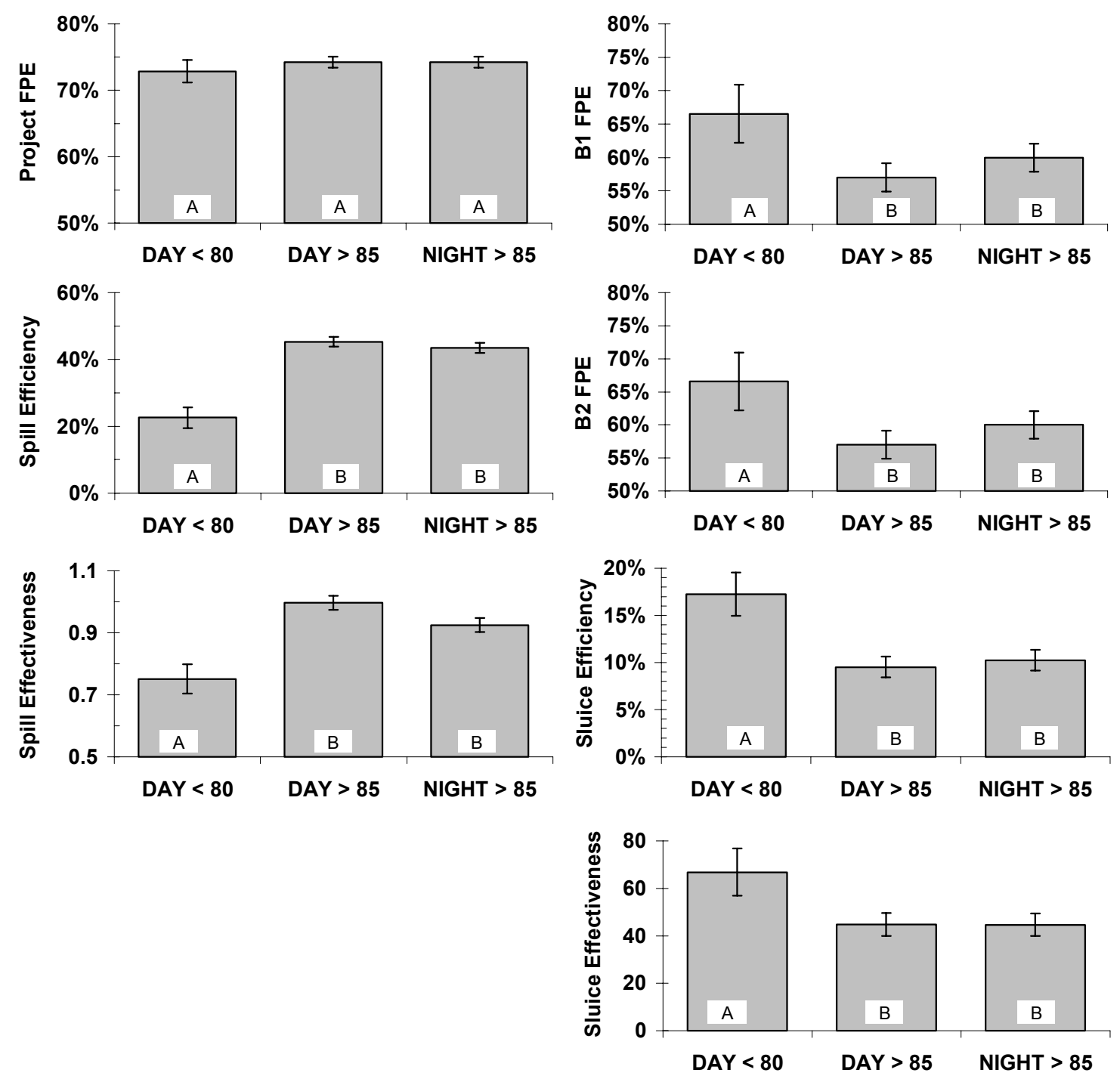

\section{SPILL CONDITION}

Figure S.19. Plots of Major Passage Metrics by Spill Condition in Summer. Bars with the same letter did not differ significantly.

\section{Recommendations}

1. If $\mathrm{B} 1$ priority is to be reduced even further, managers might want to consider effects on water quality (temperature and $\mathrm{O}_{2}$ ) and use mobile hydroacoustic monitoring in case a sizeable number of smolts enter the B1 arm of the Bonneville Dam forebay and delay there. We estimate that in 2002 some $19 \%$ of the total project fish passage went through B1 in only about $11 \%$ of the discharge in spring and about $37 \%$ passed there in summer in about $21 \%$ of the Project discharge.

2. B1 sluiceway passage opportunities should be increased because the entrance at Intake 7A was the most effective passage route at the dam in 2002. The density of fish passing there was many times higher than at any other route. The intake at 7A was especially effective at collecting fish 
because its entrance flow was not limited by channel capacity, and its proximity to the pier between units 6 and 7 may have helped. If the sluiceway channel can handle the discharge, gates toward the south end (e.g., unit 5 or 6 and perhaps at Unit 2) might be opened to provide additional surface-bypass flow. Existing hydroacoustic and radio telemetry data could inform that choice.

3. We recommend closing B1 Sluiceway Entrance 10C, because unlike entrances further south, 10C has very low entrance volume and velocity, and fish are milling there rather than entering the sluiceway. Data indicate that $10 \mathrm{C}$ passes relatively few fish and may be collecting smolts in that corner where they are subject to delay and predation. If a sluice entrance is needed toward the north end of B1, hydraulic modeling studies can determine the first entrance (from the north) that is not limited by channel capacity.

4. Future hydroacoustic studies at B1 must sample every sluiceway entrance, where entrance flow is not limited by channel capacity because passage is too high to ignore in FPE calculations. We also recommend a side-looking deployment with transducers mounted on the chain gates because passage estimates were highly correlated with estimates from four optical cameras.

5. We recommend testing equipment in fall 2003 by sampling juvenile American shad at one sluiceway entrance with hydroacoustic gear and optical cameras. The testing will help us identify needed improvements and allow time to prepare all required systems and transducers for sampling sluiceway entrances in spring 2004. Sampling sluiceway entrances is very important and may become more important if additional B1 entrances are opened or when the B2 corner collector comes on line in 2004. We have a prototype system that features increased bandwidth, shorter pulse duration, and much higher resolution, but it needs to be tested before the outmigration of 2004.

6. Generation priority should be given to center units at B2 at night when adult passage is minimal and juvenile passage is high. Hydroacoustic data suggest that B2 FPE could be increased by as much as $20 \%$ by shutting down the end units first at night. At B2, the FGEs of turbine units 11 , 12 , and 18 have been consistently lower than the others on the powerhouse. Units 11 and 12 also pass many more fish than do any of the other units. Of course unforeseen consequences, such as effects on adult lamprey migration or changes in tailrace egress, should be considered. Also, conditions at B2 may be very different after the operation of the new corner collector adjacent to units 11 and 12.

7. There may be reasons for giving generation priority to one powerhouse over the other (e.g., differences in survival), but the decision should not be made solely based upon FPE estimates made from ignoring one or the other powerhouse. The examination of metrics calculated for only B2 and the spillway (ignoring fish passage at B1) lacks valid statistical inference. Although units at B1 were off during $70 \%$ of all possible unit hours in spring and $35 \%$ in summer, those operations are quite different from no B1 operation. If B1 were truly off or most fish traveling down the Oregon side of the river were somehow kept from entering the B1 forebay, Project FPE and spill efficiency might be higher than what we can calculate by ignoring B1 fish passage. Calculations cannot account for fish densities in the river, the effect of density on fish behavior, or the closer proximity of fish passing down the Oregon side of the river to the spillway than to B2. The density of fish passage at B1 was higher than it was at the spillway or B2, so eliminating or reducing passage at B1 could greatly increase Project FPE and spill efficiency. Our exercise in computing FPE for only the spillway and B2 inevitably produces estimates considerably higher 
than those that are computed for the entire project, but the same result occurs if only B1 and the spillway are used in calculations.

8. Given the narrow entrance to the B1 forebay and the high density of fish passage at B1, we recommend that managers experiment with behavioral ways to shunt fish to the spillway (e.g., turbulence producing propellers).

9. If $\mathrm{B} 1$ generation is given low priority in the future, Unit 8 should be given among the highest operational priority because it provided the highest FGE of any turbine at Bonneville Dam in 2002.

10. In case of the need to either conserve water or limit dissolved gasses downstream, there may be an opportunity to reduce spillway discharge after the high passage pulse that occurs between 2000 $\mathrm{h}$ and midnight in spring without much cost to spillway passage and FPE. The opportunity is probably less in summer but some savings in discharge and either generation or dissolved gas might be achieved then as well. We observed a pulse in spillway passage that coincides with the onset of higher nighttime spill in both spring and summer, but spillway passage estimates fall off considerably as the night progresses although spill discharge stays high. This was especially so in spring 2002, when spillway passage estimates dropped off considerably after midnight.

11. If the District considers testing a removable spillway weir, we recommend locating it somewhere on the south half of the spillway to take advantage of the slight southerly skew in fish passage.

12. We recommend that future operations data include exact on and off times for turbines sampled with hydroacoustic methods, as they did in 2002. We were able to assign zero counts to 1-minute samples collected when turbines were off because Dam operators graciously provided exact on and off times for every turbine, and these data undoubtedly improved the accuracy of the FGE estimates by eliminating counts of un-entrained fish. Hydroacoustic equipment samples continuously, so it is critical to know exactly when units are off.

13. We recommend additional evaluations of gap loss using the acoustic camera and optical cameras (for verification). There appears to be a disparity between gap loss estimates by netting and those made by imaging devices. The highest estimates of gap loss from the acoustic camera ranged from $13 \%$ to $15 \%$ of all guided and unguided fish and $26 \%$ to $41 \%$ of the guided fraction, and these estimates were higher than those reported in netting studies.

14. We recommend an assessment of the potential for telemetry antennas to detect gap lost fish. Losses of fish between the top of the STS and the bottom of the intake ceiling may explain some of the difference between FGE estimates by hydroacoustics, netting, and radio telemetry, if some tagged fishes passing through the gap were detected by radio telemetry antennas mounted on the downstream side of the STS.

15. We recommend conducting additional studies to determine why gap losses at Intake $17 \mathrm{C}$ were so high, while those at Intake 17B were so low, even though both intakes had modified gatewell slots, turning vanes, and gap-closure devices. There may be differences in gap loss among slots in a unit based upon differences in the amount and direction of flow.

16. Managers should consider running a $\log$ boom from the north shore to the tip of Cascades Island to guide surface-oriented fish to the spillway, reduce timber loading in the B2 forebay, and increase boater safety after the large corner collector becomes functional in 2004 . 


\section{Preface}

This report was prepared by the Pacific Northwest National Laboratory (PNNL), Richland, Washington, the MEVATEC Corporation, (subcontractor to the U.S. Army Engineer Research and Development Center (ERDC), Vicksburg, Mississippi), and the School of Aquatic and Fishery Sciences, University of Washington, Seattle. The U.S. Corps of Army Engineers-Portland District provided funding and oversight.

\section{Acknowledgments}

Many people made valuable contributions to this study and deserve acknowledgment. Two Portland District biologists, Blaine Ebberts and Dennis Schwartz, provided contract oversight and coordination between the Portland District and the Bonneville Project. Mr. Ebberts was responsible for the projectwide fish-passage efficiency study and Mr. Schwartz oversaw the fish-guidance-efficiency study at modified Unit 17 and a gap-loss evaluation. Jennifer Sturgill, the Fish Biologist with the Bonneville Project, provided valuable coordination related to Project support, scheduling, and acquisition of damoperations data, which Project Operators were kind enough to record hourly. This study would not have been possible without the support of Randy Price and the other Project Riggers, who helped install and remove hydroacoustic equipment. Andy Debriae was the Structural Foreman and a key contact during installations. Gene LaDouceur was the Chief of Maintenance.

William Nagy of the Fisheries Field Unit, Portland District, has made a major contribution toward the development of standardized processing software over the last five years. He provided many hours of advice to Dr. Kenneth Ham and Eric Robinson (both of PNNL), who took the original processing software and developed a new user-friendly interface in Visual BASIC. The new software version consists of a stochastic detectability model, an integrated manual and alpha-beta automated tracker, and a sophisticated query program for developing post-processing filters. These programs not only reduce costs associated with hydroacoustic studies, but also improve the accuracy of fish-passage estimates.

The MEVATEC Corporation provided a wide range of talented staff that supported this hydroacoustic study at Bonneville Dam, as well as similar hydroacoustic studies at John Day and The Dalles dams in 2002. Deborah Patterson worked long hours managing data, kept the translator and autotracker running continuously on five computers, and collated output files. She also made logistical arrangements, ordered supplies and materials, managed Corps of Engineers property, and helped edit the draft report. Peter Johnson (Project Manager) and Mike Hanks (Senior Scientist) assisted with installations and setup of hydroacoustic equipment and provided valuable technical support. Peter Johnson also played a major role in logistical planning, which was more complex than in other years because technicians installed all hydroacoustic equipment for FPE studies at three dams in 2002. This integrated approach provided standardization and economy but required detailed planning.

Technicians were led by Kyle Bouchard (Senior Technician) and included Kathy Chandler, Julie Cowart, Chris Holzer, and Keri Taylor. This team maintained and deployed electronic equipment and miles of cable, and the four technicians manually processed data for quality control and assurance on automated data processing. Three other MEVATEC technicians (Peggy Fisher, John Phillip, and Scott 
Powell) monitored data-acquisition systems 24 hours per day throughout the sampling season so that equipment down time was kept to a minimum.

Dr. Larry Lawrence with the Engineering Research and Development Center oversaw the MEVATEC contract and was supervisor of the Fisheries Engineering Team in North Bonneville, WA. Dr. Lawrence also provided valuable assistance with District and Project coordination and scheduling.

Alan Wirtz of Precision Acoustic Systems in Seattle, Washington, calibrated all hydroacoustic equipment, helped with troubleshooting, and made whatever repairs were required in a timely manner. Schlosser Machine in Hood River fabricated transducer mounts.

Our comparisons of hydroacoustic and radio telemetry estimates of fish passage metrics would not have been possible without estimates and help provided by Scott Evans and Rachel Wardell with the U.S. Geological Survey in Cook, Washington. The radio telemetry and hydroacoustic studies overlapped but also had non-concurrent sample times that had to be eliminated before data could be compared.

Bruce Monk and John Ferguson with the National Oceanic and Atmospheric Administration (NOAA) Fisheries graciously provided us with their 2002 netting estimates of guided and unguided fish passage for Unit 17, so that we could compare them with hydroacoustic estimates from this study.

Jeffery Kamps with the Pacific States Marine Fisheries Commission provided us with smolt-index run-timing data from Bonneville. 


\section{Acronyms and Abbreviations}

\begin{tabular}{|c|c|}
\hline AFEP & Anadromous Fish Evaluation Program \\
\hline APL & University of Washington Applied Physics Laboratory \\
\hline B1 & Bonneville Dam Powerhouse 1 \\
\hline B2 & Bonneville Dam Powerhouse 2 \\
\hline $\mathrm{cfs}$ & cubic feet per second \\
\hline CFD & computational fluid dynamics \\
\hline $\mathrm{COE}$ & U.S. Army Corps of Engineers \\
\hline DART & Columbia River Data Access in Real Time \\
\hline DIDSON & Dual-Frequency Identification Sonar \\
\hline EBA & effective beam angle \\
\hline ERDC & U.S. Army Engineer Research and Development Center \\
\hline ESBS & extended submerged bar screen \\
\hline FGE & fish guidance efficiency at a turbine or intake [Guided / (Guided + Unguided)] \\
\hline FPE & fish passage efficiency [Guided / (Guided + Unguided) by Project or powerhouse] \\
\hline $\mathrm{ft}$ & feet \\
\hline $\mathrm{h}$ & hour \\
\hline HA & hydroacoustics \\
\hline JBS & Juvenile Bypass System \\
\hline $\mathrm{km}$ & kilometer \\
\hline M & million \\
\hline NMFS & National Marine Fisheries Service \\
\hline NOAA & National Oceanic and Atmospheric Administration \\
\hline PAS & Precision Acoustic Systems \\
\hline pings/s & pings per second \\
\hline PNNL & Pacific Northwest National Laboratory \\
\hline PSC & Prototype Surface Collector \\
\hline RT & radio telemetry \\
\hline $\mathrm{S}$ & second \\
\hline SAS & Statistical Analysis System \\
\hline SLE & $\begin{array}{l}\text { Sluiceway efficiency - (Sluiceway passage / Project passage) or (Sluiceway passage / } \\
\text { B1 passage) }\end{array}$ \\
\hline
\end{tabular}


SLE divided by the proportion of total discharge going through the sluiceway. SLN may be relative to the entire Project (Project SLN) or to relative to an adjacent powerhouse (B1 SLN).

SPE spill passage efficiency (spill passage / total Project passage)

SPN spill effectiveness is SE divided by the proportion of Project discharge going through the spillway

STS submerged traveling screen

TDG total dissolved gas

TIE turbine intake extension

TS target strength

USGS U.S. Geological Survey

VBS vertical barrier screen

WES U.S. Army Engineer Waterways Experiment Station (former ERDC) 


\section{Contents}

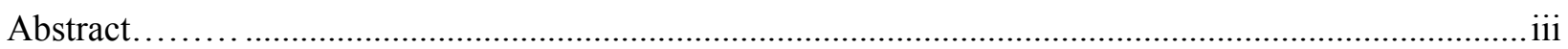

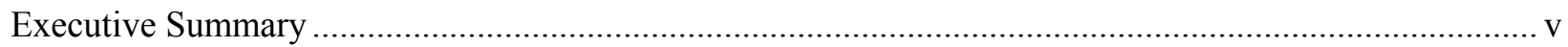

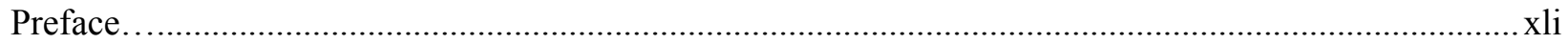

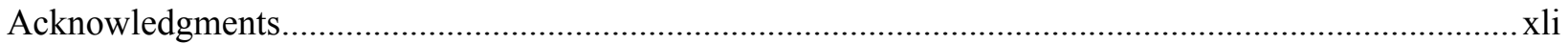

Acronyms and Abbreviations ......................................................................................................

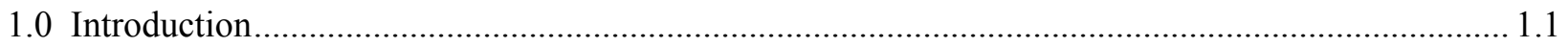

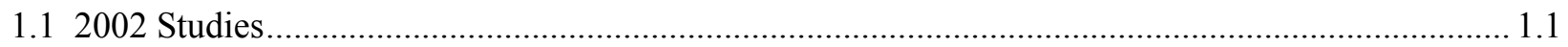

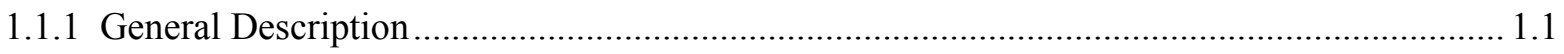

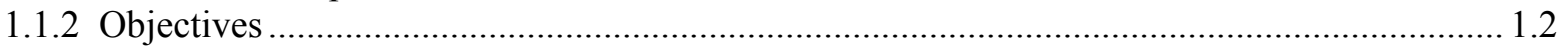

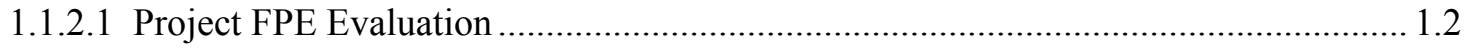

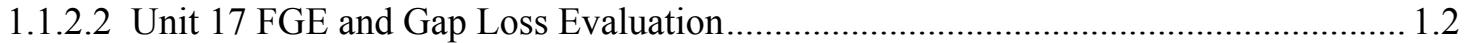

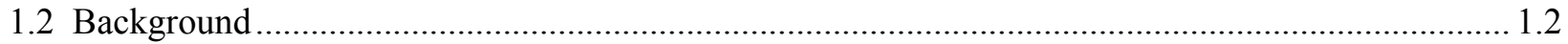

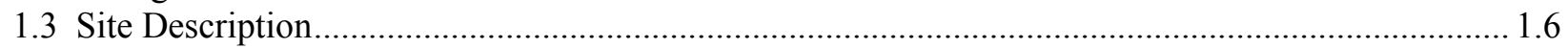

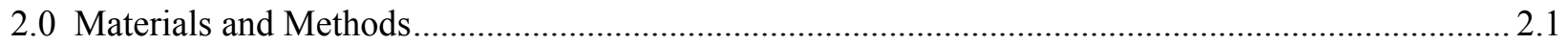

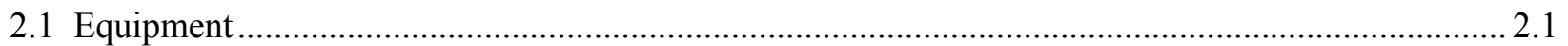

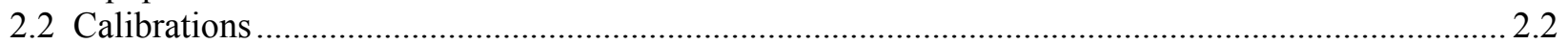

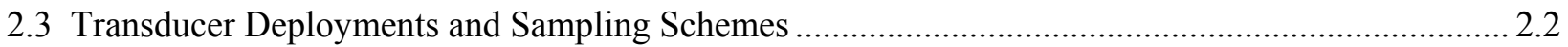

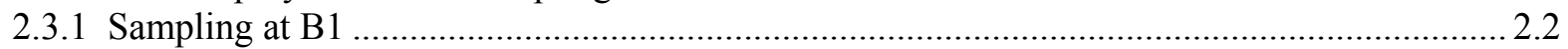

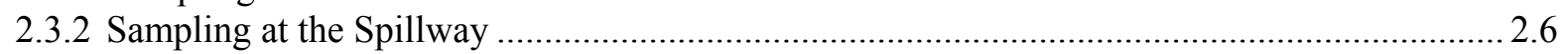

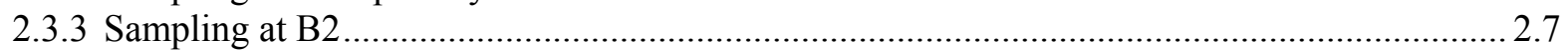

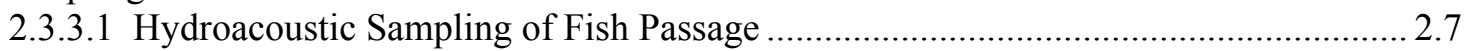

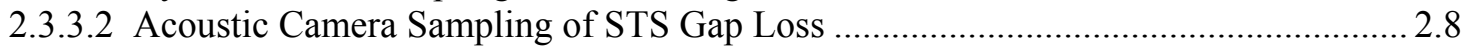

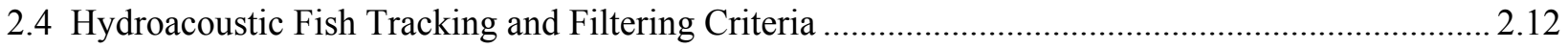

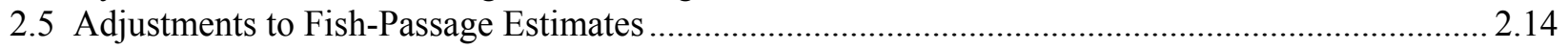

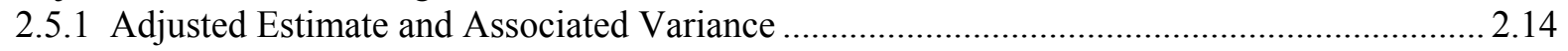

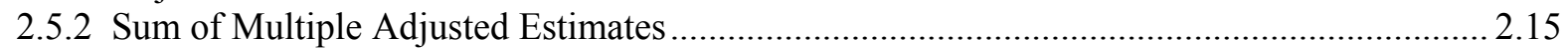

2.5.3 Estimating the Calibration Adjustment: Ratio Estimator.................................................. 2.15

2.5.4 Estimating the Calibration Adjustment: Proportion Estimator ............................................ 2.17

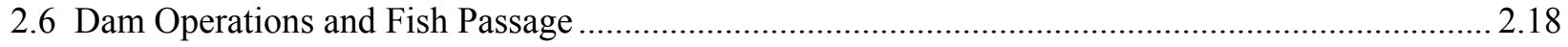

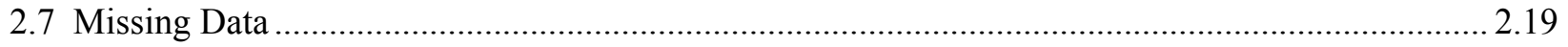

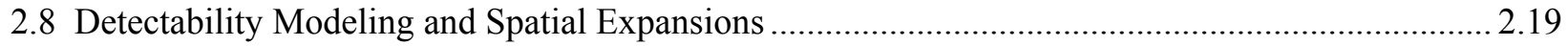

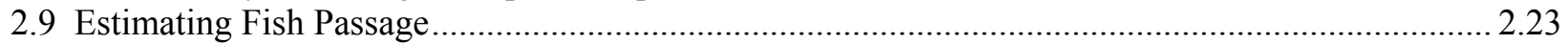

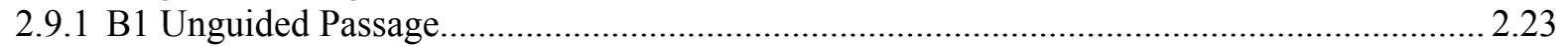

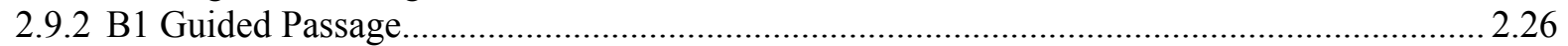

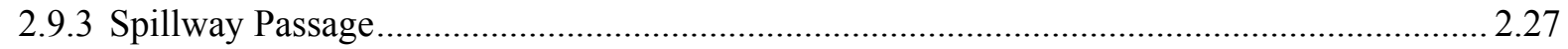

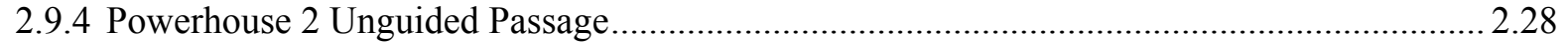

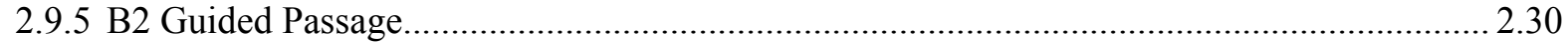

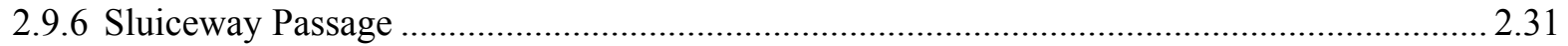

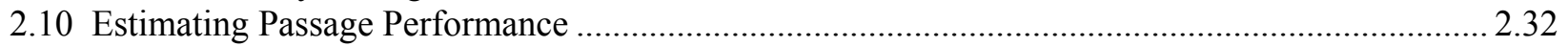

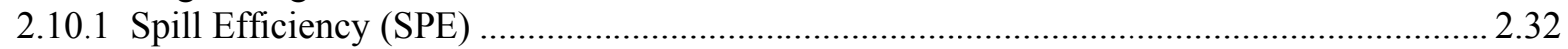

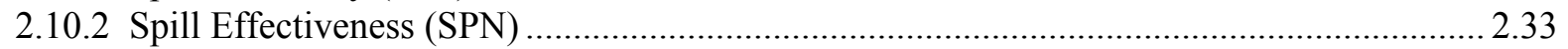

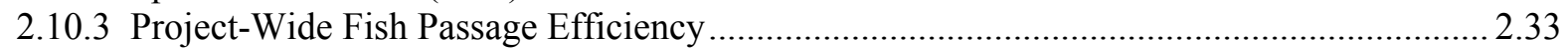

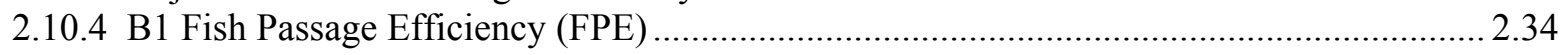

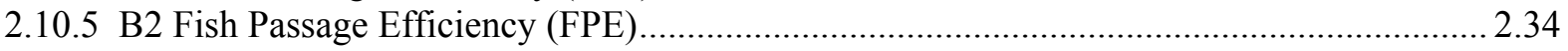




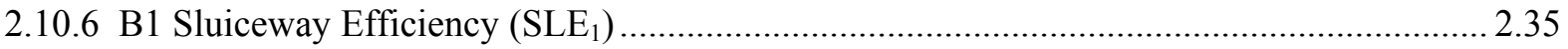

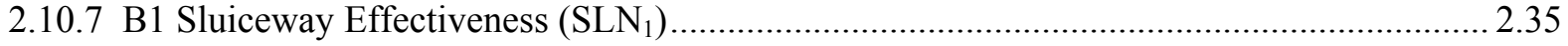

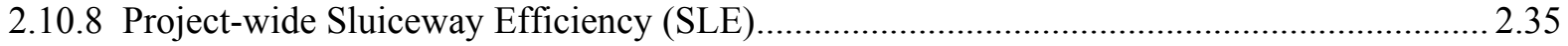

2.10.9 Project-wide Sluiceway Effectiveness (SLN) ………………………………………...... 2.36

2.11 Comparing Spill-Treatment and Location Effects ..........................................................................

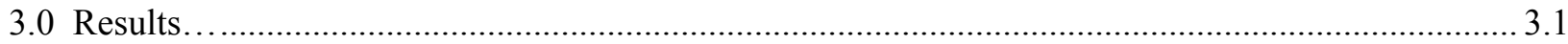

3.1 Hydroacoustic Detectability....................................................................................................... 3.1

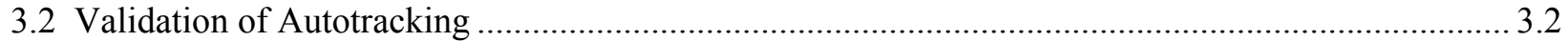

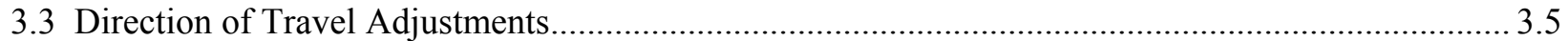

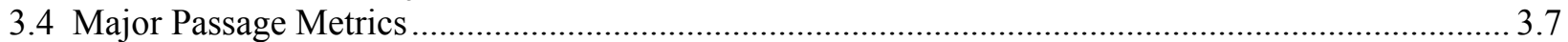

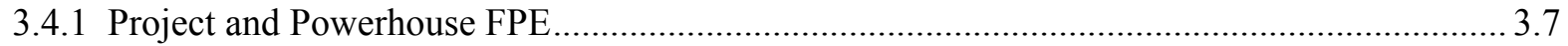

3.4.2 Spill Efficiency and Effectiveness ................................................................................... 3.8

3.4.3 Effects of Spillway Discharge Level on Spillway Fish Passage .............................................. 3.9

3.4.4 Effects of Percent Spill on Spill Efficiency and Project FPE.................................................... 3.9

3.4.5 Effects of Spill Discharge Level on Spill Efficiency and Project FPE................................... 3.10

3.4.6 Comparison with Radio Telemetry Estimates ………………………………………........ 3.12

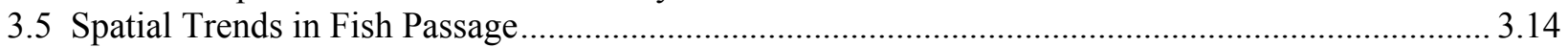

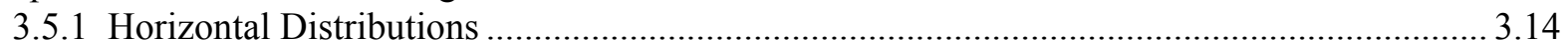

3.6 Temporal Trends in Fish Passage ………………………................................................... 3.18

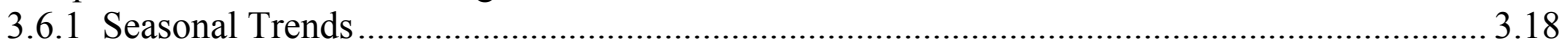

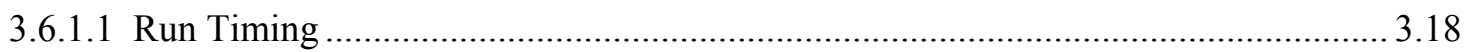

3.6.1.2 Major Fish-Passage Metrics................................................................................ 3.19

3.6.1.3 Fish-Guidance Efficiency at Modified Intake 17 ..................................................... 3.22

3.6.1.4 American Shad Run Timing ………………………………………………… 3.23

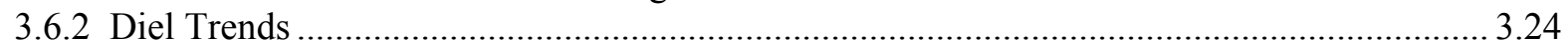

3.6.2.1 Project-wide Estimates and Spill ............................................................................ 3.24

3.6.2.2 Fish-Guidance Efficiency and Passage at Powerhouses ........................................... 3.26

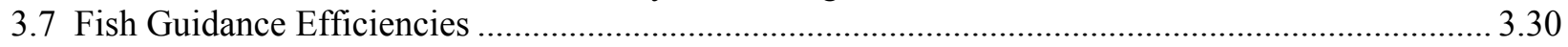

3.7.1 Comparing Performance of Fish-Guidance Structures .......................................................... 3.30

3.7.2 Comparing FGE Estimates by Different Sampling Methods ..................................................3.36

3.7.2.1 Hydroacoustic and Camera Estimates of Sluice Passage............................................ 3.36

3.7.2.2 Hydroacoustic and Netting Estimates at Modified Unit 17 ...................................... 3.38

3.7.2.3 Hydroacoustic and Radio Telemetry Estimates ......................................................... 3.39

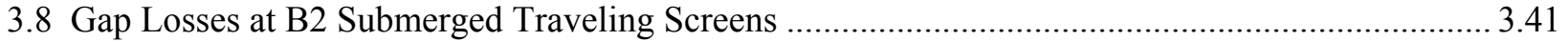

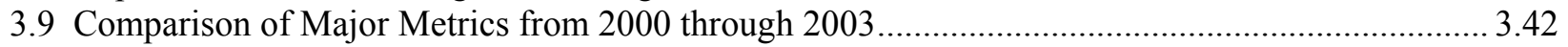

3.10 Effects of Spill Treatments on Major Metrics............................................................................. 3.43

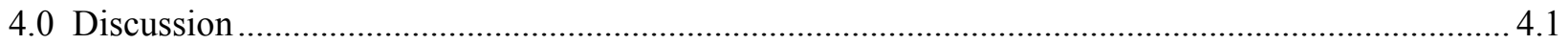

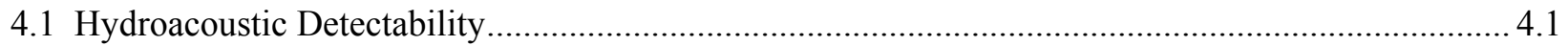

4.2 Validation of Autotracking Hydroacoustic Data .......................................................................... 4.1

4.3 Fish Swimming Direction and Implications for Sluice Management ................................................ 4.2

4.4 Major Passage Metrics........................................................................................................... 4.3

4.4.1 Project and Powerhouse FPE...……………………………………………………..... 4.4

4.4.2 Spill Efficiency and Spill Effectiveness …………………................................................. 4.5

4.4.3 Effects of Spillway Discharge on Spillway Fish Passage........................................................ 4.5

4.4.4 Effects of Spill Percent and Discharge on Spill Efficiency and Project FPE ............................ 4.7

4.4.5 Comparison with Radio Telemetry ................................................................................... 4.10

4.5 Spatial Trends in Fish Passage................................................................................................ 4.10

4.5.1 Horizontal Distributions .......................................................................................... 4.10 


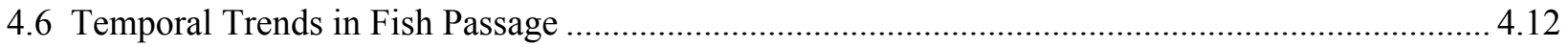

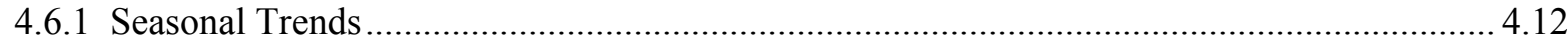

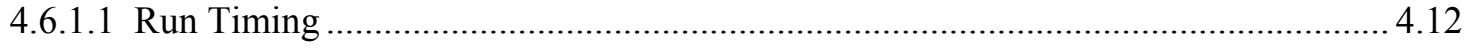

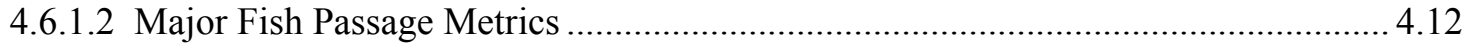

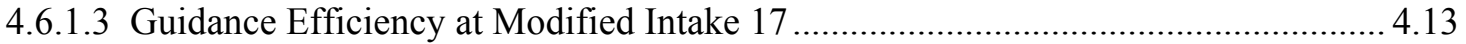

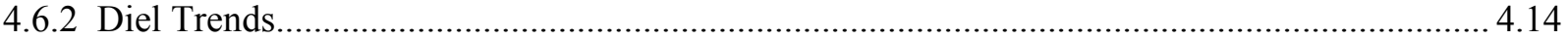

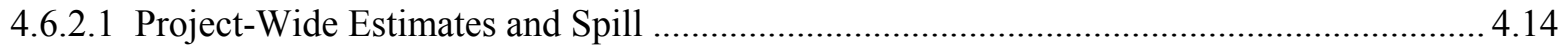

4.6.2.2 Fish Guidance Efficiency and Passage at Turbines and the B1 Sluiceway ....................... 4.15

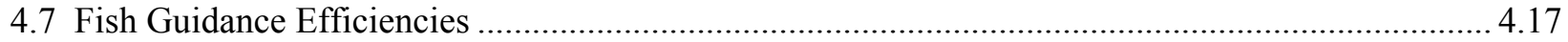

4.7.1 Comparing Performance of Fish-Guidance Structures ........................................................ 4.17

4.7.2 Comparing FGE Estimates by Different Sampling Methods ............................................. 4.18

4.7.2.1 Hydroacoustic and Camera Estimates of Sluice Passage .......................................... 4.18

4.7.2.2 Hydroacoustic versus Netting and Radio Telemetry Estimates ............................... 4.19

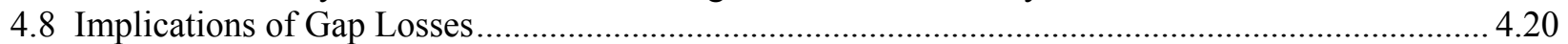

4.9 Comparison of Major Metrics from 2000 through 2002 …........................................................24

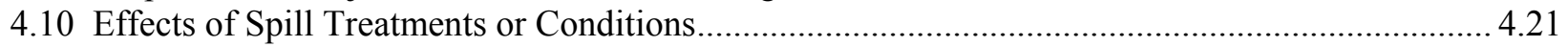

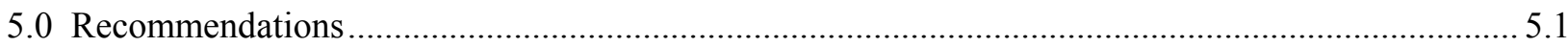

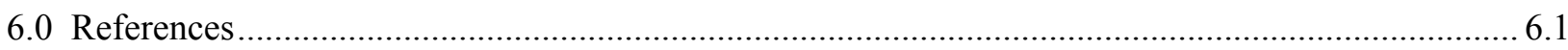

(Appendixes are on $\mathrm{CD}$ )

Appendix A - Transducer Calibrations and Receiver Gains ......................................................... A.1

Appendix B - Detailed Transducer Locations and Aiming Angles ..................................................... 1

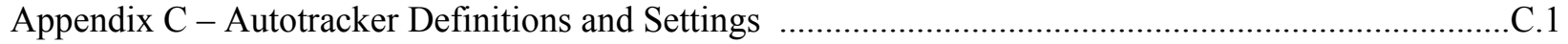

Appendix D - Statistical Analysis System Code for Filtering Echo Traces Selected by

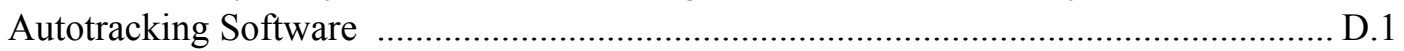

Appendix E - List of Appendix E Tables and Definitions of Variables in Headings of Hourly Fish Passage, Flow, and Forebay Elevation Data on an

Accompanying Disk

Appendix F - Statistical Analysis System Code for Estimating Effective Beam Angle based Upon Range from a Transducer ...........................................................................

Appendix G - Descriptive Statistics on Spill Treatments or Conditions, Analysis of Variance on Treatment Blocks, Treatments or Conditions, and Paired Comparisons of Least Square Means 
Hydroacoustic Evaluation of Fish Passage through Bonneville Dam in 2002

xlviii 


\section{Figures}

Figure 1.1. Plan View of the Bonneville Dam Project........................................................................... 1.7

Figure 2.1. Cross Sectional View through a B1 Intake like those Sampled in Units 1-7, 9, and 10........ 2.3

Figure 2.2. Cross-Sectional View through Intake 8B Where Up- and Down-looking, Single-Beam Transducers were Used to Sample Guided and Unguided Fish, Respectively.....

Figure 2.3. Forebay View of a Sluiceway Entrance at Intake 7a or 10c in 2002 Showing the Deployment of Opposing Split-beam Transducers for Sampling Fish Passage

Figure 2.4. Forebay View of a Sluiceway Entrance at Intake 7A in 2002 Showing the Deployment of Four Up-looking Optical Cameras for Sampling Fish Passage

Figure 2.5. Cross-Sectional View through a Spill Bay at Bonneville Dam.

Figure 2.6. Cross-Sectional View through a B2 Turbine Showing Up- and Down-Looking Transducer Beams

Figure 2.7. Cross-Sectional View of a Model of an Un-modified Intake at B2 Showing the Path and Distribution of Dye Introduced at the Trash Racks on the Left Side

Figure 2.8. Cross-Sectional View through Intakes with Un-modified and Modified Gatewells at B2 .... 2.9

Figure 2.9. Cross-Sectional Diagram of an Intake at B2 Showing the DIDSON Acoustic Camera Deployment with $960.3^{\circ}$ wide by $10^{\circ}$ Deep Acoustic Beams for Detecting Fish

Figure 2.10. Image from the DIDSON Acoustic Camera Deployed in Modified Gatewell 17C of B2 2.10

Figure 2.11. Diagram Showing the Field of View of the Acoustic Camera Deployed on the Bottom of the Uppermost Trash Rack at Intake 18A in Spring 2002

Figure 3.1. Plots of Effective Beam Angle as a Function of Range from Transducers Deployed at Bonneville Dam in Spring and Summer 2002

Figure 3.2. Regressions of Mean Human-Tracker Estimates of Hourly Fish Passage and Autotracker Estimates by Intake or Sluiceway Entrance

Figure 3.3. Regressions of Mean Human-tracker Estimates of Hourly Fish Passage and Autotracker Estimates by Spill Bay

Figure 3.4. Regressions of Mean Human-tracker Estimates of Hourly Fish Passage and Autotracker Estimates by Intake

Figure 3.5. Linear and Polar Plots of the Percentage of Fish Traveling Different Directions Across the Barrel View of Split-Beam Transducers Deployed at Sluice Entrance $10 \mathrm{C}$ in Spring and Summer 
Figure 3.6. Linear and Polar Plots of the Percentage of Fish Traveling Different Directions across the Barrel View of Split-Beam Transducers Deployed at Sluice Entrance 7A in Spring and Summer.

Figure 3.7. Linear and Polar Plots of the Percentage of Fish Traveling Different Directions across the Barrel View of Split-beam Transducers Deployed at Spill Bays in Spring and Summer

Figure 3.8. Project-Wide and Other Fish Passage Efficiency Estimates for Spring and Summer Fish Passage Seasons at Bonneville Dam in 2002

Figure 3.9. Estimated Spill Efficiency and Spill Effectiveness for the Bonneville Project and for the Spillway and Each Powerhouse Only for Spring and Summer 2002

Figure 3.10. Linear Regression Plots of Estimated Hourly Spillway Passage on Total Hourly Spillway Discharge at Bonneville Dam in Spring and Summer of 2002.

Figure 3.11. Linear Regression Plots of Hourly Spill Efficiency on Percent Spill at Bonneville Dam in Spring and Summer of 2002

Figure 3.12. Linear Regression Plots of Hourly Project FPE on Percent Spill at Bonneville Dam in Spring and Summer of 2002

Figure 3.13. Regression Plots of Hourly Spill Efficiency on Spillway Discharge at Bonneville Dam in Spring and Summer of 2002

Figure 3.14. Regression Plots of Hourly Project FPE on Spillway Discharge at Bonneville Dam in Spring and Summer of 2002

Figure 3.15. Regression Plots of Hourly Spill Efficiency and Project FPE on Spillway Discharge at Bonneville Dam in Summer of 2002

Figure 3.16. Horizontal Distribution of Fish Passage through Bonneville Dam in Spring of 2002 ....... 3.14

Figure 3.17. Horizontal Distribution of Discharge through Bonneville Dam in Spring of 2002........... 3.15

Figure 3.18. Horizontal Distribution of Fish Density (Fish/ $\mathrm{M} \mathrm{m}^{3}$ ) through Bonneville Dam in Spring of 2002

Figure 3.19. Horizontal Distribution of Fish Passage through Bonneville Dam in Summer of 2002 .... 3.16

Figure 3.20. Horizontal Distribution of Discharge through Bonneville Dam in Summer of 2002 ......... 3.17

Figure 3.21. Horizontal Distribution of Fish Density $\left(\right.$ Fish $/ \mathrm{M} \mathrm{m}^{3}$ ) through Bonneville Dam in Summer of 2002

Figure 3.22. Patterns of Run Timing Estimated by Hydroacoustics and by the JBS Smolt Index at Bonneville Dam in 2002.

Figure 3.23. Correlation of the Smolt Index from the Bonneville Dam Juvenile Bypass System with Hydroacoustic Estimates of Fish Passage. 
Figure 3.24. Estimated Project FPE and Spill Efficiency, and the Proportion of Water Spilled at Bonneville in 2002

Figure 3.25. Regression of Daily Fish Passage Efficiency Estimates for B1 on Sluice 7A Efficiency

Relative to B1 and Daily Fish Passage Efficiency Estimates for B1 and B2

Figure 3.26. Daily Effectiveness Estimates for the Spillway and Sluiceway 7A and Trends

in Daily Spill Effectiveness and Daily 95\% Confidence Intervals.

Figure 3.27. Daily Estimates of Fish Guidance Efficiency and the Number of

Smolt-Sized Fish Passing through Intakes 17B and 17C....

Figure 3.28. Run Timing of Up-Migrating American Shad through the

Bonneville Project in 2000, 2001, and 2002

Figure 3.29. Diel Patterns of Fish Passage Efficiency, Spill Efficiency, and Spill Effectiveness

during the Spring and Summer at Bonneville Dam in Spring and Summer of 2002

Figure 3.30. Estimates of Diel Trends in Total Fish Passage and Discharge in Spring

and Summer through Bonneville Dam in 2002.

Figure 3.31. Estimates of Diel Trends in Spilled Fish and Discharge over the Spillway in

Spring and Summer through Bonneville Dam in 2002

Figure 3.32. Diel Estimates of Fish Guidance Efficiency and Total Fish Passage for B1

during Spring and Summer at Bonneville Dam in 2002

Figure 3.33. Diel Estimates of Fish Guidance Efficiency and Total Fish Passage for B1

during Spring and Summer at Bonneville Dam in 2002

Figure 3.34. Diel Estimates of Fish Guidance Efficiency and Total Fish Passage for B2

during Spring and Summer at Bonneville Dam in 2002

Figure 3.35. Comparison of FGE and Fish Passage among Turbines at Bonneville Dam

in Spring and Summer 2002

Figure 3.36. Scatter Plots of Video-Camera and Hydroacoustic Sampling Counts of Juvenile Salmonids Passing into Sluice Entrance 7A at B1

Figure 3.37. Plots of Video-Camera and Hydroacoustic-Sampling Counts of Juvenile Salmonids Passing into Sluice Entrance 7A at B1 during the Hours

Processed in Spring and Summer.

Figure 3.38. Plots of the Horizontal Distribution of Fish Passage Based Upon Video

Camera Sampling and Hydroacoustic Sampling of Juvenile Salmonids

Passing into Sluice Entrance 7A at B1

Figure 3.39. Plot of FGE Estimates Based Upon Hydroacoustic Sampling in this Study and

Net Sampling by NOAA Fisheries During the Same Nights in 2002 
Figure 3.40. Plots of the Percent of Total Fish Passage Estimated by Hydroacoustics and Radio Telemetry at B2 in Spring and Summer

Figure 3.41. Plots of Fish Guidance Efficiency by Turbine Unit at B2 According to Sampling with Hydroacoustics.

Figure 3.42. Plots of Major Passage Metrics by Spill Treatment in Spring.

Figure 3.43. Plots of Major Passage Metrics by Spill Treatment in Summer

Figure 4.1. Relations between Entrance Flow and Forebay Elevations at Sluiceway Entrances $7 \mathrm{~A}$ and $10 \mathrm{C}$ at $\mathrm{B} 1$

Figure 4.2. Distribution of Project Discharge and Estimated Fish Passage through Different Structures at Bonneville Dam in Spring and Summer of 2002

Figure 4.3. Time Histories of Spillway Discharge and Estimated Spillway Passage at Bonneville Dam in Spring and Summer of 2002

Figure 4.4. Time Histories of Hourly Percent Spill and Estimated Spill Efficiency at Bonneville Dam in Spring and Summer of 2002

Figure 4.5. Time Histories of Hourly Percent Spill and Estimated Project Fish Passage Efficiency at Bonneville Dam in Spring and Summer of 2002

Figure 4.6. Plots of Seasonal Trends of Intake-specific FGE for B2 in 2002

Figure 4.7. Diel Trends in Hydroacoustic Estimate of Fish Passage through B1 Sluiceway 7A

Figure 4.8. Seasonal Trend in the FGE of Unit 8 with an Extended Submerged Bar Screen

Figure 4.9. Plot of the Difference (Hydroacoustic - Radio Telemetry) in Estimates of FGE as a Function of the Total Number of Radio-Tagged Fish Detected at a Turbine Unit 


\section{Tables}

Table 2.1. Deployment-Specific Variables that Were Input to a Stochastic Detectability Model for Estimating Effective Beam Angle as a Function of Range from a Transducer ....

Table 2.2. Polynomial Inputs or Constants for the Detectability Model for Beam Patterns, Fish Trajectories, and Fish Speeds for Every Deployment

Table 3.1. Estimates of Major Passage Metrics based upon Hydroacoustic Sampling from $4 / 20$ through $6 / 2$ (spring) and from $6 / 3$ through $7 / 15$ (summer)

Table 3.2. Comparison of Major Fish-Passage Metrics Estimated by Hydroacoustics (HA) and Radio Telemetry (RT) at Bonneville Dam in 2002

Table 3.3. Comparison of the Seven Highest Fish-Guidance Efficiencies Estimates for Units at Bonneville Dam by Season

Table 3.4. Fish Guidance Efficiency of B2 Intakes by Season

Table 3.5. Two-way ANOVA on Effects of Slot and TIE on the FGE at B2 by Season.

Table 3.6. Percent of Smolt-Sized Fish Lost through the Gap between the Top of the Submerged Traveling Screen and the Intake Ceiling in Modified and Un-Modified Gatewells in Spring and Summer 2002

Table 3.7. Comparison of Major Fish-Passage Metrics among the Three Years of Full-Project Hydroacoustic Studies

Table 4.1. Analysis of Variance Table and Multiple Range Comparison of Average Hourly Fish Counts by Spill Bay Discharge Range 
Hydroacoustic Evaluation of Fish Passage through Bonneville Dam in 2002 


\subsection{Introduction}

\subsection{Studies}

\subsubsection{General Description}

Bonneville Dam is the most downstream of all of the hydropower dams in the Columbia-Snake River system so more in-river migrating fish must pass Bonneville Dam than any other dam in the system. Unfortunately, Bonneville Dam has had consistently low passage efficiency so there is a concerted effort to improve passage conditions for downstream migrants there. The work reported here is a part of that effort.

In this report, we present results of two studies of juvenile salmonid passage at Bonneville Dam that were carried out by Pacific Northwest National Laboratory (PNNL) and MEVATEC in the 2002 downstream passage seasons. Both were funded by the U.S. Army Corps of Engineers - Portland District and conducted at Bonneville Dam from April 20 through July 15, 2002. The Project-wide fish passage efficiency (FPE) study provided hourly estimates of fish passage and variance through all operating turbine units at both powerhouses, all spill bays, and the two open sluiceway entrances at Powerhouse 1 (B1), as well as estimates of a variety of fish-passage efficiency and effectiveness measures. This was the third consecutive year of full-project hydroacoustic sampling and passage estimation.

The second study was a more narrowly focused evaluation at Powerhouse 2 (B2) that had two goals: 1) to sample the fish guidance efficiency (FGE) at two modified turbine intakes and compare efficiencies with efficiencies of other B2 units that were sampled in the first study, and 2) to evaluate proportions of fish passing up into gatewell slots versus through gaps between the top of submerged traveling screens (STS) and intake ceilings at a modified and an unmodified unit in each season. In 2000, physical modeling of B2 intakes raised concerns that flow moving above the STSs and up the gatewell was limiting FGE and that a high proportion of flow was moving between the top of the STS and the intake ceiling. In an attempt to improve FGE, the Portland District modified gatewell slots in Unit 15 before the 2001 smolt migration and gatewells at Unit 17 before the 2002 migration.

Modifications consisted of removing a lot of concrete, greatly expanding the surface area of the vertical barrier screen (VBS), and adding a turning vane and gap closure device to direct more water up the slot and away from the gap between the top of the STS and the intake ceiling. The objective of the gatewell modifications was to increase flow above the STS and up into the gatewell slot in an attempt to increase smolt guidance efficiency. In a few days of preliminary sampling with an acoustic camera in 2001, we recorded large numbers of fish passing through STS gaps in the unmodified units of B2. Those observations prompted the investigations reported here. 


\subsubsection{Objectives}

\subsubsection{Project FPE Evaluation}

1. Estimate the proportion of smolt-sized fish that pass the project above and below in-turbine screens, through sluiceway openings with water depths $>1 \mathrm{~m}$, and through spill bays each season.

2. Estimate a variety of fish-passage metrics by hour, day, and season. The metrics include Project FPE, FPE by powerhouse, spill efficiency and effectiveness, B1 sluice efficiency and effectiveness relative to both the entire Project and to just B1, and FGE by turbine unit.

3. Characterize horizontal distributions of smolt-sized fish passing through the project, B1, B2, two B1 sluiceway entrances, and the spill bays.

4. Describe changes in vertical and lateral distributions of smolt-sized fish passing B1, B2, the B1 sluiceway entrances, and the spillway.

5. Describe diel changes in the passage of smolt-sized fish at B1, B1 sluiceway entrances, B2, and the spillway.

\subsubsection{Unit 17 FGE and Gap Loss Evaluation}

1. Hydroacoustically sample fish passage at two units with modified gatewell slots at B2, estimate FGE, and compare those estimates to FGE estimates of other units with unmodified gatewell slots, as determined in the project FPE evaluation described above.

2. Deploy a down-looking acoustic camera in one unmodified and one modified gatewell at B2 and sample for two days each season to record the proportions of juvenile salmonids moving up into the gatewell versus downstream through the gap between the top of the STS and the ceiling of the intake.

3. Deploy an acoustic camera on the downstream side of the trash racks to determine the feasibility of recording the rate of fish loss through a gap between the side of the screen and the wall of the intake near the tip of the screen.

\subsection{Background}

The U.S. Army Corps of Engineers - Portland District is striving to meet the goal, set in the 2000 Biological Opinion on the Federal Columbia River Power System (NMFS 2000), of maximizing fish passage efficiency (FPE) and obtaining 95\% survival for juvenile salmon (Oncorhynchus spp.) passing the Bonneville Dam Project.

Project FPE is the percent of all juvenile salmon passing the project by non-turbine routes, but FPE also can be calculated for individual powerhouses, of which there are two (B1 and B2) at Bonneville Dam. The proportions of juvenile salmon that pass through all major routes must be estimated to calculate project FPE. In a typical water year, the goal of maximizing FPE largely influences the operation of the project. Managers presume that large volumes of spill are necessary to compensate for 
the low fish guidance efficiency (FGE) of screens at both powerhouses, particularly in summer. Spill volumes are, in a typical year, limited to between 50,000 and $75,000 \mathrm{ft}^{3} / \mathrm{sec}$ during the day and up to $120 \%$ of the gas cap set to control total dissolved gas supersaturation (NMFS 2000). In 2000, the water passed through the project was $97 \%$ of the ten-year (1993-2002) average but the Northwest had an unusually dry year (62\% of the ten-year average annual discharge) in 2001 and that, combined with high generation demand, led to unusually low spill volumes over an unusually short spill season (Ploskey et al. 2002c). Total project discharge in spring was roughly half (46\% in spring and $54 \%$ in summer) of what it was in 2000. In 2001, the project spilled $16 \%$ of the total discharge in spring and $11 \%$ in summer, down from $31 \%$ and $50 \%$, respectively, in 2000 . Total spill volume was less than one-fourth $(23 \%)$ in spring and less than one-eighth (12\%) in summer of what it was in 2000. In 2002, the project discharged $91 \%$ of the ten-year average annual discharge (data from Columbia River DART website) so flows were nearly back to normal.

Spill under $50,000 \mathrm{ft}^{3} / \mathrm{s}$ creates eddies and slack water areas in the spillway tailrace. Predation is assumed in the tailrace where currents do not carry fish downstream quickly. Spill levels above 75,000 $\mathrm{ft}^{3} / \mathrm{s}$ during the day can lead to high numbers of adult salmon falling back through the spillway, as adults exit the Bradford Island ladder and follow the shoreline around to the spillway forebay. Adult salmon do not pass through the ladder at night, and therefore spill can be increased in an attempt to reach $80 \%$ FPE for a 24-hour period. However, spill above $120,000 \mathrm{ft}^{3} / \mathrm{s}$ typically causes total dissolved gas (TDG) levels to exceed $120 \%$ saturation. State water-quality standard waivers allow supersaturation up to $120 \%$. Levels of TDG above this may increase fish mortality.

The Portland District acquired mobile hydroacoustic data on fish distributions in both powerhouse forebays at Bonneville Dam in 1996 (Ploskey et al. 1998) and 1997 (BioSonics Inc. 1998). For B1, these data indicated that higher average fish densities occurred upstream of units 4 through 6 in spring and upstream of units 4 through 6 and 8 and 9 in summer. For B2, average fish densities were highest upstream of units 11 through 13 (adjacent to the south eddy and sluice chute) in spring and in summer. Fish densities also were high upstream of Unit 18 in 1996 but not in 1997. Vertical distribution data usually showed that over $80 \%$ of the fish were in the upper $15 \mathrm{~m}$ of the water column. The low fish guidance efficiency of many submerged traveling screens at Bonneville Dam would not be expected from an examination of the vertical distribution data collected within $10 \mathrm{~m}$ of the dam. If fish did not alter their vertical distribution from what was observed in forebay areas, data from 1996 and 1997 would suggest that fish guidance efficiency usually would exceed $80 \%$. Data acquired from in-turbine sampling and from fixed up-looking transducers deployed on the bottom of the B2 forebay in 2000 also indicated that FGE estimates were much lower than expected from vertical distributions in the forebay (Ploskey et al. 2002b).

Diel (24-hour) patterns of smolt passage are not uniform in either sluiceways (Uremovich et al. 1980; Willis and Uremovich 1981) or the juvenile bypass system (JBS) (Hawkes et al. 1991; Wood et al. 1994). Diel passage through the JBS often has a bimodal distribution with a major peak occurring just after dark and a minor peak after sunrise. In contrast, passage through sluiceways usually is higher during the day than at night (Willis and Uremovich 1981). However, patterns apparently are influenced by the operation of sluice gates (Uremovich et al. 1980), flow, unit outages, and species (Willis and Uremovich 1981). Netting required to estimate FGE is intensive but, because netting is limited to a few hours per day, it does not provide diel information. Diel patterns of fish passage above and below screens were estimated in spring and summer 1996 for randomly selected intakes of every turbine at B2 and every intake of units 
3 and 5 at B1. Estimates also were made in the spring and summer of 1998 and 2000. These indicate that fish passage through turbines usually is higher at night than it is during the day (Ploskey et al. 2001a; Ploskey et al. 2002a), which is consistent with historical findings at Bonneville Dam and other projects in the Northwest (Thorne and Johnson 1993).

Available data indicate that the horizontal distribution of smolt passage among turbine intakes is not uniform. Gatewell sampling has indicated that the number and location of operating units and sluice gates as well as the species of smolt determine lateral distributions of juvenile salmon at B1 (Willis and Uremovich 1981). Interactions among factors may account for a lack of consistency in measures of horizontal patterns by Uremovich et al. (1980), who found fish concentrated at units 6, 7, and 10; Willis and Uremovich (1981), who found variable patterns depending on operations; and Krcma et al. (1982), who observed most fish passage at units 4 through 6 . Much of the FGE data collected at B2 with inturbine hydroacoustics (e.g., Magne et al. 1989; Stansell et al. 1990) and netting (Gessel et al. 1988; Muir et al. 1989) are of limited value for evaluating the horizontal distribution of passage because they typically focused on one or two units at a time.

The Portland District's Fishery Field Unit attempted hydroacoustic sampling of juvenile salmon passing through several spillway gates in the mid 1980s. Transducers were mounted on the bottom of gates and aimed upward and out from the gate. Apparently, noise generated by sound echoing off of vortices at some gates masked echoes from juvenile salmon and prevented equalized sampling efforts among gates. BioSonics tested several methods for sampling spillway passage in 1997 (BioSonics 1998). Their best approach was to mount their transducers on piers and aim them toward the ogee just upstream of the gates. BioSonics also designed a mount to deploy transducers and estimate passage through the second B2 sluice chute. Transducers were placed at the bottom center of the upstream bulkhead slot and aimed vertically and slightly upstream.

Vertical distributions of juvenile salmon sampled by fixed-aspect hydroacoustics also vary seasonally and daily but this information has not been considered for improving juvenile fish passage at B2. For example, late spring and summer operations at B2 now prioritize the use of turbines 11 and 18 for adult salmon attraction. However, previous studies clearly showed that these units have the lowest FGE for juveniles passing downstream and that juvenile passage through Unit 11 is exceptionally high relative to other B2 units. The FGE of traveling screens was highest at units near the center of the second powerhouse. If Units 11 and 18 did not have turbines or had turbines with much more benign passage conditions than those presently installed, current operations would benefit both adults and juveniles. However, given the low FGE at units 11 and 18 in summer, $85 \%$ to $90 \%$ of the juvenile fish passing B2 go through turbines rather than the bypass.

In the 1980s and early 1990s, hydroacoustics had been used on limited spatial and temporal scales to evaluate sampling potential or relative passage among a few routes. Thorne and Kuehl (1989) evaluated the effects of noise on hydroacoustic assessment of passage within several turbines at B1. Results showed that acoustic sampling is feasible at the units they tested. Magne et al. (1986, 1989), Magne (1987), and Stansell et al. (1990) made hydroacoustic estimates of FGE for turbine units 11 and 17 and found that estimates were closer to netting estimates by the National Marine Fisheries Service (NMFS) when they sampled longer than just a few hours with hydroacoustic gear (see also Ploskey and Carlson 1999). 
A corner collector is being constructed at the south end of B2. Ploskey et al. (1998) and BioSonics (1998) found high densities of fish upstream of units 11 through 13, and Unit 11 had the highest passage of any intake sampled in 1996. Like the Fisheries Field Unit in previous years, BioSonics found that large numbers of fish passed through the sluice chute when that route was available. However, is it not known what contribution the sluice chute or a corner collector could make to guidance at B2 or to projectwide FPE. Data from Ploskey et al. (1998) indicated that the combined FGE of units 11, 12, and 13 was only $35 \%$. However, operation of the chute increased the combined FGE to $87 \%$ after sluice passage was added to the guided fish terms. This finding could be significant because 1996 mobile hydroacoustic sampling indicated that there was a 2:1 skew in the distribution of fish toward the south end of B2. An important factor contributing to successful fish passage in 1998 was removal of one-half of the turbine intake extensions (TIEs) at units 11 to 14 , which increased lateral flow toward the sluice chute. When in place, TIES reduce lateral flows along the face of the powerhouse. In 2001, with B2 generation priority and TIEs in place, estimated fish passage was again skewed to the south and highest at Unit 11 in both spring and summer (Ploskey et al. 2002c).

From 1998 through 2000, the Portland District evaluated two distinct smolt bypass approaches for B1, surface flow bypass and extended-length submersible bar screens. The year 2001 was scheduled for a decision on which complement of smolt passage devices to emphasize for long-term smolt protection at B1. The Corps prepared a special document, called the decision document, to analyze the relative merits of surface bypass and screens at B1.

Research conducted on surface flow bypass from 1998 through 2000 was summarized by Johnson and Carlson (2000). The goal of the surface flow bypass program was to develop and evaluate surface bypass and collection prototype concepts that would lead, if justified by prototype test results, to permanent systems for improving survival of juvenile salmon. In 1998, a prototype surface collector (PSC) was installed at units 3 through 6 and was extensively studied (see Johnson and Giorgi 1999 for a review). In 1999, limited research occurred to prepare for tests in 2000. In 2000, the PSC was extended from units 3 through 6 to also cover units 1 and 2, because a noticeable number of smolts were observed in 1998 and 1999 to move obliquely from north to south along the face of the PSC. A thorough evaluation of the PSC was conducted in 2000 as part of the Anadromous Fish Evaluation Program (AFEP). The 2000 PSC evaluation emphasized forebay fish behavior as well as PSC performance, i.e., efficiency and effectiveness. It included the following biological research (AFEP study codes in parentheses):

- fixed radio telemetry to determine species-specific PSC performance relative to the rest of the project as well as to movement patterns for yearling chinook salmon and steelhead (SBE-P-95-6)

- acoustic telemetry to study three-dimensional movement patterns upstream of the PSC and PSC performance on a species-specific basis (SBE-P-00-14)

- fixed hydroacoustics to estimate fish-passage rates to determine PSC performance for the run-at-large (SBE-P-98-8a) relative to rates at the rest of the project. This was the first year that a project-wide FPE study was conducted using fixed-aspect hydroacoustics.

- multi- and split-beam hydroacoustics to assess fish movements near the PSC (SBE-P-98-8b) 
- numerical modeling to integrate hydraulic data from a computational fluid dynamics model with three-dimensional fish movement data (SBE-P-00-13).

In 2001, the PNNL and ERDC again used hydroacoustic methods to provide a second set of projectwide fish passage efficiency and effectiveness estimates. This study provided similar metrics to those estimated in 2000, but there the PSC was not functioning and estimates of fish passage through units 16 focused upon the FGE of the submerged traveling screens instead. In addition, 2001 happened to be a drought year in which spill was limited in duration and amount each season. While the drought provided unique opportunities to examine the effect of spill and no spill, it also made difficult comparisons of metrics between the two years. In addition, the priority for generation at the powerhouses was reversed from B1 in 2000 when the PSC was tested to B2 in 2001 because estimates of survival of fish passing through B1 were poor relative to that of fish passing through B2.

This hydroacoustic evaluation was conducted to complement a radio telemetry study because hydroacoustics samples the run at large, whereas telemetry only provides data on individuals of species and age classes that are chosen for study. Estimates of FPE can be made by radio telemetry, but only for tagged fish and under the assumption that tagged fish behave like untagged fish. Radio telemetry provides species-specific information, reservoir passage routes and rates, forebay delay times, and other insights that hydroacoustics cannot, but it cannot provide the robust horizontal and vertical distribution information for assessing changes in fish passage or for suggesting improvements in interception facilities. Telemetry sample sizes sometimes may be too small when divided among 36 or more passage routes at a project. Hydroacoustic sampling not only provides overall measures of project performance, but also can indicate where improvements can be made and what kind and how much of a change might be required. For example, continuous hydroacoustic sampling allows for regression of performance measures (such as spill efficiency) on continuous operations data such as spill volume. These types of regressions can suggest project operations to optimize juvenile fish passage at a project. Provision of continuous fish-passage data on run-of-river fish is a unique strength of hydroacoustic sampling.

\subsection{Site Description}

Estimation of FPE and quantification of any enhancement by fish guidance devices is difficult because the Bonneville Project is among the most complex on the Columbia River. From the Oregon shore north toward Washington, the project is composed of a navigation lock, a first powerhouse (B1) with ten turbine units, Bradford Island, an 18-gate spillway, Cascades Island, and a second powerhouse (B2) with eight turbine units (Figure 1.1). Principal passage routes include the spillway and two powerhouses, but within each powerhouse, fish passage can be through ice/trash sluiceways, turbines, or the juvenile bypass system (JBS). Smolts enter the JBS after they encounter screens in the upper part of turbine intakes and are diverted to gatewell slots and orifices opening to a bypass channel. In 2000, units 1 to 6 at B1 were modified to create a prototype surface collector (PSC) for testing the efficacy of deepslot surface collection (Ploskey et al. 2002a). The PSC was removed before the beginning of the 2001 passage seasons. 


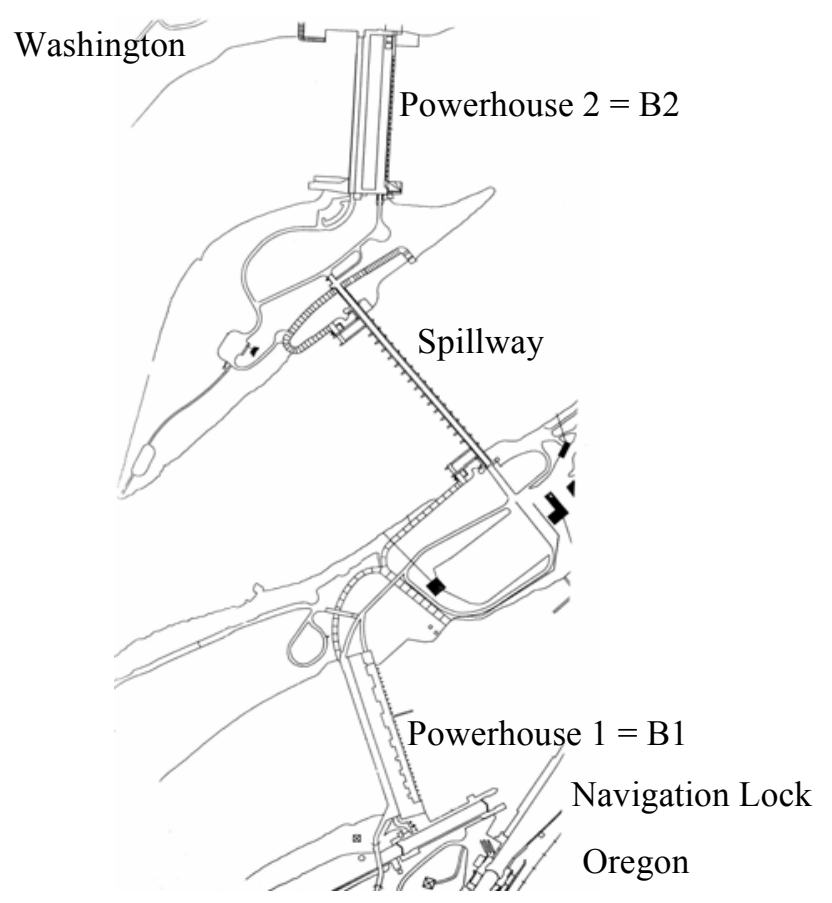

Figure 1.1. Plan View of the Bonneville Dam Project 
Hydroacoustic Evaluation of Fish Passage through Bonneville Dam in 2002 


\subsection{Materials and Methods}

\subsection{Equipment}

Fish passage at B1 turbines was sampled using three hydroacoustic systems and another system sampled the sluiceway entrances at intakes $7 \mathrm{~A}$ and $10 \mathrm{C}$. At the spillway four systems sampled the 18 spill bays and at B2 three systems sampled the turbines. Each system consisted of an echosounder, cables, transducers, an oscilloscope, and a computer system. Echosounder and computer pairs were plugged into uninterruptible power supplies. An echosounder generates electric signals of specific frequency and amplitude and at the required pulse durations and repetition rates, and cables conduct those transmit signals from the echosounder to transducers and return data signals from the transducers to the echosounder. Transducers convert voltages into sound on transmission and sound into voltages after echoes return to the transducer. The oscilloscopes were used to display echo voltages and calibration tones as a function of time, and the computer system controlled echosounder activity and recorded data to a hard disk. The $420 \mathrm{kHz}$, circular, single- or split-beam Precision Acoustic Systems (PAS) transducers were controlled by PAS 103 echosounders and Hydroacoustic Assessments' HARP software running on Pentium-class computers.

Sluiceway entrances 7A and 10C at B1 were sampled by one of the hydroacoustic systems described in the previous paragraph, and Entrance 7A also was sampled with four Inuktun FireflEYE (sic) optical cameras. The cameras were black and white units, with resolution of 430 lines of NTSC video, light sensitivity of 0.03 lux, and a field of view of about 60 degrees in the horizontal plane, with a $2.9-\mathrm{mm}$ fixed focus lens. A Leightonics MiniT-Pro programmable video switcher allowed us to sequentially sample the four cameras, and sampling was remotely controlled by the Panasonic AG-DV2000 video tape recorder. The large format DV tapes were Panasonic model \# AY-DV 186PQ, which hold 3 hours of digital video each.

We deployed a down-looking acoustic camera (DIDSON) on a traversing beam in several gatewells of B2 to record proportions of juvenile salmonids moving up into the gatewell and through the gap between the top of the STS and the ceiling of the intake. The Dual-Frequency Identification Sonar (DIDSON) was developed by the Applied Physics Laboratory (APL) at the University of Washington for the Space and Naval Warfare Systems Center harbor surveillance program. It can detect objects out to 48 meters and can provide video-quality images to identify objects out to about 9 meters. The DIDSON was designed to bridge the gap between existing sonar, which can detect acoustic targets at long ranges but cannot record the shapes or sizes of targets and optical systems, which can videotape fish in clear water but are limited at low light levels or turbidity. It has a high resolution and fast frame rate designed to allow it to substitute for optical systems in turbid or dark water. The images within $9 \mathrm{~m}$ of the device are so clear that one can see fish undulating as they swim and can tell the head from the tail. The DIDSON is a non-intrusive device that is not limited by turbidity or light and that is not as sensitive to entrained air as are the 6-10 degree beams that are typically used for hydroacoustic sampling.

The DIDSON was attached to a programmable traversing mount so that samples could be taken from five lateral locations across the gatewell when operators were present to remotely control the DIDSON's position. The traversing part of the 6.1-m-wide beam was moved by a stepper motor and controlled by 
custom designed software on a laptop computer through a serial communication port. Stepper motor feedback to the computer provided position information, which could be verified by five position sensors located along the beam.

\subsection{Calibrations}

Before deployment, all hydroacoustic equipment was transported to Seattle, Washington, where PAS electronically checked the echosounders and transducers and calibrated the transducers using several standard transducers. After calibration, we calculated receiver gains to equalize the output voltages among transducers for on-axis targets ranging in hydroacoustic size from -56 to $-35 \mathrm{~dB} \| 4 \pi \mathrm{m}^{2}$ (Appendix A). Lengths of fish corresponding to that acoustic size range would be about 1.3 and 12 inches, respectively, for fish insonified within $21^{\circ}$ of dorsal aspect (Love 1977). Inputs for receiver-gain calculations included calibration data (i.e., echosounder source levels and $40 \log$ [range] receiver sensitivities for specific transducers and cable lengths) and acquisition equipment data and settings (installed cable lengths, maximum output voltage, and on-axis target strengths of the smallest and largest fish of interest). In most instances, calibrated and installed cable lengths were identical. When installed cable lengths differed from calibrated cable lengths because we had insufficient cable for a deployment, we used an empirically derived correction factor to compensate for cable length effects on source levels, receiver sensitivity, and receiver gain settings.

\subsection{Transducer Deployments and Sampling Schemes}

This section describes hydroacoustic deployments and sampling schemes with text and figures. We also describe technical details about transducer locations and aiming angles in Appendix B.

\subsubsection{Sampling at B1}

In turbine units 1 to 4 and 6 to 10, we sampled one randomly selected intake slot out of three intakes per unit. Unit 5 did not run in 2002. We mounted one upward- and one downward-angled, $6^{\circ}$ transducer in the selected slots to monitor guided and unguided passage, respectively (Figures 2.1 and 2.2). The lateral location of each opposed pair of transducers within the same intake was randomly selected to be on the north, center, or south side of the trash rack (Appendix B) so that some of the lateral variation in passage within intakes would be captured in the variance estimate for the entire powerhouse.

Transducers deployed in unit 9 were $6^{\circ}$ split-beams to provide target strength data for detectability modeling. Sampling the 12.2-m-long extended submerged bar screen (ESBS) at Unit 8 required a different deployment of transducers. Fish passing above and below the ESBS of Unit 8 were sampled with upward- and a downward-angled $6^{\circ}$ single-beam transducers to estimate guided and unguided numbers, respectively, but the down-looking transducer was mounted on the downstream side of the ESBS instead of on trash racks (Figure 2.2). Therefore, fish passage at Unit 8 could differ from estimates at other B1 units for a variety of reasons, e.g., screen type, unit location, intake selected for sampling, and differences in detectability among deployments. Our modeling of and correction for differences in detectability among deployments should have minimized the last effect. Paired transducers in every intake were fast multiplexed to acquire 15 1-minute samples from each intake per hour on each single- 
beam system and 201 -min samples/h on the split-beam system. The pulse repetition rate was 13 pings per second for the split-beam transducers in Unit 9, and 14 pings/s for all other B1 units.

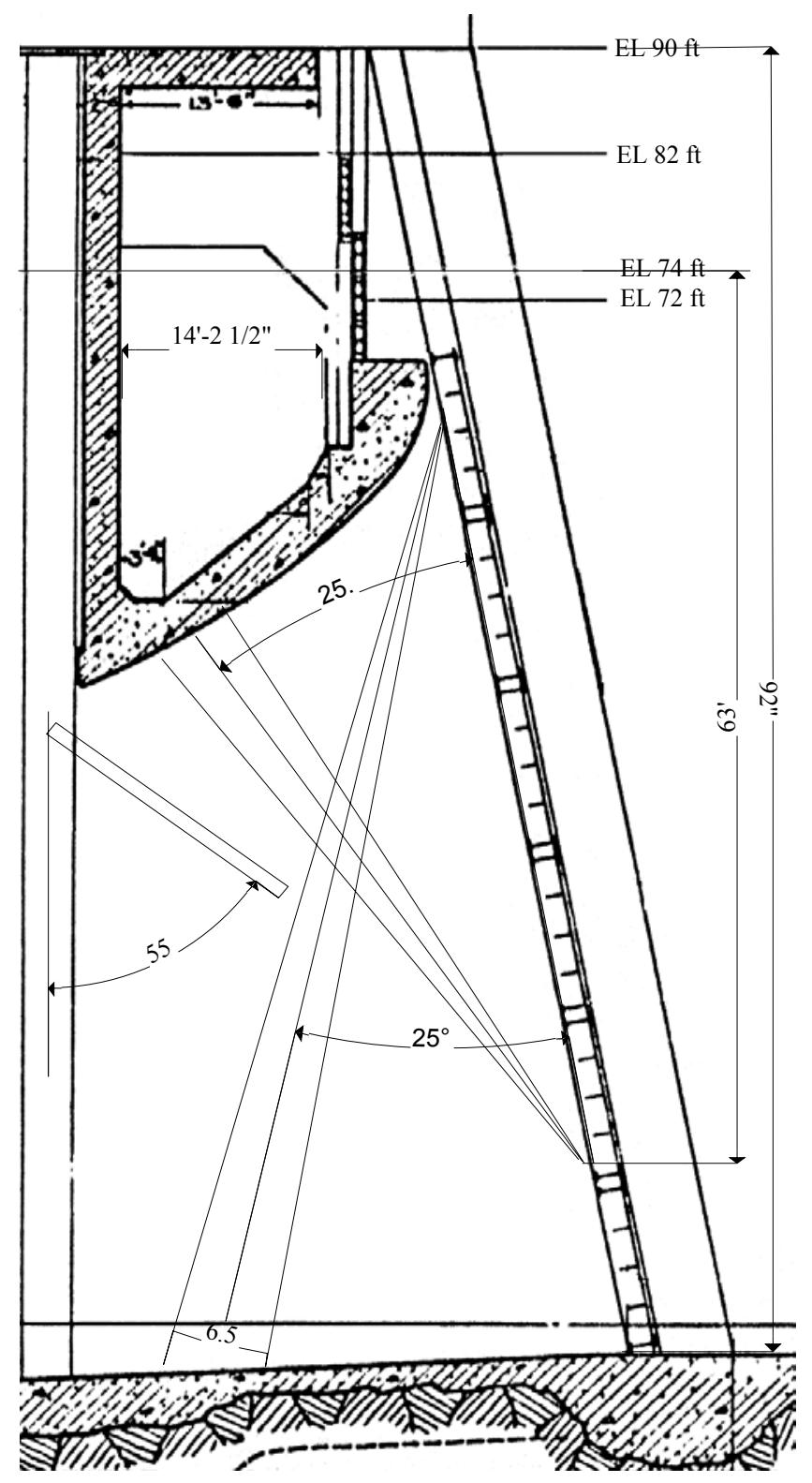

Figure 2.1. Cross Sectional View through a B1 Intake Like Those Sampled in Units 1 to 7, 9, and 10. The drawing shows up- and down-looking hydroacoustic beams, aiming angles, and cutoff ranges for sampling guided and unguided fish. Minimum ranges for sampling guided and unguided fish were 8.0 and $10 \mathrm{~m}$, respectively. Flow into the intake is from right to left. 


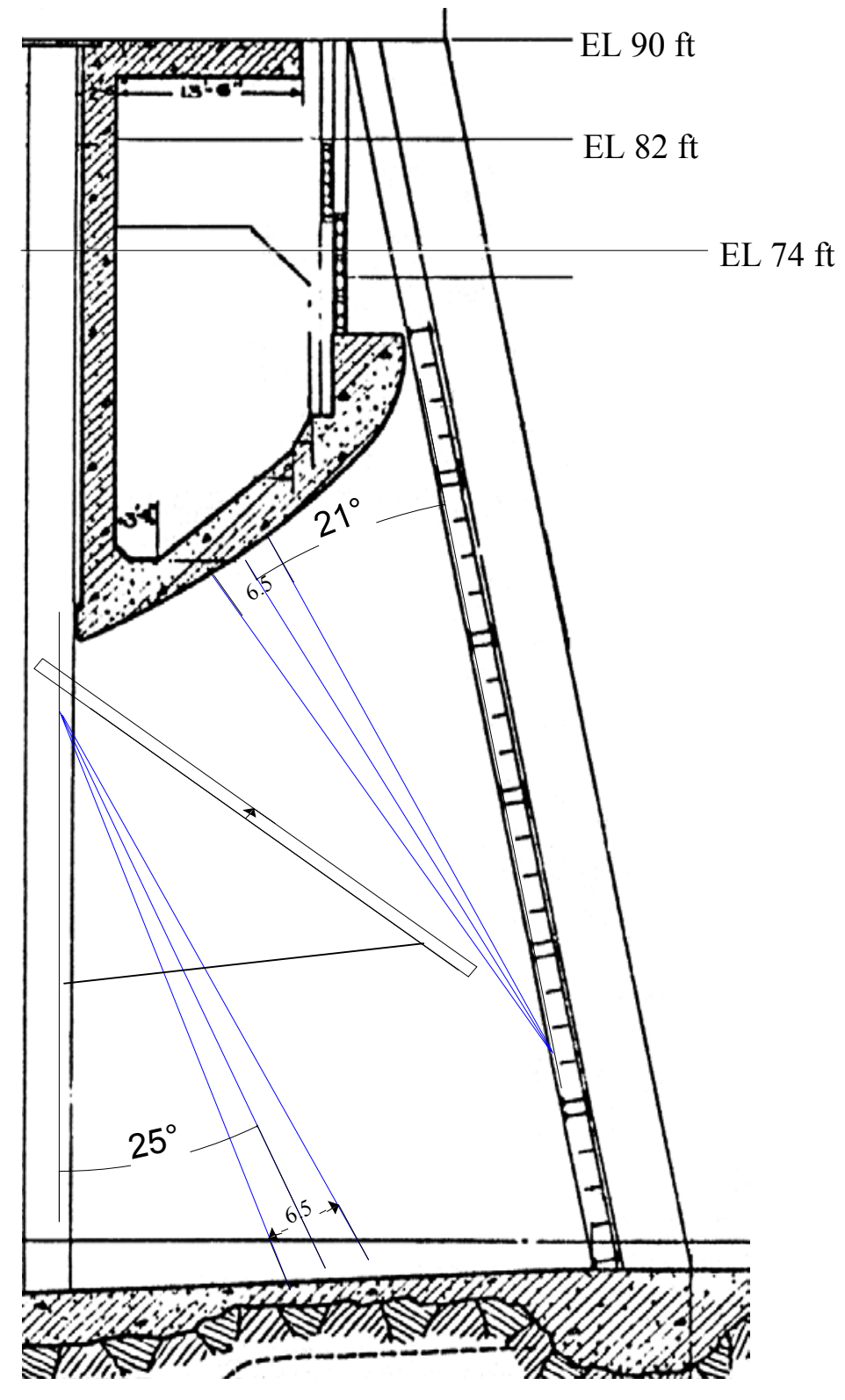

Figure 2.2. Cross-Sectional View through Intake 8B where Up- and Down-Looking Single-Beam Transducers were Used to Sample Guided and Unguided Fish, Respectively. Minimum ranges for sampling guided and unguided fish were 1.82 and $5.8 \mathrm{~m}$, respectively. Flow into the intake is from right to left.

At sluiceway entrances above turbine intakes 7A and 10C, two opposing 6-degree split-beam transducers were aimed across the entrance and sampled throughout the spring and summer seasons. One transducer was aimed toward the south, and the other transducer was aimed to the north, as illustrated in Figure 2.3, and only the far half of each beam was used to count fish passing through one-half of the entrance. The split-beams provided data on fish speed, trajectory, direction of movement, and target strength. Transducers were fast-multiplexed at 50 pings per second ( 25 pings/s each) and each sluiceway was sampled for 15 2-min intervals every hour. 


\section{S o u th}

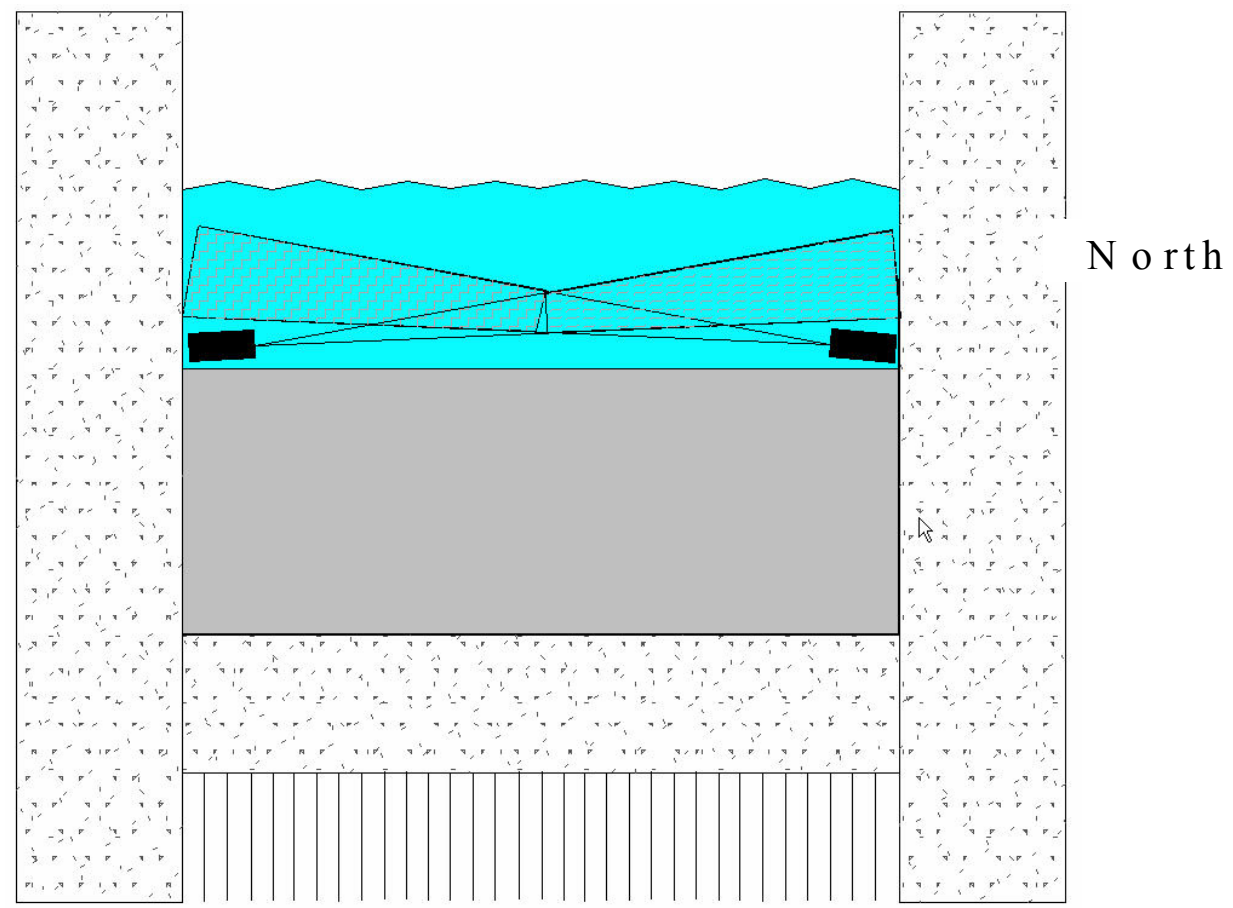

Figure 2.3. Forebay View of a Sluiceway Entrance at Intake 7a or 10c in 2002 Showing the Deployment of Opposing Split-Beam Transducers for Sampling Fish Passage. The transducers were mounted on top of the chain gate. The minimum range for sampling fish in each of the acoustic beams was $2.9 \mathrm{~m}$. Flow into the entrance is from the reader's location toward the page.

Four optical cameras provided a second independent estimate of fish passage into Sluice Entrance 7A (Figure 2.4). The up-looking cameras were equally spaced along the upstream side of the chain gate and lenses were flush with top of the gate. The four cameras were sequentially switched and sampled a combined 15 minutes per hour ( $3 \mathrm{~min}, 45 \mathrm{~s}$ intervals per camera). Tapes were changed twice a day and sampling was conducted 24 hours per day. Data collection started on 6 May 2002 and continued through 19 July. Only video recorded during daylight hours proved to be usable, due to constraints on infrared lighting methods. There were infrared LEDs built into the molded epoxy housing of the cameras, but these proved to be inadequate for the demands of this deployment. Total running time for the recorded video was 465 hours, yielding approximately 300 hours of usable daylight recordings. This represents 1,200 hours that were sampled and available for analysis, since sampling represented $1 / 4$ of each hour. Out of this, 126 hourly samples $(10.5 \%)$ were processed manually and visual counts were spatially and temporally expanded to estimate fish passage. 


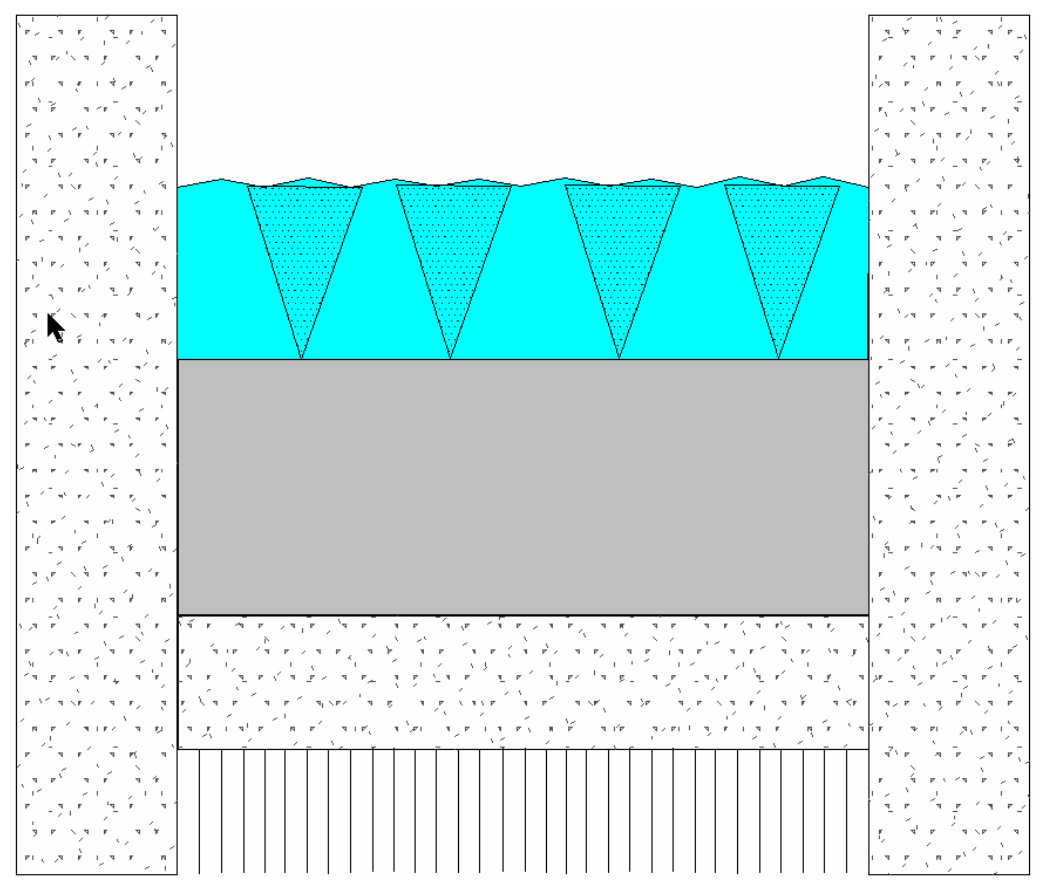

Figure 2.4. Forebay View of a Sluiceway Entrance at Intake 7A in 2002 Showing the Deployment of Four Up-looking Optical Cameras for Sampling Fish Passage. The cameras were mounted on the upstream top surface of the chain gate and lenses were flush with the top of the gate. The range of counting depended upon forebay elevation. Flow into the entrance is from the reader's location toward the page.

\subsubsection{Sampling at the Spillway}

Each of the 18 spill bays was sampled with one transducer. Most transducers were $10^{\circ}$ single-beams, except for three $12^{\circ}$ split-beams on spill bays 6,9 , and 16 . The split-beams provided data on fish speed, trajectory, direction of movement, and target strength. All transducers were mounted $8.5 \mathrm{~m}$ below the tops of the spill gates. The $10^{\circ}$ single beams were aimed about $6^{\circ}$ upstream from vertical so that the downstream edges of the beams were adjacent to the spill gates (Figure 2.5). The $12^{\circ}$ beams in spill bays 6,9 , and 16 were aimed about $7^{\circ}$ upstream from vertical (Appendix B). The maximum gate opening in 2002 was about $1.9 \mathrm{~m}$, which provided for about $14,200 \mathrm{cfs}$ of water discharge. The lateral location of each transducer within a bay was randomly selected to be on the north, center, or south side so that some of the lateral variation in passage within bays would be captured in the variance estimate for the entire spillway. All transducers had a pulse repetition rate of 25 pings per second. Single-beam transducers in 15 bays took 12 1-min samples each hour and split-beam transducers in bays 6, 9, and 16 took 201 -min samples per hour. 


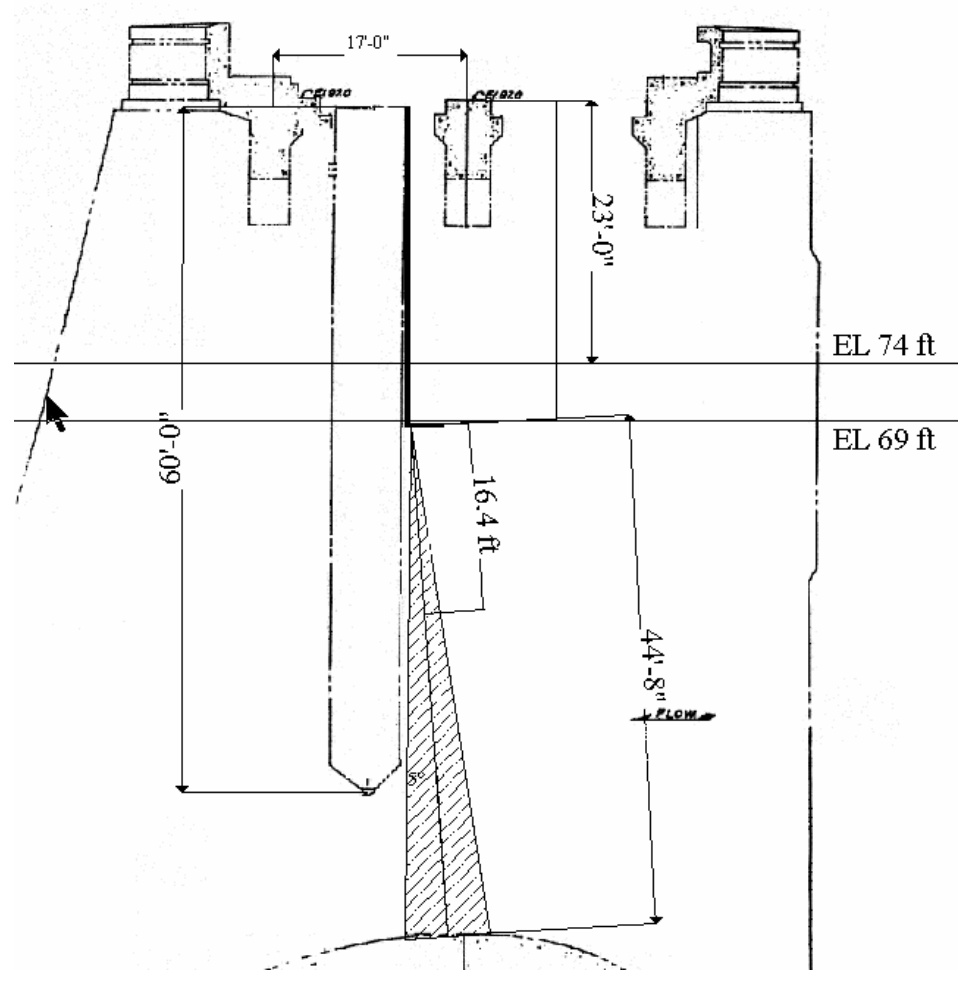

Figure 2.5. Cross-Sectional View through a Spill Bay at Bonneville Dam. The diagram shows a transducer mount on the upstream side of a spill gate and the orientation of the hydroacoustic beam. Flow was from right to left through the beam. The minimum range for sampling fish regardless of slope criteria was $5 \mathrm{~m}$ from the transducer. Flow under the gate is from right to left.

\subsubsection{Sampling at B2}

\subsubsection{Hydroacoustic Sampling of Fish Passage}

At B2, one out of three intakes at every turbine unit was randomly selected for sampling, except at Unit 17, where two of three intakes were randomly selected for sampling. Three transceivers and computers were used to control the 18 transducers. In each sampled intake, we mounted a pair of transducers on the downstream side of the trash racks (Figure 2.6; Appendix B). One transducer of each pair was mounted near the bottom of the uppermost trash rack and aimed downward to sample unguided fish passing below the traveling screen. The second transducer of each pair was mounted near the bottom of the fourth trash rack from the top and aimed upward to sample fish passing above the screen. The lateral location of both transducers within the same intake was randomly selected to be on the north, center, or south side of the trash rack (Appendix B). The two transducers deployed in Unit 12 were split beams to provide data on fish speed, trajectory, direction of movement, and target strength.

Each transducer transmitted sound pulses at 14 pings per second, and both transducers of a pair usually were sampled simultaneously. This fast multiplexing allowed us to estimate covariances for the simultaneous samples of guided and unguided fish and to collect 151 -minute samples per hour at every intake. 


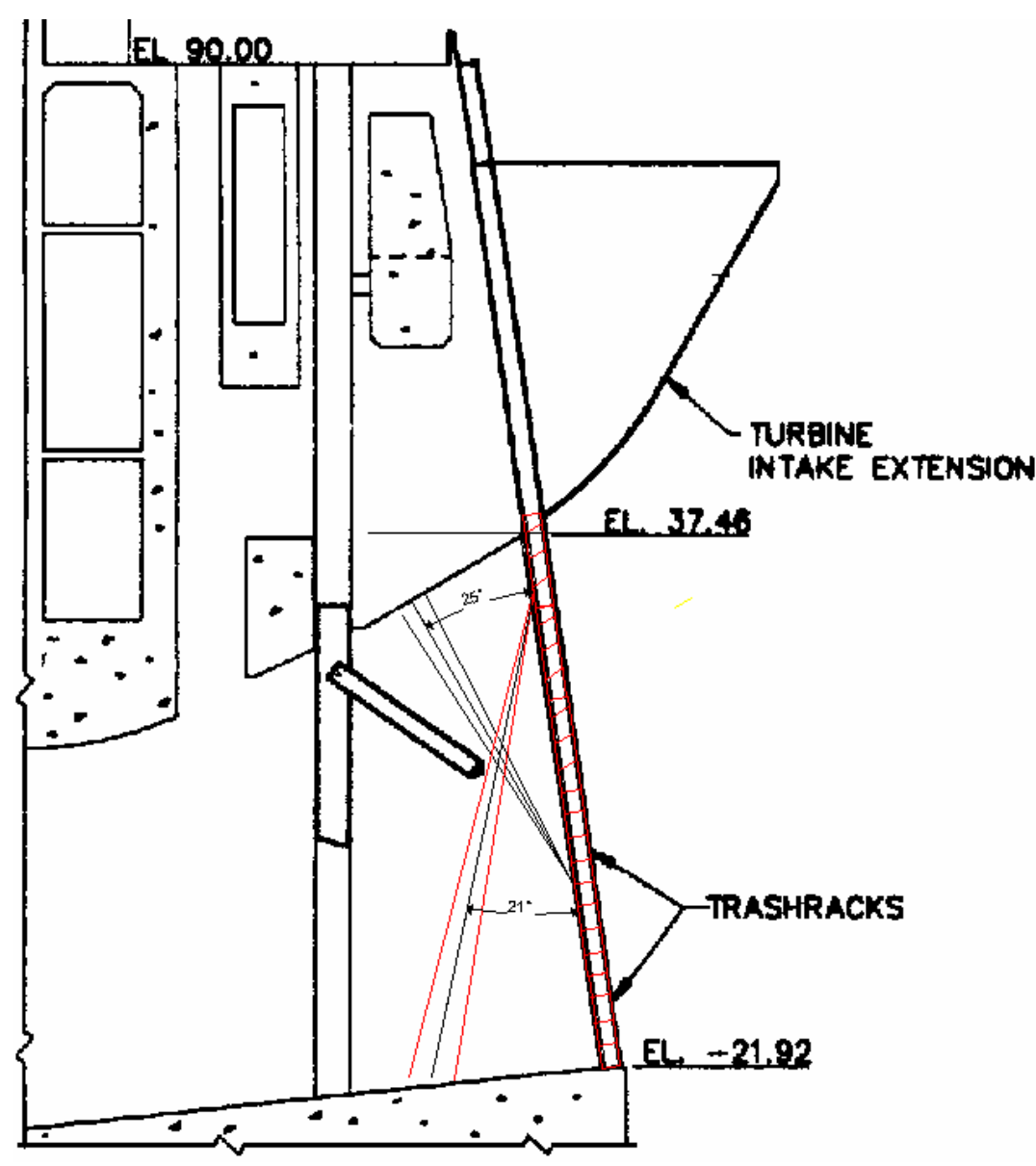

Figure 2.6. Cross-Sectional View through a B2 Turbine Showing Up- and Down-Looking Transducer Beams. The minimum ranges for sampling guided and unguided fish were 4.9 and $5.6 \mathrm{~m}$, respectively. Flow into the intake is from right to left.

\subsubsection{Acoustic Camera Sampling of STS Gap Loss}

Physical modeling of B2 intakes raised concerns that flow moving above the STS and up the gatewell was limiting FGE and that a high proportion of flow was moving between the top of the STS and the intake ceiling (Figure 2.7). In an attempt to improve FGE, the Portland District modified gatewell slots in unit 15 before the 2001 smolt migration and gatewells at Unit 17 before the 2002 migration. The objective was to increase flow above the STS and up into the gatewell slot in an attempt to increase smolt guidance efficiency (Figure 2.8). Modifications consisted of removing a lot of concrete, greatly expanding the surface area of THE vertical barrier screen (VBS), and adding a turning vane and gap closure device to direct more water up the slot and away from the gap between the top of the STS and the intake ceiling. In 2002, the mesh size of the VBS was reduced from about 0.25 inches to about 0.125 inches to guide salmonid fry. 


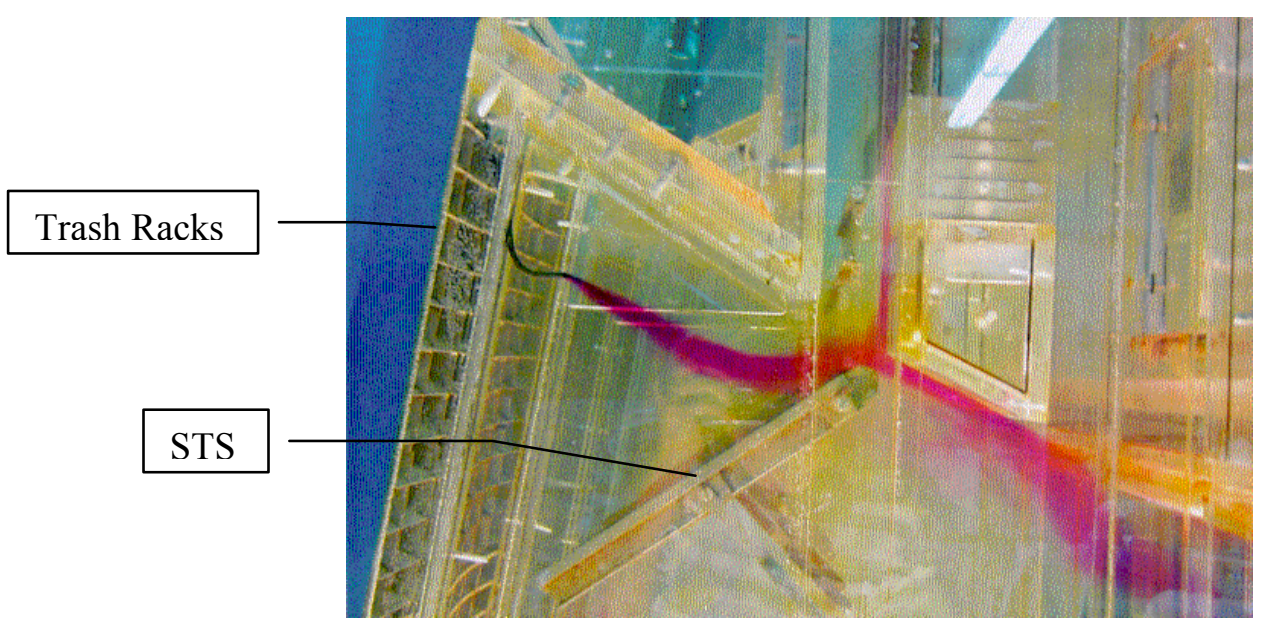

Figure 2.7. Cross-Sectional View of a Model of an Un-modified Intake at B2 Showing the Path and Distribution of Dye Introduced at the Trash Racks on the Left Side. The relatively high proportion of dye passing through the gap between the top of the STS and the intake ceiling raised concerns for smolts passage. The model was built by the Hydraulics Laboratory of the Engineer Research and Development Center, Vicksburg, MS). Flow into the intake model is from left to right.

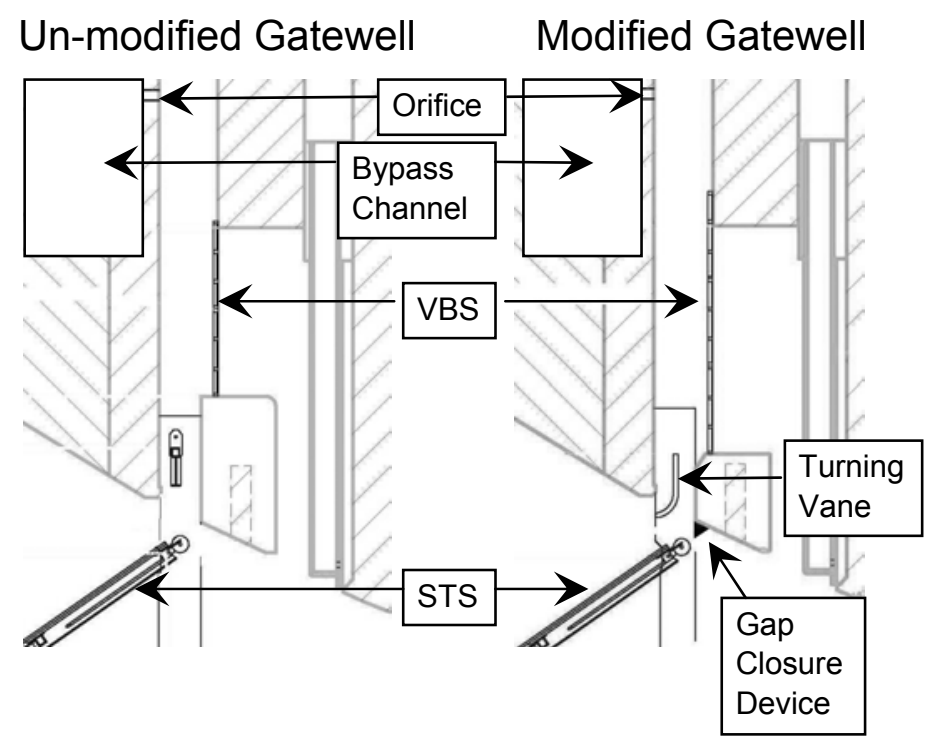

Figure 2.8. Cross-Sectional View through Intakes with Un-modified and Modified Gatewells at B2. Intakes of units 15 and 17 were modified (right diagram) to increase flow above the STS and through the VBS, thereby leaving more smolts in the gatewell to find their way to the orifice and juvenile bypass channel. Modifications consisted of removing concrete, increasing the area of the VBS, and adding a turning vane and a gap-closure device. Flow into the intake would be from left to right.

To evaluate gap loss proportions, we deployed a DIDSON acoustic camera on a 6.1 -m-long beam with a traversing mechanism in the gatewells of modified intake 17B and unmodified intake $18 \mathrm{~A}$ in spring and in modified intake 17C and unmodified intake 13B in summer (Figure 2.9 and 2.10). At each gatewell, we sampled proportions of fish moving up into the gatewell and through the gap for most of two 
consecutive 24-h periods. We actively sampled five lateral positions across the $6.1-\mathrm{m}$-wide gatewell for at least 4 hours from about 2000 until midnight (sometimes as long as 8 hours) before we moved the DIDSON to the center of the gatewell and let the system acquire data for the rest of the 24-h period.

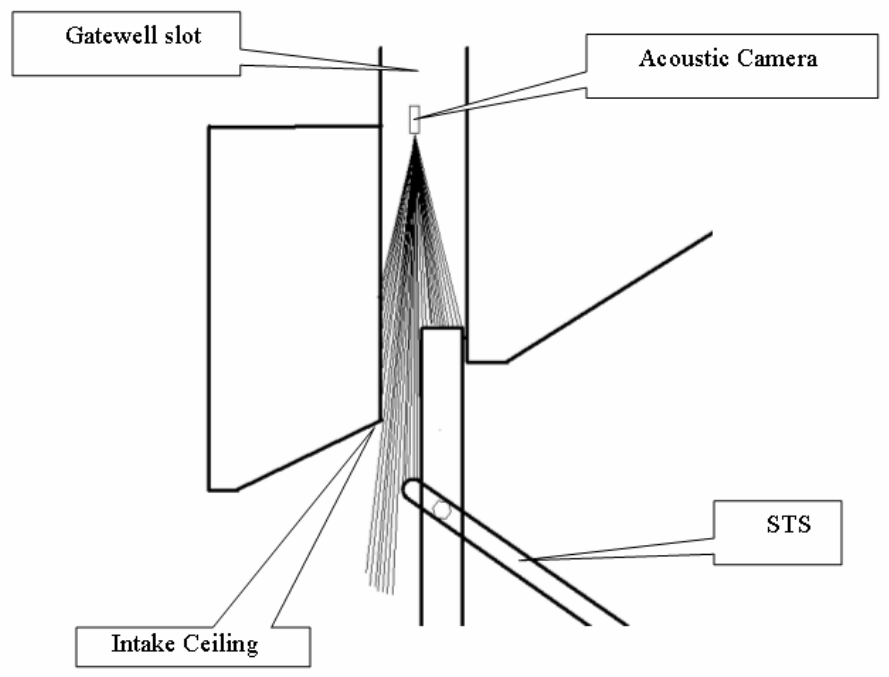

Figure 2.9. Cross-Sectional Diagram of an Intake at B2 Showing the DIDSON Acoustic Camera Deployment with $960.3^{\circ}$ wide by $10^{\circ}$ Deep Acoustic Beams for Detecting Fish. The DIDSON detects fish in two dimensions, either moving toward or away from the device (up or down) or laterally across the array of beams. Flow is from right to left and splits just upstream of the intake ceiling and gap. The acoustic camera was moved along a beam to sample multiple locations across the width of the gatewell slots (toward and away from the reader).

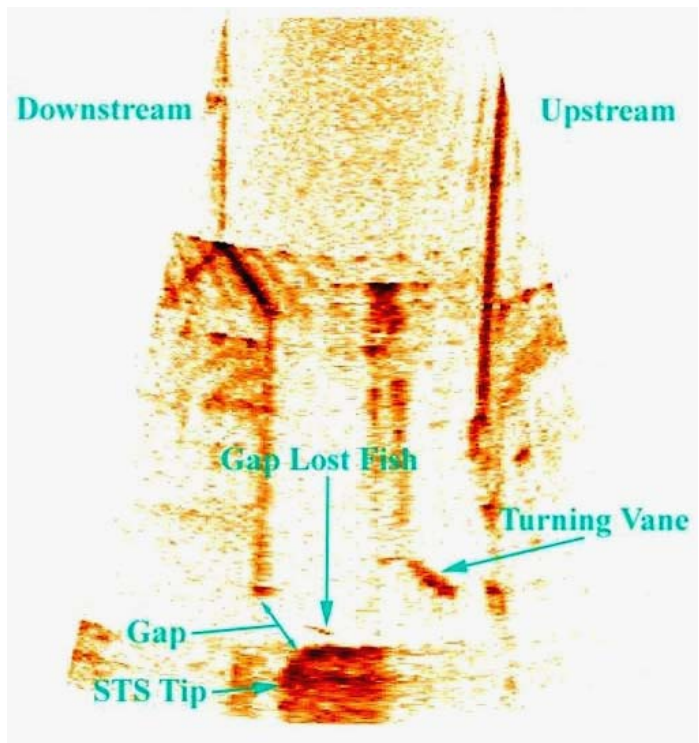

Figure 2.10. Image from the DIDSON Acoustic Camera Deployed in Modified Gatewell 17C of B2. Flow is moving from right to left below the tip of the turning vane and upward above the tip of the vane. 
Digital video data files of fish passing through the gap and up the gatewell were processed manually by recording the range of first detection and the fate of every fish (i.e., gatewell or gap lost). We expanded the count of every fish using the following equation:

$$
E C=\frac{G W}{\left[F R \times T A N\left(\frac{10}{2}\right) \times 2\right]}
$$

where $\mathrm{EC}=$ expanded count, $\mathrm{GW}=$ gatewell width $(6.1 \mathrm{~m}), \mathrm{FR}=$ first range of detection $(\mathrm{m}), \mathrm{TAN}$ is the tangent, and 10 degrees is the spreading angle of the 96 acoustic beams with range relative to GW. The expansion increased the count of fish in the gatewell fraction relative to the gap-lost fraction because gaplost fish were detected at slightly greater range than were fish moving up into the gatewell. The frame rate of the DIDSON ranged from 8 to 10 per second depending upon noise conditions. Images of gatewell-bound fish were captured in multiple frames ( 5 to 30) compared to the 1 to 2 frames available to detect fish moving much faster through the gap.

We also deployed the acoustic camera on the bottom of the uppermost trash racks of Intake 18A for one night in spring to see whether the camera could detect smolts passing through the gap between the side of the STS and the side of the intake (Figure 2.11).

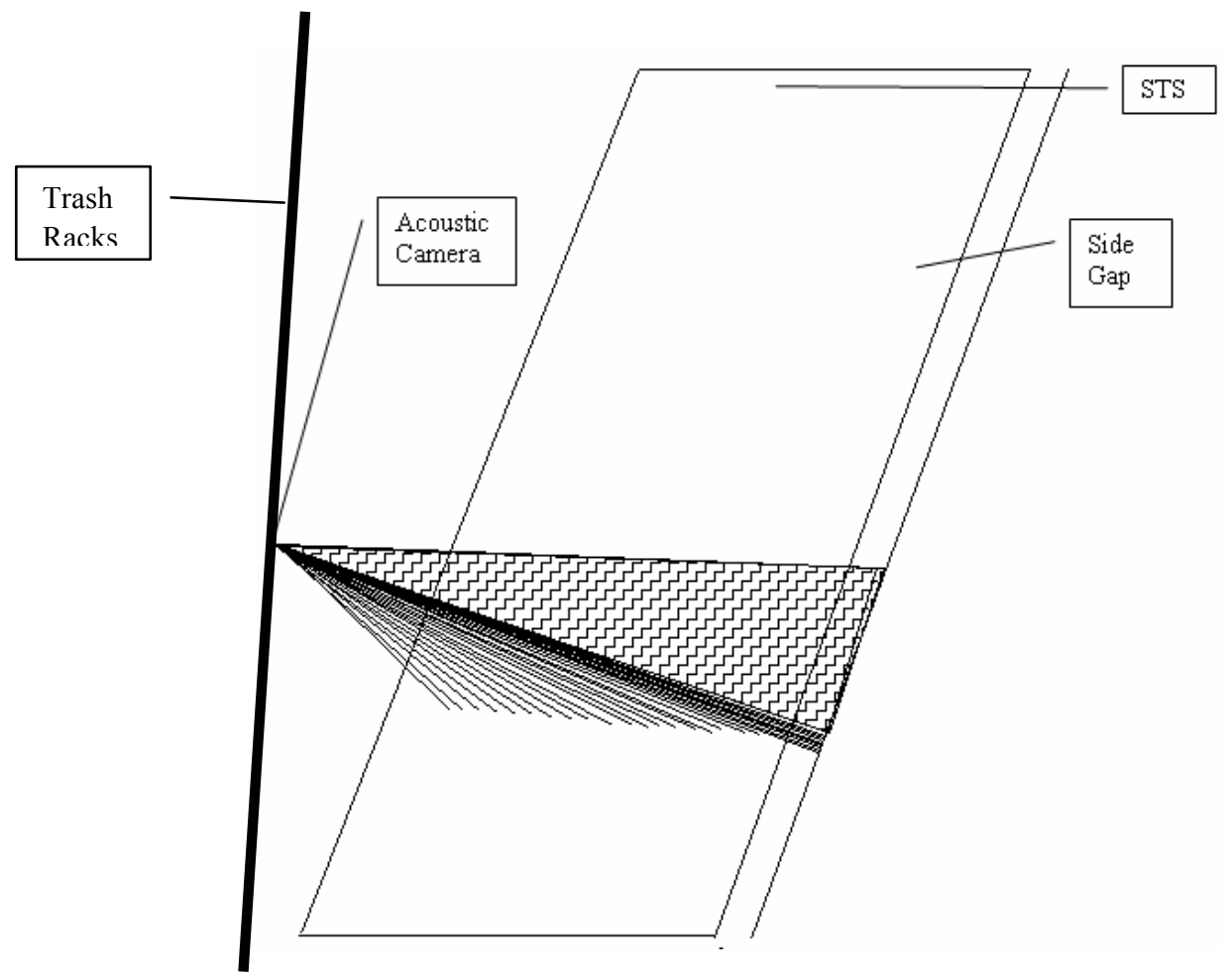

Figure 2.11. Diagram Showing the Field of View of the Acoustic Camera Deployed on the Bottom of the Uppermost Trash Rack at Intake 18A in Spring 2002. Flow is moving from left to right and into the page. 


\subsection{Hydroacoustic Fish Tracking and Filtering Criteria}

Since the hydroacoustic sampling effort on Bonneville Dam was so extensive and generated such a large volume of data in 2002, we could not feasibly manually process enough data to make reliable fishpassage estimates with available staff. Therefore, we relied on autotracking software developed from 1998 through 2002 by the Corps of Engineers and PNNL to process raw data into tracked fish observations. The autotracker software tells the processing computer to:

1. 1. Identify and remove echoes at constant range from structure.

2. 2. Find seed echoes for candidate tracks.

3. Go to every echo.

4. Define a 10-ping by 1-m window centered on that echo.

5. Place all echoes in the window into 5-degree angle bins.

6. If any bin-count $>3$, flag the center echo as a candidate seed.

7. 3. Re-examine candidate seed echoes.

8. Go to every seed-echo window.

9. Count echoes in all possible line features (Hough transform).

10. If no echoes in the window are part of a strong line feature then drop the seed echo (to distinguish between dense noise and dense fish tracks).

11. 4. Initiate alpha-beta tracking.

12. Track forward, starting at each seed echo.

13. Track backward from the same seed echo after forward tracking has ended.

14. Check the track segment against criteria (echo density, minimum and maximum gap).

15. 5. Link collinear track segments into single tracks. This involves projecting the first track segment forward and the second segment backward and linking them into one fish if the ping gap $\leq 20$ pings and the two segments line up and meet a track link criteria.

16. 6. Write out track statistics (echo statistics optional).

We describe and present autotracker parameters and the settings used to process the 2002 data in Appendix C. During most of spring and early summer, we reviewed samples of the autotracker's performance for every deployment on a fish-by-fish basis to evaluate and fine-tune the autotracker and to develop post-processing filters for eliminating false traces from the autotracker's output. We released the 
autotracker to process data for a given deployment only after we determined that it was missing few of the echo patterns that we would have tracked.

In Appendix D, we describe criteria and present SAS (Statistical Analysis System) code used to reject non-fish traces that the autotracker selected. In another part of the processing program, we eliminated fish detected at ranges less than those described in the legends of Figures 2.1, 2.2, 2.3, 2.5, and 2.6. Filtering out non-fish traces based upon variables like range, slope, and noise level is a critical feature of autotracking software, because the autotracker is more likely to track intermittent series of structural echoes or noise than are technicians. Filters were designed to eliminate echo traces that had a high probability of being from structure, noise, or large non-target fish based upon their track statistics.

Although the autotracker was a very efficient tool, we evaluated its performance and post-processing filters in both seasons by comparing counts of fish by the software and by trained technicians. We did extensive training and testing on raw hydroacoustic data from previous years and from early 2002 data before the 2002 tracking season began. In previous years (Ploskey et al. $2001 \mathrm{a}-\mathrm{c}$ and $2002 \mathrm{a}-\mathrm{c}$ ), we found that consistent differences occurred among different human trackers of hydroacoustic data and that these differences, if not carefully controlled, can seriously bias counts used either for passage estimates or for quality control and assurance of automatic tracking. For that reason, we always compare our automatically tracked estimates with the average estimate from more than one human tracker. Average hourly counts and variances in 2002 were calculated from counts by three of the four technicians processing data. This approach allowed technicians to manually track a quarter more data than if all four technicians had tracked each hour.

We selected 10 days throughout spring and 10 days throughout summer from which to select manual tracking data. From each of those selected days we chose three hours of raw data for each of the 12 hydroacoustic systems on the dam, for quality control and assurance analysis. These included the usually highest passage hour in spring (2100 hour) and summer ( 2200 hour) except for cases when B1 data from those hours were unavailable because units there were not operating. In those cases, the closest operating hours to the 2100 and 2200 hours were selected from the available data. The high passage hours were selected to provide the best possible range for regression analysis. The other two hours per chosen day were randomly selected. This scheme gave us 60 hours of raw data from each transducer from throughout spring and summer for comparing autotracked and human results. We used hourly samples for comparison because that is the smallest scale on which we could produce passage estimates. Raw echogram data were tracked by humans and the autotracker, and the resulting data were filtered and expanded identically.

Each tracker's output, whether from a human or from the autotracker, was processed with a channelspecific software "filter" that automatically rejects traces that do not meet specific criteria. Output files from each human or automatic tracker were post processed identically. Post-processing included deployment-specific "filtering" for trace length, trace slope, echo or target strength, structure, and other regular noise, and other characteristics described in Appendix D. The resulting filtered fish counts on each day were then summed separately by the transducer channel that was sampled.

We compared human and autotracked counts for each of 58 transducers channels because there are important differences in passage characteristics, ranges of interest, trace slopes and lengths, and noise conditions for each transducer's site and aiming angle. Comparing at the system level, which involves 
several transducer channels with different deployments, could mask error (Ploskey et al. 2002c). Uplooking transducer channels sampling guided fish have very different noise regimes than down-looking transducer channels and the slopes of regression lines fitted to autotracker and mean human counts often differ too. They can even vary in opposite directions, so that up-looking transducer channels have higher autotracked counts and down-looking transducer channels have higher human-tracked counts. In those cases, comparing at the system level would mask some of the disagreement between the humans and the autotracker. Even with the same aiming (such as all of the down-looking channels at a powerhouse), different channels have different noise, clutter, and range of interest characteristics. The most appropriate analysis for quality control and assurance is hourly data samples from throughout the sampling seasons and diel cycles comparing filtered and expanded autotracker results to the mean filtered and expanded human results for the same data hours on a channel-by-channel basis.

\subsection{Adjustments to Fish-Passage Estimates}

We adjusted autotracker counts and variances in two ways according to the general methods described below.

First, we regressed hourly fish counts by technicians on autotracker counts for each transducer and used slopes of regression lines with intercepts forced through zero to convert autotracker counts into mean technician counts and thereby remove systematic bias in autotracker counts among deployments. Regressions provided a measure of the agreement between the two methods in the form of the coefficient of determination $\left(\mathrm{r}^{2}\right)$ and a slope with which to assess the degree of under counting or over counting that the autotracker does relative to the human trackers. Plots of the regressions of mean technician counts on autotracker counts for every deployment are presented in the Results section of this report. Manually analyzing the hydroacoustic tracks is generally considered the most reliable and accurate method of processing raw hydroacoustic data. However, because of the sheer magnitude of the data collected, automated tracking algorithms programmed for pattern recognition are often employed to process the raw hydroacoustic data. The pattern recognition abilities of people are generally considered superior to computer algorithms that can only identify patterns that have been pre-specified. To account for errors in pattern recognition, the regression analyses described above were performed.

Second, we examined the azimuth direction of travel of fish through all routes and found that the proportion of fish detected moving downstream through routes was significantly less than $100 \%$ for the sluiceway entrances at B1 and for the three spill bays sampled with split-beam transducers. We reduced counts at sluiceway and spillway routes by multiplying passage estimates by the average hourly proportion of fish detected moving downstream toward the openings. Direction of travel was based upon a line fitted to all echoes in a fish trace.

\subsubsection{Adjusted Estimate and Associated Variance}

Let $\hat{X}$ be an estimate of smolt passage and $\hat{B}$ be an estimate of a "calibration" adjustment. The calibration adjustments could include:

1. Adjustment of autotracker counts for manual counts

2. Adjustment of passage numbers for proportion of fish detected that enter a passage route. 
The adjusted estimate was written as

$$
\tilde{X}=\hat{B} \hat{X}
$$

with the associated variance estimator

$$
\widehat{\operatorname{Var}}(\tilde{X})=\widehat{\operatorname{Var}}(\hat{X}) \hat{B}^{2}+\widehat{\operatorname{Var}}(\hat{B}) \hat{X}^{2}-\widehat{\operatorname{Var}}(\hat{X}) \cdot \widehat{\operatorname{Var}}(\hat{B})
$$

when $\hat{X}$ and $\hat{B}$ are estimated independently. The variance can alternatively be expressed as

$$
\begin{aligned}
\widehat{\operatorname{Var}}(\tilde{X}) & =(\hat{B} \hat{X})^{2}\left[\frac{\widehat{\operatorname{Var}}(\hat{X})}{\hat{X}^{2}}+\frac{\widehat{\operatorname{Var}}(\hat{B})}{\hat{B}^{2}}-\frac{\widehat{\operatorname{Var}}(\hat{X}) \cdot \widehat{\operatorname{Var}}(\hat{B})]}{\hat{X}^{2} \hat{B}^{2}}\right] \\
& =(\hat{B} \tilde{X})^{2}\left[C V(\hat{X})^{2}+C V(\hat{B})^{2}-C V(\hat{X})^{2} \cdot C V(\hat{B})^{2}\right]
\end{aligned}
$$

\subsubsection{Sum of Multiple Adjusted Estimates}

Assume there are multiple passage estimates, each with its own calibration adjustment that need to be summed such that

$$
\tilde{X}=\sum_{i=1}^{n} \tilde{X}_{i}=\sum_{i=1}^{n} \hat{B}_{i} \hat{X}_{i}
$$

Then the variance of $\tilde{X}$ was estimated by

$$
\begin{aligned}
\widehat{\operatorname{Var}}(\tilde{X}) & =\operatorname{Var}\left(\sum_{i=1}^{n} \tilde{X}_{i}\right) \\
\widehat{\operatorname{Var}}(\tilde{X}) & =\operatorname{Var}\left(\sum_{i=1}^{n} \hat{B}_{i} \hat{X}_{i}\right) \\
& =\sum_{i=1}^{n}\left[\widehat{\operatorname{Var}}\left(\hat{X}_{i}\right) \hat{B}_{i}^{2}+\widehat{\operatorname{Var}}\left(\hat{B}_{i}\right) \hat{X}_{i}^{2}-\widehat{\operatorname{Var}}\left(\hat{X}_{i}\right) \cdot \widehat{\operatorname{Var}}\left(\hat{B}_{i}\right)\right]
\end{aligned}
$$

\subsubsection{Estimating the Calibration Adjustment: Ratio Estimator}

Consider the case of autotracking versus manual counts. Let $\hat{X}$ be the passage estimate based on autotracking and let $\tilde{X}$ be the estimate of passage for manual counts where

$$
\tilde{X}=\hat{B} \cdot \hat{X} \text {. }
$$


The estimator $\hat{B}$ was obtained from the straight-line regression through the origin where

$$
y_{i}=B x_{i}
$$

and where

$$
\begin{aligned}
& y_{i}=\text { manual count for the } i \text { th observation, } \\
& x_{i}=\text { autotracker count for the } i \text { th observation. }
\end{aligned}
$$

The regression was plotted as follows:

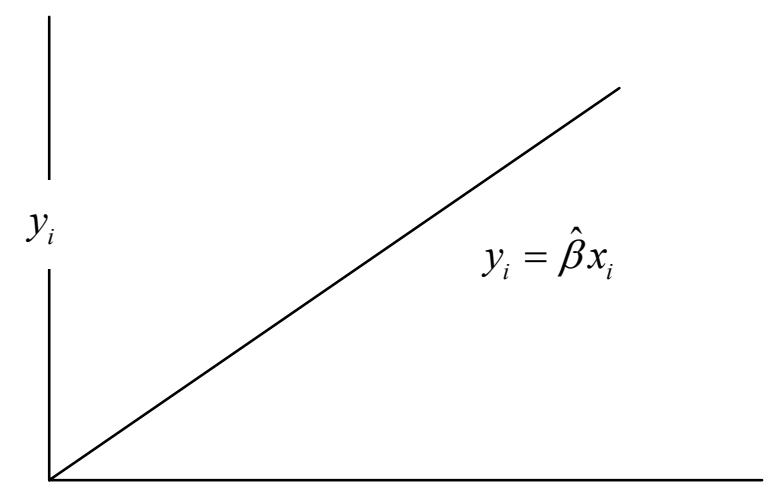

The estimator of the slope was

$$
\hat{\beta}=\frac{\sum_{i=1}^{n} y_{i}}{\sum_{i=1}^{n} x_{i}}
$$

The values of $x_{i}$ and $y_{i}$ used in the estimation of $\hat{B}$ were hourly counts, as was the estimate of $\tilde{X}$. The variance of $\hat{B}$ was estimated by the expression

$$
\widehat{\operatorname{Var}}(\hat{B})=\frac{\sum_{i=1}^{n}\left(y_{i}-\hat{\beta} x_{i}\right)^{2}}{n(n-1) \bar{x}^{2}}
$$

or equivalently, 


$$
\widehat{\operatorname{Var}}(\hat{B})=\frac{\sum_{i=1}^{n} y_{i}^{2}-2 \hat{B} \sum_{i=1}^{n} y_{i} x_{i}+\hat{B}^{2} \sum_{i=1}^{n} x_{i}^{2}}{n(n-1) \bar{x}^{2}}
$$

and where

$$
\bar{x}=\frac{\sum_{i=1}^{n} x_{i}}{n}
$$

\subsubsection{Estimating the Calibration-Adjustment Proportion Estimator}

Consider the case where the calibration adjustment is the proportion of observed smolts entering a passage route. The estimate of the adjustment was

$$
\hat{B}=\frac{\hat{V}}{\hat{V}+\hat{W}}
$$

where

$\hat{V}=$ estimated number of smolts that entered the passage route in the $i$ th observation,

$\hat{W}=$ estimated number of smolts that did not enter the passage route in the $i$ th observation.

The variance of $\hat{B}$ in this case was estimated as follows:

$$
\widehat{\operatorname{Var}}(\hat{B})=\frac{\hat{B}(1-\hat{B})}{(\hat{V}+\hat{W})}+\hat{B}^{2}(1-\hat{B})^{2}\left[\frac{\widehat{\operatorname{Var}}(\hat{V})}{\hat{V}^{2}}+\frac{\widehat{\operatorname{Var}}(\hat{W})}{\hat{W}^{2}}-\frac{2 \widehat{\operatorname{Cov}}(\hat{V}, \hat{W})}{\hat{V} \hat{W}}\right]
$$

The variance of $\hat{V}$ and $\hat{W}$ depends on how the total passage was estimated from multiple locations over time, so

$$
\hat{V}=\sum_{i=1}^{L} \sum_{j=1}^{D} \sum_{k=1}^{24}\left[\frac{N}{n} \sum_{l=1}^{n} v_{i j k l}\right]
$$

where

$$
\begin{aligned}
v_{i j k l}= & \text { expanded fish count for the } i \text { th sampling interval }(l=1, \ldots, n) \text { in the } k \text { th hour } \\
& (k=1, \ldots, 24) \text { for the } j \text { th day }(j=1, \ldots, D) \text { at the } i \text { th location }(i=1, \ldots, L) ; \\
n= & \text { number of intervals sampled per hour; }
\end{aligned}
$$


$N=$ number of possible sampling intervals within an hour.

$$
\widehat{\operatorname{Var}}(\hat{V})=\sum_{i=1}^{L} \sum_{j=1}^{D} \sum_{k=1}^{24}\left[\frac{N^{2}\left(1-\frac{n}{N}\right)}{n} s_{v_{i j k}}^{2}\right]
$$

where

$$
s_{v_{i j k}}^{2}=\frac{\sum_{l=1}^{n}\left(v_{i j k l}-\bar{v}_{i j k l}\right)^{2}}{(n-1)}
$$

$$
\bar{v}_{i j k}=\frac{\sum_{l=1}^{n} v_{i j k l}}{n}
$$

The variance of $\hat{W}$ was computed analogously.

The covariance of $\hat{V}$ and $\hat{W}$ was estimated as follows:

$$
\widehat{\operatorname{Cov}}(\hat{V}, \hat{W})=\sum_{i=1}^{L} \sum_{j=1}^{D} \sum_{k=1}^{24}\left[\frac{N^{2}\left(1-\frac{n}{N}\right)}{n} \operatorname{cov}\left(v_{i j k}, w_{i j k}\right)\right]
$$

where $\operatorname{cov}\left(v_{i j k}, w_{i j k}\right)=\frac{\sum_{l=1}^{n}\left(v_{i j k l}-\bar{v}_{i j k}\right)\left(w_{i j k l}-\bar{w}_{i j k}\right)}{(n-1)}$.

\subsection{Dam Operations and Fish Passage}

Hourly operations data, including discharge by spill bay and turbine unit, were provided by Bonneville Dam operators, who recorded results in a spreadsheet. Hourly operations data were integrated with fish passage data, and fish passage was set to zero when passage routes were closed for an entire hour. Spill bays happened to be opened and discharging water throughout the spring and summer sampling seasons so closure adjustments were unnecessary, but most turbines were on and off several times a day. This was important because transducers sampled continuously regardless of operations, and samples from closed turbine units or spill bays will include many traces that may be tracked as passed fish, often multiple times, even when a turbine unit is off or a spill bay is closed. Fortunately, operators recorded exact times that every turbine was started and shut down each day so we were able to set 1-min samples of fish passage to zero whenever a turbine was off. Polynomial regression equations (Figures S.1 and 4.1) were used to estimate flow into sluiceway entrances at intakes 7A and 10C from average hourly forebay elevations, which were obtained from project operations data. 
Hourly rates and variances in fish passage and hourly rates of water discharge through various routes at Bonneville Dam are presented in Appendix E on the accompanying compact disk. Tables 1 and 2 of Appendix E describe the variables in the comma-separated variable files.

\subsection{Missing Data}

We made a special effort to make certain that missing samples were accounted for in the spring and summer data sets. First, we created a data set consisting of all possible sample locations and times each season and set an expanded fish variable to missing in every observation. Second, we merged the missing data set with the acquired data set; counts of expanded fish, if present in the acquired data, overwrote missing counts. When a sample was not acquired for whatever reason, there was nothing in the acquired data set to overwrite the missing value for expanded fish. Therefore, the observation was appropriately designated as missing and could be interpolated before data were analyzed.

All hydroacoustic systems were operated continuously, except for about 15 minutes every morning when data were copied from the acquisition computer onto a portable FireWire ${ }^{\mathrm{TM}}$ hard drive or when equipment failed and data from the affected routes were not collected. Short equipment failures lasting up to 45 minutes were not a problem because fish counts and associated variances could still be estimated from the remaining within-hour samples. Computer lock-ups usually were fixed within an hour because we had staff monitoring systems 24 hours per day. Transducer cables failed on units 9 and 11 and both were fixed within a day, as soon as project support or divers became available. The failure at Unit 11 occurred in March before the fish passage season began. Each missing hourly estimate of passage for Unit 9 was calculated by averaging fish-passage estimates for the same hour during the two days before and after the outage, and the variance was estimated from a regression equation relating hourly variances to hourly passage rates (sums). This preserved the diel pattern within days but estimated hourly passage and variance from among four days.

Missing hourly sums and variances that resulted from equipment outages $>45$ minutes were estimated by temporal linear interpolation for periods $<6$ hours and by spatial interpolation or linear regression for periods $>6$ hours. Occasionally the ratio of guided to unguided numbers at adjacent turbines with similar screens was useful for interpolating estimates of guided or unguided numbers. Regression equations relating hourly variances with hourly sums were sometimes used to estimate missing variance estimates. We interpolated fish passage estimates from passage through adjacent bays for Bay 16 in both seasons because of severe structural noise problems there and for Bay 2 after 8 June because of an undetected intermittent signal from that transducer.

\subsection{Detectability Modeling and Spatial Expansions}

Detectability modeling and adjustments are very important for FPE studies that estimate proportions of fish passing a dam by all major routes or even FGE estimation for a single turbine because accurate estimates assume that all types of samples have equal detectability. The need for equal detectability applies to radio telemetry as well as to hydroacoustic methods. Differences in deployments make it very unlikely that equal detectability will occur, and therefore, some adjustment is required to improve the assumption of equal detectability. For hydroacoustic sampling, we adjust for differences in detectability as a function of range from every transducer by expanding every fish count by the ratio of the width (vertical beams) or depth (horizontal beams) of a route to the diameter of the hydroacoustic beam at the 
range a fish is detected. Calculating the diameter of the beam at the range of detection requires modeling of the effective-beam angle, which is an index to hydroacoustic detectability.

Effective beam angle (EBA) depends upon the detectability of fish of different sizes in the acoustic beam and is a function of nominal beam width, ping rate, trace criteria, fish size, aspect, trajectory, velocity, and range. We modeled detectability for every transducer deployment to determine effective beam angle as a function of range from a transducer. We obtained target-strength estimates and fish velocity and trajectory by $1-\mathrm{m}$ range strata from manually tracked split-beam data. These data and other hydroacoustic-acquisition data (e.g., ping rate, target-strength threshold, number of echoes, and maximum ping gaps) were entered into a detectability model. Inputs to the detectability model are presented in Tables 2.1 and 2.2. Model output consisted of effective beam angle as a function of range from a transducer. Polynomials fitted to those data were substituted for EBA in Equation 13 below to correct for differences in detectability by range among transducers and locations. 
Table 2.1. Deployment-specific Variables that Were Input to a Stochastic Detectability Model for Estimating Effective Beam Angle as a Function of Range from a Transducer. Constants were as follows: Target Strength (TS) threshold $=-56 \mathrm{~dB}$; Maximum ping gap $=4$; Minimum echo count $=4$ echoes in 5 pings; Tilt $=0$ since we used beam coordinates for fish plunge and speed.

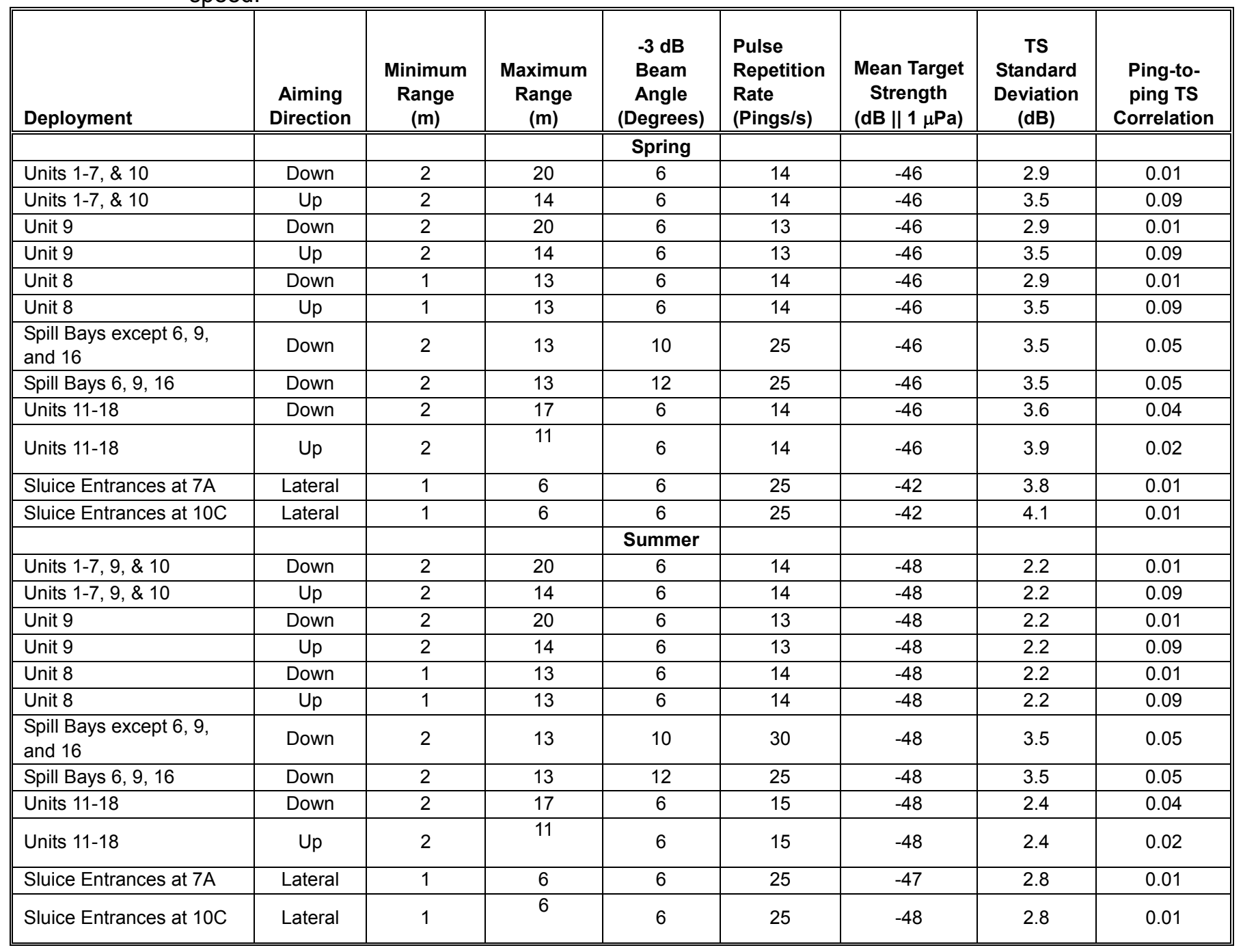


Table 2.2. Polynomial Inputs or Constants for the Detectability Model for Beam Patterns, Fish Trajectories, and Fish Speeds for Every Deployment

\begin{tabular}{|c|c|c|}
\hline Deployment & Variable & Polynomial or Constants \\
\hline \multirow{3}{*}{$\begin{array}{l}\text { Units 1-4, 6-8 \& } 10 \\
\text { Down-looking }\end{array}$} & Beam Shape & $B=-0.00333023 X^{4}+0.01747145 X^{3}-0.31014261 X^{2}+0.03575387 X-0.00484960$ \\
\hline & Trajectory & Plunge $=0.0116 X^{4}-0.5045 X^{3}+7.2823 X^{2}-40.8657 X+121.2253$ \\
\hline & Speed & $m p s=0.0006 X^{4}-0.0271 X^{3}+0.4496 X^{2}-3.0357 X+7.9141$ \\
\hline \multirow{3}{*}{$\begin{array}{l}\text { Units 1-4, 6-8 \& } 10 \\
\text { Up-looking }\end{array}$} & Beam Shape & $B=-0.00333023 X^{4}+0.01747145 X^{3}-0.31014261 X^{2}+0.03575387 X-0.00484960$ \\
\hline & Trajectory & Plunge $=-0.0137 X^{4}+0.7900 X^{3}-14.6351 X^{2}+108.4485 X-275.8850$ \\
\hline & Speed & $m p s=0.0013 X^{4}-0.0450 X^{3}+0.5789 X^{2}-3.2352 X+7.5436$ \\
\hline \multirow[t]{3}{*}{ Unit 9 Down-looking } & Beam Shape & $B=-0.00009907 X^{4}-0.02580679 X^{3}-0.22579740 X^{2}-0.09601164 X-0.01283168$ \\
\hline & Trajectory & Plunge $=0.0116 X^{4}-0.5045 X^{3}+7.2823 X^{2}-40.8657 X+121.2253$ \\
\hline & Speed & $m p s=0.0006 X^{4}-0.0271 X^{3}+0.4496 X^{2}-3.0357 X+7.9141$ \\
\hline \multirow[t]{3}{*}{ Unit 9 Up-looking } & Beam Shape & $B=-0.00009907 X^{4}-0.02580679 X^{3}-0.22579740 X^{2}-0.09601164 X-0.01283168$ \\
\hline & Trajectory & Plunge $=-0.0137 X^{4}+0.7900 X^{3}-14.6351 X^{2}+108.4485 X-275.8850$ \\
\hline & Speed & $m p s=0.0013 X^{4}-0.0450 X^{3}+0.5789 X^{2}-3.2352 X+7.5436$ \\
\hline \multirow{3}{*}{$\begin{array}{c}\text { Unit 7A Sluiceway } \\
\text { Side-looking }\end{array}$} & Beam Shape & $B=0.01187307 X^{4}-0.16588522 X^{3}+0.24937889 X^{2}-0.51959804 X+0.05524655$ \\
\hline & Trajectory & Plunge $=-0.1321 X^{4}+3.0734 X^{3}-25.9539 X^{2}+78.3327 X-66.2385$ \\
\hline & Speed & $m p s=0.0340 X^{4}-0.4307 X^{3}+1.9152 X^{2}-3.4743 X+3.2645$ \\
\hline \multirow{3}{*}{$\begin{array}{c}\text { Unit 10C Sluiceway } \\
\text { Side-looking }\end{array}$} & Beam Shape & $B=0.01187307 X^{4}-0.16588522 X^{3}+0.24937889 X^{2}-0.51959804 X+0.05524655$ \\
\hline & Trajectory & Plunge $=-3.7355 X^{4}+44.6232 X^{3}-187.4939 X^{2}+323.3796 X-200.8135$ \\
\hline & Speed & $m p s=0.0131 X^{4}-0.1143 X^{3}+0.2670 X^{2}-0.0619 X+0.3067$ \\
\hline \multirow{3}{*}{$\begin{array}{l}\text { Spill Bays } 6 \& 9 \\
\text { Down-looking }\end{array}$} & Beam Shape & $B=0.00017264 X^{4}-0.01119448 X^{3}-0.01413437 X^{2}-0.02634802 X-0.00715715$ \\
\hline & Trajectory & Plunge $=0.1249 X^{4}-3.6016 X^{3}+35.7822 X^{2}-155.6252 X+325.4253$ \\
\hline & Speed & $m p s=-0.0196 X^{4}+0.6168 X^{3}-7.0487 X^{2}+35.0144 X-62.0893$ \\
\hline \multirow{3}{*}{$\begin{array}{l}\text { Spill Bays 1-5, 7-8, 10-15, } \\
17, \& 18 \\
\text { Down-looking }\end{array}$} & Beam Shape & $B=-0.00047925 X^{4}+0.00581607 X^{3}-0.17653166 X^{2}+0.10805768 X-0.00157376$ \\
\hline & Trajectory & Plunge $=0.1249 X^{4}-3.6016 X^{3}+35.7822 X^{2}-155.6252 X+325.4253$ \\
\hline & Speed & $m p s=-0.0196 X^{4}+0.6168 X^{3}-7.0487 X^{2}+35.0144 X-62.0893$ \\
\hline \multirow[t]{3}{*}{ Spill Bay 16 Down-looking } & Beam Shape & $B=0.00010683 X^{4}-0.00335610 X^{3}-0.04951865 X^{2}-0.02031800 X-0.00655960$ \\
\hline & Trajectory & Plunge $=0.1249 X^{4}-3.6016 X^{3}+35.7822 X^{2}-155.6252 X+325.4253$ \\
\hline & Speed & $m p s=-0.0196 X^{4}+0.6168 X^{3}-7.0487 X^{2}+35.0144 X-62.0893$ \\
\hline \multirow{3}{*}{$\begin{array}{l}\text { Units } 11 \text { \& 13-18 } \\
\text { Down-looking }\end{array}$} & Beam Shape & $B=-0.00333023 X^{4}+0.01747145 X^{3}-0.31014251 X^{2}+0.03575387 X-0.00484960$ \\
\hline & Trajectory & Plunge $=0.0239 X^{4}-0.9285 X^{3}+13.1575 X^{2}-84.7626 X+257.7337$ \\
\hline & Speed & $m p s=-0.0008 X^{4}+0.0351 X^{3}-0.5450 X^{2}+3.5037 X-6.4648$ \\
\hline \multirow{3}{*}{$\begin{array}{l}\text { Units } 11 \text { \& 13-18 } \\
\text { Up-looking }\end{array}$} & Beam Shape & $B=-0.00333023 X^{4}+0.01747145 X^{3}-0.31014251 X^{2}+0.03575387 X-0.00484960$ \\
\hline & Trajectory & Plunge $=1.3132 X^{4}-38.2140 X^{3}+413.4321 X^{2}-1979.7043 X+3538.9708$ \\
\hline & Speed & $m p s=0.0083 X^{4}-0.2933 X^{3}+3.7567 X^{2}-20.6749 X+41.973$ \\
\hline \multirow[t]{3}{*}{ Unit 12 Down-looking } & Beam Shape & $B=-0.00464744 X^{4}+0.02004565 X^{3}-0.37435825 X^{2}+0.03550214 X-0.00117570$ \\
\hline & Trajectory & Plunge $=0.0239 X^{4}-0.9285 X^{3}+13.1575 X^{2}-84.7626 X+257.7337$ \\
\hline & Speed & $m p s=-0.0008 X^{4}+0.0351 X^{3}-0.5450 X^{2}+3.5037 X-6.4648$ \\
\hline \multirow[t]{3}{*}{ Unit 12 Up-looking } & Beam Shape & $B=-0.00464744 X^{4}+0.02004565 X^{3}-0.37435825 X^{2}+0.03550214 X-0.00117570$ \\
\hline & Trajectory & Plunge $=1.3132 X^{4}-38.2140 X^{3}+413.4321 X^{2}-1979.7043 X+3538.9708$ \\
\hline & Speed & $m p s=0.0083 X^{4}-0.2933 X^{3}+3.7567 X^{2}-20.6749 X+41.973$ \\
\hline
\end{tabular}

Polynomial regressions were used to describe the relationships between predictions of effective beam angle with range from a transducer for every type of deployment. Those equations and passage width (or depth) data were used to expand the count of each detected fish and to equalize detectability among sample ranges and deployments. The coding solved a deployment-specific polynomial equation for effective beam angle based upon the range of detection of each individual fish (Appendix F), calculated the corresponding beam diameter at the same range, and multiplied the fish's count (i.e., one) by the ratio of the passage width to the beam diameter. The polynomials presented in Appendix F can be used to generate the detectability curves. Minimum ranges for modeling detectability (Table 2.1) usually were 
less than minimum ranges for counting fish (see legends of Figures 2.1, 2.2, 2.3, 2.5, and 2.6) to improve curve fitting, but only the portion of the curves where fish were counted were used for deriving spatial expansion factors. Sampling ranges that were used to solve for effective beam angle truncated the polynomial curves to appropriate ranges.

The count of every fish (1) was spatially expanded based upon the ratio of the opening width to beam diameter at the range of detection:

$$
E X P_{-} N U M=\frac{O W}{\left[M I D_{-} R \times T A N\left(\frac{E B A}{2}\right) \times 2\right]}
$$

where OW is opening width (or depth) in m, MID_R is the mid-point range of a trace in m, TAN is the tangent, and EBA is effective beam angle in degrees.

\subsection{Estimating Fish Passage}

This section describes in detail the estimation of fish passage at B1, B2, and the spillway at Bonneville Dam in 2002. Estimates of passage from these methods are used to calculate subsequent measures of fish passage performance (Section 2.10 below). Within every hour, we sampled 12 to 30 minutes systematically depending upon location, and we assumed that these systematic samples would behave as if they were simple random samples. This approach will be unbiased when the passage is random and upwardly biased when there is linear trend, positive autocorrelation, or stratification effect. Negative bias would only occur in unusual situations. We also estimated more than just the temporal variation in passage within intakes by post-stratifying adjacent turbine units and estimating the variation in passage between intakes of the multi-unit strata. This approach usually would include more betweenintake variation than we would expect from sampling two or more intakes of individual units because variation among-units usually exceeds the variation among intakes within a unit.

Confidence intervals for individual intakes or spill bays were calculated as 1.96 times the square root of temporal variance estimate for the time frame of interest (day, week, or season). The following subsections describe procedures for estimating temporal variances in fish passage through individual intakes and spill bays as first steps for estimating the variance for strata of intakes or bays or for each powerhouse and the spillway.

\subsubsection{B1 Unguided Passage}

Sampling at B1 was viewed as a two-stage sampling scheme. The first stage is the sampling of intake slots within a stratum composed of neighboring turbine units that were operating simultaneously. Typically, two consecutive turbine units were grouped together to form a stratum, and it would be assumed that two of six intake slots were randomly selected for monitoring. In some instances, the closure of a turbine unit would result in some strata no longer having the within-strata replication needed for variance estimation.

The solution was to post-stratify the operational turbine units into strata according to their proximity to one another. The re-stratification at times is somewhat arbitrary, because there was no unique way to 
group the locales. Priority was given to grouping locations into the most proximal sets of locations while still retaining the ability to calculate the spatial sampling variances. The resulting variance estimates can generally be considered conservative for they often include more between-intake variance than expected under the original sampling design.

The unguided fish passage at B1(TU) will be estimated by the quantity

$$
\widehat{T U}=\sum_{i=1}^{D} \sum_{j=1}^{23} \sum_{k=1}^{K_{i j}}\left[\frac{A_{i j k}}{a_{i j k}}\left[\sum_{l=1}^{a_{i j k}} \widehat{T U}_{i j k l}\right]\right]
$$

where

$\widehat{T U}_{i j k l}=$ estimated fish passage in the $l$ th intake slot $\left(l=1, \ldots, a_{i j k}\right)$ within the $k$ th turbine stratum $\left(k=1, \ldots K_{i j}\right)$ during the $j$ th hour $(j=1, \ldots, 24)$ on the $i$ th day $(i=1, \ldots, D)$;

$a_{i j k}=$ number of intake slots actually sampled in the $k$ th turbine stratum $\left(k=1, \ldots K_{i j}\right)$ during the $j$ th hour $(j=1, \ldots, 24)$ on the $i$ th day $(i=1, \ldots, D)$;

$A_{i j k}=$ total number of intake slots within the $k$ th turbine stratum $\left(k=1, \ldots K_{i j}\right)$ during the $j$ th hour $(j=1, \ldots, 24)$ on the $i$ th day $(i=1, \ldots, D)$;

$K_{i j}=$ number of turbine strata created during the $j$ th hour $(j=1, \ldots, 24)$ on the $i$ th day $(i=1, \ldots, D)$.

Because of the varying power loads over time, the number of spatial strata (i.e., $K_{i j}$ ) formed by poststratification of adjacent turbine units sometimes varied between hours $(j=1, \ldots, 24)$ and days $(i=1, \ldots, D)$.

The estimate of $\widehat{T U}_{i j k l}$ was based on the assumption of simple random sampling within a slot-hour, in which case

$$
\widehat{T U}_{i j k l}=\frac{B_{i j k l}}{b_{i j k l}} \sum_{g=1}^{b_{i j k l}} z_{i j k l g} .
$$

Combining Equations (13) and (14), the overall estimate of unguided fish passage at B1 during $D$ days was expressed as

$$
\widehat{T U}=\sum_{i=1}^{D} \sum_{j=1}^{23} \sum_{k=1}^{K_{i j}}\left[\frac{A_{i j k}}{a_{i j k}}\left[\frac{B_{i j k l}}{b_{i j k l}} \sum_{g=1}^{b_{i j k l}} z_{i j k l g}\right]\right]
$$

where 
$z_{i j k l g}=$ expanded fish count in the $g$ th sampling unit $\left(g=1, \ldots, b_{i j k l}\right)$ in the $l$ th intake slot $\left(l=1, \ldots, a_{i j k}\right)$ within the $k$ th turbine stratum $\left(k=1, \ldots K_{i j}\right)$ during the $j$ th hour $(j=1, \ldots, 23)$ on the $i$ th day $(i=1, \ldots, D)$;

$b_{i j k l}=$ number of sampling units actually observed in the $l$ th intake slot $\left(l=1, \ldots, a_{i j k}\right)$ within the $k$ th turbine stratum $\left(k=1, \ldots K_{i j}\right)$ during the $j$ th hour $(j=1, \ldots, 23)$ on the $i$ th day $(i=1, \ldots, D)$;

$B_{i j k l}=$ total number of sampling units within the $l$ th intake slot $\left(l=1, \ldots, a_{i j k}\right)$ within the $k$ th turbine stratum $\left(k=1, \ldots K_{i j}\right)$ during the $j$ th hour $(j=1, \ldots, 23)$ on the $i$ th day $(i=1, \ldots, D)$.

Nominally, $B_{i j k l}=60 \forall i j k l$ and $b_{i j k l}=15$ or 20 , depending on location. Based on the assumption of simple random sampling

$$
\widehat{\operatorname{Var}}\left(\widehat{T U}_{i j k l}\right)=\frac{B_{i j k l}^{2}\left(1-\frac{b_{i j k l}}{B_{i j k l}}\right) s_{z_{i j k l}^{2}}}{b_{i j k l}}
$$

where

$$
s_{z_{i j k l}^{2}}=\frac{\sum_{g=1}^{b_{i j k l}}\left(z_{i j k l g}-\overline{z_{i j k l}}\right)^{2}}{\left(b_{i j k l}-1\right)}
$$

and where

$$
\overline{z_{i j k l}}=\frac{1}{b_{i j k l}} \sum_{g=1}^{b_{i j k l}} z_{i j k l g}
$$

The variance of $\widehat{T U}$ can then be extended by the formula

$$
\widehat{\operatorname{Var}}(\widehat{T U})=\sum_{i=1}^{D} \sum_{j=1}^{24} \sum_{k=1}^{K_{i j}}\left[\frac{A_{i j k}^{2}\left(1-\frac{a_{i j k}}{A_{i j k}}\right) s_{\widehat{T U}}^{2}}{a_{i j k}}+\frac{A_{i j k l} \sum_{l=1}^{a_{i j k}} \widehat{\operatorname{Var}}\left(\widehat{T U}_{i j k l}\right)}{a_{i j k}}\right]
$$

where

$$
\begin{aligned}
& s_{\widehat{T U}_{i j k}^{2}}=\frac{\sum_{l=1}^{a_{i j k}}\left(\widehat{T U}_{i j k l}-\widehat{T U}_{i j k}\right)^{2}}{\left(a_{i j k}-1\right)} \\
& \widehat{T U}_{i j k}=\frac{1}{a_{i j k}} \sum_{l=1}^{i_{i j k}} \widehat{T U}_{i j k l}
\end{aligned}
$$




\subsubsection{B1 Guided Passage}

The post-stratification used in estimating unguided passage at B1 was the same as used to estimate guided passage at Powerhouse 1. Hence, the estimator for guided fish passage at B1 was written as

$$
\widehat{T G}=\sum_{i=1}^{D} \sum_{j=1}^{23} \sum_{k=1}^{K_{i j}}\left[\frac{A_{i j k}}{a_{i j k}}\left[\frac{B_{i j k l}}{b_{i j k l}} \sum_{g=1}^{b_{i j k}} y_{i j k l g}\right]\right]
$$

where

$y_{i j k l g}=$ expanded fish passage in the $g$ th sampling unit $\left(g=1, \ldots, b_{i j k l}\right)$ in the $l$ th intake slot $\left(l=1, \ldots, a_{i j k}\right)$ within the $k$ th turbine stratum $\left(k=1, \ldots K_{i j}\right)$ during the $j$ th hour $(j=1, \ldots, 23)$ on the $i$ th day $(i=1, \ldots, D)$.

The estimated variance of $\widehat{T G}$ was then expressed as

$$
\widehat{\operatorname{Var}}(\widehat{T G})=\sum_{i=1}^{D} \sum_{j=1}^{24} \sum_{k=1}^{K_{i j}}\left[\frac{A_{i j k}^{2}\left(1-\frac{a_{i j k}}{A_{i j k}}\right) s_{\widehat{T G}}^{2}}{a_{i j k}}+\frac{A_{i j k l} \sum_{l=1}^{a_{i j k}} \widehat{\operatorname{Var}}\left(\widehat{T G}_{i j k l}\right)}{a_{i j k}}\right]
$$

where

$$
\begin{aligned}
\widehat{\operatorname{Var}}\left(\widehat{T G}_{i j k l}\right) & =\frac{B_{i j k l}^{2}\left(1-\frac{b_{i j k l}}{B_{i j k l}}\right) s_{y_{i j k l}^{2}}}{b_{i j k l}} \\
s_{y_{i j k l}^{2}}^{2} & =\frac{\sum_{g=1}^{b_{i j k l}}\left(y_{i j k l g}-\bar{y}_{i j k l}\right)^{2}}{\left(b_{i j k l}-1\right)} \\
\bar{y}_{i j k l} & =\frac{1}{b_{i j k l}} \sum_{g=1}^{b_{i j k l}} y_{i j k l g}
\end{aligned}
$$

and where

$$
\begin{aligned}
& s_{\widehat{T G}_{i j k}}^{2}=\frac{\sum_{l=1}^{a_{i j k}}\left(\widehat{T G}_{i j k l}-\widehat{T G}_{i j k}\right)^{2}}{\left(a_{i j k}-1\right)} \\
& \widehat{T G}_{i j k}=\frac{1}{a_{i j k}} \sum_{l=1}^{a_{i j k}} \widehat{T G}_{i j k l}
\end{aligned}
$$


Because the $z_{i j k l g}$ and the $y_{i j k l g}$ within a turbine intake were measured simultaneously, they were correlated as were the estimators $\widehat{T U}$ and $\widehat{T G}$. The covariances between $\widehat{T G}$ and $\widehat{T U}$ can then be estimated by the quantity

$\widehat{\operatorname{Cov}}(\widehat{T U}, \widehat{T G})=\sum_{i=1}^{D} \sum_{j=1}^{23} \sum_{k=1}^{K_{i j}}\left[\frac{A_{i j k}^{2}\left(1-\frac{a_{i j k}}{A_{i j k}}\right) \widehat{\operatorname{Cov}}\left(\widehat{T U}_{i j k}, \widehat{T G}_{i j k}\right)}{a_{i j k}}+\frac{A_{i j k l} \sum_{l=1}^{a_{i j k}} \widehat{\operatorname{Cov}}\left(\widehat{T U}_{i j k l}, \widehat{T G}_{i j k l}\right)}{a_{i j k}}\right]$

where

$$
\widehat{\operatorname{Cov}}\left(\widehat{T U}_{i j k}, \widehat{T G}_{i j k}\right)=\frac{\sum_{l=1}^{a_{i j k}}\left(\widehat{T U}_{i j k l}-\widehat{\overline{T U}}_{i j k l}\right)\left(\widehat{T G}_{i j k l}-\widehat{\overline{T G}}_{i j k l}\right)}{\left(a_{i j k}-1\right)}
$$

and where

$$
\widehat{\operatorname{Cov}}\left(\widehat{T U}_{i j k l}, \widehat{T G}_{i j k l}\right)=\frac{B_{i j k l}^{2}\left(1-\frac{b_{i j k l}}{B_{i j k l}}\right) \operatorname{Cov}\left(z_{i j k l g}, y_{i j k l g}\right)}{b_{i j k l}}
$$

and where

$$
\operatorname{Cov}\left(z_{i j k l g}, y_{i j k l g}\right)=\frac{\sum_{g=1}^{b_{i j k l}}\left(z_{i j k l g}-\bar{z}_{i j k l}\right)\left(y_{i j k l g}-\bar{y}_{i j k l}\right)}{\left(b_{i j k l}-1\right)} .
$$

\subsubsection{Spillway Passage}

During spring 2002, hydroacoustic transducers were placed in each of the operational spill bays, one transducer per spill bay. Sampling was envisioned as systematic sampling within individual spill bayhour.

The estimate of total spillway passage was estimated by the formula

$$
\hat{S}=\sum_{i=1}^{H} \sum_{j=1}^{D} \sum_{k=1}^{23} \frac{T_{i j k}}{t_{i j k}} \sum_{l=1}^{t_{i j k}} p_{i j k l}
$$

where

$p_{i j k l}=$ expanded fish passage in the lth sampling interval $\left(l=1, \ldots, t_{i j k}\right)$ during the kth hour $(k=1, \ldots, 23)$ in the $j$ th day $(j=1, \ldots, D)$ at the ith spill bay $(i=1, \ldots, 17)$; 
$T_{i j k}=$ total number of possible sampling units in the kth hour $(k=1, \ldots, 23)$ in the $\mathrm{jth}$ day $(j=1, \ldots, D)$ at the ith spill bay $(i=1, \ldots, 17)$;

$t_{i j k}=$ actual number of sampling units drawn within the kth hour $(k=1, \ldots, 23)$ in the jth day $(j=1, \ldots, D)$ at the ith spill bay $(i=1, \ldots, 17)$.

Assuming the systematic sampling within an hour can be approximated by a random sampling formula, the estimated variance of $\hat{S}$ was written as

$$
\widehat{\operatorname{Var}}(\hat{S})=\sum_{i=1}^{H} \sum_{j=1}^{D} \sum_{k=1}^{23}\left[\frac{T_{i j k}^{2}\left(1-\frac{t_{i j k}}{T_{i j k}}\right) s_{p_{i j k}^{2}}}{t_{i j k}}\right]
$$

where

$$
\begin{aligned}
s_{p_{i j k}}^{2} & =\frac{\sum_{l=1}^{t_{i j k}}\left(p_{i j k l}-\bar{p}_{i j k}\right)^{2}}{\left(t_{i j k}-1\right)} \\
\bar{p}_{i j k}= & \frac{\sum_{l=1}^{t_{i j k}} p_{i j k l}}{t_{i j k}}
\end{aligned}
$$

Nominally, $T_{i j k}=60 \forall i j k$ and $t_{i j k}=12$ or 20 depending on location.

\subsubsection{Powerhouse 2 Unguided Passage}

The same two-stage sampling scheme used to estimate fish passage at B1 was used to estimate fish passage at B2, units 11 to 18 . Nominally, two consecutive turbine units (e.g., 11 and 12, 13 and 14, ..) were combined to form a stratum with two or six intake slots selected for monitoring. In reality, a single intake slot among the three within a turbine intake was randomly selected. Very occasionally, unit shutdowns because of load demands required further post-stratification to assure within-stratum replication of turbine slots. Under these circumstances, the turbine units at B2 were grouped into three or fewer strata. To accommodate all circumstances, the estimators and variances are expressed generically.

Using the fish counts from the down-looking transducers, total unguided fish passage at B2 was estimated by the quantity

$$
\widehat{H U}=\sum_{i=1}^{D} \sum_{j=1}^{23} \sum_{k=1}^{K_{i j}}\left[\frac{C_{i j k}}{c_{i j k}}\left[\frac{D_{i j k l}}{d_{i j k l}} \sum_{g=1}^{d_{i j k l}} x_{i j k l g}\right]\right]
$$

where 
$x_{i j k l g}=$ expanded fish passage in the $g$ th sampling unit $\left(g=1, \ldots, b_{i j k l}\right)$ in the $l$ th intake slot $\left(l=1, \ldots, a_{i j k}\right)$ within the $k$ th turbine stratum $\left(k=1, \ldots K_{i j}\right)$ during the $j$ th hour $(j=1, \ldots, 23)$ on the $i$ th day $(i=1, \ldots, D)$;

$d_{i j k l}=$ number of sampling units actually observed in the $l$ th intake slot $\left(l=1, \ldots, a_{i j k}\right)$ within the $k$ th turbine stratum $\left(k=1, \ldots K_{i j}\right)$ during the $j$ th hour $(j=1, \ldots, 23)$ on the $i$ th day $(i=1, \ldots, D)$;

$D_{i j k l}=$ total number of sampling units within the $l$ th intake slot $\left(l=1, \ldots, a_{i j k}\right)$ within the $k$ th turbine stratum $\left(k=1, \ldots K_{i j}\right)$ during the $j$ th hour $(j=1, \ldots, 23)$ on the $i$ th day $(i=1, \ldots, D)$;

$c_{i j k}=$ number of intake slots actually sampled in the $k$ th turbine stratum $\left(k=1, \ldots K_{i j}\right)$ during the $j$ th hour $(j=1, \ldots, 23)$ on the $i$ th day $(i=1, \ldots, D)$;

$C_{i j k}=$ total number of intake slots within the $k$ th turbine stratum $\left(k=1, \ldots K_{i j}\right)$ during the $j$ th hour $(j=1, \ldots, 23)$ on the $i$ th day $(i=1, \ldots, D)$;

$K_{i j}=$ number of turbine strata created during the $j$ th hour $(j=1, \ldots, 23)$ on the $i$ th day $(i=1, \ldots, D)$.

Nominally, $D_{i j k l}=60 \forall i j k l$ and $d_{i j k l}=15$ or 20 depending on location.

The variance of $\widehat{H U}$ was then be estimated by the formula

$$
\widehat{\operatorname{Var}}(\widehat{H U})=\sum_{i=1}^{D} \sum_{j=1}^{23} \sum_{k=1}^{K_{i j}}\left[\frac{C_{i j k}^{2}\left(1-\frac{c_{i j k}}{C_{i j k}}\right) s_{\widehat{H U} i j k}^{2}}{c_{i j k}}+\frac{C_{i j k l} \sum_{l=1}^{c_{i j k}} \widehat{\operatorname{Var}}\left(\widehat{H U}_{i j k l}\right)}{c_{i j k}}\right]
$$

where

$$
\begin{aligned}
\widehat{\operatorname{Var}}\left(\widehat{H U}_{i j k l}\right) & =\frac{D_{i j k l}^{2}\left(1-\frac{d_{i j k l}}{D_{i j k l}}\right) s_{x_{i j k l}^{2}}}{d_{i j k l}} \\
s_{x_{i j k l}}^{2} & =\frac{\sum_{g=1}^{d_{i j k l}}\left(x_{i j k l g}-\bar{x}_{i j k l}\right)^{2}}{\left(d_{i j k l}-1\right)} \\
\bar{x}_{i j k l} & =\frac{1}{d_{i j k l}} \sum_{g=1}^{d_{i j k l}} x_{i j k l g}
\end{aligned}
$$

and where 


$$
\begin{aligned}
& s_{\widehat{H U}_{i j k}^{2}}^{2}=\frac{\sum_{l=1}^{a_{i j k}}\left(\widehat{H U}_{i j k l}-\widehat{H U}_{i j k}\right)^{2}}{\left(a_{i j k}-1\right)} \\
& \widehat{H U}_{i j k}=\frac{1}{a_{i j k}} \sum_{l=1}^{a_{i j k}} \widehat{H U}_{i j k l}
\end{aligned}
$$

\subsubsection{B2 Guided Passage}

The same two-stage sampling scheme used to estimate unguided passage (HU) at B1 was used to simultaneously sample guided passage $(\mathrm{HG})$ at B2 and the estimator for guided fish passage at B2 was written as

$$
\widehat{H G}=\sum_{i=1}^{D} \sum_{j=1}^{23} \sum_{k=1}^{K_{i j}}\left[\frac{C_{i j k}}{c_{i j k}}\left[\frac{D_{i j k l}}{d_{i j k l}} \sum_{g=1}^{d_{i j k l}} w_{i j k l g}\right]\right]
$$

where

$w_{i j k l g}=$ expanded fish passage in the $g$ th sampling unit $\left(g=1, \ldots, b_{i j k l}\right)$ in the $l$ th intake slot $\left(l=1, \ldots, a_{i j k}\right)$ within the $k$ th turbine stratum $\left(k=1, \ldots K_{i j}\right)$ during the $j$ th hour $(j=1, \ldots, 23)$ on the $i$ th day $(i=1, \ldots, D)$.

The estimated variance of $\widehat{H G}$ was then expressed as

$$
\widehat{\operatorname{Var}}(\widehat{H G})=\sum_{i=1}^{D} \sum_{j=1}^{23} \sum_{k=1}^{K_{i j}}\left[\frac{C_{i j k}^{2}\left(1-\frac{c_{i j k}}{C_{i j k}}\right) s_{\widehat{H G}}^{2}}{c_{i j k}}+\frac{C_{i j k l} \sum_{l=1}^{c_{i j k}} \widehat{\operatorname{Var}}\left(\widehat{H G}_{i j k l}\right)}{c_{i j k}}\right]
$$

where

$$
\begin{aligned}
\widehat{\operatorname{Var}}\left(\widehat{H G}_{i j k l}\right) & =\frac{D_{i j k l}^{2}\left(1-\frac{d_{i j k l}}{D_{i j k l}}\right) s_{w_{i j k l}^{2}}^{2}}{d_{i j k l}} \\
s_{w_{i j k l}}^{2} & =\frac{\sum_{g=1}^{d_{i j k l}}\left(w_{i j k l g}-\bar{w}_{i j k l}\right)^{2}}{\left(d_{i j k l}-1\right)} \\
\bar{w}_{i j k l} & =\frac{1}{d_{i j k l}} \sum_{g=1}^{d_{i j k l}} w_{i j k l g}
\end{aligned}
$$


and where

$$
\begin{aligned}
& s_{\widehat{H G}_{i j k}}^{2}=\frac{\sum_{l=1}^{c_{i j k}}\left(\widehat{H G}_{i j k l}-\widehat{H G}_{i j k}\right)^{2}}{\left(c_{i j k}-1\right)} \\
& \widehat{H G}_{i j k}=\frac{1}{c_{i j k}} \sum_{l=1}^{c_{i j k}} \widehat{H G}_{i j k l}
\end{aligned}
$$

The response variables $x_{i j k l g}$ and $w_{i j k l g}$ were measured simultaneously in the same water volume by the fast multiplex transducers and, as such, were correlated. Hence, the estimates of fish passage $\widehat{H U}$ and $\widehat{H G}$ for $\mathrm{B} 2$ were correlated. Their covariance was estimated by the quantity

$$
\widehat{\operatorname{Cov}}(\widehat{H U}, \widehat{H G})=\sum_{i=1}^{D} \sum_{j=1}^{23} \sum_{k=1}^{K_{i j}}\left[\frac{C_{i j k}^{2}\left(1-\frac{c_{i j k}}{C_{i j k}}\right) \widehat{\operatorname{Cov}}\left(\widehat{H U}_{i j k}, \widehat{H G}_{i j k}\right)}{c_{i j k}}+\frac{C_{i j k l} \sum_{l=1}^{c_{i j k}} \widehat{\operatorname{Cov}}\left(\widehat{H U}_{i j k l}, \widehat{H G}_{i j k l}\right)}{c_{i j k}}\right]
$$

where

$$
\widehat{\operatorname{Cov}}\left(\widehat{H U}_{i j k}, \widehat{H G}_{i j k}\right)=\frac{\sum_{l=1}^{c_{i j k}}\left(\widehat{H U}_{i j k l}-\widehat{H U}_{i j k}\right)\left(\widehat{H G}_{i j k l}-\widehat{H G}_{i j k}\right)}{\left(c_{i j k}-1\right)}
$$

and where

$$
\begin{gathered}
\widehat{\operatorname{Cov}}\left(\widehat{H U}_{i j k l}, \widehat{H G}_{i j k l}\right)=\frac{D_{i j k l}^{2}\left(1-\frac{d_{i j k l}}{D_{i j k l}}\right) \widehat{\operatorname{Cov}}\left(x_{i j k l g}, w_{i j k l g}\right)}{d_{i j k l}} \\
\widehat{\operatorname{Cov}}\left(x_{i j k l g}, w_{i j k l g}\right)=\frac{\sum_{g=1}^{d_{i j k l}}\left(x_{i j k l g}-\bar{x}_{i j k l}\right)\left(w_{i j k l g}-\bar{w}_{i j k l}\right)}{\left(d_{i j k l}-1\right)}
\end{gathered}
$$

It should be noted that formulas (15) and (18) for B1 are analogous to formulas (23) and (25) for B2. The estimators $\widehat{T U}$ and $\widehat{T G}$ are analogous to the estimators $\widehat{H U}$ and $\widehat{H G}$, respectively.

\subsubsection{Sluiceway Passage}

For the sluiceways above turbine intakes $7 \mathrm{~B}$ and $10 \mathrm{C}$ at B1, the estimation of smolt passage is based on stratified sampling. Each half of one of the sluiceways was considered a spatial stratum, in which case, total sluiceway passage was estimated by the quantity 


$$
\widehat{S L}=\sum_{g=1}^{2} \sum_{h=1}^{2} \sum_{i=1}^{D} \sum_{j=1}^{23} \frac{E}{e} \sum_{k=1}^{l} v_{g h i j k}
$$

where

$v_{\text {ghijk }}=$ expanded fish counts in the $k$ th sample interval $(k=1, \ldots, e)$ in the $j$ th hour $(j=1, \ldots, 23)$ of the $i$ th day $(i=1, \ldots, D)$ at the $h$ th half-section $(h=1,2)$ of the gth sluiceway $(g=1,2)$;

$E=$ total number of possible sampling intervals within an hour;

$e=$ actual number of sampling intervals drawn within an hour.

Nominally, $E=60$ and $e=15$ for all hours at all sluiceway locations.

The variance of $\widehat{S L}$, based on simple random sampling within an hour, was then

$$
\widehat{\operatorname{Var}}(\widehat{S L})=\sum_{g=1}^{2} \sum_{h=1}^{2} \sum_{i=1}^{D} \sum_{j=1}^{23}\left[\frac{E^{2}\left(1-\frac{e}{E}\right) s_{v_{g h i j}}^{2}}{e}\right]
$$

where

$$
\begin{aligned}
s_{v_{g h i j}}^{2} & =\frac{\sum_{k=1}^{e}\left(v_{g h i j k}-\bar{v}_{g h i j}\right)^{2}}{(e-1)} \\
\bar{v}_{g h i j} & =\frac{\sum_{k=1}^{e} v_{g h i j k}}{e}
\end{aligned}
$$

\subsection{Estimating Passage Performance}

Estimates of fish passage through the powerhouses and the spillway were used to estimate measures of project-wide passage performance. This section presents the estimators and associated variance estimators.

\subsubsection{Spill Efficiency (SPE)}

The spill efficiency at the Bonneville project was estimated by the quotient

$$
\widehat{S P E}=\frac{\hat{S}}{[\widehat{T U}+\widehat{T G}+\widehat{H U}+\widehat{H G}+\widehat{S L}+\hat{S}]}=\frac{\hat{S}}{\widehat{N S}+\hat{S}}
$$

where the numerator is the estimated spill bay passage and the denominator was total project passage. The variance of $\widehat{S P E}$ was estimated by 


$$
\widehat{\operatorname{Var}}(\widehat{S P E})=\widehat{S P E}^{2}(1-\widehat{S P E})^{2}\left[\frac{\widehat{\operatorname{Var}}(\hat{S})}{\hat{S}^{2}}+\frac{\widehat{\operatorname{Var}}(\widehat{N S})}{\widehat{N S}^{2}}\right]
$$

where

$$
\widehat{N S}=\widehat{T U}+\widehat{T G}+\widehat{H U}+\widehat{H G}+\widehat{S L}
$$

and where

$$
\begin{aligned}
\widehat{\operatorname{Var}}(\widehat{N S})= & \widehat{\operatorname{Var}}(\widehat{T U})+\widehat{\operatorname{Var}}(\widehat{T G})+\widehat{\operatorname{Var}}(\widehat{H U})+\widehat{\operatorname{Var}}(\widehat{H G})+\widehat{\operatorname{Var}}(\widehat{S L})+2 \widehat{\operatorname{Cov}}(\widehat{T U}, \widehat{T G}) \\
& +2 \widehat{\operatorname{Cov}}(\widehat{H U}, \widehat{H G})
\end{aligned}
$$

\subsubsection{Spill Effectiveness (SPN)}

The spill effectiveness at the Bonneville project was estimated by the quantity

$$
\widehat{S P N}=\frac{\left(\frac{\hat{S}}{V_{S}}\right)}{\frac{(\widehat{N S}+\hat{S})}{V_{T}}}=\widehat{S P E} \cdot \frac{V_{T}}{V_{S}}
$$

where

$$
V_{S}=\text { volume of water spilled, }
$$

$V_{T}=$ total volume of water passing the dam during the period of inference.

The variance of $\widehat{S P N}$ can be estimated by

$$
\widehat{\operatorname{Var}}(\widehat{S P N})=\left(\frac{V_{T}}{V_{S}}\right)^{2} \cdot \widehat{\operatorname{Var}}(\widehat{S P E})
$$

\subsubsection{Project-Wide Fish Passage Efficiency}

The project-wide FPE was estimated by the quotient

$$
\widehat{F P E}=\frac{[\widehat{S}+\widehat{T G}+\widehat{H G}+\widehat{S L}]}{[\widehat{T U}+\widehat{T G}+\widehat{H U}+\widehat{H G}+\widehat{S L}+\hat{S}]}
$$

where the numerator was the estimated spillway and bypass guided passage, and the denominator was total project passage and alternatively expressed as 


$$
\widehat{F P E}=\frac{\hat{G}}{\hat{G}+\hat{U}}
$$

where

$$
\begin{aligned}
& \widehat{G}=\hat{S}+\widehat{T G}+\widehat{H G}+\widehat{S L} \\
& \widehat{U}=\widehat{T U}+\widehat{H U}
\end{aligned}
$$

The variance of $\widehat{F P E}$ was then be estimated by

$$
\widehat{\operatorname{Var}}(\widehat{F P E})=\widehat{F P E}^{2}(1-\widehat{F P E})^{2}\left[\frac{\widehat{\operatorname{Var}}(\hat{G})}{\hat{G}^{2}}+\frac{\widehat{\operatorname{Var}}(\hat{U})}{\hat{U}^{2}}-\frac{2 \operatorname{Cov}(\hat{G}, \hat{U})}{\hat{G} \cdot \hat{U}}\right]
$$

and where

$$
\begin{aligned}
\widehat{\operatorname{Var}}(\hat{G}) & =\widehat{\operatorname{Var}}(\hat{S})+\widehat{\operatorname{Var}}(\widehat{\operatorname{TG}})+\widehat{\operatorname{Var}}(\widehat{H G})+\widehat{\operatorname{Var}}(\widehat{\operatorname{SL}}), \\
\widehat{\operatorname{Var}}(\hat{U}) & =\widehat{\operatorname{Var}}(\widehat{T U})+\widehat{\operatorname{Var}}(\widehat{H U}), \\
\widehat{\operatorname{Cov}}(\hat{G}, \hat{U}) & =\widehat{\operatorname{Cov}}(\widehat{T U}, \widehat{T G})+\widehat{\operatorname{Cov}}(\widehat{H U}, \widehat{H G}) .
\end{aligned}
$$

\subsubsection{B1 Fish Passage Efficiency (FPE)}

For B1, FPE was estimated by the quantity

$$
\widehat{F P E}_{1}=\frac{\widehat{T G}+\widehat{S L}}{\widehat{T G}+\widehat{T U}+\widehat{S L}}
$$

with the associated variance estimator

$$
\widehat{\operatorname{Var}}\left(\widehat{F P E}_{1}\right)=\widehat{F P E}_{1}^{2}\left(1-\widehat{F P E}_{1}\right)^{2}\left[\frac{\widehat{\operatorname{Var}}(\widehat{T G})+\widehat{V a r}(\widehat{T U})}{(T G+S L)^{2}}+\frac{\widehat{\operatorname{Var}}(\widehat{T U})}{\widehat{T U}^{2}}-\frac{2 \operatorname{Cov}(\widehat{T G}, \widehat{T U})}{\widehat{T U}(\widehat{T G}+\widehat{S L})}\right] \text {. }
$$

\subsubsection{B2 Fish Passage Efficiency (FPE)}

For B2, FPE was estimated by the quantity

$$
\widehat{F P E}_{2}=\frac{\widehat{H G}}{\widehat{H G}+\widehat{H U}}
$$

with associated variance estimator 


$$
\widehat{\operatorname{Var}}\left(\widehat{F P E}_{2}\right)=\widehat{F P E}_{2}^{2}\left(1-\widehat{F P E}_{2}\right)^{2}\left[\frac{\widehat{\operatorname{Var}}(\widehat{H G})}{\widehat{H G}^{2}}+\frac{\widehat{\operatorname{Var}}(\widehat{H U})}{\widehat{H U}^{2}}-\frac{2 \operatorname{Cov}(\widehat{H U}, \widehat{H G})}{\widehat{H U} \cdot \widehat{H G}}\right]
$$

\subsubsection{B1 Sluiceway Efficiency (SLE 1 )}

Passage efficiency of the sluiceway at B1 was estimated by the quantity

$$
\widehat{S L E}_{1}=\frac{\widehat{S L}}{\widehat{T G}+\widehat{T U}+\widehat{S L}}
$$

with the associated variance estimator

$$
\widehat{S L E}_{1}=\widehat{S L E}_{1}^{2}\left(1-\widehat{S L E}_{1}\right)^{2}\left[\frac{\widehat{\operatorname{Var}}(\widehat{S L})}{\widehat{S L}^{2}}+\frac{\widehat{\operatorname{Var}}(\widehat{T G})+\widehat{\operatorname{Var}}(\widehat{T U})+2 \operatorname{Cov}(\widehat{T G, T U})}{(\widehat{T U}+\widehat{T G})^{2}}\right]
$$

\subsubsection{B1 Sluiceway Effectiveness $\left(\mathrm{SLN}_{1}\right)$}

For Powerhouse 1, the sluiceway effectiveness was estimated by the quantity

$$
\begin{aligned}
\widehat{S L N}_{1} & =\frac{\left(\frac{\widehat{S L}}{V_{6}}\right)}{\left(\frac{\widehat{T G}+\widehat{T U}+\widehat{S L}}{V_{3}}\right)} \\
& =\widehat{S L E}_{1}\left(\frac{V_{3}}{V_{6}}\right)
\end{aligned}
$$

with associated variance estimator

$$
\widehat{\operatorname{Var}}\left(\widehat{S L N}_{1}\right)=\left(\frac{V_{3}}{V_{6}}\right) \cdot \widehat{\operatorname{Var}}\left(\widehat{S L E}_{1}\right)
$$

where

$V_{6}=$ volume of water passing through the sluiceways of B1,

$V_{3}=$ total volume of water passing through B1.

\subsubsection{Project-Wide Sluiceway Efficiency (SLE)}

Across the entire project, sluiceway efficiency was estimated by the quantity 


$$
\widehat{S L E}=\frac{\widehat{S L}}{\widehat{T U}+\widehat{T G}+\widehat{H U}+\widehat{H G}+\widehat{S}+\widehat{S L}}
$$

where the numerator was the estimated sluiceway passage and the denominator was the total project passage. The variance of $\widehat{S L E}$ was estimated by the quantity

$$
\widehat{\operatorname{Var}}(\widehat{S L E})=\widehat{S L E}^{2}(1-\widehat{S L E})^{2}\left[\frac{\widehat{\operatorname{Var}}(\widehat{S L})}{\widehat{S L}^{2}}+\frac{\widehat{\operatorname{Var}}(\widehat{N S L})}{\widehat{N S L}^{2}}\right]
$$

where

$$
\widehat{N S L}=\widehat{T U}+\widehat{T G}+\widehat{H U}+\widehat{H G}+\widehat{S}
$$

and where

$$
\begin{aligned}
\widehat{\operatorname{Var}}(\widehat{N S L})= & \widehat{\operatorname{Var}}(\widehat{T U})+\widehat{\operatorname{Var}}(\widehat{T G})+\widehat{\operatorname{Var}}(\widehat{H U})+\widehat{\operatorname{Var}}(\widehat{H G})+\widehat{\operatorname{Var}}(\hat{S})+2 \operatorname{Cov}(\widehat{T U}, \widehat{T G}) \\
& +2 \operatorname{Cov}(\widehat{H U}, \widehat{H G}) .
\end{aligned}
$$

\subsubsection{Project-Wide Sluiceway Effectiveness (SLN)}

Project-wide sluiceway effectiveness was estimated by the quantity

$$
\begin{aligned}
\widehat{S L N} & =\frac{\left(\frac{\widehat{S L}}{V_{6}}\right)}{\left(\frac{\widehat{T U}+\widehat{T G}+\widehat{H U}+\widehat{H G}+\widehat{S}+\widehat{S L}}{V_{T}}\right)} \\
& =\widehat{S L E}\left(\frac{V_{T}}{V_{6}}\right)
\end{aligned}
$$

with associated variance estimator

$$
\widehat{\operatorname{Var}}(\widehat{S L N})=\left(\frac{V_{T}}{V_{6}}\right)^{2} \cdot \widehat{\operatorname{Var}}(\widehat{S L E})
$$

where

$V_{T}=$ total volume of water passing through the project,

$V_{6}=$ volume of water passing through the sluiceways at Powerhouse 1. 


\subsection{Comparing Spill-Treatment and Location Effects}

We used weighted analysis of variance (ANOVA) on daily estimates of major fish-passage metrics to evaluate the effects of three spill treatments, which were part of a randomized block design by the Portland District. The weighting factor was daily fish passage at the entire Project for Project FPE, spill efficiency, spill effectiveness, sluiceway efficiency, and sluiceway effectiveness).

The three spill treatments in 2002 were as follows:

1. Day $<80,000 \mathrm{cfs}$-- from 0500 until 1900 hours in spring and from 0400 until 2200 hours in summer.

2. Day $>85,000 \mathrm{cfs}$-- from 0500 until 1900 hours in spring and from 0400 until 2200 hours in summer.

3. Night $>85,000 \mathrm{cfs}--$ from 1900 until 0500 hours in spring and from 2200 until 0400 hours in summer.

The randomized block design consisted of four-day blocks in which two consecutive daytime periods had either high or low spill and the other two consecutive daytime periods had the opposite treatment. The night treatment always consisted of high spill (to the gas cap) throughout each 4-day block. Operators were able to provide the treatments as prescribed during 9 of 10 blocks in spring but only during 4 of 10 blocks in summer. Consequently, we set up a two-way ANOVA using Proc GLM in SAS to examine effects of blocks, treatments, and the interaction between blocks and treatments in spring based upon Type III sums of squares, but resorted to evaluating actual daily spill conditions in summer by using Proc Mixed (SAS) with repeating Julian-day span (e.g., 185-186) to account for autocorrelation within spill conditions. The latter approach provided much more power than using the four good blocks that occurred in summer. We tested for differences among all pairs of least-square means using the LSMEAN statement with Tukey-Kramer adjustment for the unbalanced design in summer and with a LSMEAN statement and no adjustment for the balance design in spring.

We also used weighted ANOVA on daily estimates of FGE to evaluate effects of turbine unit location, B2 intake location (slot $\mathrm{A}, \mathrm{B}$, or $\mathrm{C}$ ), and the presence or absence of turbine intake extensions (TIES) at B2. Testing was limited to a one-way ANOVA with turbine units as conditions at B1 because unit operations were too sporadic to examine among intake effects. Daily passage-weighted FGE estimates were used as replicates in ANOVAs which had either unit, slot, or TIE versus no TIE as factors. We used Proc Mixed (SAS) to do the analysis of variance and included repeating Julian day in an AR(1) design to account for autocorrelation within location conditions. We tested for differences among all pairs of least-square means using the LSMEAN statement with Tukey-Kramer adjustment for the unbalance design each season. Unbalanced conditions resulted from varying dam operations. 
Hydroacoustic Evaluation of Fish Passage through Bonneville Dam in 2002 


\subsection{Results}

\subsection{Hydroacoustic Detectability}

Figure 3.1 shows detectability curves for every type of deployment. Unit 9 curves are representative of curves for deployments at Units 1-4, 6-7, and 9-10. Unit 12 curves are representative of curves for B2 deployments. Curves for spill bays 7 and 9 are representative of curves for $10^{\circ}$ single beams and $12^{\circ}$ split beams at the spillway, respectively. In spring, most effective beam angles over the range that fish were tracked were within one degree of or above the nominal $(-3 \mathrm{~dB})$ beam angles (see Appendix $\mathrm{B}$ for nominal angles) for each transducer at minimum sampling ranges. The only exception was the transducer sampling guided fish at Unit 8 . In summer, curves for effective beam angle by range had similar shapes to those modeled for spring, although angles at all ranges were narrower in summer than they were in spring because mean target strength estimates were slightly lower in summer. Smaller effective beam angles translate into bigger spatial expansion factors.
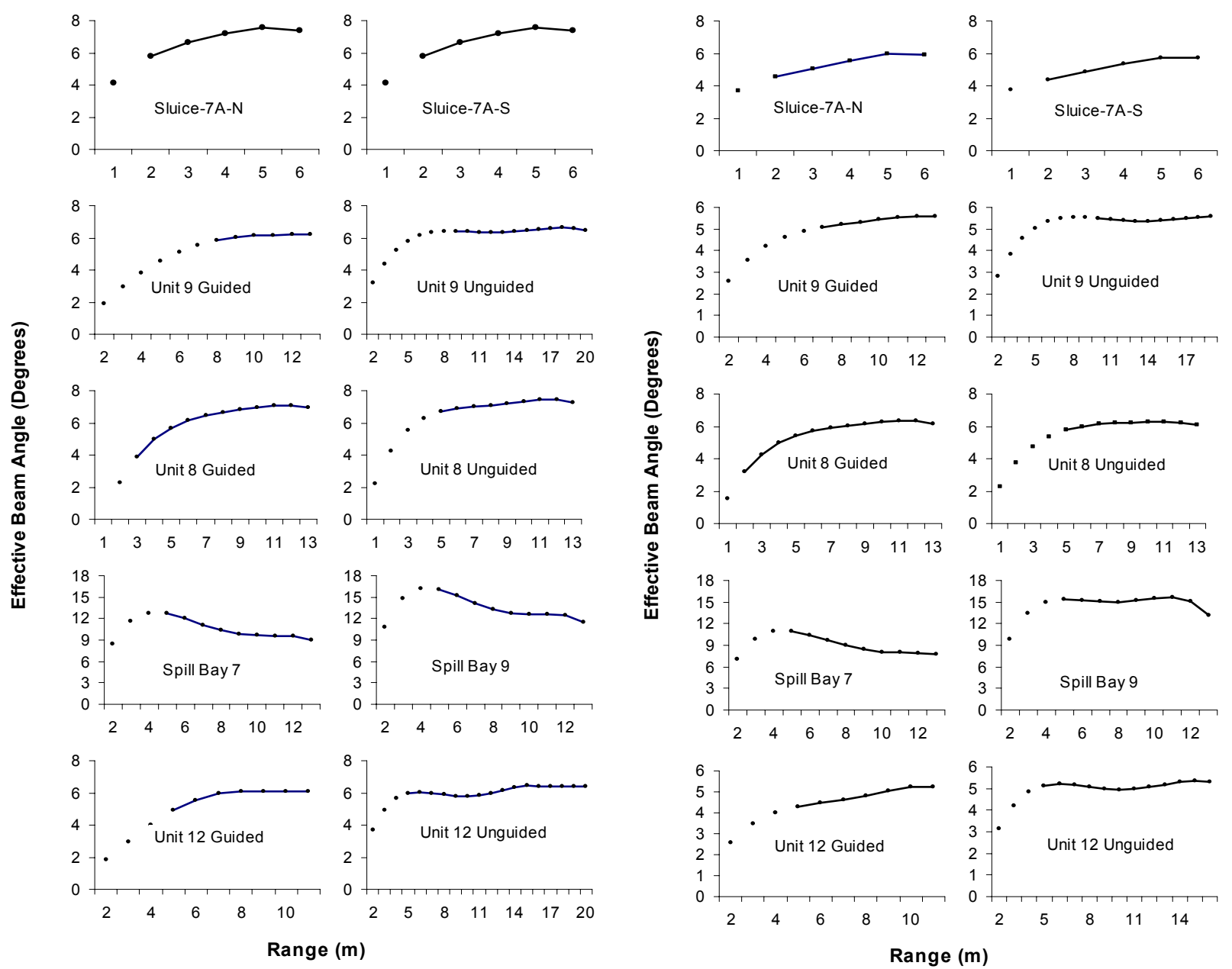

Figure 3.1. Effective Beam Angle as a Function of Range from Transducers Deployed in Spring (left) and Summer (right) 2002. Points joined by a solid line represent the effective beam angle over the range that fish were tracked. Note $-\mathrm{x}$ and $\mathrm{y}$ scales vary among plots. 


\subsection{Validation of Autotracking}

We found good correspondence between average technician counts of fish and autotracker counts for every deployment at Powerhouse 1 (Figures 3.2), the Spillway (Figure 3.3), and Powerhouse 2

(Figure 3.4), but there were deployment-specific differences in slopes and fits of regression lines.
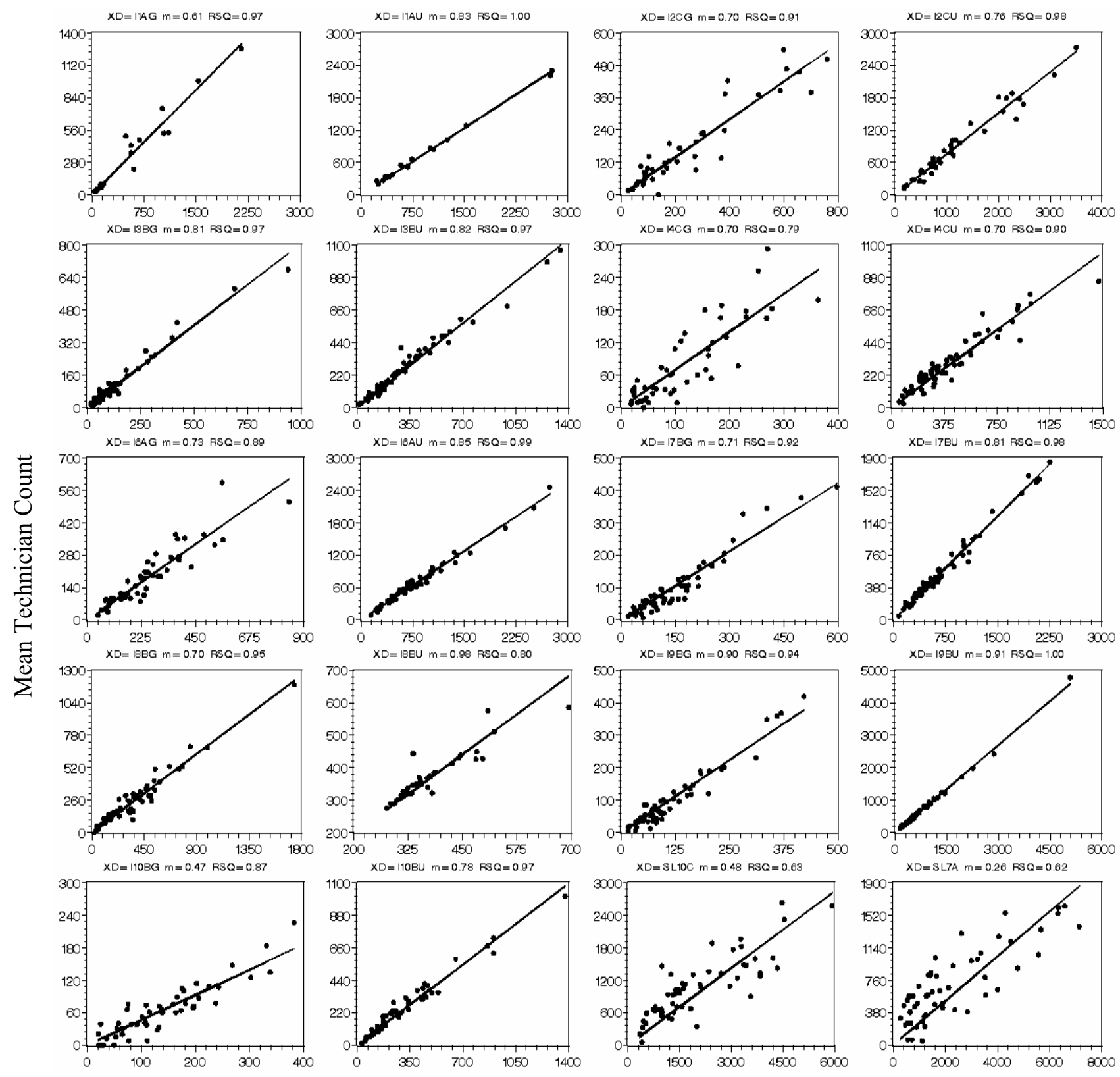

Autotracker Count

Figure 3.2. Regressions of Mean Human-Tracker Estimates of Hourly Fish Passage and Autotracker Estimates by Intake (XD beginning with I) or Sluiceway Entrance (XD beginning with $S L$ ). The number in the XD name refers to the turbine unit, the letter after the number to the intake slot, and the last letter (a "G" or "U") to guided or unguided. " $m$ " = the slope of the regression line forced through zero; "RSQ" = the coefficient of determination. 

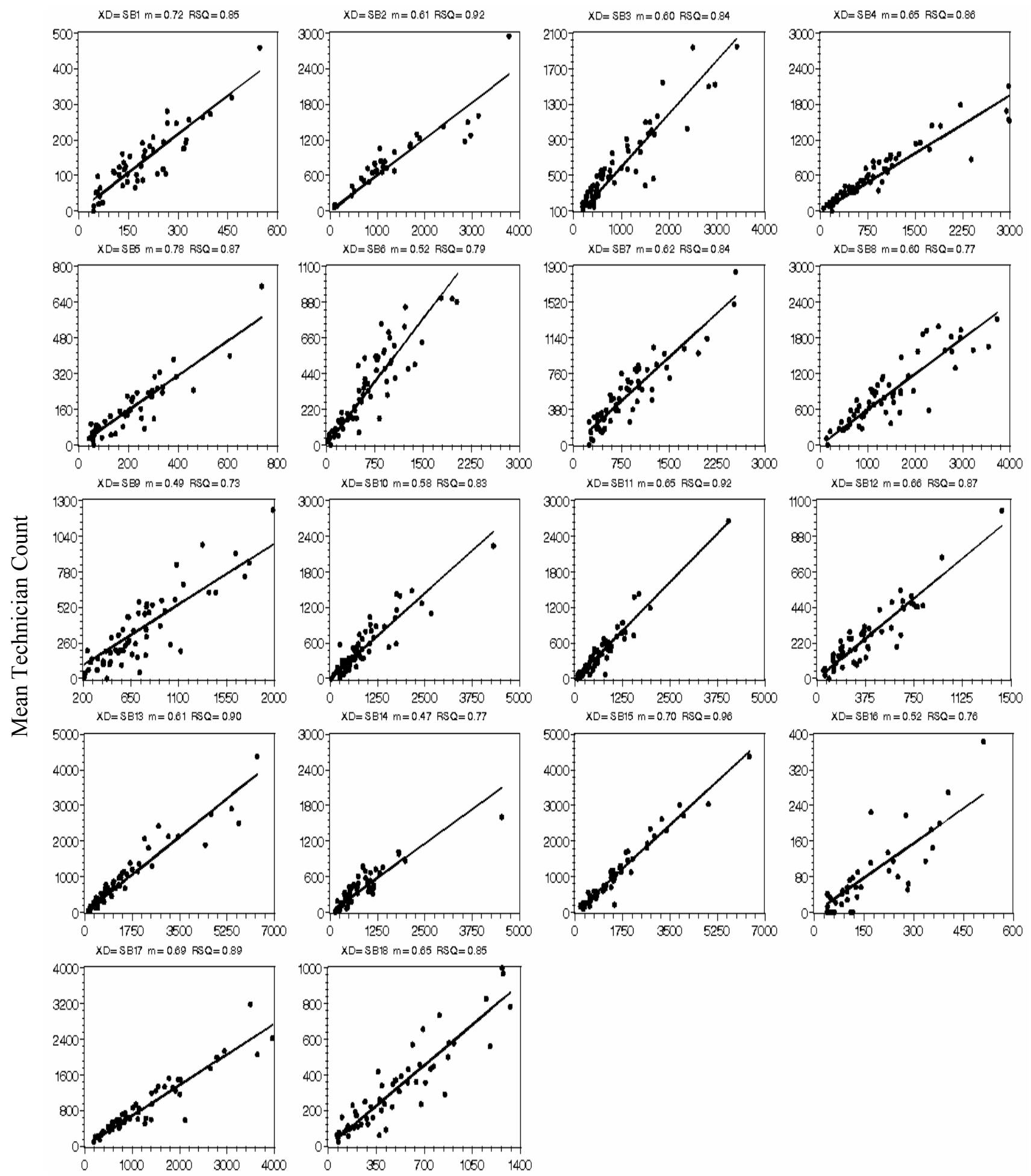

Autotracker Count

Figure 3.3. Regressions of Mean Human-Tracker Estimates of Hourly Fish Passage and Autotracker Estimates by Spill Bay (XD beginning with $S B$ ). The number in the XD name refers to the spill bay number. Abbreviations " $m$ " and "RSQ" refer to the slope of the regression line forced through zero and the coefficient of determination, respectively. 

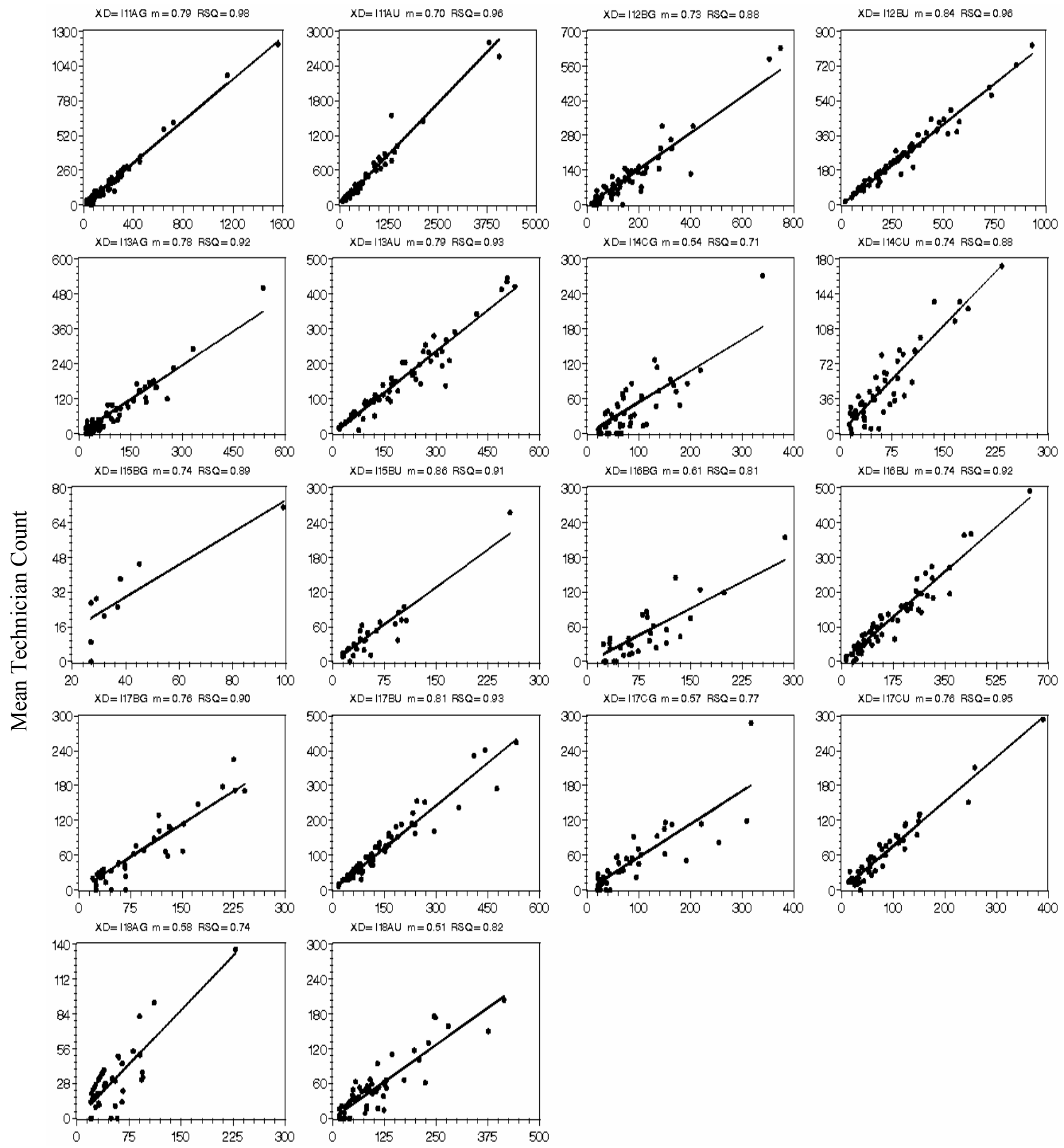

\section{Autotracker Count}

Figure 3.4. Regressions of Mean Human-Tracker Estimates of Hourly Fish Passage and Autotracker Estimates by Intake (XD beginning with I). The number in the XD name refers to the turbine unit, the letter after the number to the intake slot, and the last letter (a " $G$ " or " $U$ ") to guided or unguided. Abbreviations " $m$ " and "RSQ" refer to the slope of the regression line forced through zero and the coefficient of determination, respectively. 


\subsection{Direction of Travel Adjustments}

We examined the direction of travel of smolts through split beams sampling each type of passage route to evaluate a basic assumption of the acoustic screen model, i.e., that most detected fish are actually passing through the route being sampled. Where fish were entrained in turbine intakes, the percent of detected fish moving downstream consistently ranged from $96 \%$ to $100 \%$, but the downstream percentage ranged from 50\% to 59\% for Sluiceway Entrance 10C (Figure 3.5), 71\% to 89\% for Sluiceway Entrance 7A (Figure 3.6) and from $88 \%$ to $90 \%$ for spill bays, (Figure 3.7). In analyzing data, we reduced the count of fish detected by single beams and split beams by the fraction moving downstream $(>90$ and $<$ 270 degrees) through split-beams so that passage estimates were based only on the fraction that met the assumption of the model.
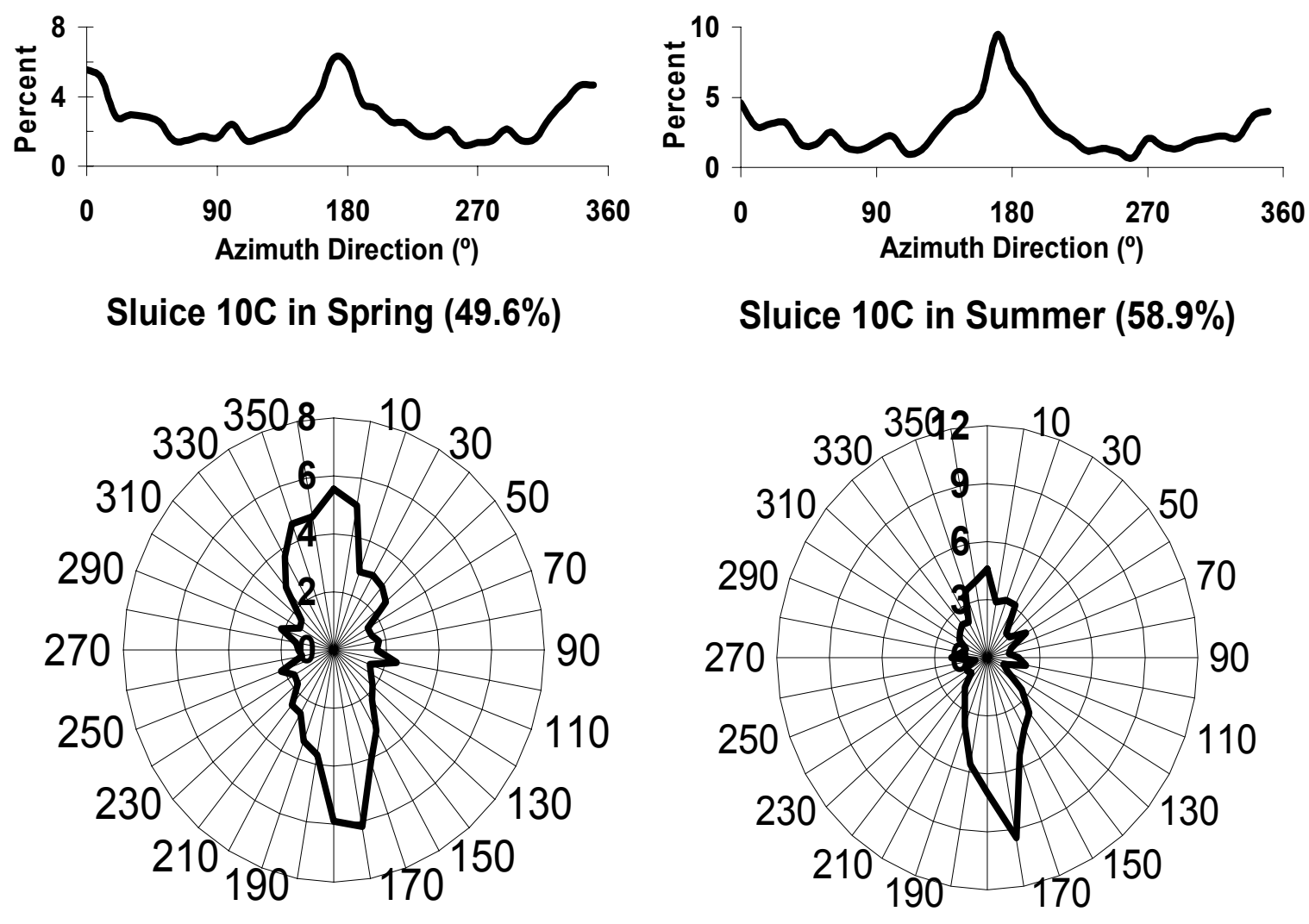

Figure 3.5. Linear and Polar Plots of the Percentage of Fish Traveling Different Directions Across the Barrel View of Split-beam Transducers Deployed at Sluice Entrance 10C in Spring (left) and Summer (right). Angles $>90^{\circ}$ and $<270^{\circ}$ indicate movement in a downstream direction across the upstream / downstream plane, and directly upstream $\left(0^{\circ}\right.$ or $\left.360^{\circ}\right)$ and downstream $\left(180^{\circ}\right)$ would be perpendicular to that plane. Titles of polar plots also indicate the cumulative percentage of fish moving downstream each season. 


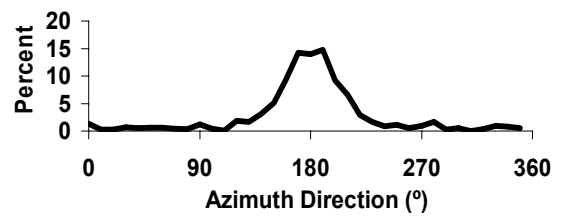

Sluice $7 \mathrm{~A}$ in Spring (88.4\%)

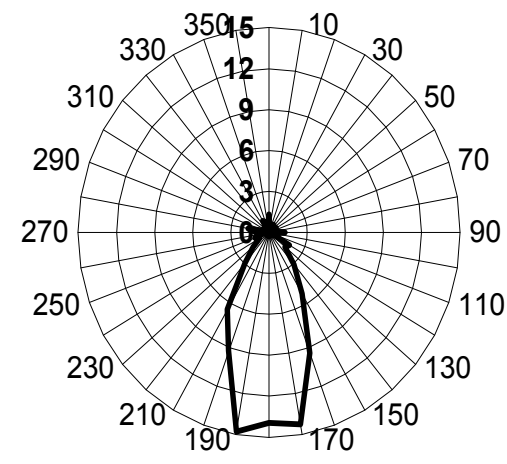

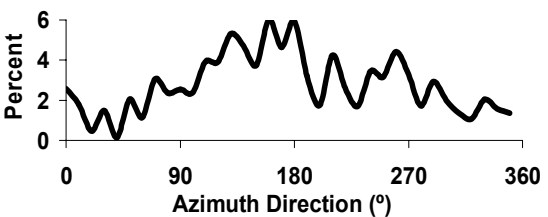

Sluice $7 \mathrm{~A}$ in Summer $\mathbf{( 7 1 . 0 \% )}$

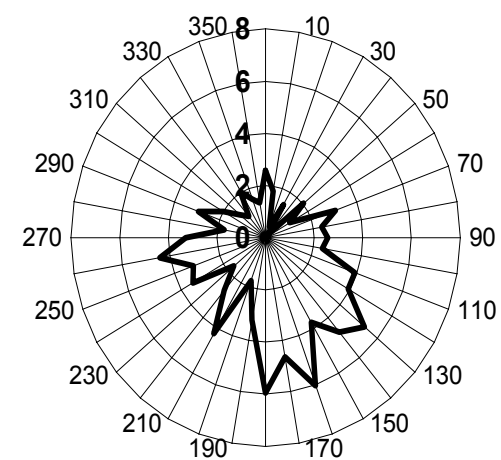

Figure 3.6. Linear and Polar Plots of the Percentage of Fish Traveling Different Directions Across the Barrel View of Split-Beam Transducers Deployed at Sluice Entrance 7A in Spring (left) and Summer (right). Angles $>90^{\circ}$ and $<270^{\circ}$ indicate movement in a downstream direction across the upstream / downstream plane, and directly upstream $\left(0^{\circ}\right.$ or $\left.360^{\circ}\right)$ and downstream $\left(180^{\circ}\right)$ would be perpendicular to that plane. Titles of polar plots also indicate the cumulative percentage of fish moving downstream each season.

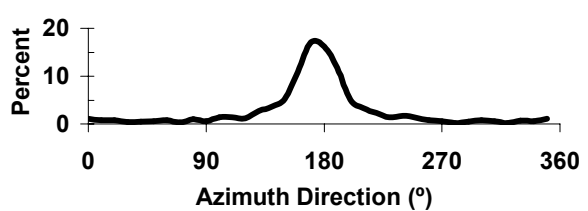

Spillway in Spring (88.1\%)

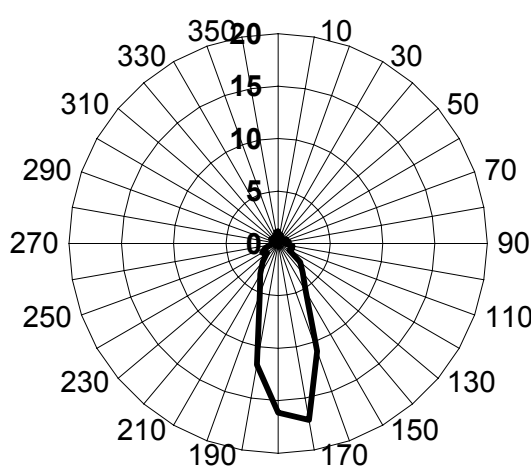

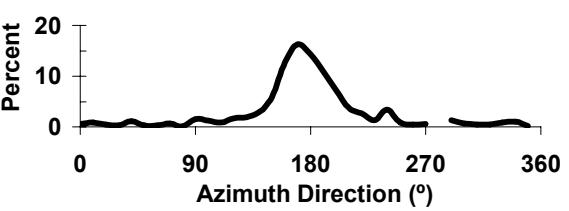

Spillway in Summer (90.4\%)

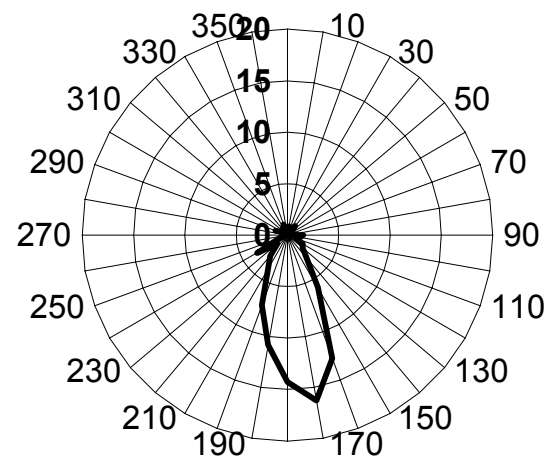

Figure 3.7. Linear and Polar Plots of the Percentage of Fish Traveling Different Directions Across the Barrel View of Split-Beam Transducers Deployed at Spill Bays in Spring (left) and Summer (right). Angles $>90^{\circ}$ and $<270^{\circ}$ indicate movement in a downstream direction across the upstream / downstream plane, and directly upstream $\left(0^{\circ}\right.$ or $\left.360^{\circ}\right)$ and downstream $\left(180^{\circ}\right)$ would be perpendicular to that plane. Titles of polar plots also indicate the cumulative percentage of fish moving downstream each season. 


\subsection{Major Passage Metrics}

Estimates of major passage metrics for 2002 are presented in Table 3.1. All confidence intervals for seasonal estimates were within $1 \%$ to $2 \%$ of the listed values. A more detailed presentation of results, including metrics calculated for portions of the Project follow below.

Table 3.1. Estimates of Major Passage Metrics based upon Hydroacoustic Sampling from 4/20 through $6 / 2$ (spring) and from 6/3 through 7/15 (summer). The efficiency and effectiveness estimates for the B1 sluiceway are calculated relative to both the entire Project and to B1.

\begin{tabular}{|lcc|}
\hline \multicolumn{1}{|c|}{ Major Passage Metric } & Spring & Summer \\
\hline \hline Project FPE & $79 \pm 0.1 \%$ & $74 \pm 0.2 \%$ \\
B1 FPE & $58 \pm 0.4 \%$ & $61 \pm 0.3 \%$ \\
B2 FPE & $53 \pm 0.3 \%$ & $46 \pm 0.7 \%$ \\
Spill Efficiency & $52 \pm 0.5 \%$ & $42 \pm 0.5 \%$ \\
Spill Effectiveness & $1.08 \pm 0.01$ & $0.96 \pm 0.01$ \\
Sluiceway Efficiency Project & $6.0 \pm 0.1 \%$ & $11 \pm 0.1 \%$ \\
Sluiceway Effectiveness ${ }_{\text {Project }}$ & $21.9 \pm 0.01$ & $47.9 \pm 0.03$ \\
Sluiceway Efficiency B1 $_{\text {Sluiceway Effectiveness }}{ }_{\text {B1 }}$ & $33 \pm 0.9 \%$ & $29 \pm 0.7 \%$ \\
\hline \hline
\end{tabular}

\subsubsection{Project and Powerhouse FPE}

Project-wide FPE estimates are presented in Figure 3.8, as are FPE estimates calculated for various portions of the project. Project-wide FPE was $79 \%$ in spring and $74 \%$ in summer. The B1 estimate, including sluiceway passage, was $58 \%$ in spring and $61 \%$ in summer. When sluiceway passage was ignored, the estimated FPE at B1 (the combined FGE for all B1 turbines) was $37 \%$ in spring and $45 \%$ in summer. The FPE estimate for B2, which had no sluiceway operation in 2002, was 53\% in spring and $46 \%$ in summer. For only B1 (including the sluiceway) and the spillway, but excluding B2, the estimated FPE was about $89 \%$ in spring and $82 \%$ in summer. Without B2, estimated FPE was $10 \%$ higher in spring and $8 \%$ higher in summer than for the entire project. For only B2 and the spillway (excluding B1) estimated FPE was $83 \%$ in spring and $82 \%$ in summer, or $4 \%$ higher in spring and $8 \%$ higher in summer than were the corresponding estimates for the entire project. Confidence limits for all estimates by season in Figure 3.8 were $<1 \%$. 


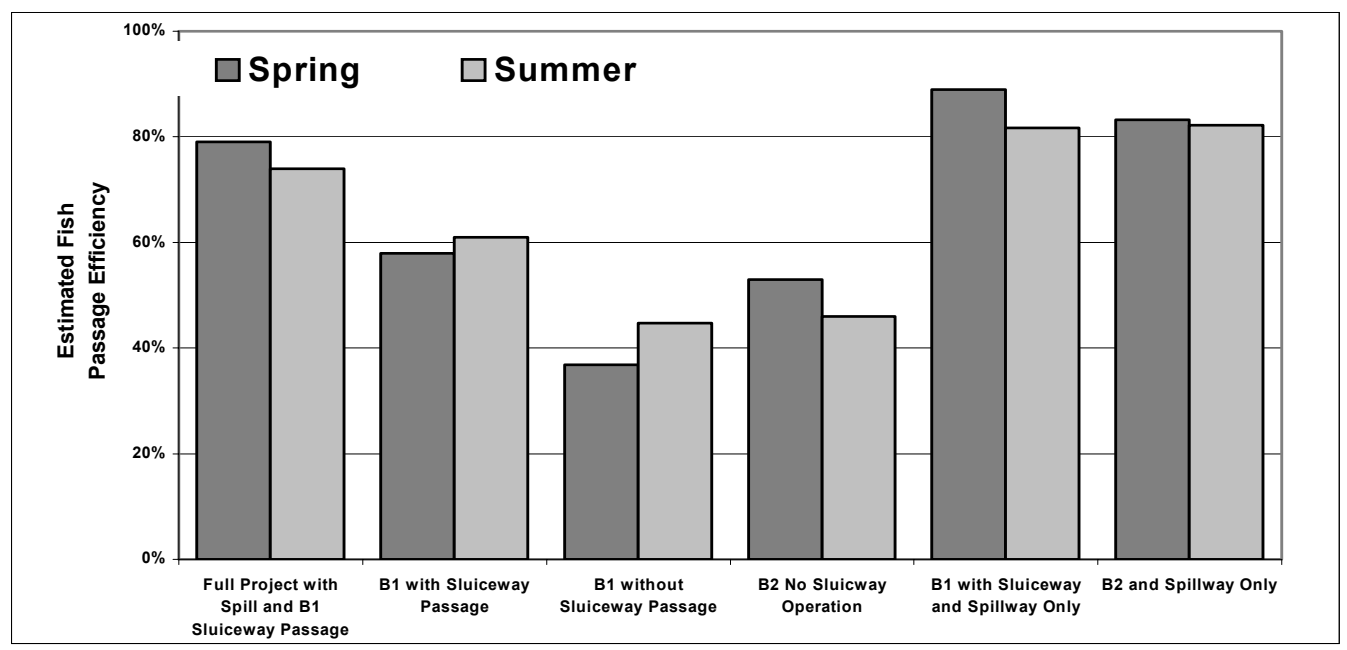

Figure 3.8. Project-Wide and Other Fish Passage Efficiency Estimates for Spring and Summer Fish Passage Seasons at Bonneville Dam in 2002. B1 estimates are presented both with and without consideration of sluiceway passage. The B2 sluiceway did not operate in 2002 . The last two sets of columns present the estimated FPE considering only B1 and the spillway and B2 and the spillway, respectively.

\subsubsection{Spill Efficiency and Effectiveness}

Spill efficiency and effectiveness estimates for the project and for the various combinations of structures are presented in Figure 3.9. Estimated spill efficiency for the entire project was $52 \%$ in spring and $42 \%$ in summer. Spill efficiency for just B1 and the spillway (excluding B2) was estimated to be $74 \%$ in spring and 53\% in summer. For only B2 and the spillway (excluding B1) FPE was estimated to be $64 \%$ in spring and $67 \%$ in summer. Spill effectiveness for the entire project was estimated to be 1.08 in spring and 0.96 in summer. Spill effectiveness for just B1 and the spillway was estimated to be 0.91 in spring and 0.78 in summer whereas, for just B2 and the spillway, spill effectiveness was estimated to be 1.17 in spring and 1.20 in summer.

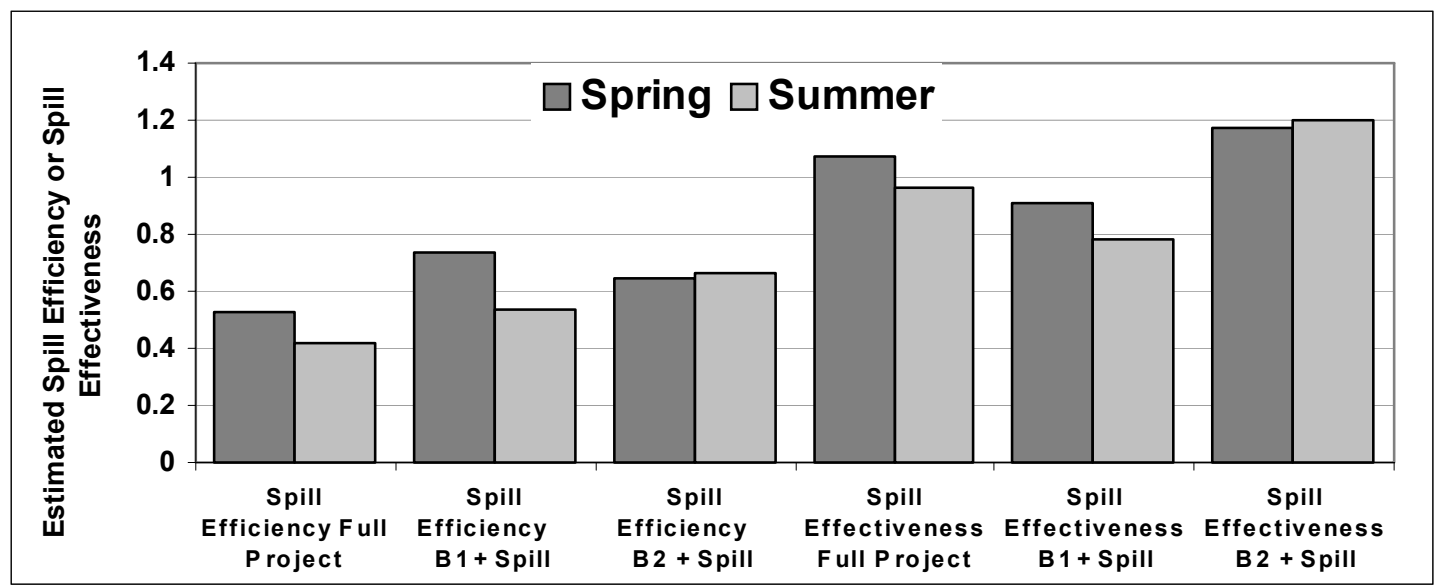

Figure 3.9. Estimated Spill Efficiency and Spill Effectiveness for the Bonneville Project and for the Spillway and Each Powerhouse Only for Spring and Summer 2002. The left three sets of columns represent spill efficiency and the right three sets of columns represent spill effectiveness for the entire project, B1 and the spillway only, and B2 and the spillway only. 


\subsubsection{Effects of Spillway Discharge Level on Spillway Fish Passage}

We compared hourly total spillway discharge with total estimated spillway passage in both spring and summer by linear regression (Figure 3.10). Durbin-Watson tests for autocorrelation of errors terms in all regressions on hourly spill discharge and spill percent (next section) were not significant, indicating that the assumption of independence of hourly errors was valid. For both seasons there was a positive association between spillway discharge and spillway passage but the variability was very high, especially in spring when the coefficient of determination $\left(\mathrm{r}^{2}\right.$ value) was only about 0.2 . The highest variability in estimated fish passage was at about $150,000 \mathrm{cfs}$ and ranged across an order of magnitude from 5 to 50,000 fish per hour estimated to have passed the spillway. In summer spillway passage estimates were lower, never reaching 30,000 in any hour and staying mostly below 10,000 fish per hour. The summer $\mathrm{r}^{2}$ was about 0.5 .

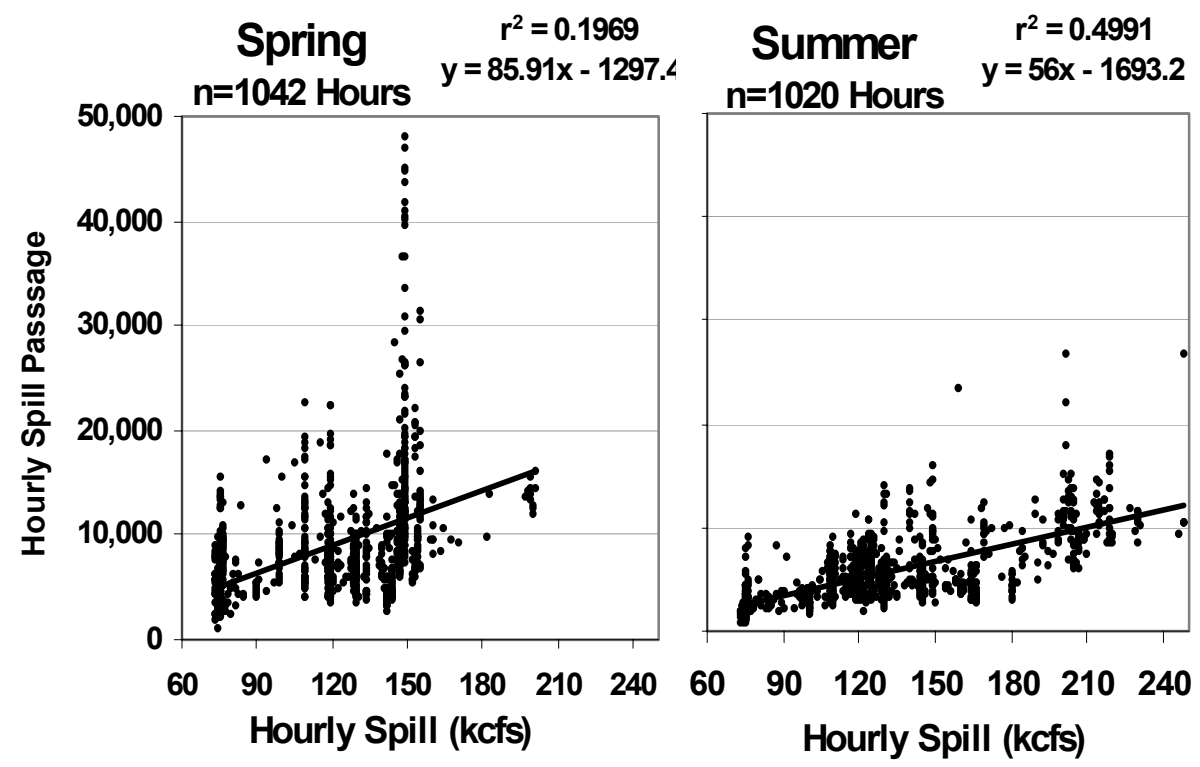

Figure 3.10. Linear Regression Plots of Estimated Hourly Spillway Passage on Total Hourly Spillway Discharge at Bonneville Dam in Spring and Summer of 2002.

\subsubsection{Effects of Percent Spill on Spill Efficiency and Project FPE}

We plotted estimates of hourly spill efficiency and hourly project FPE against the hourly percent spill for all sampled hours of spring and summer in $2002(\mathrm{n}=1,042$ sampled hours in spring and 1,020 sampled hours in summer, see Figure 3.11 and 3.12). Percent spill ranged from about $25 \%$ to just over $80 \%$ in each season. Linear regressions of the spring and summer spill efficiency vs. percent spill distributions are presented in Figure 3.11 and indicate a high correlation with $\mathrm{r}^{2}$ values of about $69 \%$ in spring and just less than $62 \%$ in summer. The slope was close to one in both seasons. 

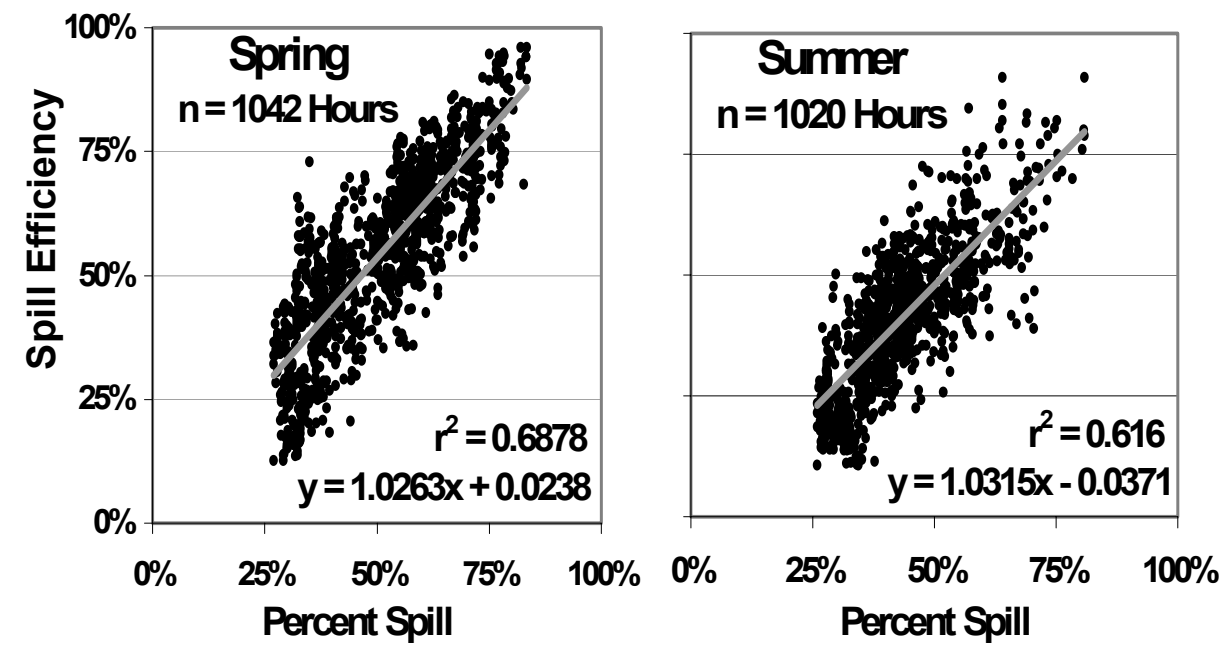

Figure 3.11. Linear Regression Plots of Hourly Spill Efficiency on Percent Spill at Bonneville Dam in Spring and Summer of 2002. Data are hourly hydroacoustic estimates of spill efficiency and operational data from the Bonneville Project.

Similarly obtained plots comparing Project FPE and percent spill are presented in Figure 3.12. In this case the spring's $r^{2}$ value is much higher (about $47 \%$ ) than is the summer's (only about $17 \%$ ) and the spring's slope (about 0.47) is higher than is the summer's (about 0.29).
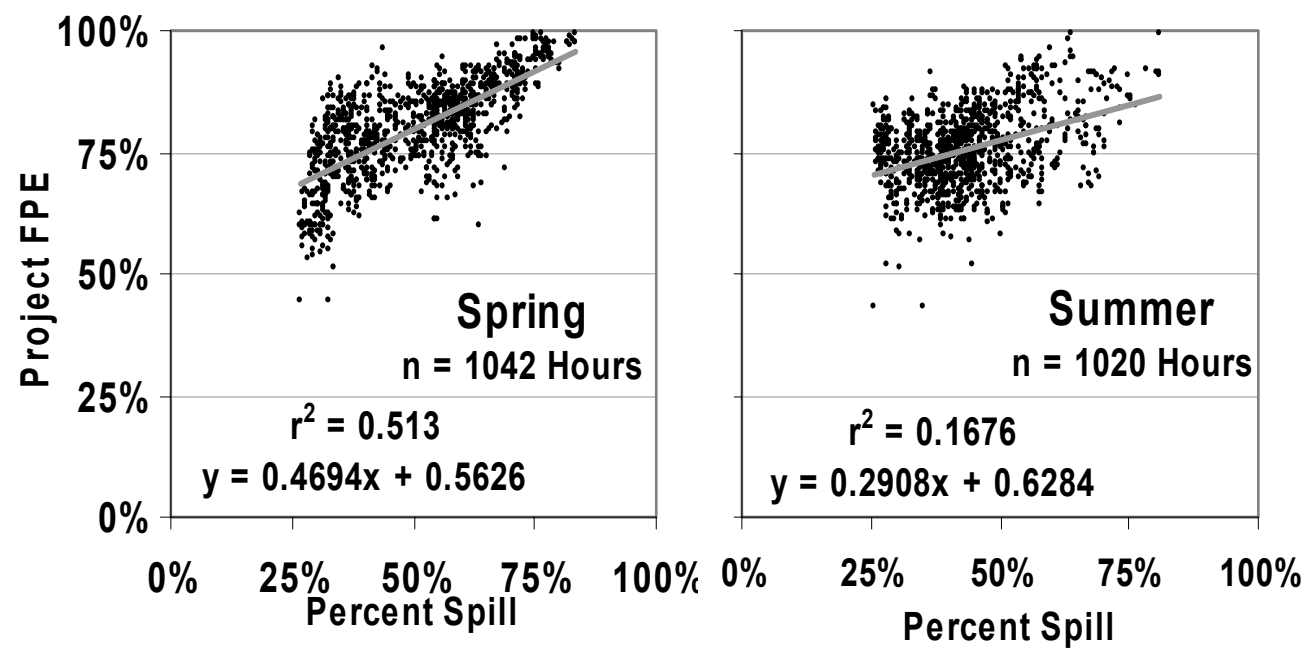

Figure 3.12. Linear Regression Plots of Hourly Project FPE on Percent Spill at Bonneville Dam in Spring and Summer of 2002. Data are hourly hydroacoustic estimates of Project FPE and operational data from the Bonneville Project.

\subsubsection{Effects of Spill Discharge Level on Spill Efficiency and Project FPE}

Since percent spill is a product of discharge through all routes we also plotted the absolute hourly spillway discharge against both hourly spill efficiency (Figure 3.13) and hourly project FPE (Figure 3.14). In the case of spillway efficiency a quadratic equation provided about a $2 \%$ better fit to the data ( $\mathrm{R}^{2}$ just over 0.52$)$ than did a linear equation $\left(r^{2}=0.50\right)$. For the summer data the quadratic improved the coefficient of determination from 0.43 to 0.47 , an increase of $4 \%$. 


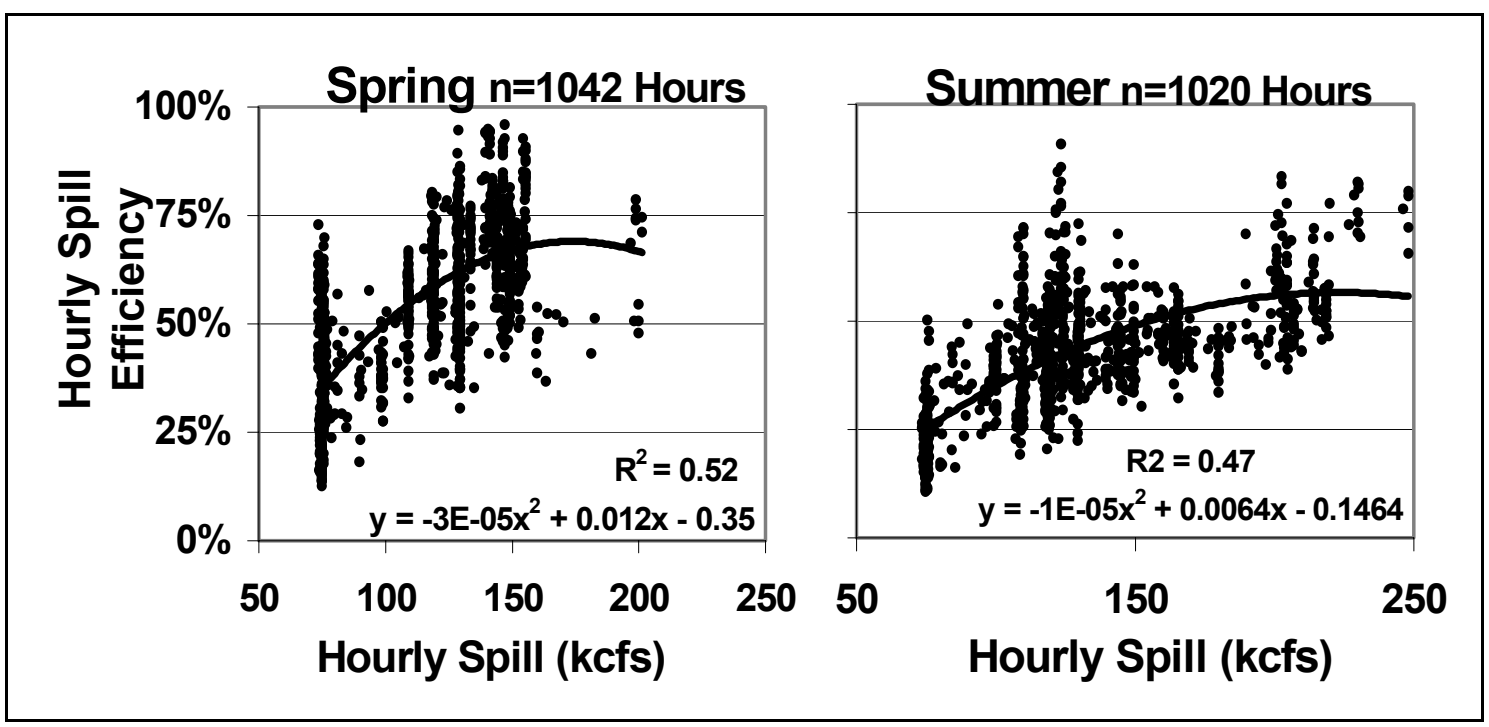

Figure 3.13. Regression Plots of Hourly Spill Efficiency on Spillway Discharge at Bonneville Dam in Spring and Summer of 2002.

As was the case with the plots of spill efficiency and Project FPE against percent spill, the fits of Project FPE against spillway discharge were poorer than were those for spill efficiency against spillway discharge. For spring data the quadratic equation provided about a $4 \%$ better fit $\left(\mathrm{R}^{2}=0.20\right)$ than did a straight line $\left(r^{2}=0.16\right)$ but for the summer spill efficiency the linear fit $\left(r^{2}=0.34\right)$ was somewhat better than was the quadratic $\left(\mathrm{R}^{2}=0.31\right)$.

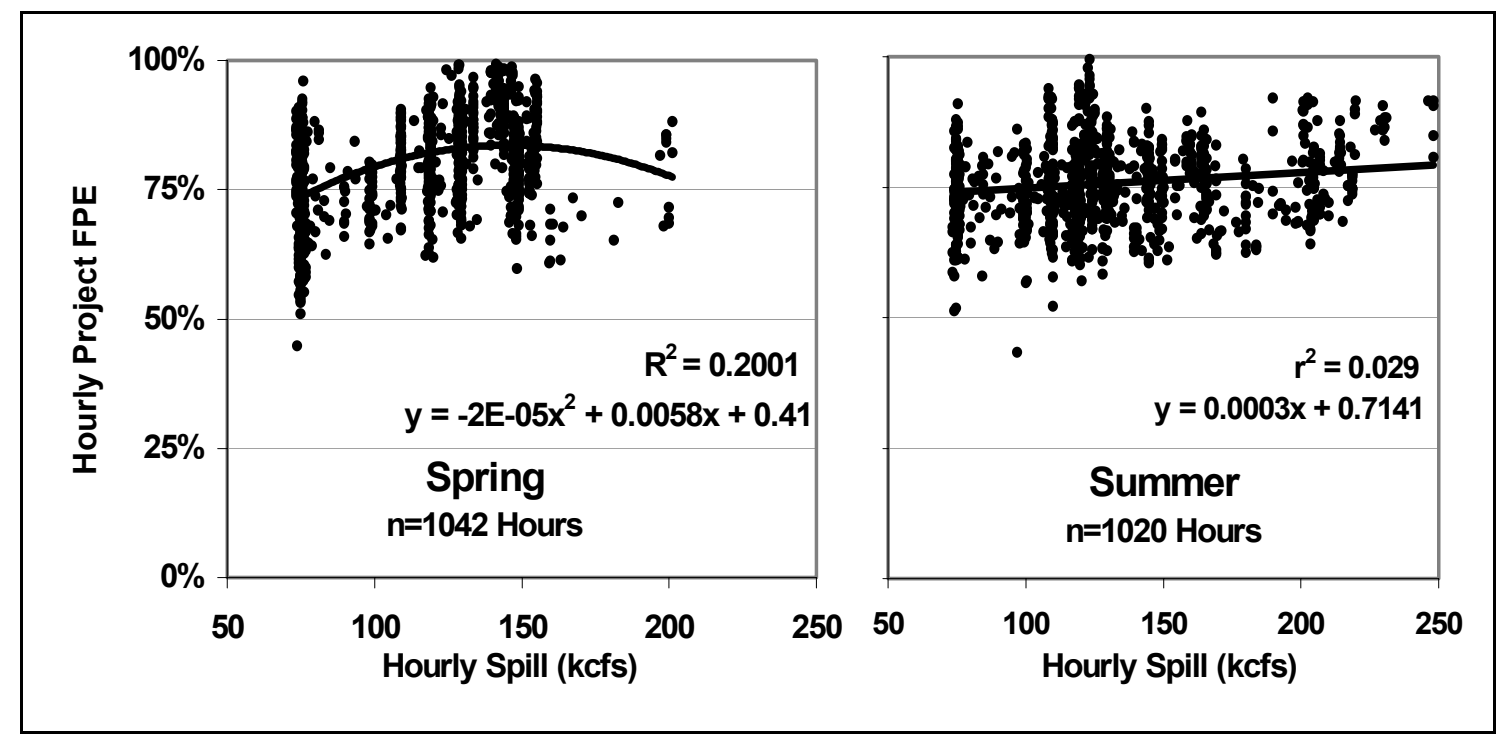

Figure 3.14. Regression Plots of Hourly Project FPE on Spillway Discharge at Bonneville Dam in Spring and Summer of 2002.

In summer 2002, there were 107 hours in which the spillway discharged over $200 \mathrm{kcfs}$. Since this is a rather unusual occurrence we deleted those hours from the data and again plotted summer hourly spill efficiency and project FPE estimates. Without the data from those unusually high-spill hours, the summer 
data's regressions took on a form similar to that from spring. The relationship between spill efficiency and spillway discharge in summer was best described by a quadratic equation $\left(R^{2}=0.45\right)$ rather than by a linear one $\left(r^{2}=0.33\right)$. The curvilinear relationship for Project FPE was less clear but the quadratic equation again produced a slightly better but still very poor fit $\left(\mathrm{R}^{2}=0.021\right)$ than did the linear equation $\left(\mathrm{r}^{2}\right.$ $=0.0014$ ). Plots of summertime hourly spill efficiency and Project FPE without data from hours when more than $200 \mathrm{kcfs}$ passed the spillway are presented in Figure 3.15.

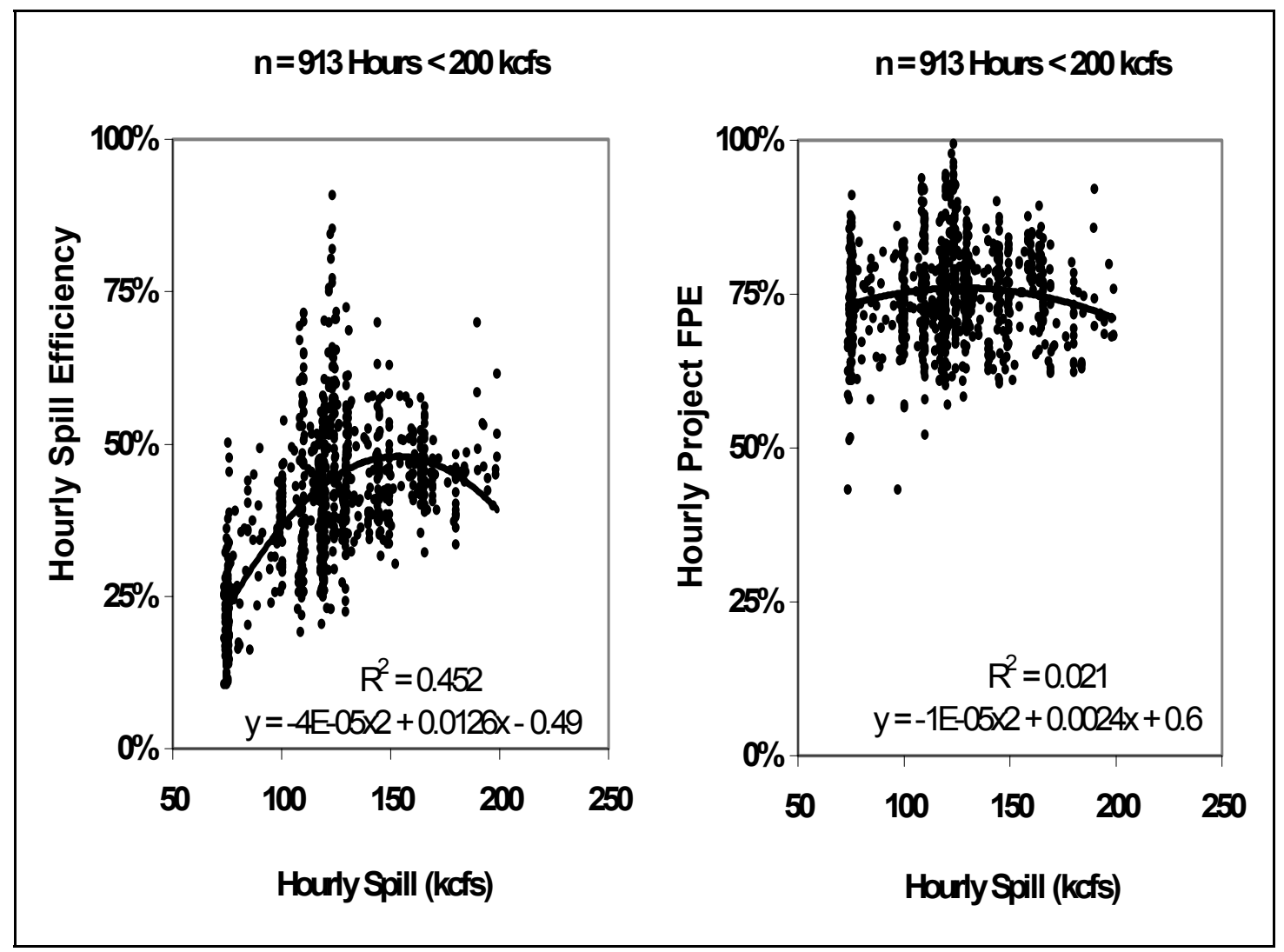

Figure 3.15. Regression Plots of Hourly Spill Efficiency and Project FPE on Spillway Discharge at Bonneville Dam in Summer of 2002. Data from 107 hours in which the spillway passed more than $200 \mathrm{kcfs}$ have been deleted.

\subsubsection{Comparison with Radio Telemetry Estimates}

We recalculated hydroacoustic estimates based on the USGS's radio telemetry data collection schedule in spring and they recalculated their data based on our schedule in summer so that we would be comparing the same days each season. Major fish passage data from the two methods (hydroacoustics = $\mathrm{HA}$ and radio telemetry $=\mathrm{RT}$ ) are presented in Table 3.2. The two methods were in close agreement (within 1\% in spring and within 4\% in summer) for Project FPE. For estimates based upon concurrent sample dates, $100 \%$ of the 12 pairs of efficiency estimates were within $16 \%$ of each other, $83 \%$ were within $10 \%$, and $42 \%$ were within $5 \%$. The six measures of effectiveness were much less concordant, varying from within $12 \%$ to $59 \%$ of each other (mean difference $=30.5 \%$ ). 
Table 3.2. Comparison of Major Fish-Passage Metrics Estimated by Hydroacoustics (HA) and Radio Telemetry (RT) at Bonneville Dam in 2002. Data from non-overlapping parts of seasons have been deleted and adjusted so that time periods reported here are the same for both methods. Those dates are May 2-June 9 for spring and June 23-July 15 for summer. Some hydroacoustic FGEs are slightly different than those reported elsewhere in this report because the times have been adjusted to match those for radio telemetry. Numbers after the \pm symbol are $95 \%$ confidence limits for the season.

\begin{tabular}{|c|c|c|}
\hline Major Passage Metric & HA Estimate & RT Estimate \\
\hline Spring Project FPE & $78 \pm 0.1 \%$ & $78 \%$ \\
\hline Spring B1 FPE & $58 \pm 0.4 \%$ & $74 \%$ \\
\hline Spring B2 FPE & $53 \pm 0.3 \%$ & $43 \%$ \\
\hline Spring Spill Efficiency & $50 \pm 0.5 \%$ & $56.2 \%$ \\
\hline Spring Spill Effectiveness & $1.01 \pm 0.01$ & 1.15 \\
\hline Spring Sluice Efficiency Project & $8 \pm 0.1 \%$ & $3 \%$ \\
\hline Spring Sluice Effectiveness Project & $29 \pm 0.02$ & 12 \\
\hline Spring Sluice Efficiency в1 & $33 \pm 0.9 \%$ & $40.5 \%$ \\
\hline Spring Sluice Effectiveness ${ }_{B 1}$ & $17 \pm 0.07$ & 21 \\
\hline Summer Project FPE & $76 \pm 0.2 \%$ & $79 \%$ \\
\hline Summer B1 FPE & $63 \pm 0.3 \%$ & $70 \%$ \\
\hline Summer B2 FPE & $50 \pm 0.7 \%$ & $44 \%$ \\
\hline Summer Spill Efficiency & $40 \pm 0.5 \%$ & $54 \%$ \\
\hline Summer Spill Effectiveness & $0.96 \pm 0.01$ & 1.30 \\
\hline Summer Sluice Efficiency Project & $11 \pm 0.1 \%$ & $7 \%$ \\
\hline Summer Sluice Effectiveness Project & $48 \pm 0.03$ & 31 \\
\hline Summer Sluice Efficiency в1 & $29 \pm 0.7 \%$ & $45 \%$ \\
\hline Summer Sluice Effectiveness ${ }_{\text {B1 }}$ & $25 \pm 0.07$ & 37 \\
\hline
\end{tabular}




\subsection{Spatial Trends in Fish Passage}

\subsubsection{Horizontal Distributions}

During the 44 spring days that we sampled, we estimate that just over $17.3 \mathrm{M}$ fish passed the Project with nearly $52 \%(9 \mathrm{M})$ passing the spillway, about 18.6\% (3.2 M) passing B1 (including the sluiceway), and about 29\% (5 M) passing B2 (Figure 3.16). Total Project discharge in spring was 25,358 $\mathrm{M} \mathrm{m}^{3}$ with spillway discharge of $49 \%$, B2 discharge of $40 \%$, and about $11.5 \%$ at B1 (Figure 3.17). The overall fish density (the number of fish per million cubic meters of water) was 683. Fish passage density was highest at B1 $\left(1,110\right.$-fish $\left./ \mathrm{M} \mathrm{m}^{3}\right)$, followed by the spillway $\left(733 \mathrm{fish} / \mathrm{M} \mathrm{m}^{3}\right)$, and then B2 (498 fish $/ \mathrm{M} \mathrm{m}^{3}$;

Figure 3.18).

We estimate that about $62 \%$ of the $3.2 \mathrm{M}$ fish that passed $\mathrm{B} 1$ in spring passed through only three routes, the B1 sluiceway weir at Intake 7A (33.2\%), turbine unit $6(17.5 \%)$, and turbine unit $7(11.1 \%)$. The sluiceway showed the highest fish density of $14,929-$ fish $/ \mathrm{M} \mathrm{m}^{3}$ in the project and also the second highest fish passage $(1 \mathrm{M})$ among all routes in the project.

At B2, where an estimated $5 \mathrm{M}$ fish passed in spring, the overall highest fish passage (1.2 $\mathrm{M}$ or $24 \%$ of the total spring estimate) occurred at Unit 12 with discharge of $1,329 \mathrm{M} \mathrm{m}^{3}$ (24\% of the B2 total discharge) in spring. More than 43\% of B2 spring fish passed at units 11 and 12 with a combined discharge of $28 \%$ of the $\mathrm{B} 2$ total. Unit 18 had the highest discharge (1,525 $\mathrm{M} \mathrm{m}^{3}, 15 \%$ of the total) overall but estimated lowest fish passage $(224,000$ or $4.5 \%$ of the total B2 passage estimate).

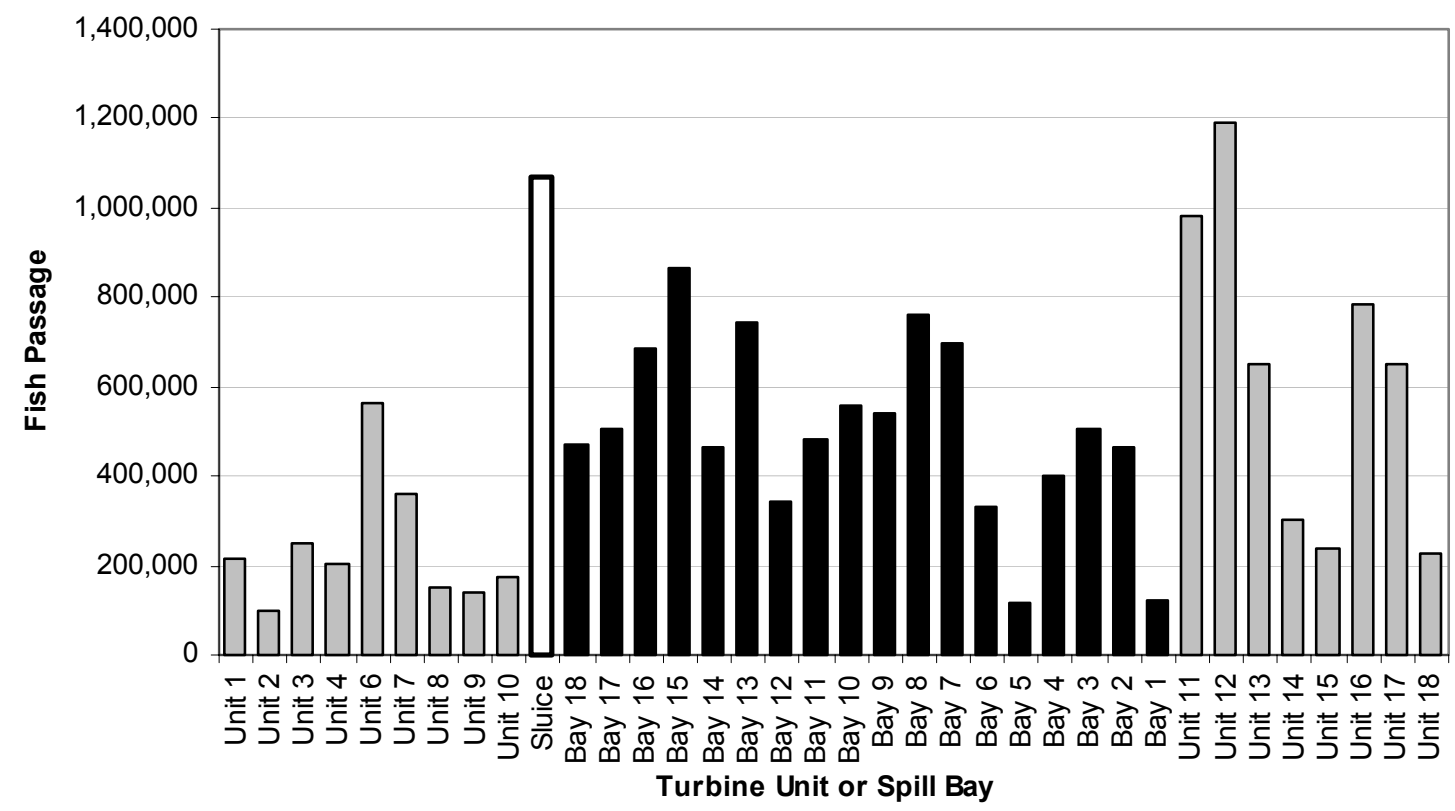

Figure 3.16. Horizontal Distribution of Fish Passage through Bonneville Dam in Spring of 2002. Passage through B1 and B2 turbines is represented by gray bars, through the B1 sluiceway by the white bar, and through spill bays by black bars. Turbine Unit 5 did not operate in 2002. 


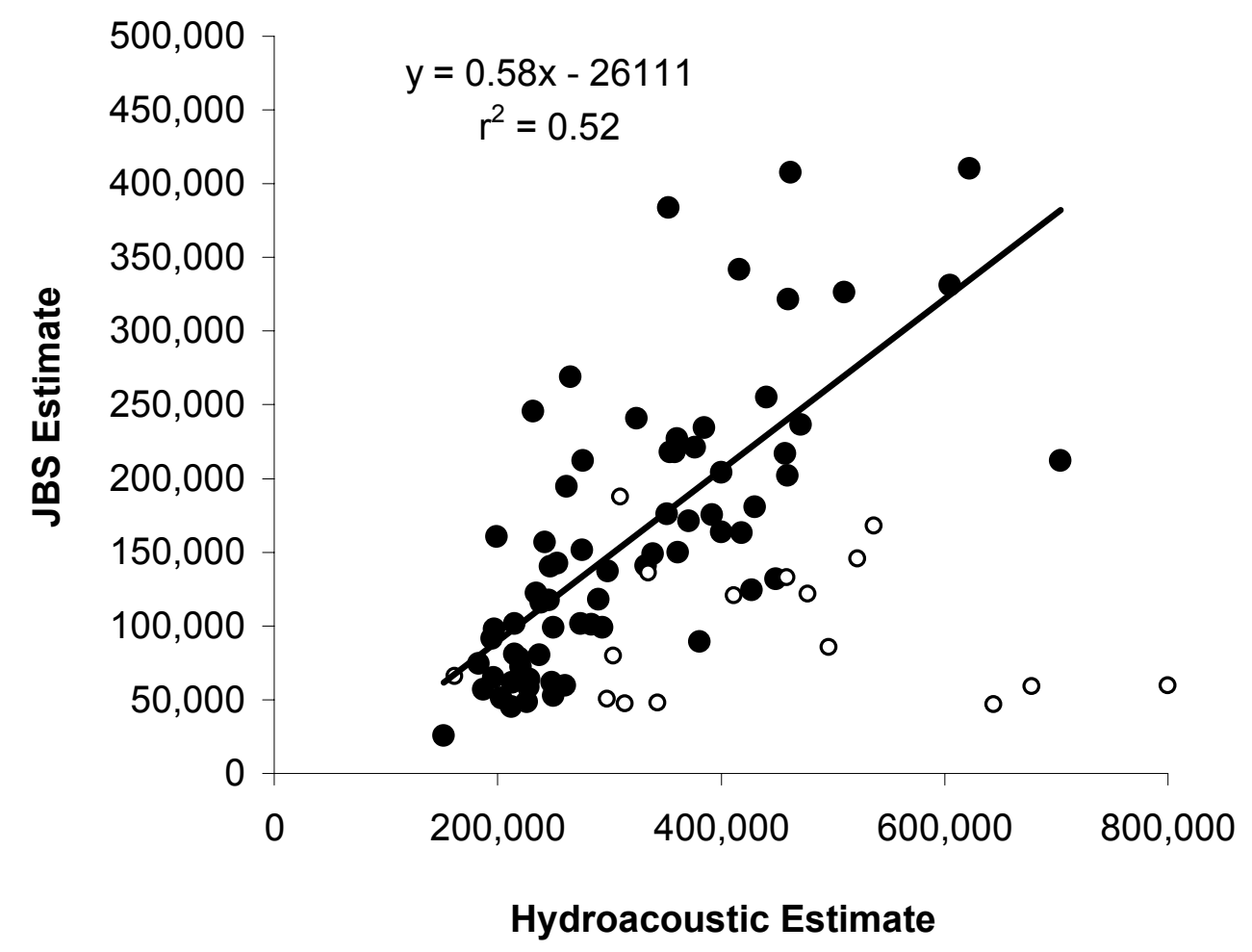

Figure 3.23. Correlation of the Smolt Index from the Bonneville Dam Juvenile Bypass System with Hydroacoustic Estimates of Fish Passage. Circles show points for eight days before April 29,2003 , and eight days between June 1 and 8,2003 , that were excluded from the regression equation because most fish from large hatchery releases passed through the spillway on those days.

\subsubsection{Major Fish-Passage Metrics}

The daily trends in FPE, spill efficiency, and sluice efficiency were related to percent spill in 2002 (Figure 3.24). Project FPE was 79\% in spring and $74 \%$ in summer, had daily estimates ranging from $65 \%$ to $92 \%$ during sampling, and had a weak positive correlation with percent spill. Spill efficiency averaged $52 \%$ in spring and $43 \%$ in summer, had daily estimates ranging from $32 \%$ to $75 \%$ during sampling, and had a strong positive correlation with percent spill. Spill efficiency varied considerably from day to day as did the percent of water spilled, and there was great among-day variability in spring when operators had more control than in June when total Project discharge was highest and control was less (Figure 3.24). The purposeful effort to impose high and low spill treatments is clearly evident before June. Except for the last week of summer sampling, peaks in Project FPE and spill efficiency were higher in spring than in summer. Sluiceway $7 \mathrm{~A}$ efficiency averaged $6 \%$ in spring and $11 \%$ in summer, and it had a weak negative correlation with percent spill. 

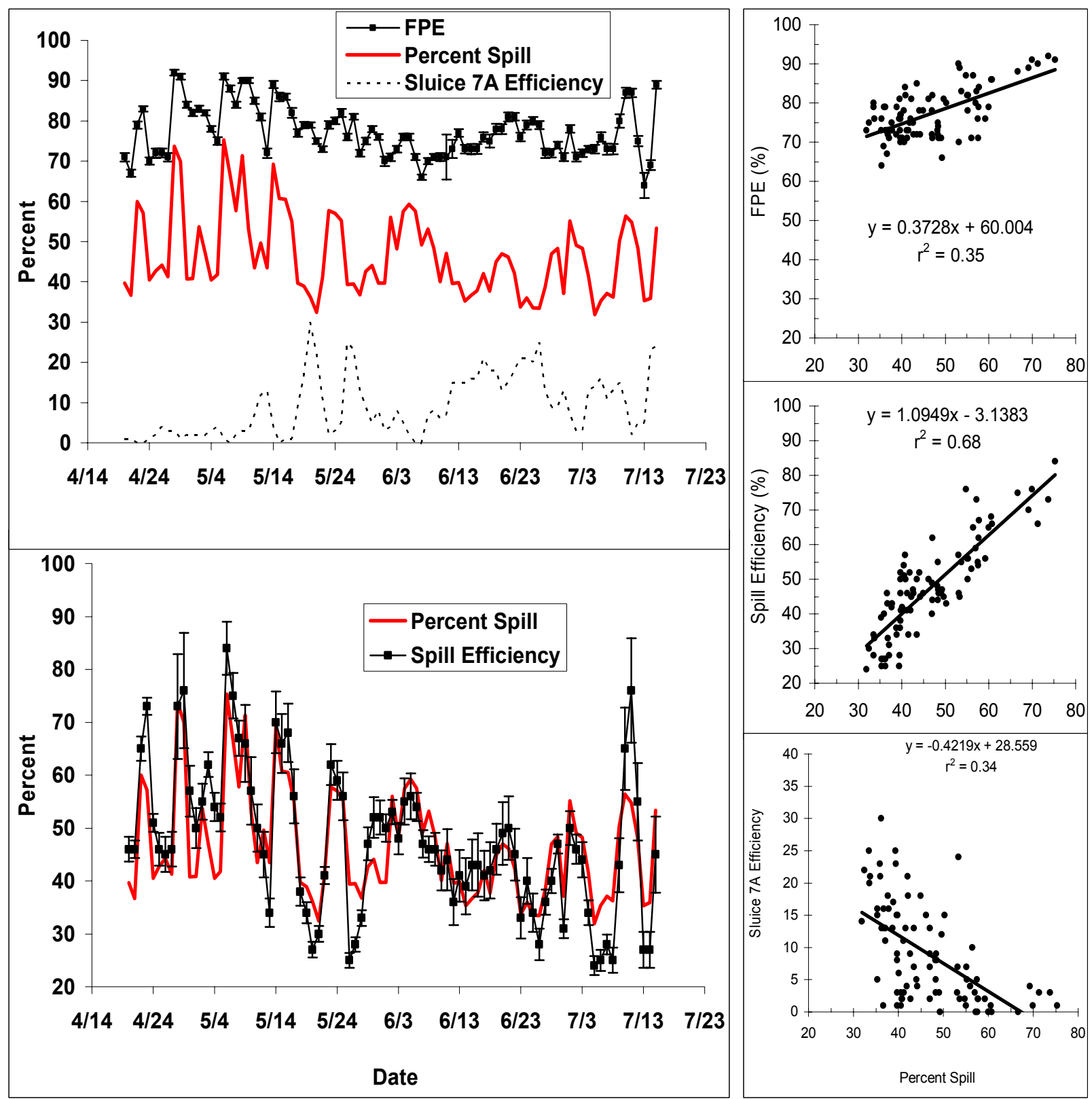

Figure 3.24. Estimated Project FPE and Spill Efficiency, and the Proportion of Water Spilled at Bonneville in 2002. Error bars represent $95 \%$ confidence limits on daily estimates.

The B1 FPE estimates that included the contribution of Sluiceway 7A usually were similar to or higher than FPE estimates for B2, which had no sluiceway route in 2002, but B1 FPE estimates that ignored the sluiceway contribution usually were lower than turbine-based estimates for B2, in spring (Figure 3.25). For most of summer (excluding the last week), B1 and B2 estimates of FPE based solely upon turbine guidance were similar. Daily estimates of Sluiceway $7 \mathrm{~A}$ efficiency explained $84 \%$ of the variation in B1 FPE over both seasons, and the intercept of 39\% indicates the average guidance that can be expected from screens alone (Figure 3.25). Estimates of B1 FPE approaching 100\% only occurred on days when most of the B1 turbines were off. 


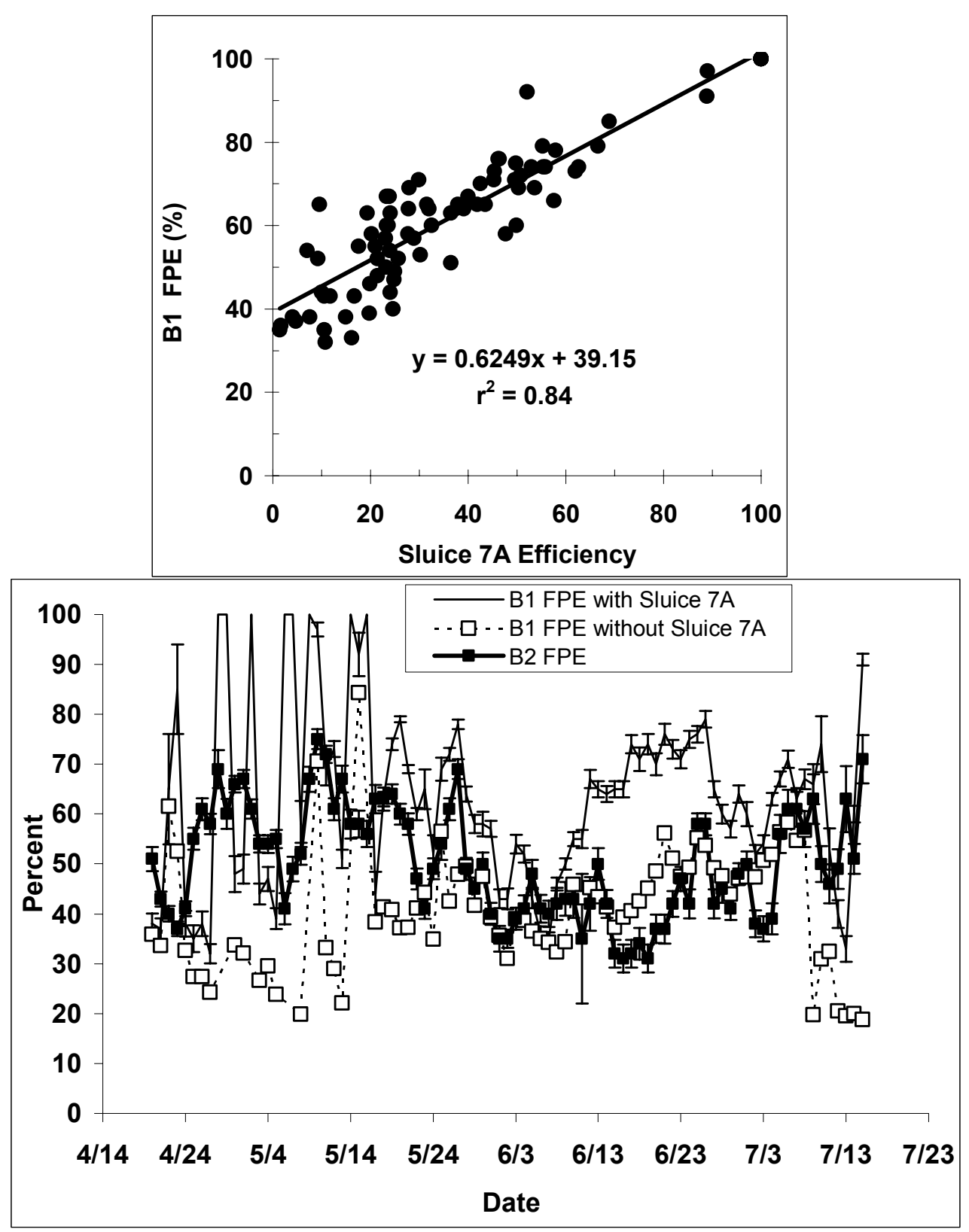

Figure 3.25. Regression of Daily Fish Passage Efficiency Estimates for B1 on Sluice 7A Efficiency Relative to B1 (upper plot) and Daily Fish Passage Efficiency Estimates for B1 (with and without the Contribution of Sluiceway $7 \mathrm{~A}$ ) and B2 (lower plot). Error bars represent $95 \%$ confidence limits based upon temporal and among intake variation in guided and unguided fish passage estimates.

Daily estimates of Sluiceway 7A effectiveness ranged from 1 to 10 orders of magnitude higher than estimates of spill effectiveness (Figure 3.26). Daily spill effectiveness estimates averaged 1.08 in spring and 0.98 in summer and significant decreases were evident between about May 10 and May 24 and between June 24 and July 15, two periods that included major peaks in spring and summer juvenile passage. 


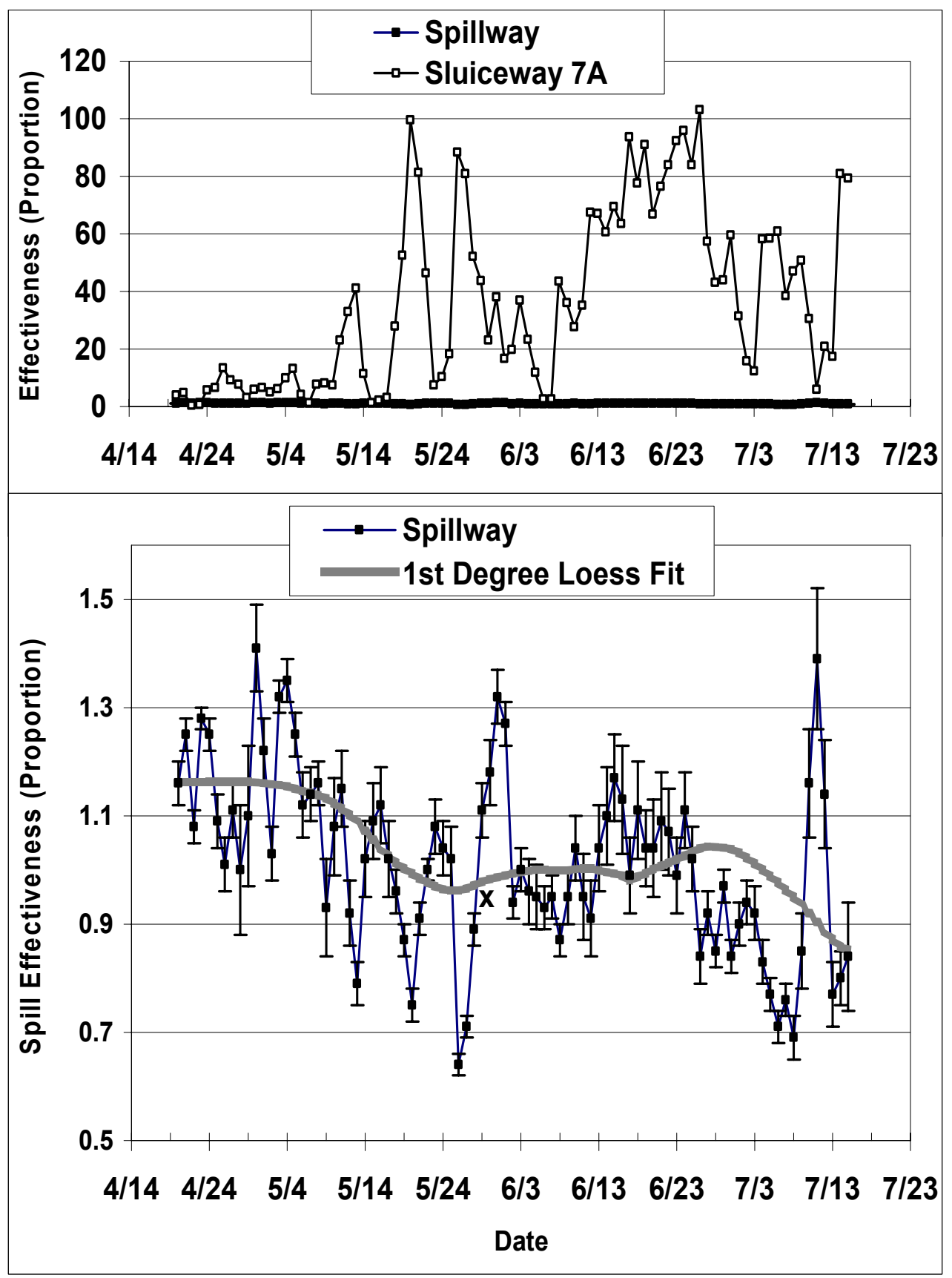

Figure 3.26. Daily Effectiveness Estimates for the Spillway and Sluiceway 7A (upper plot) and Trends in Daily Spill Effectiveness and Daily 95\% Confidence Intervals (lower plot). The Loess smoothing fit was based upon a $1^{\text {st }}$ degree polynomial and $30 \%$ sampling.

\subsubsection{Fish Guidance Efficiency at Modified Intake 17}

The FGE at modified intake 17B was about 14\% higher than that for Intake $17 \mathrm{C}$ in spring, although variability among days was high, and estimates for $17 \mathrm{~B}$ declined more precipitously than those for $17 \mathrm{C}$ from mid-June through mid-July (Figure 3.27). The FGE estimates of Intake 17B for all of spring (72\%) 
and summer (69\%) actually were closer than un-weighted FGE estimates in Figure 3.27 suggests because most fish passed through the intake in late April, early May, and early June when FGE happened to be high (Figure 3.27). Likewise, the overall FGE for all of Unit 17 was more like the estimates for Intake 17B than for Intake 17C because most fish passed through 17B (Figure 3.27), except after about 15 June when passage was similar in both intakes.
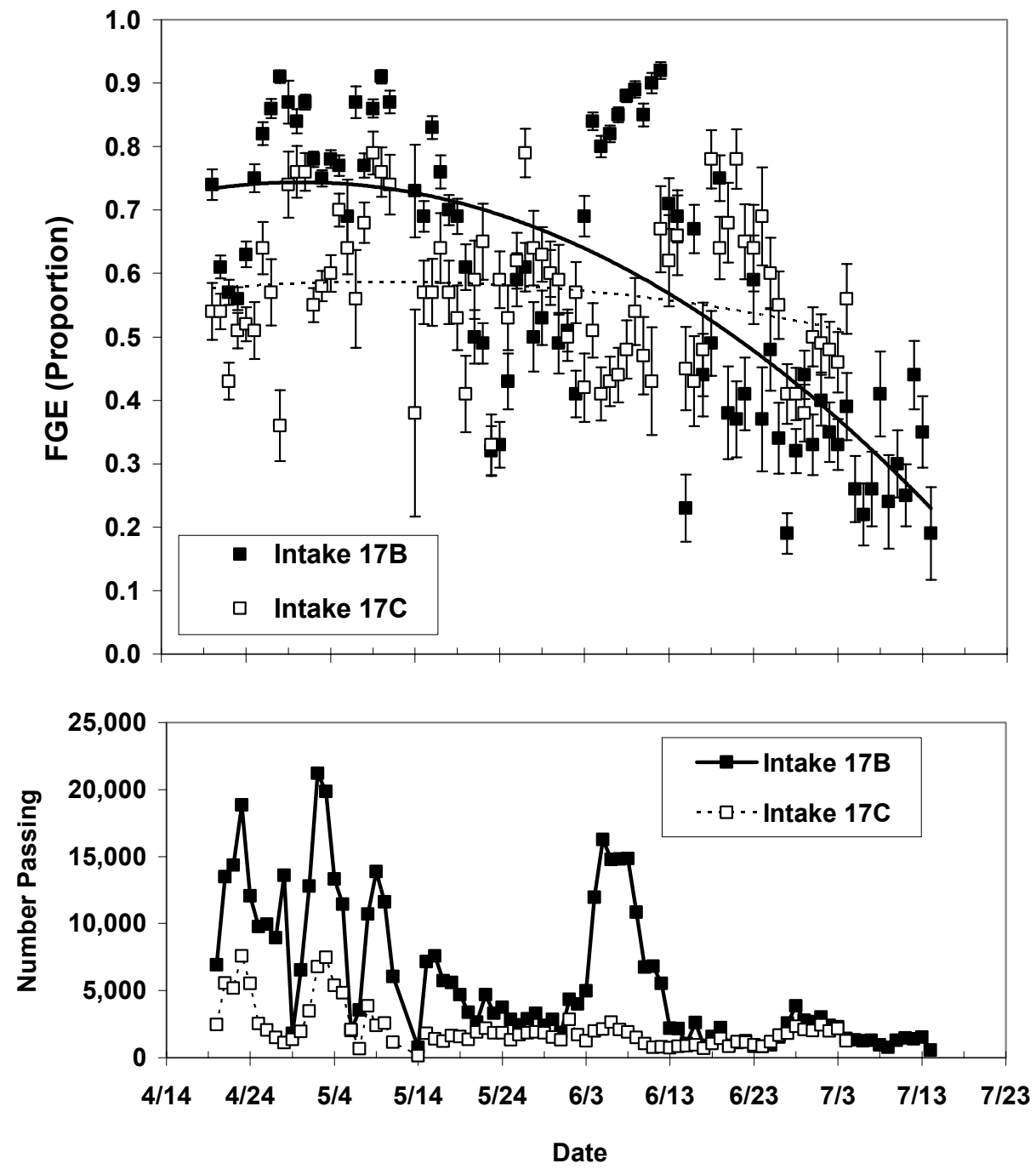

Figure 3.27. Daily Estimates of Fish Guidance Efficiency (FGE) and the Number of Smolt-Sized Fish Passing through Intakes 17B and 17C. Error bars represent 95\% confidence intervals.

\subsubsection{American Shad Run Timing}

The population of American shad has steadily increased over the last three years (Figure 3.28). American shad may present a problem for hydroacoustic sampling because adults may fall back through the spillway during periods of high spill discharge. In addition, by July, large numbers of spent American shad usually begin to show up at smolt-passage routes, particularly sluiceways and in guided fractions of 
turbines, by July so some caution must be exercised in interpreting hydroacoustic data during the last week or two of sampling.

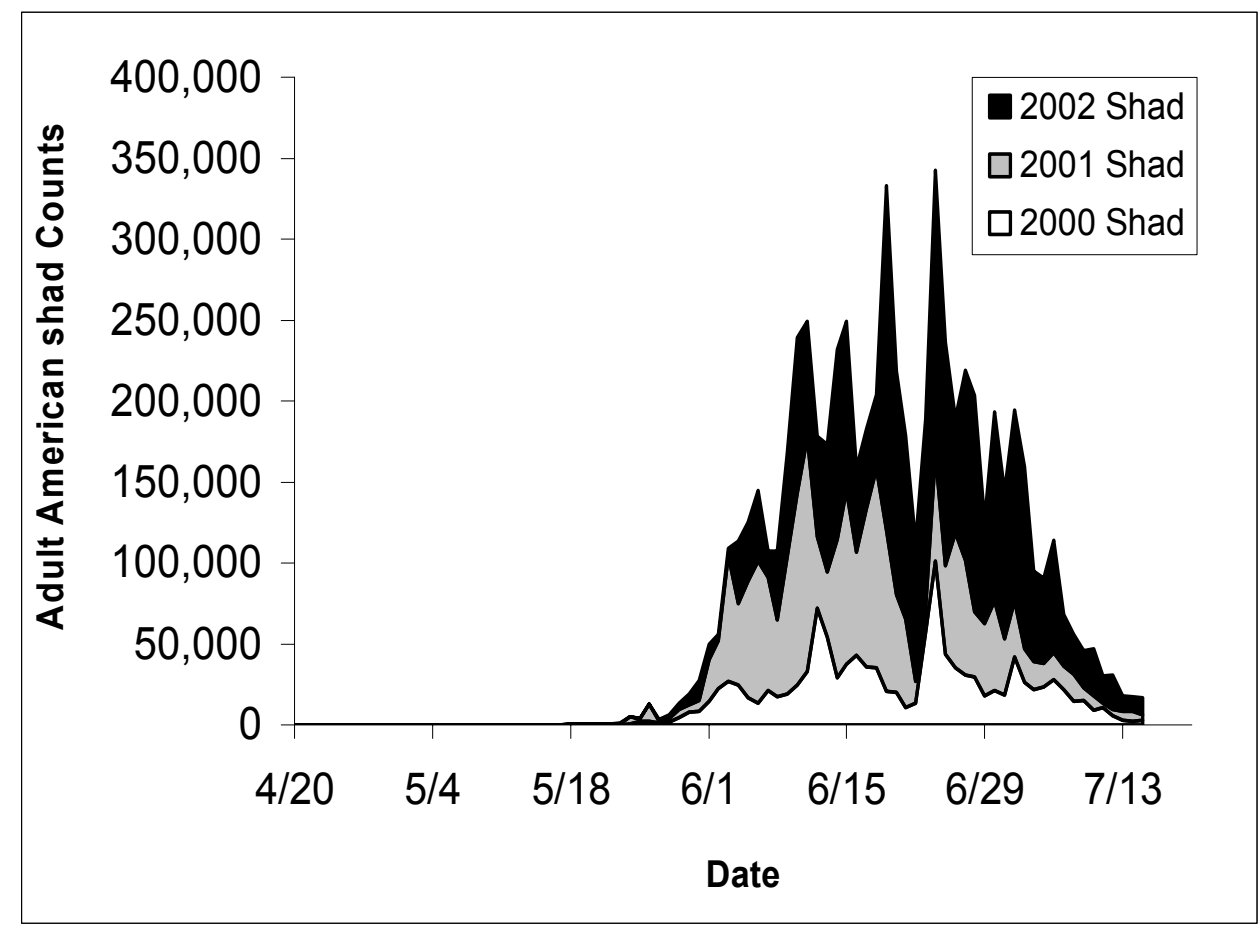

Figure 3.28. Run Timing of Up-migrating American Shad through the Bonneville Project in 2000, 2001, and 2002.

\subsubsection{Diel Trends}

\subsubsection{Project-Wide Estimates and Spill}

Diel patterns for Project FPE, spill efficiency, and spill effectiveness are presented in Figure 3.29, and all were higher in the springtime than in summer. Project FPE and spill efficiency were higher at night than during daytime whereas spill effectiveness was highest during daytime and declined to the lowest levels in the evenings ( $2100 \mathrm{~h}$ in spring and $1900 \mathrm{~h}$ in summer). 


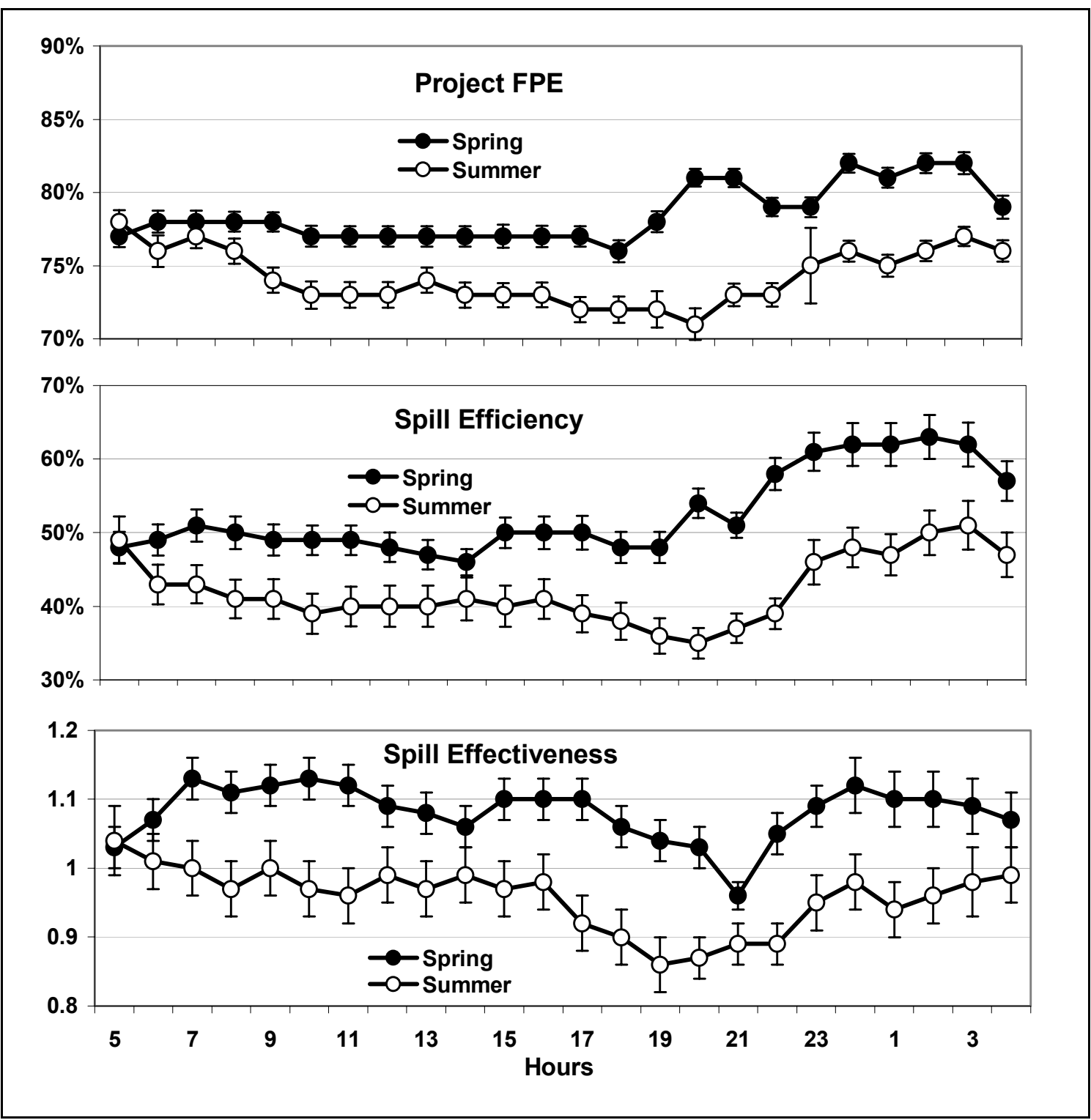

Figure 3.29. Diel Patterns of Fish Passage Efficiency, Spill Efficiency, and Spill Effectiveness during the Spring and Summer at Bonneville Dam in Spring and Summer of 2002. Error bars represent $95 \%$ confidence limits for hydroacoustic estimates.

The next five figures present passage, discharge, and FPE data for the Project, the spillway, and the two powerhouses, in both spring and summer. Wherever possible the vertical scale has been held constant for both seasons within each graph. In the one case where this was not possible, the discrepancy has been noted in the caption.

There were passage peaks in the evenings (1900-2300) in both seasons (Figure 3.30). In spring, the evening passage peak was greater than was the evening increase in discharge whereas in summer the evening passage peak was less abrupt but lasted somewhat longer. In both seasons, estimated passage held fairly constant through the predawn hours although discharge declined, especially in summer. Estimated project-wide fish passage through all routes generally followed project-wide discharge (i.e., as 
flow decreased, passage decreased) at night. However, during daytime, especially in early mornings (0500-0800) in spring and throughout mornings (0500-1200) in summer there was a roughly inverse relationship with lower estimated passage as discharge increased (Figure 3.30).

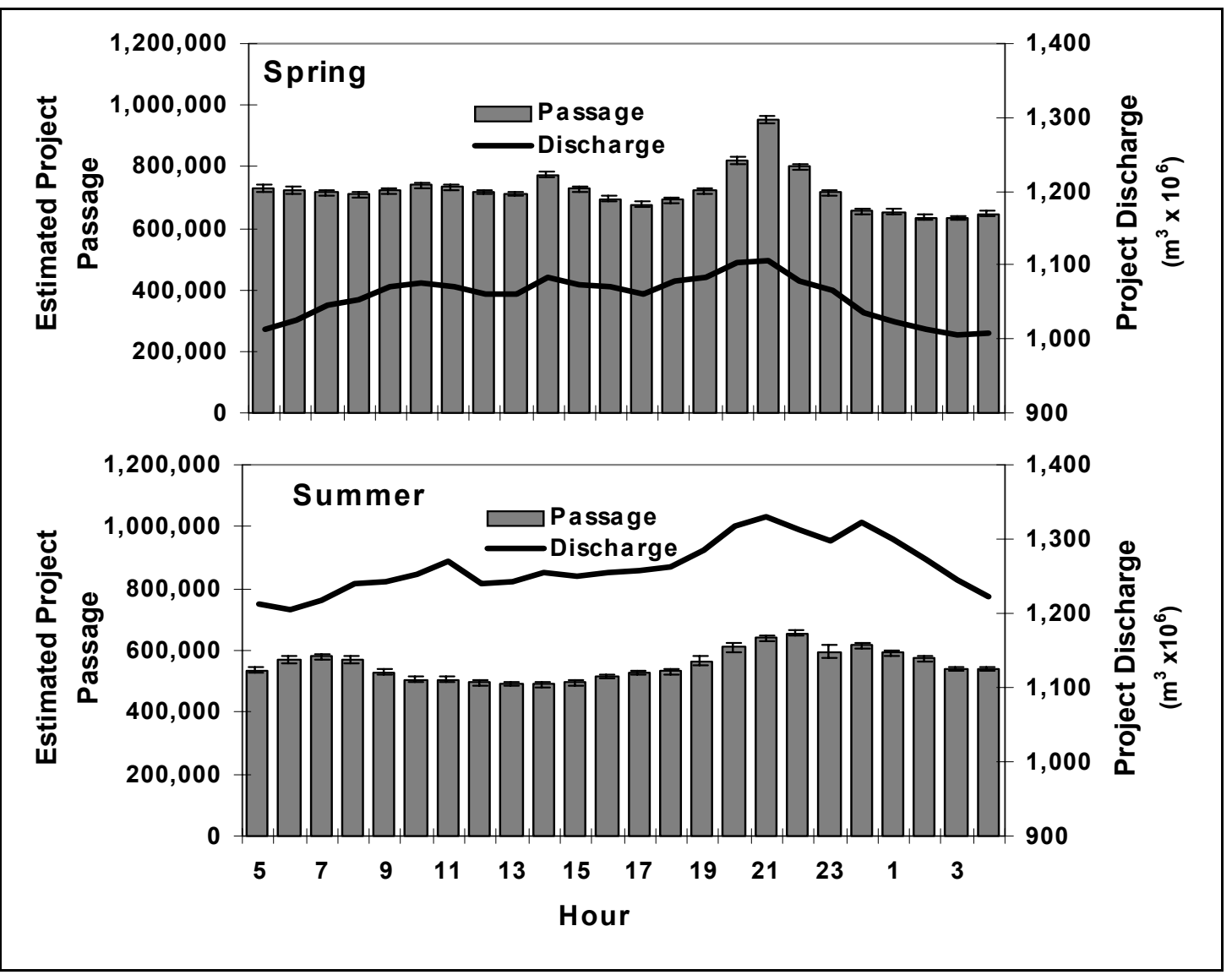

Figure 3.30. Estimates of Diel Trends in Total Fish Passage and Discharge in Spring (top) and Summer through Bonneville Dam in 2002. Error bars represent 95\% confidence intervals on fish passage estimates.

Estimated numbers of fish spilled in the spring generally followed spillway discharge except that the evening passage peak that started about sunset $(2000 \mathrm{~h})$ and coincided with the onset of the nighttime spill pattern dropped off after midnight whereas spillway discharge remained high (Figure 3.31). Note that whereas the discharge scales are the same for spring and summer, the spring scale for fish passage is twice the summer scale. In summer, the estimated fish passage was less than in spring although the magnitude of the spillway discharge was similar. Daytime estimated passage was lower relative to spill and the evening passage peak was more gradual in onset and decline, lasting from $2100 \mathrm{~h}$ to $0300 \mathrm{~h}$.

\subsubsection{Fish Guidance Efficiency and Passage at Powerhouses}

Estimates of the diel trends in FPE and total (guided and unguided) fish passage at the two Bonneville powerhouses are presented in Figures 3.32 and 3.33 (B1) and 3.34 (B2). Figure 3.32 presents data for the B1 powerhouse including the sluiceway, which ran throughout both seasons, and Figure 3.33 presents estimates calculated excluding sluiceway passage. 


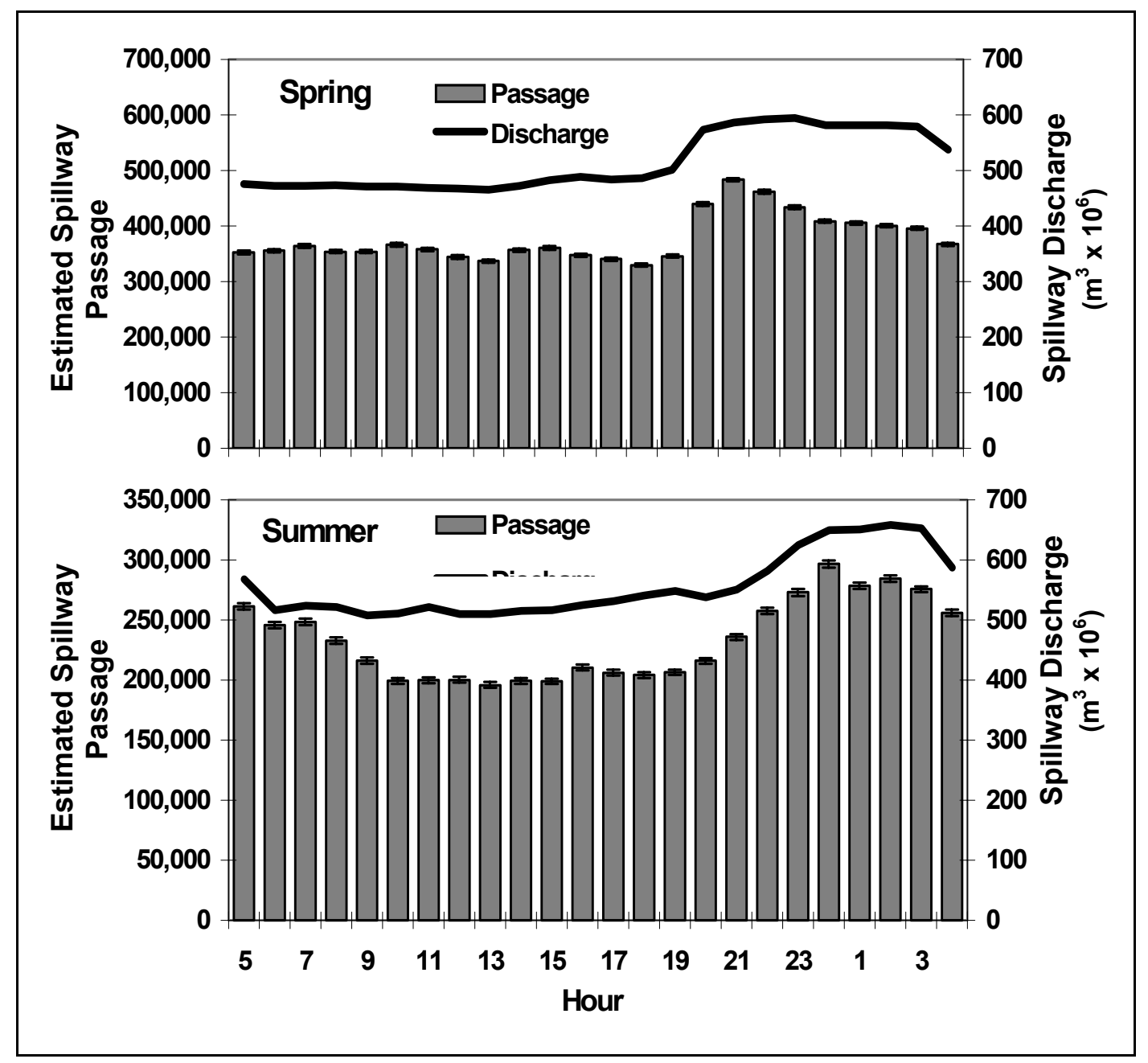

Figure 3.31. Estimates of Diel Trends in Spilled Fish and Discharge over the Spillway in Spring (top) and Summer through Bonneville Dam in 2002. Note that the scale of the vertical passage (left) axis in spring extends to twice what it does in summer. Error bars represent 95\% confidence intervals on fish passage estimates.

At B1 in spring and summer, fish passage had significant diel trends, whereas B1 FPE was more stable (Figure 3.32). The diel pattern in fish passage was higher during the day than at night in the spring and also in the summer, except for a peak around twilight.

We recalculated diel distributions of B1 FPE excluding sluiceway passage, i.e., the sum of turbine guided passage divided by total turbine passage (Figure 3.33). Excluding the sluiceway samples removes a large proportion of the total passage estimate and unavoidably lowers the FPE from mostly over 55\% to mostly under $45 \%$ in both seasons. Removal of the sluiceway influence made the diel trend in B1 FPE more prominent and reduced the magnitude of daytime passage, although it still exceeded nighttime passage, which was in line with the turbine discharge pattern. 


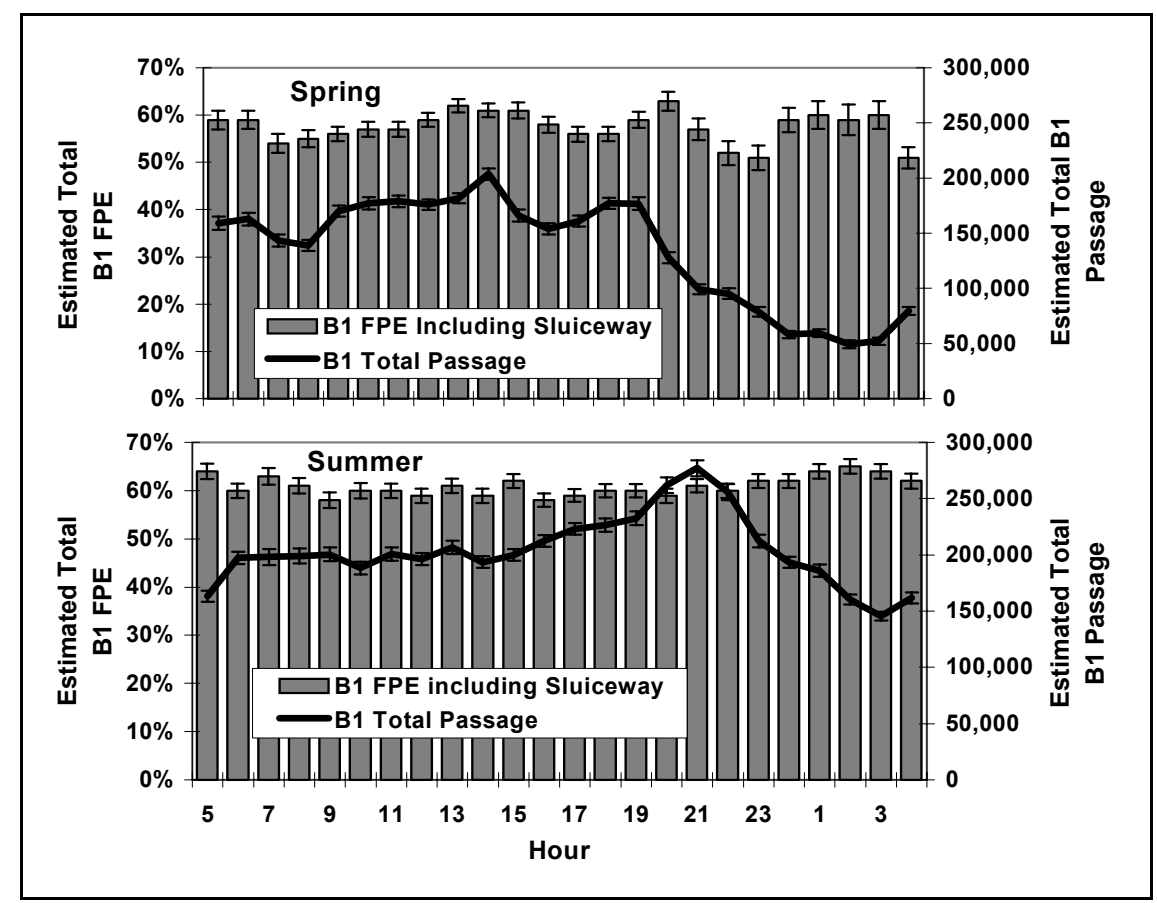

Figure 3.32. Diel Estimates of Fish Guidance Efficiency and Total Fish Passage for B1 during Spring (top) and Summer at Bonneville Dam in 2002. Passage estimates for the sluiceway are included. Error bars represent $95 \%$ confidence limits on hydroacoustic estimates.

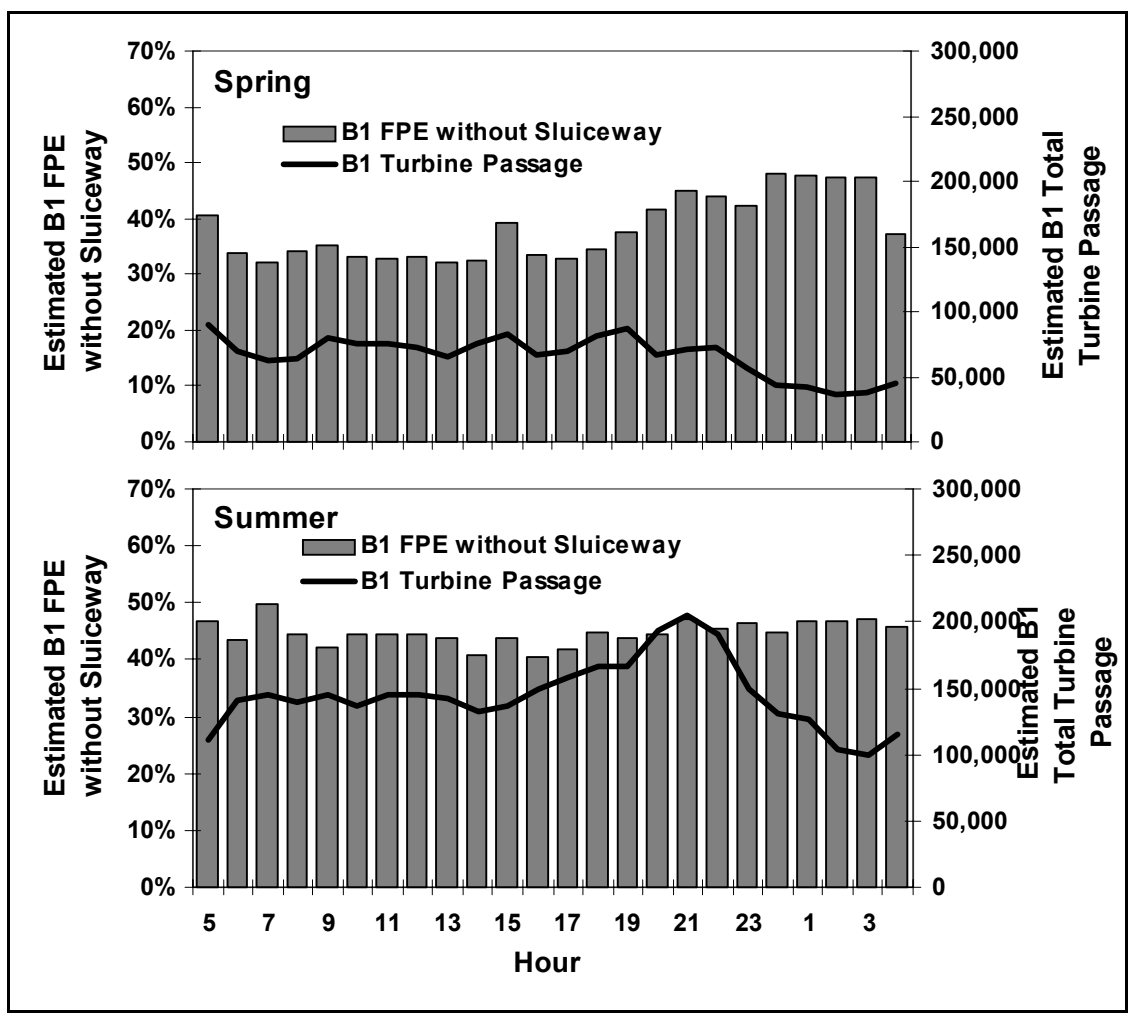

Figure 3.33. Diel Estimates of Fish Guidance Efficiency and Total Fish Passage for B1 during Spring (top) and Summer at Bonneville Dam in 2002. 
The hourly FPE of B2 generally was higher during the day than it was at night in both seasons (Figure 3.34). Fish passage was much higher from 1900 to 2200 hours in spring than at other times of the day, but the diel trend in summer was weaker than it was in spring. Summer FPE was more variable throughout the diel cycle than was spring. In summer, B2 FPE ranged from a high of about $55 \%$ in the $0800 \mathrm{~h}$ to a low of about $36 \%$ in the $0100 \mathrm{~h}$. The evening passage and FPE peak in summer was broader and less dramatic than was the evening peak in spring.

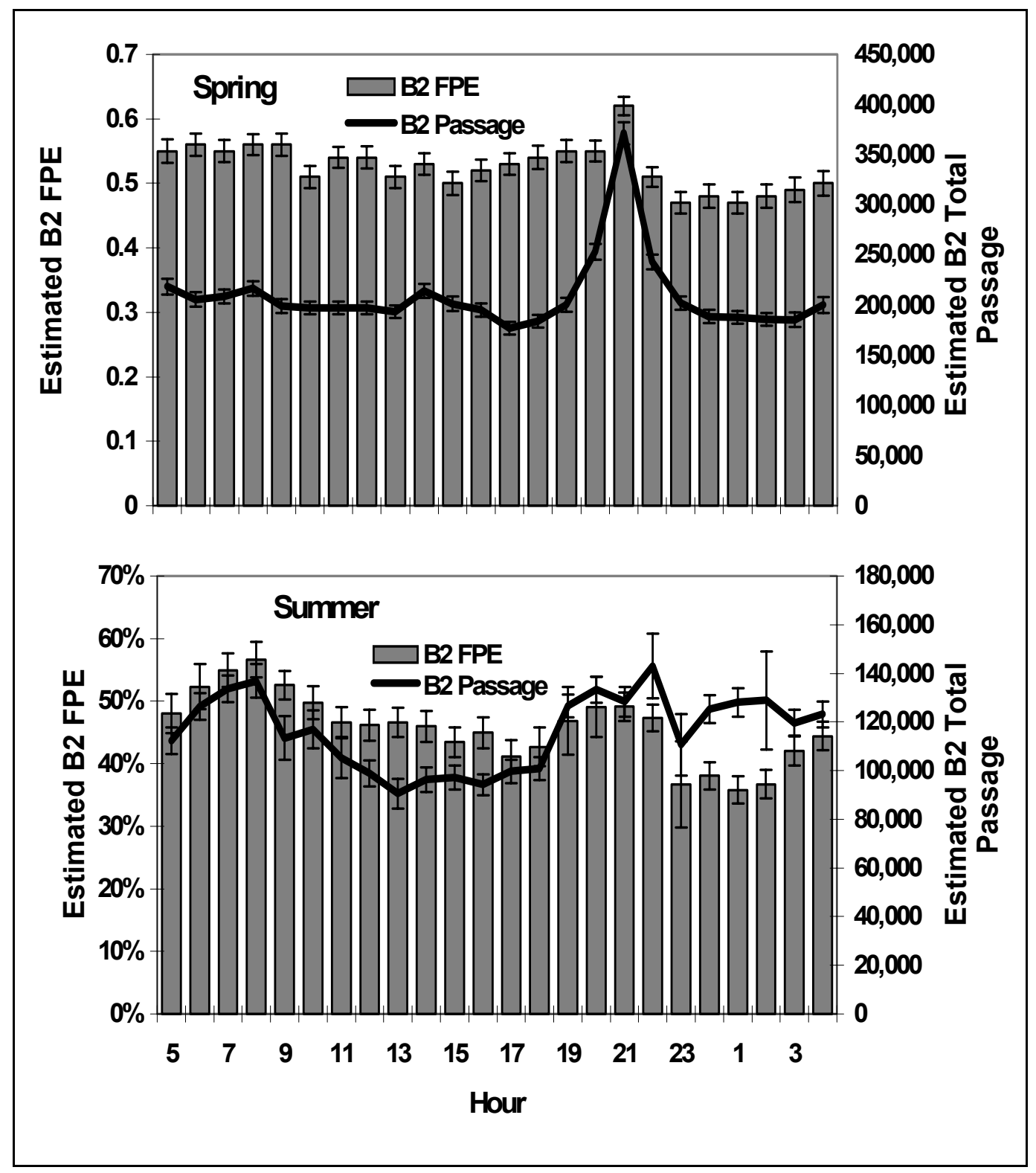

Figure 3.34. Diel Estimates of Fish Guidance Efficiency and Total Fish Passage for B2 during Spring (top) and Summer at Bonneville Dam in 2002. Error bars represent 95\% confidence limits. 


\subsection{Fish Guidance Efficiencies}

\subsubsection{Comparing Performance of Fish-Guidance Structures}

In spring and summer, the FGE of the ESBS at Unit 8 was significantly higher than was that of all STS-equipped units; the next highest were Units 15 and 17, which had modified gatewells and performed better than units with unmodified gatewells (Figure 3.35). Except for the FGE at Unit 16 in summer, there was a tendency for fish guidance at B2 (turbines 11-18) to be higher at units near the center of the powerhouse than at the ends. The effect of unit-specific FGE on the FPE of a powerhouse depends upon the distribution of fish passage as well as FGE, so we included passage estimates in Figure 3.35. The units with the highest FGEs did not happen to pass the most fish (Figure 3.35). At B2, fish passage was highest at units 11 and 12 in both seasons, whereas passage at B1 tended to be highest at units 6 and 7 in spring and at 2,6, and 7 in summer.

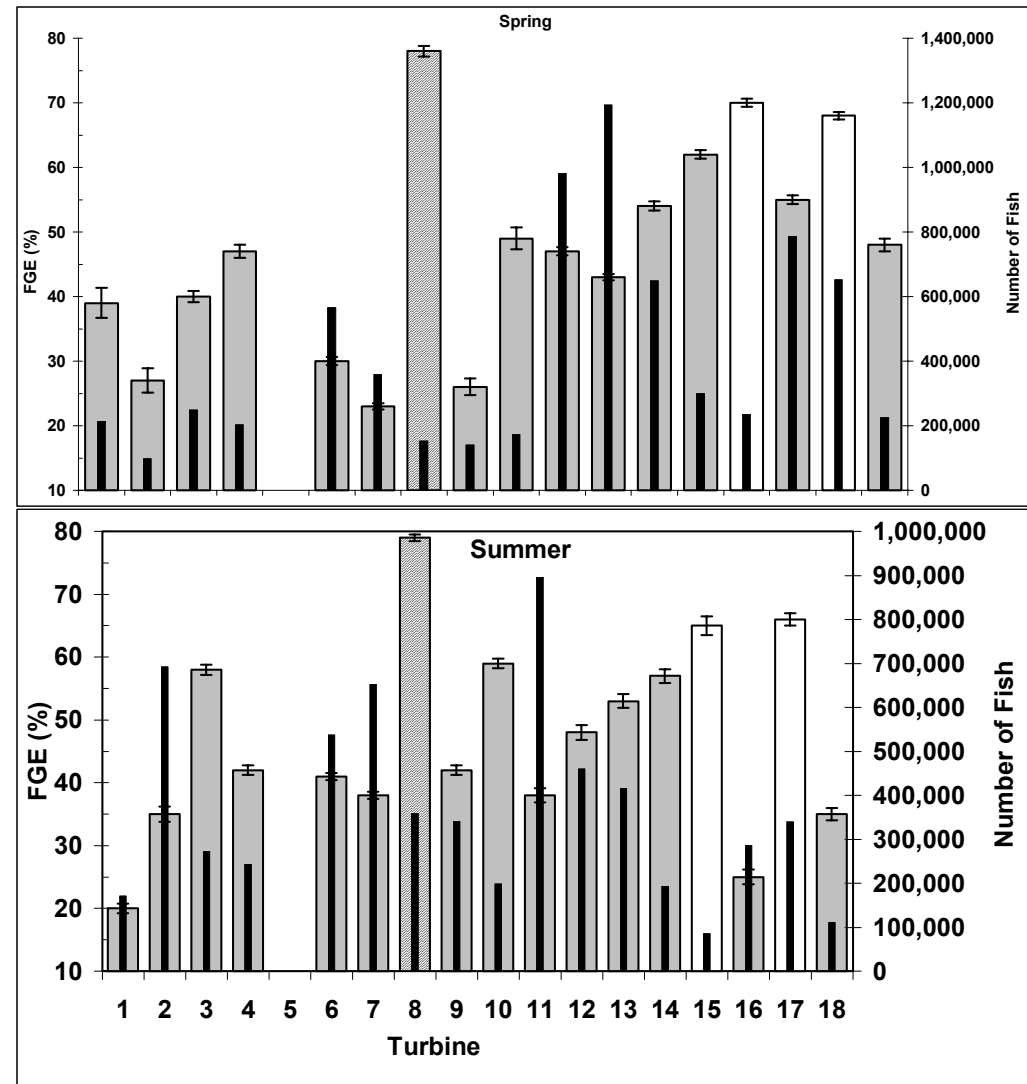

Figure 3.35. Comparison of FGE (wide bars) and Fish Passage (narrow black bars) among Turbines at Bonneville Dam in Spring and Summer 2002. Turbines 1-10 are located at B1 and turbines $11-18$ are at B2. All turbine intakes have submerged traveling screens except for intakes at Unit 8 (diagonal striped bars), which had extended submerged bar screens. The gatewells at units 15 and 17 (white bars) were modified to increase flow up the slot relative to gatewells at other units (11-14, 16, and 18). Error bars are 95\% confidence limits.

Analysis of variance tests daily passage-weighted FGE among units, intakes, slots, or TIE versus no TIE slots were all highly significant $(\mathrm{P}<0.0001)$ according to Type III sums of squares in Proc Mixed. Probabilities associated with a Chi Square statistics in Null Model Likelihood Ratio tests all indicated that 
modeling covariances to account for autocorrelation among daily estimates was not necessary, although we did so just in case.

An ANOVA on daily weighted estimates of FGE among the seven units with the highest estimates was significant, and differences in least square means indicated that Unit 8 provided significantly higher FGE than did STS-equipped units in both seasons, except for Unit 15 in spring (Table 3.3). Mean FGE at units 15 and 17 did not differ significantly in either season, but both were higher than the FGE of most other STS in both seasons (Figure 3.35 and Table 3.3). The exception included means of units 17 and 14, which did not differ in spring, and means of units 15,14 , and 10 , which did not differ in summer. Units 15 and 17 had modified gatewell slots and units 10 and 14 had standard gatewell slots.

Table 3.3. Comparison of the Seven Highest Fish Guidance Efficiency Estimates for Units at Bonneville Dam by Season. Differences in pairs of least square means with $\operatorname{Pr}>|t|<0.05$ were considered significantly different.

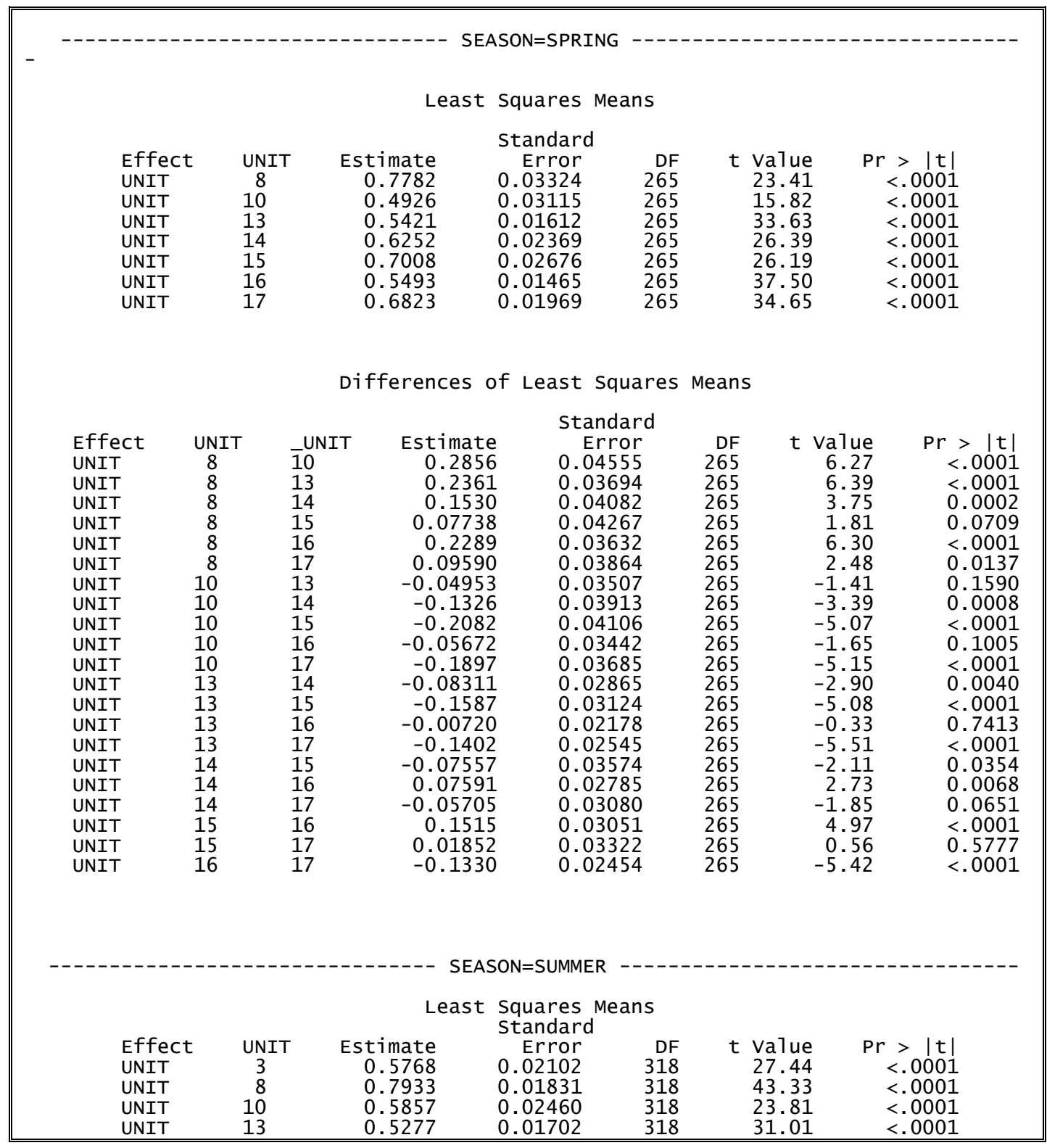




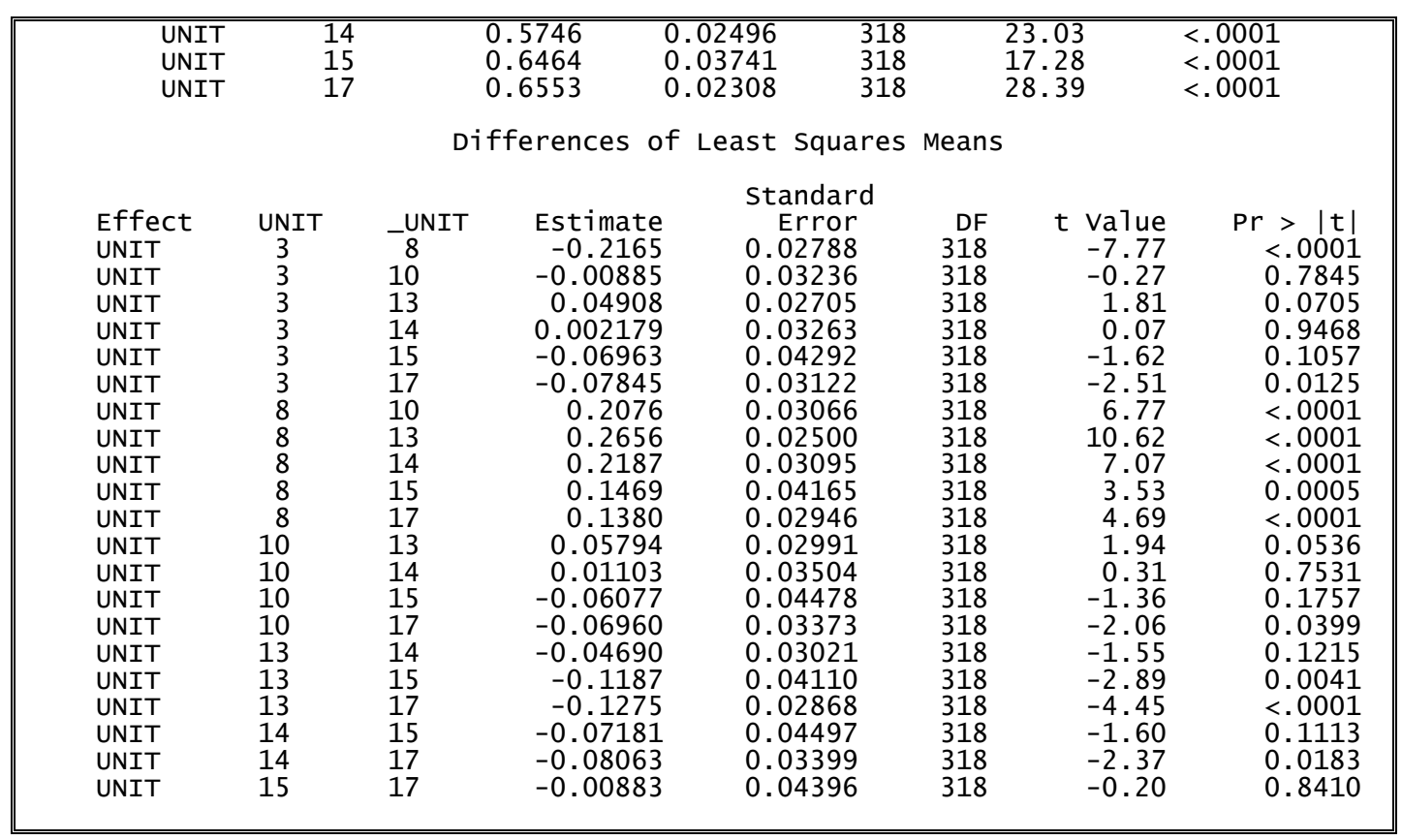

In spring, mean-daily-passage-weighted FGE was significantly higher at intakes 17B and 15B (which did not differ) than it was for all other B2 intakes sampled, except for the mean of Intake 14C, which did not differ from the mean of Intake 15B (Table 3.4). Among intakes in units with modified gatewell slots, the mean for Intake $17 \mathrm{C}$ was significantly lower than that of $15 \mathrm{~B}$ and $17 \mathrm{~B}$. The lowest means occurred at intakes nearest the ends of the powerhouse (i.e., intakes 12B, 11A, and 18A).

In summer, intakes in units with modified gatewell slots (Intakes 15B, 17B, and 17C) had mean FGEs that did not differ significantly, but they produced higher means than unmodified intakes 11A, 12B, 16B, and 18A (Table 3.4). Means for unmodified intakes $14 \mathrm{C}$ and 13A did not differ significantly from means of intakes 15B or 17C, although they were less than that estimated for modified Intake 17B. The lowest FGEs in summer occurred at unmodified intakes 16, 18, and 11, two of which were in units at the ends of the powerhouse. Within Unit 17, the FGE of Intake 17B, which was between TIES, was 14\% higher than the FGE of Intake 17C (behind a TIE) in each season, and differences were significant in spring (P = $0.0163)$ and nearly significant in summer $(\mathrm{P}=0.0700)$.

Table 3.4. Fish Guidance Efficiency of B2 Intakes by Season. Differences in pairs of least square means with $\operatorname{Pr}>|t|<0.05$ were considered significantly different.

\begin{tabular}{|c|c|c|c|c|c|c|}
\hline \multicolumn{7}{|c|}{$\begin{array}{l}\text { The Mixed Procedure } \\
\text { Least Squares Means } \\
\text { Standard }\end{array}$} \\
\hline $\begin{array}{l}\text { Effect } \\
\text { INTAKE } \\
\text { INTAKE } \\
\text { INTAKE } \\
\text { INTAKE } \\
\text { INTAKE } \\
\text { INTAKE } \\
\text { INTAKE } \\
\text { INTAKE } \\
\text { INTAKE }\end{array}$ & $\begin{array}{l}\text { INTAKE } \\
11 \mathrm{~A} \\
12 \mathrm{~B} \\
13 \mathrm{~A} \\
14 \mathrm{C} \\
15 \mathrm{~B} \\
16 \mathrm{~B} \\
17 \mathrm{~B} \\
17 \mathrm{C} \\
18 \mathrm{~A}\end{array}$ & $\begin{array}{r}\text { Estimate } \\
0.4729 \\
0.4289 \\
0.5421 \\
0.6252 \\
0.7008 \\
0.5493 \\
0.7171 \\
0.5826 \\
0.4812\end{array}$ & $\begin{array}{r}\text { Error } \\
0.01625 \\
0.01474 \\
0.01999 \\
0.02938 \\
0.03319 \\
0.01817 \\
0.02838 \\
0.04798 \\
0.03397\end{array}$ & $\begin{array}{r}\text { DF } \\
358 \\
358 \\
358 \\
358 \\
358 \\
358 \\
358 \\
358 \\
358\end{array}$ & $\begin{array}{r}\mathrm{t} \text { Value } \\
29.09 \\
29.09 \\
27.12 \\
21.28 \\
21.11 \\
30.23 \\
25.27 \\
12.14 \\
14.17\end{array}$ & $\begin{aligned} \mathrm{Pr} & >|\mathrm{t}| \\
& <.0001 \\
& <.0001 \\
& <.0001 \\
& <.0001 \\
& <.0001 \\
& <.0001 \\
& <.0001 \\
& <.0001 \\
& <.0001\end{aligned}$ \\
\hline
\end{tabular}




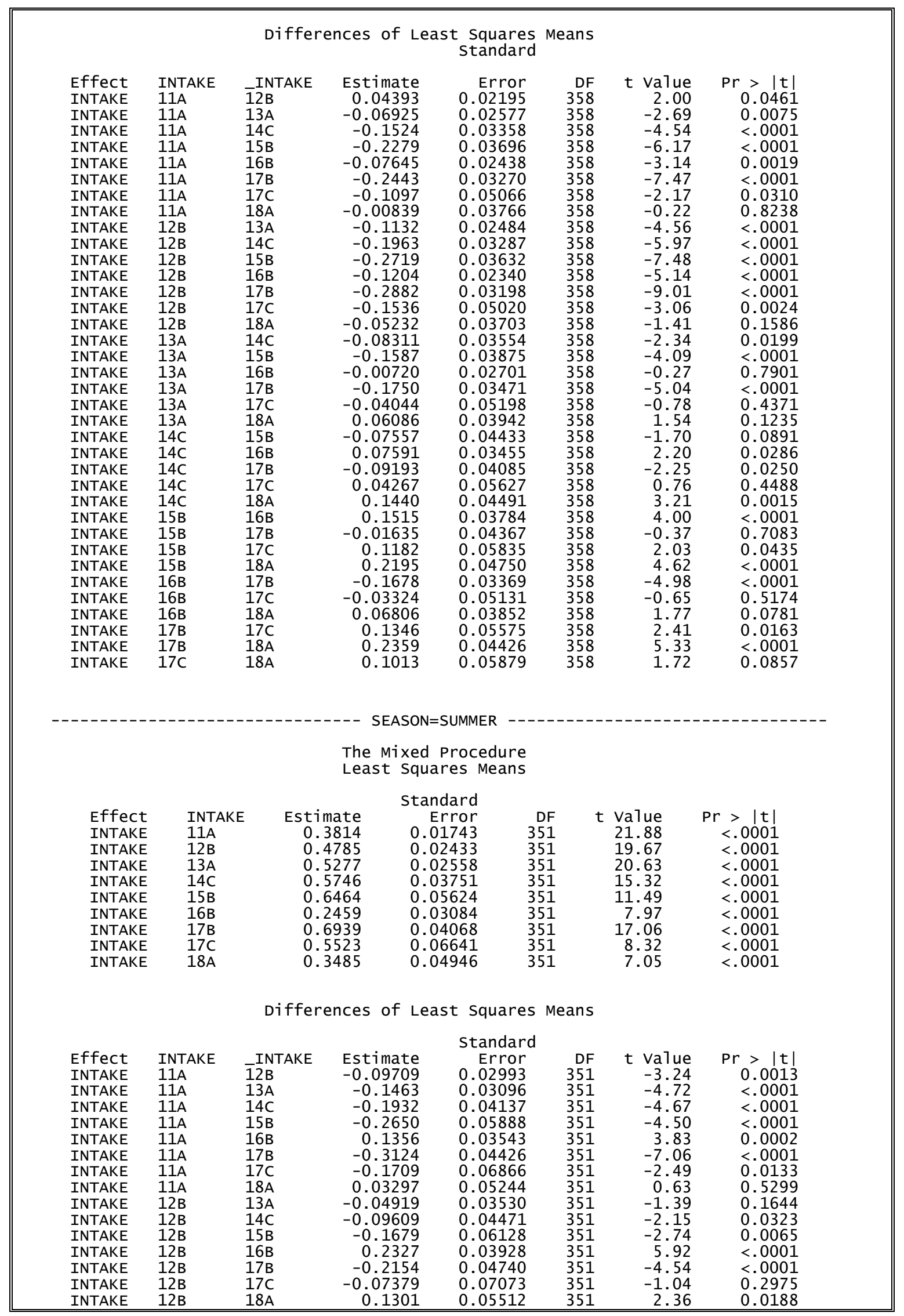




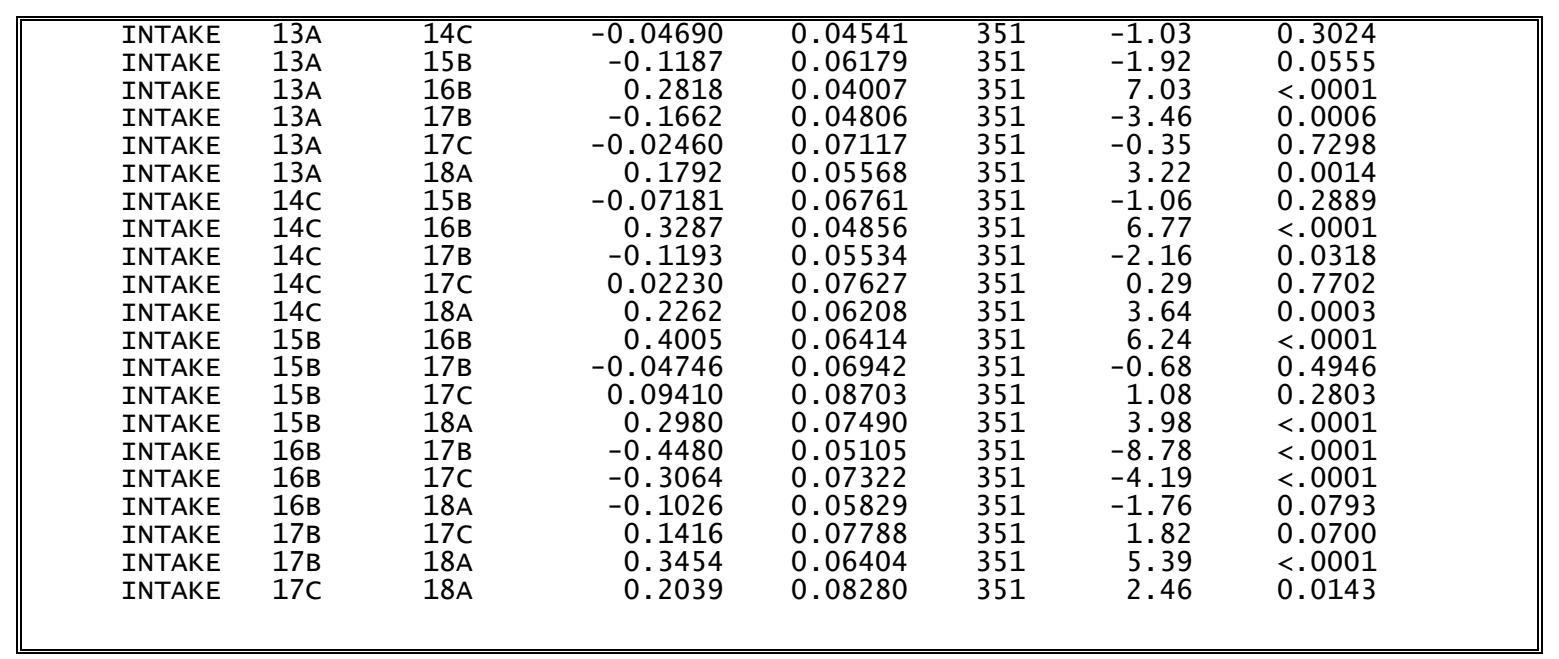

In spring and summer data, we found significant effects of SLOT (A, B, or C), TIE (between two TIES or behind a TIE), and an interaction between SLOT and TIE on FGE at B2 (Table 3.5). Differences in least square means indicated that $\mathrm{B}$ and $\mathrm{C}$ slots tended to have higher FGEs than A slots, and intakes between TIES have $8 \%$ to $9 \%$ higher means than intakes behind a TIE.

Table 3.5. Two-Way ANOVA on Effects of Slot and TIE on the FGE at B2 by Season. Differences in pairs of least square means with $\operatorname{Pr}>|t|<0.05$ were considered significantly different.

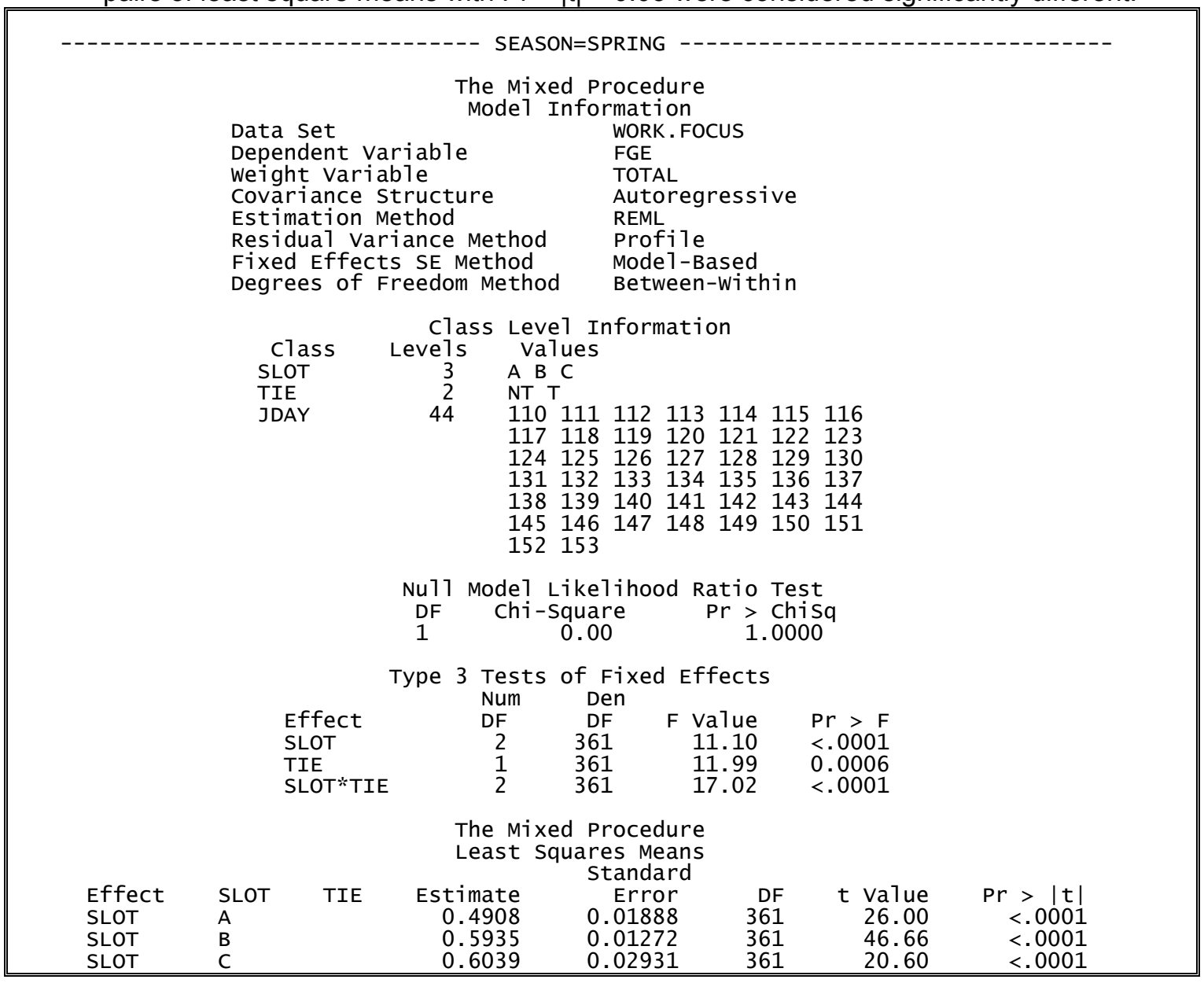




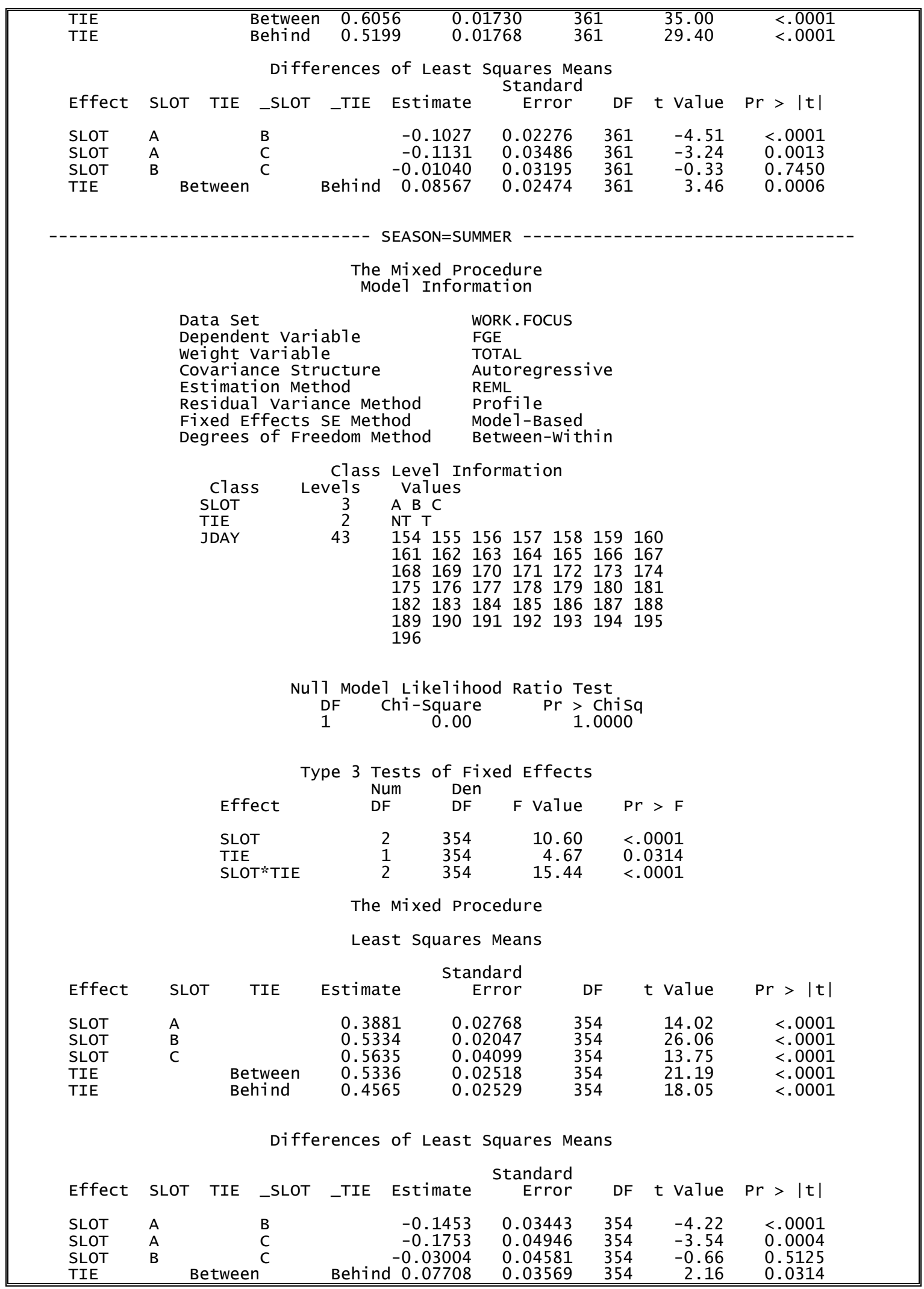




\subsubsection{Comparing FGE Estimates by Different Sampling Methods}

We sampled the Sluice Entrance 7A with hydroacoustics and optical cameras, and we had the opportunity to compare our estimates of the FGE of turbine units at B2 with estimates by two other methods. The USGS estimated FGE for every unit at B2 based upon the distribution of passage of radiotagged fish, and NOAA Fisheries estimated FGE for modified Unit 17 by gatewell dipping and fyke netting. Comparison with radio tagging estimates of FGE could be examined for more units, but sampling with the hydroacoustics and radio telemetry was not simultaneous. We did not make unitspecific comparisons of FGE for B1 because operations of most individual units were limited and sporadic. Scott Evans (USGS) provided radio telemetry estimates and John Ferguson (NOAA Fisheries) provided gatewell and fyke-net estimates presented in this section.

\subsubsection{Hydroacoustic and Camera Estimates of Sluice Passage}

Video camera counts of smolts passing into Sluice Entrance 7A were significantly correlated with hydroacoustic autotracker counts based upon 70 hours of simultaneous sampling in spring and 55 hours in summer (Figure 3.36). The best fits of lines to the points were linear in spring and quadratic in summer.
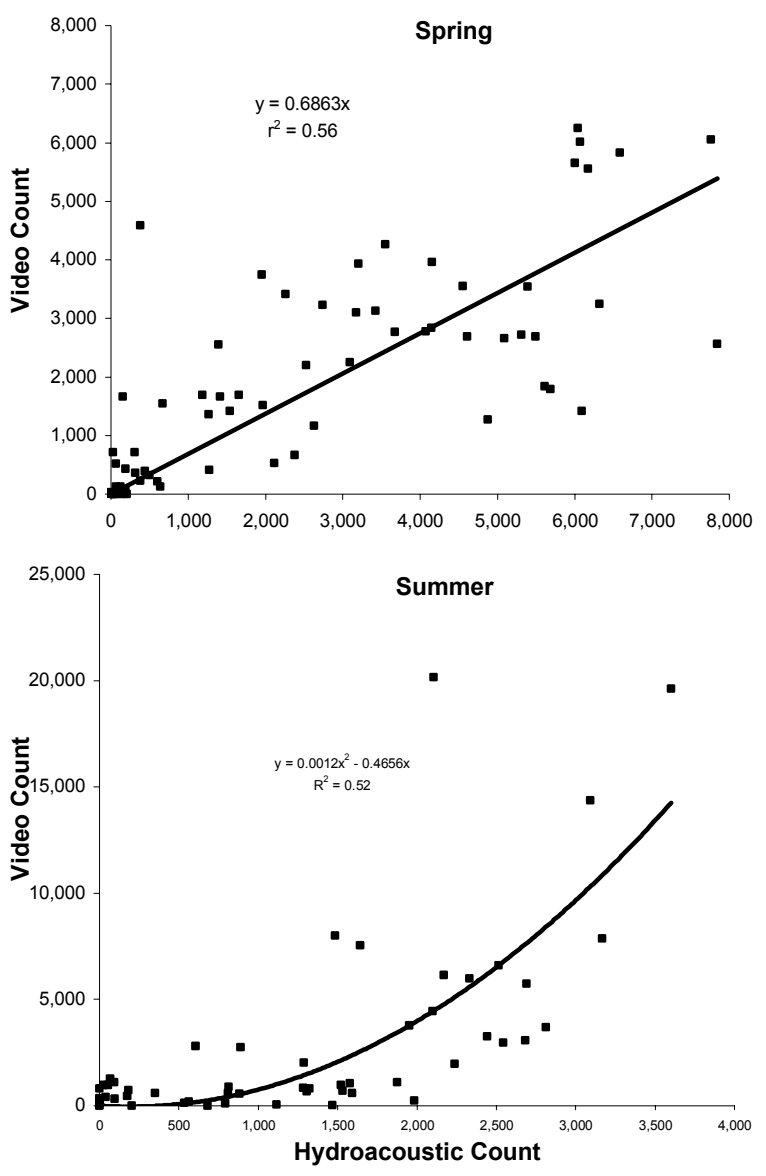

Figure 3.36. Scatter Plots of Video-Camera and Hydroacoustic-Sampling Counts of Juvenile Salmonids Passing into Sluice Entrance 7A at B1. 


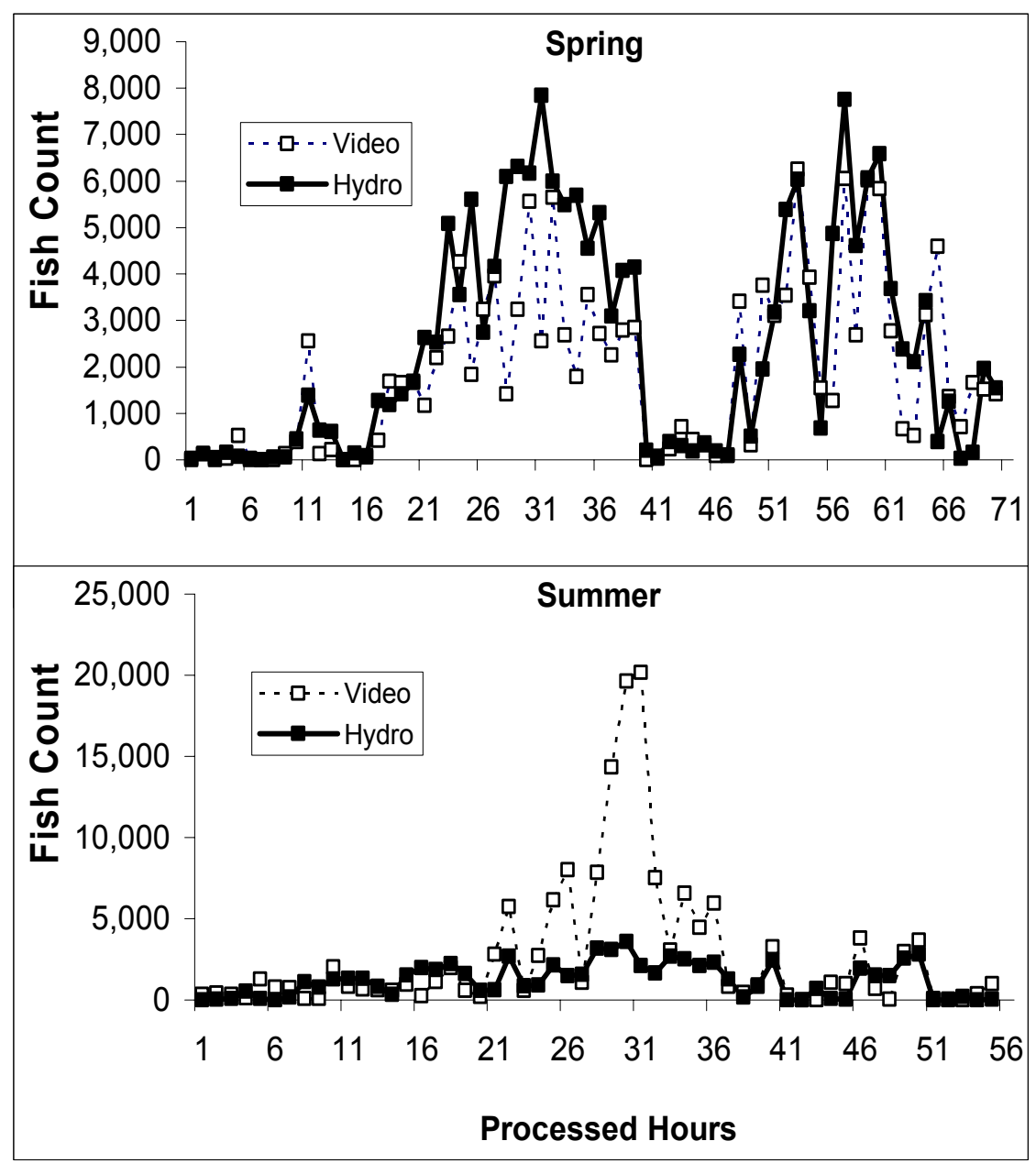

Figure 3.37. Plots of Video-camera and Hydroacoustic-Sampling Counts of Juvenile Salmonids Passing into Sluice Entrance 7A at B1 during Hours Processed in Spring and Summer

The horizontal distribution of juvenile salmonid passage into Sluiceway Entrance 7A was higher in the middle than near the sides and was slightly skewed toward the south in both spring and summer (Figure 3.38). The horizontal distributions estimated by both methods were similar, although the hydroacoustic sampling provided much finer resolution than did the four optical cameras. 


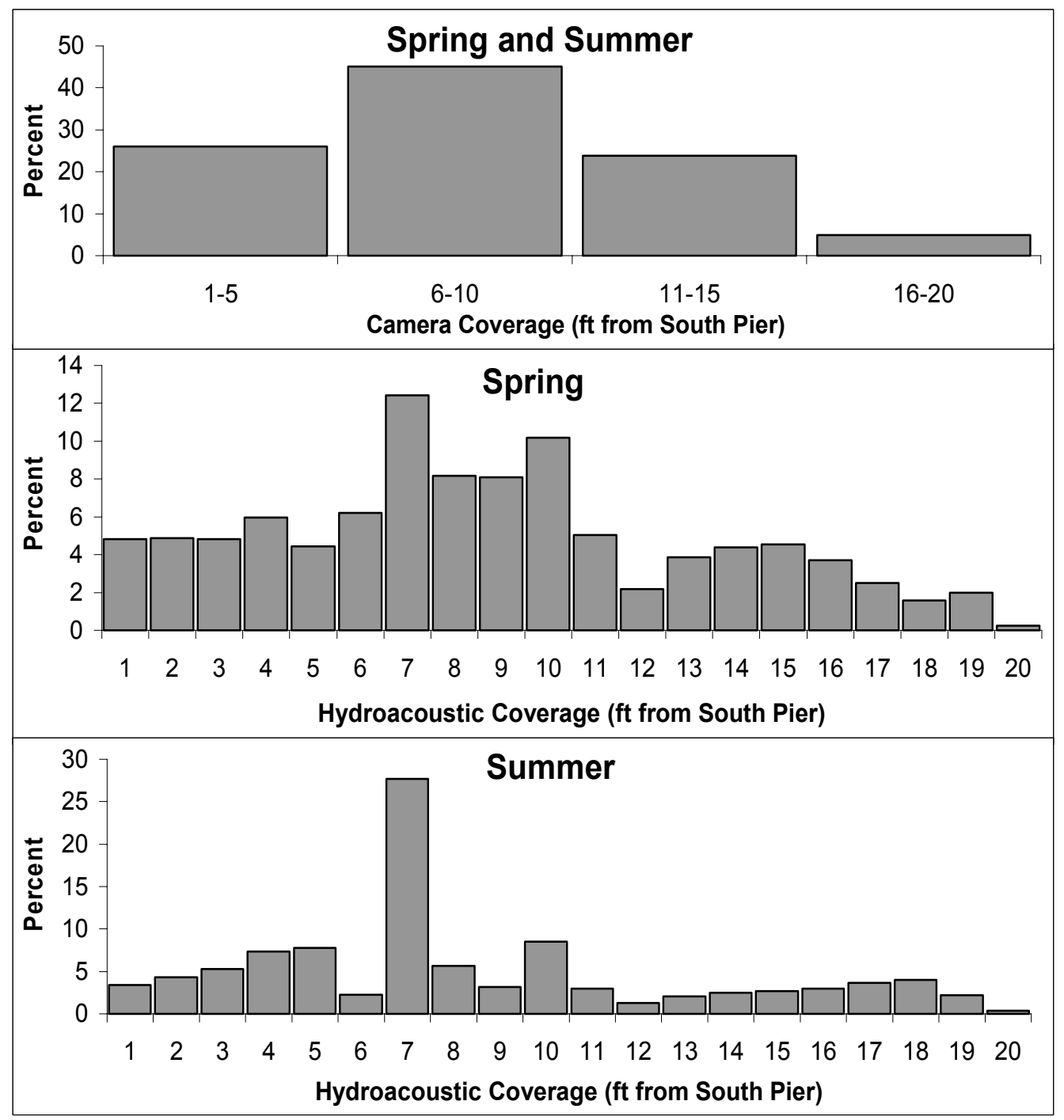

Figure 3.38. Plots of the Horizontal Distribution of Fish Passage Based upon Video-Camera Sampling (top) and Hydroacoustic Sampling (middle and bottom) of Juvenile Salmonids Passing into Sluice Entrance $7 \mathrm{~A}$ at B1

\subsubsection{Hydroacoustic and Netting Estimates at Modified Unit 17}

Hydroacoustic FGE estimates based upon nighttime sampling the same nights that 1 to 2 hour netting samples were taken by NOAA Fisheries were within $8 \%$ to $12 \%$ of ethe netting estimates in both seasons (Figure 3.39). The hydroacoustic estimates were $8 \%$ higher than netting estimates at the B slot and 12\% higher at the $\mathrm{C}$ slot in spring. They were $8 \%$ lower than netting estimates for the $\mathrm{B}$ slot in summer. Hydroacoustic sampling was not conducted in the A slot during either season, and netting was not done in the $\mathrm{C}$ slot in summer. 


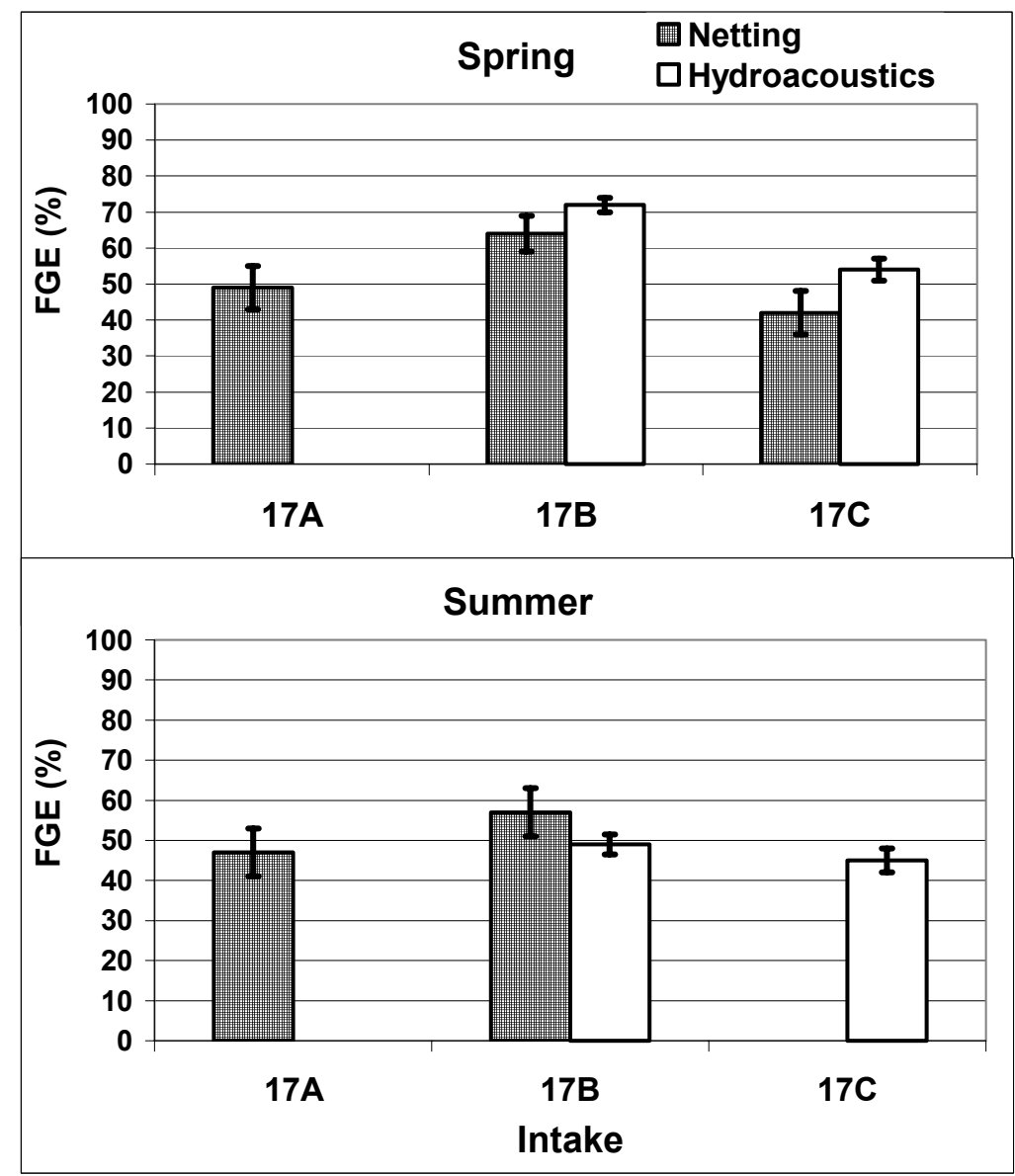

Figure 3.39. Plot of FGE Estimates Based upon Hydroacoustic Sampling in this Study and Net Sampling by NOAA Fisheries During the Same Nights in 2002. Netting was done for 1 to 2 hours beginning about 2000 hours and hydroacoustic sampling was from 2000 through 0500 hours. Vertical bars depict $95 \%$ confidence limits on the estimates.

\subsubsection{Hydroacoustic and Radio Telemetry Estimates}

In spring, we found more agreement between hydroacoustic and radio telemetry estimates of the percent distribution of fish passage among B2 units than we did between FGE estimates for specific units (compare Figures 3.40 and 3.41). Both methods detected a southerly skew in the distribution of fish passage. The estimated percentage of fish that passed through the south half of B2 was $64 \%$ by hydroacoustic sampling and $73 \%$ by radio telemetry (Figure 3.40 ). Units 11 and 12 accounted for $40 \%$ (radio telemetry) to $45 \%$ (hydroacoustics) of all fish passing at B2. The FGE estimates by both methods were within $5 \%$ and $8 \%$ of each other at units 11 and 12, respectively (Figure 3.41), where fish passage numbers were highest (Figure 3.40). The greatest deviations in estimates by the two methods occurred at the north end of the powerhouse. At Unit 17, there was a $39 \%$ difference in estimates (FGE $=66 \%$ by hydroacoustics and $27 \%$ by telemetry; Figure 3.41 ). The netting estimate by NOAA fisheries averaged $60 \%$, about $5 \%$ below the hydroacoustic estimate and $33 \%$ above the radio telemetry estimate. 

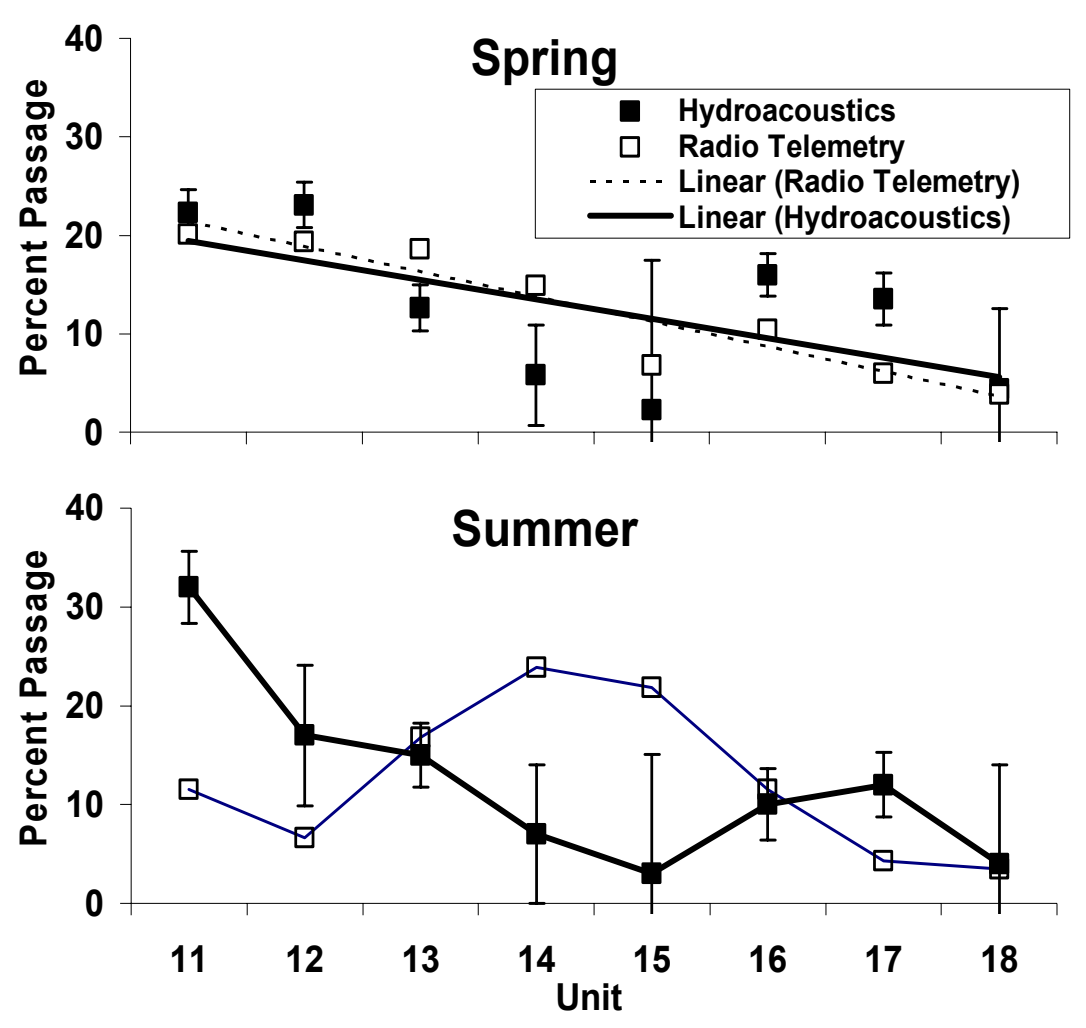

Figure 3.40. Plots of the Percent of Total Fish Passage Estimated by Hydroacoustics and Radio Telemetry at B2 in spring and summer. Estimates were based upon the percent of passage during the same days in 2002. Vertical bars on hydroacoustic estimates are $95 \%$ confidence limits.

In summer, we found more agreement between hydroacoustic and radio telemetry estimates of FGE for most B2 units than we did between respective estimates of the distribution of fish passage (compare Figures 3.40 and 3.41). Hydroacoustic estimates still showed a southerly skew in the passage distribution much as was observed in spring (Figure 3.40), but the radio telemetry data indicated that most passage was near the center of the powerhouse. The pattern in FGEs among units was similar for units 11 to 16 but the similarity ended at units 17 and 18 where hydroacoustic estimates were much higher than were the radio telemetry estimates. Estimates for units 11 to 16 were all within $15 \%$ of each other and estimates for units 12,13, and 14 were within 5\%. The netting estimate of FGE at Unit 17 by NOAA Fisheries was $14 \%$ less than the hydroacoustic estimate and $30 \%$ greater than the radio telemetry estimate. 


\section{Spring aUSGS Radio Telemetry 田 NOAA Netting}
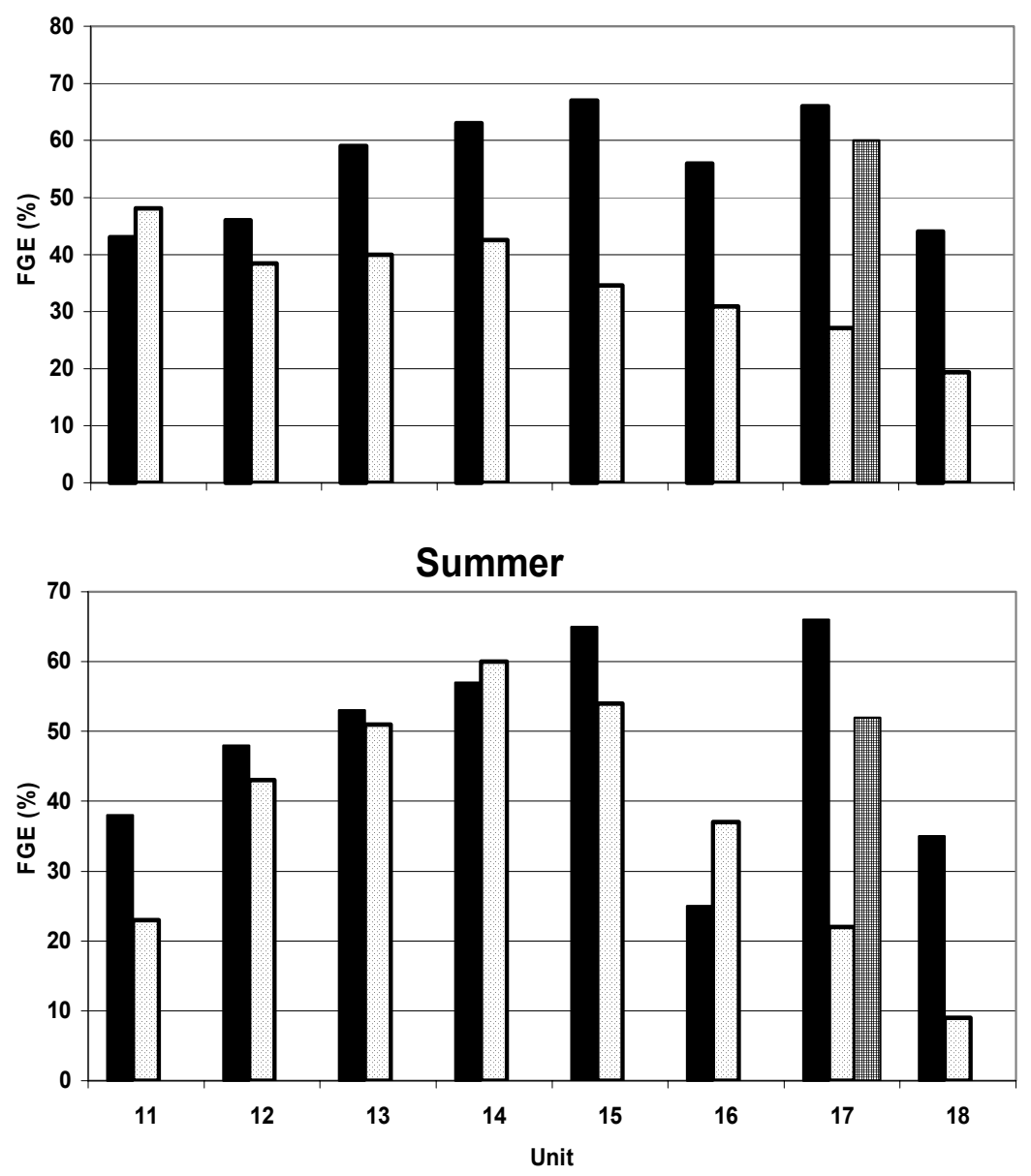

Figure 3.41. Plots of Fish Guidance Efficiency by Turbine Unit at B2 According to Sampling with Hydroacoustics, Radio Telemetry (USGS), and Netting (NOAA Fisheries). For Unit 17, the netting estimates represent the average for all intakes and species sampled and hydroacoustic estimates combined guided and unguided passage at intakes 17B and 17C.

\subsection{Gap Losses at B2 Submerged Traveling Screens}

The acoustic camera estimates of gap loss at un-modified intakes and modified Intake 17C were higher than expected (i.e., $26 \%-41 \%$ of gatewell counts and $12 \%-14 \%$ of total intake passage) from historical estimates by gap netting (1\%-2\%). Gap-losses for modified Intake 17B were closer to the 1\% netting estimates by NOAA Fisheries (Table 3.6). Intake 17B and 17C both had similar configurations including turning vanes and gap-closure devices. 
Table 3.6. Percent of Smolt-Sized Fish Lost through the Gap between the Top of the Submerged Traveling Screen and the Intake Ceiling in Modified and Un-Modified Gatewells in Spring and Summer 2002

\begin{tabular}{|c|c|c|c|c|c|c|c|}
\hline \multirow[t]{2}{*}{ Gatewell } & \multirow[t]{2}{*}{ Intake } & \multicolumn{2}{|c|}{$\begin{array}{l}\text { Fish Counted } \\
\text { \& Fate }\end{array}$} & \multicolumn{2}{|c|}{$\begin{array}{c}\text { Expanded Estimates } \\
\text { of Fate* }\end{array}$} & \multirow{2}{*}{$\begin{array}{c}\text { Estimated } \\
\text { Gap Loss } \\
(\% \text { of } \mathrm{G}) \\
\end{array}$} & \multirow{2}{*}{$\begin{array}{c}\text { Estimated } \\
\text { Gap Loss } \\
\text { (\% of Total) }\end{array}$} \\
\hline & & Gatewell & Gap & Gatewell & Gap & & \\
\hline \multicolumn{8}{|c|}{ Spring } \\
\hline Modified & 17B & 194 & 9 & 1,117 & 47 & 4.0 & 2.7 \\
\hline Un-modified & $18 \mathrm{~A}$ & 110 & 90 & 677 & 470 & 41.0 & 14.7 \\
\hline \multicolumn{8}{|c|}{ Summer } \\
\hline Modified & $17 \mathrm{C}$ & 152 & 62 & 872 & 324 & 27.1 & 12.6 \\
\hline Un-modified & $13 \mathrm{~B}$ & 149 & 67 & 969 & 340 & 26.0 & 12.5 \\
\hline
\end{tabular}

* Observed Count x Gatewell Width / [Tan (10/2) * Range]/2, which adjusts for beam diameter at the range of detection.

Our 24-h deployment of the acoustic camera on the downstream side of the uppermost trash rack at Intake 18A successfully detected fish approaching and passing above and below the STS but detected only one fish moving into the side gap between the intake wall and one side of the STS. Even with the best aiming angle, the field of view of the side gap was limited to 2 to 3 linear $\mathrm{ft}$ of the 20 - $\mathrm{ft}$-long gap that occurs on either side of the STS. A linear expansion of the one detected fish to the entire length of gap would yield only 13 to 20 fish in $24 \mathrm{~h}$. At most, this would represent $2 \%$ to $3 \%$ of the expanded gatewell count shown in Table 3.7.

\subsection{Comparison of Major Metrics from 2000 through 2003}

We compared major fish passage metrics for the three years that full-project hydroacoustic studies have been conducted because a major purpose of the multi-year effort was to establish a baseline for evaluating future management improvements (Table 3.7). We found significant differences in most metrics in two or three of the years studied. For example, Project FPE was lower in 2001 than in 2000 or 2002, as was spill efficiency. Spill effectiveness was lower in spring 2001 than it was in spring of 2000 or 2002, but it was higher in summer 2001 than it was in summer of 2002 or 2003 . The FPE of B1 was higher in 2000 than it was in 2001 or 2002. Only the B2 FGE estimates did not differ substantially among years; they were within $4 \%$ of each other in spring and within $11 \%$ of each other in summer across all three years. 
Table 3.7. Comparison of Major Fish-Passage Metrics among the Three Years of Full-Project Hydroacoustic Studies

\begin{tabular}{|c|c|c|c|}
\hline Major Passage Metric & $\begin{array}{l}2000 \\
\text { (PSC) } \\
\text { (B1 Priority) }\end{array}$ & $\begin{array}{l}2001 \\
\text { (Drought) } \\
\text { (B2 Priority) }\end{array}$ & $\begin{array}{l}2002 \\
\text { (B2 Priority) }\end{array}$ \\
\hline Spring Project FPE & $79 \pm 0.2 \%$ & $63 \pm 0.3 \%$ & $79 \pm 0.1 \%$ \\
\hline Spring B1 FPE (without Sluiceway) & $67 \pm 0.4 \%$ & $49 \pm 2.3 \%$ & $37 \pm 0.4 \%$ \\
\hline Spring B2 FPE & $54 \pm 0.8 \%$ & $57 \pm 0.3 \%$ & $53 \pm 0.3 \%$ \\
\hline Spring B2 + Spillway FPE (without B1) & N/A (B1 Priority) & $64 \pm 0.3 \%$ & $83 \pm 0.4 \%$ \\
\hline Spring Spill Efficiency & $44 \pm 0.4 \%$ & $14 \pm 0.2 \%$ & $52 \pm 0.5 \%$ \\
\hline Spring Spill Effectiveness & $1.36 \pm 0.010$ & $0.84 \pm 0.004$ & $1.08 \pm 0.010$ \\
\hline Summer Project FPE & $79 \pm 0.2 \%$ & $53 \pm 0.4 \%$ & $74 \pm 0.2 \%$ \\
\hline Summer B1 FPE (without Sluiceway) & $61 \pm 0.2 \%$ & $40 \pm 1.8 \%$ & $45 \pm 1.2 \%$ \\
\hline Summer B2 FPE & $35 \pm 2.2 \%$ & $42 \pm 0.4 \%$ & $46 \pm 0.7 \%$ \\
\hline Summer B2 + Spillway FPE (without B1) & N/A (B1 Priority) & $54 \pm 0.4 \%$ & $82 \pm 0.5 \%$ \\
\hline Summer Spill Efficiency & $49 \pm 0.4 \%$ & $20 \pm 0.3 \%$ & $42 \pm 0.5 \%$ \\
\hline Summer Spill Effectiveness & $1.03 \pm 0.01$ & $1.83 \pm 0.01$ & $0.96 \pm 0.01$ \\
\hline
\end{tabular}

\subsection{Effects of Spill Treatments on Major Metrics}

Based upon ANOVA and tests for differences in least-square means, we found that spill treatments had significant effects on most fish passage metrics (Figure 3.42 and 3.43; Appendix G).

In spring, Project FPE, spill efficiency, and B1 FPE were all higher during high spill treatments (day or night) than during low daytime treatments (Figure 3.42), although the difference was greater for Project spill efficiency (at least 23.5\%) than it was for Project FPE (7.6\%). However, spill effectiveness did not differ among the three spill treatments. Estimates of B1 FPE, based upon all days sampled, also was significantly higher during high spill treatments than it was during low spill treatments, but during eight of the days and nine of the nights of high spill, all turbines were shut down and the only passage through B1 was through the sluiceway $(\mathrm{B} 1 \mathrm{FPE}=100 \%)$. In contrast to significantly higher Project FPE and spill efficiency during high spill than during low spill, B1 FPE sluice efficiency, B1 sluice effectiveness, and B2 FPE were significantly lower during days or nights of high spill than they were during days of low spill. When day and night sluice-only operation at B1 was excluded from the analysis of variance, we found no significant difference between estimates of B1 FPE among the three spill treatments. 

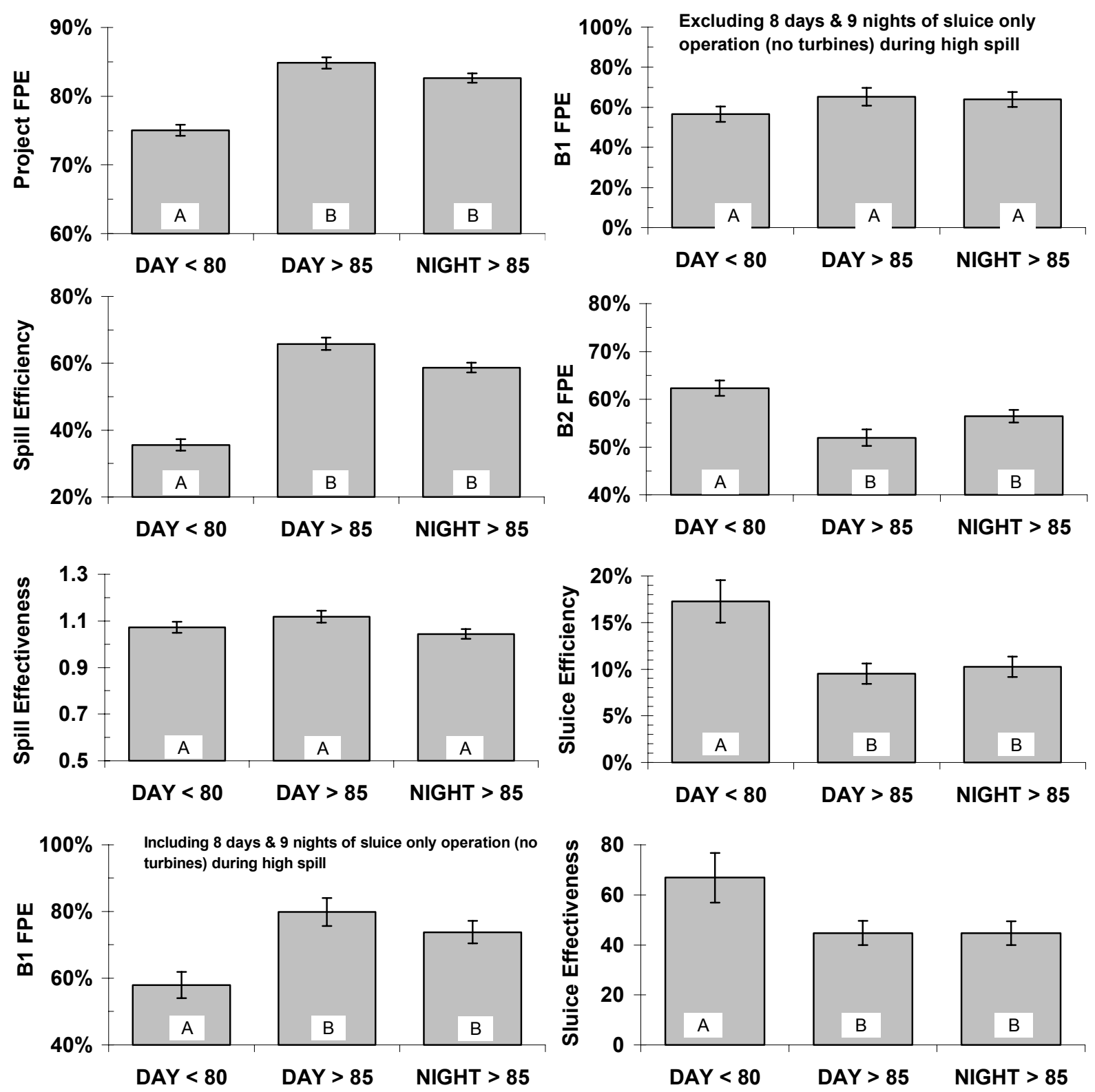

\section{Spill Treatment}

Figure 3.42. Plots of Major Passage Metrics by Spill Treatment in Spring. Bars with the same letter did not differ significantly. Error bars are standard error about the least-square mean.

In summer, high spill during the day or night also resulted in higher spill efficiency $(\geq 20.9 \%)$ and spill effectiveness ( $\geq 18.8 \%$ ) than did low spill during the day (Figure 3.43), but Project FPE did not differ significantly among the spill conditions tested. In contrast, B1 FPE, B2 FPE, B1 sluice efficiency, and B1 sluice effectiveness were significantly lower during days or nights of high spill than they were during days of low spill. 

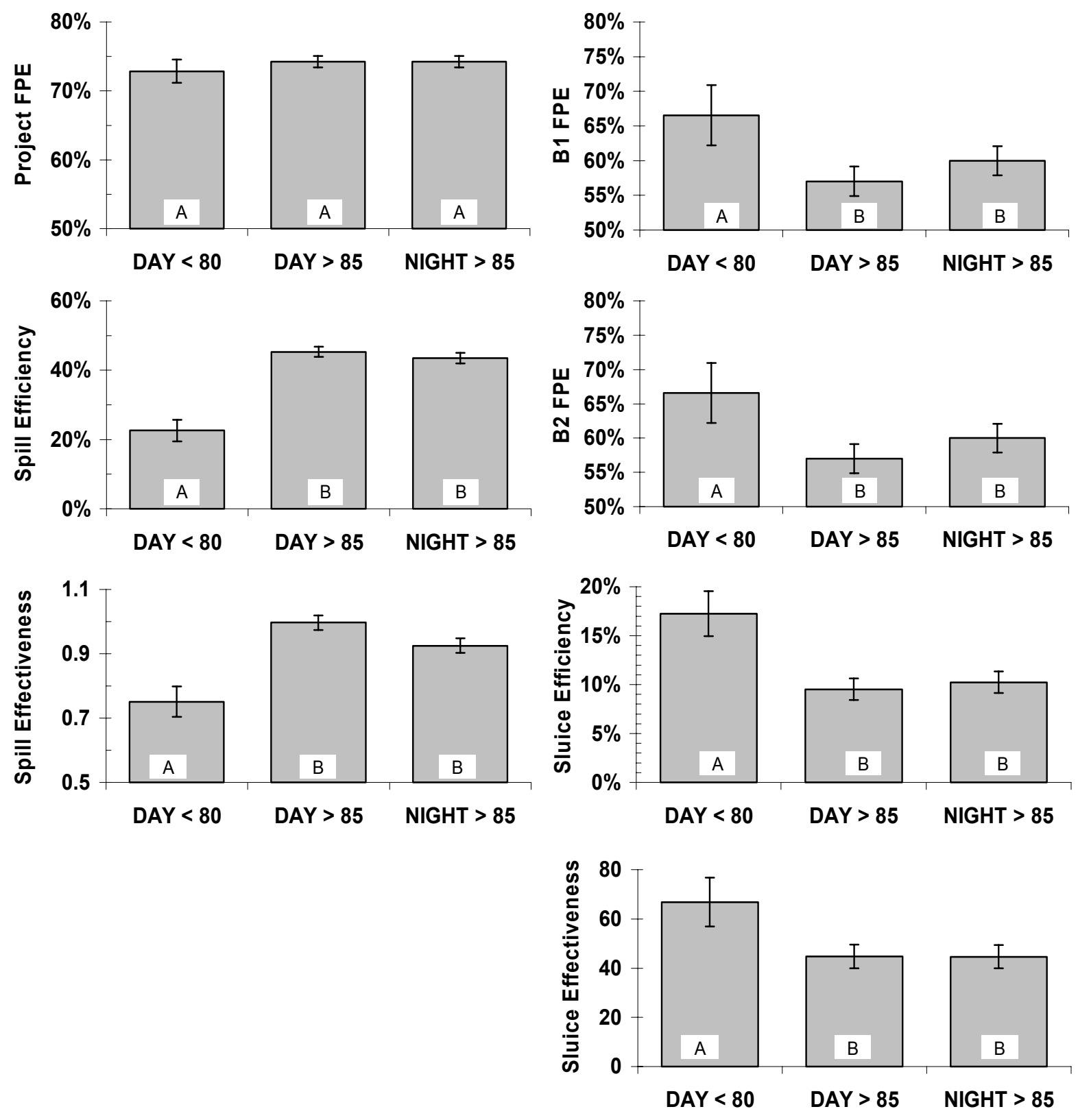

\section{Spill Condition}

Figure 3.43. Plots of Major Passage Metrics by Spill Condition in Summer. Bars with the same letter did not differ significantly. Error bars are standard error about the least-square mean. 
Hydroacoustic Evaluation of Fish Passage through Bonneville Dam in 2002 


\subsection{Discussion}

\subsection{Hydroacoustic Detectability}

The motivation for efforts to improve detectability modeling is the desire to provide hydroacoustic estimates that are quantitative as well as relative indices to fish passage. Ratio estimators such as fish guidance efficiency only require that the hydroacoustic beams sampling guided and unguided fish have equal detectability so that the ratios of counts, not necessarily the counts themselves, are accurate. Combining counts from different locations such as powerhouses and a spillway also requires equal detectability so that counts from different locations are comparable, although the counts themselves may not be accurate. Nevertheless, accurate counts estimated by proper expansion of detected fish have the potential to provide estimates with inherent quantitative value as well as providing acceptable relative estimates.

We are comfortable that detectability was adequate at all deployments in 2002 because most effective beam angles were near the nominal beam or higher over ranges that fish were counted. Exceptions included guided fish at Unit 8 where sampling had to begin within $2 \mathrm{~m}$ of the up-looking transducer and at the sluiceway where sampling began within $2.9 \mathrm{~m}$ of the transducer. Nevertheless, spatial expansions incorporated effective beam angle so there was appropriate compensation for lower detectability at short ranges.

Apparently, our pulse repetition rate of $25 \mathrm{pings} / \mathrm{s}$ at the spillway was adequate for even the highest spill discharge observed in 2002. Loss of detectability with increased spill-bay discharge could result in the misinterpretation of relations between spill efficiency or effectiveness and spill discharge, but an examination of the mean number of echoes per fish trace and fish counts by discharge range suggested that this was not a problem. Lower detectability may result if higher fish speed through the beam at higher discharge resulted in fewer than the minimum number of echoes. The average number of echoes per fish trace detected at spill bays fell from 9.9 at 3,000-6,000 cfs to 8.7 at 6,000-9,000 cfs to 8.0 at 9,000-12,000 cfs to 7.4 at 12,000-14,000 cfs, the highest discharge observed. Nevertheless, 7.4 echoes per trace are well above the 4-echo minimum criterion. Another way to check the adequacy of detectability is to examine numbers of fish per spill-bay hour as a function of discharge volume. An ANOVA and multiple-range test indicated that the average hourly fish count was highest at the highest discharge range in summer when the 2002 hydrograph peaked (Table 4.1).

\subsection{Validation of Autotracking Hydroacoustic Data}

The high coefficients of determination for regressions of human-based counts on autotracker counts for each deployment (Figures 3.2, 3.3, and 3.4) indicate that the estimates were closely related. Rather than pooling data by deployment type, we adjusted autotracker counts on a channel specific basis because some of the regression slopes for different channels of a similar deployment were different. Differences likely result from channel-specific differences in noise regimes. Slopes of most regression lines of mean manual tracker count on autotracker counts were $<1$, so corrections of autotracker counts usually were downward offsetting the tendency of the autotracker to overestimate passage. We consider this method of evaluation and correction, when based on large samples of data analyzed and compared at the level of 
Table 4.1. Analysis of Variance Table and Multiple Range Comparison of Average Hourly Fish Counts by Spill Bay Discharge Range

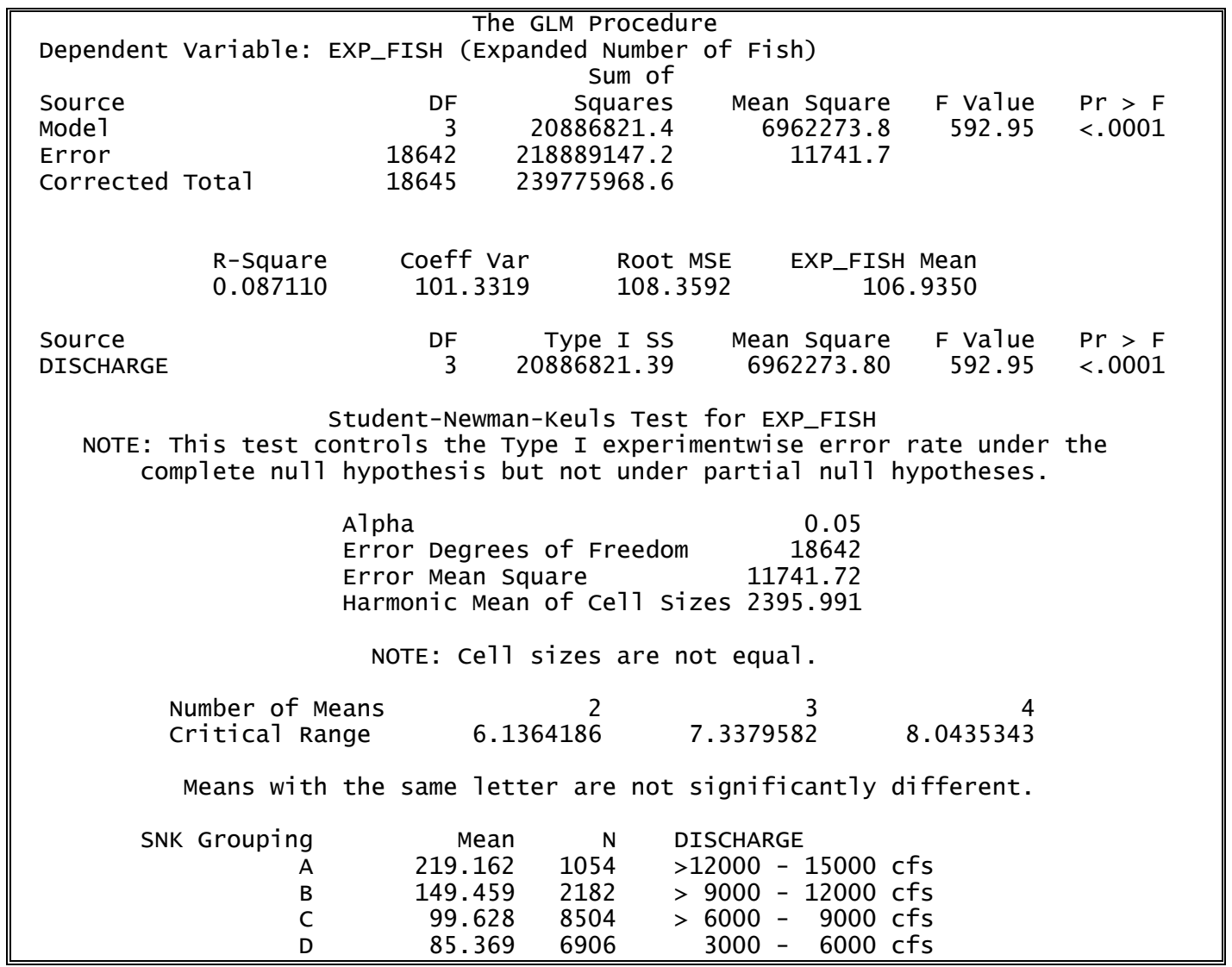

channel hour, to be an adequate method of quality control and assurance for our autotracked estimates. This approach is not only more economical but qualitatively superior to manual tracking by individual humans.

\subsection{Fish Swimming Direction and Implications for Sluice Management}

Even at high forebay elevations, Sluiceway Entrance 10C does not pass much water (Figure 4.1) and smolts congregating and milling there likely are more vulnerable to predation than they would be at other entrances. The low flow at Entrance 10C resulted from limited channel capacity at the most upstream location along the sluiceway channel. The number of hydroacoustic detections of smolt-sized fish at Entrance 10C usually was higher than that at Entrance 7A, but the difference most likely resulted from multiple detections at 10C. As many fish were detected moving upstream as downstream at that entrance in spring, and the net flux of smolts in a downstream direction was only $18 \%$ in summer. We could and did not make passage estimates for Entrance 10C. In contrast, flow into Entrance 7A was unimpeded by channel capacity and most detected smolts $(88.4 \%$ in spring and $71 \%$ in summer) were moving downstream into the entrance. 
We recommend that an alternate entrance located further down the ice and trash sluiceway channel be opened instead of Entrance 10C in the future. Good choices include an entrance at units 5 on the south side of the pier between units 6 and 7 and another entrance near unit 1 or 2. Previous mobile sampling indicated high concentrations of fish upstream of units 4-6 near the center of B1 and south of the pier between units 6 and 7 (Ploskey et al. 1998). Forebay circulation south of unit 4 is toward the south.

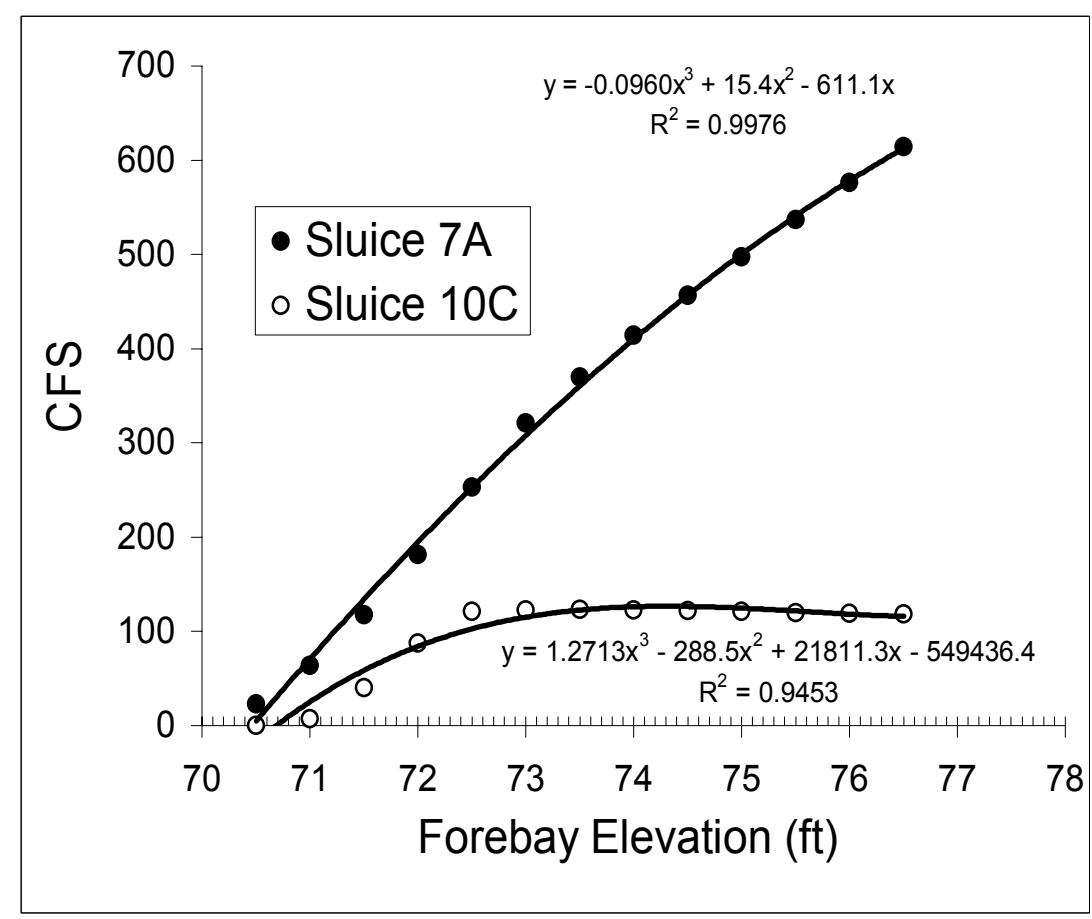

Figure 4.1. Relations between Entrance Flow and Forebay Elevations at Sluiceway Entrances 7A and $10 \mathrm{C}$ at B1. Flows estimates were calculated from polynomials derived from model data provided by Kyle McCune (USAE District, Portland).

\subsection{Major Passage Metrics}

This 2002 passage study made the third consecutive year in which we produced full-project estimates of juvenile fish passage at Bonneville Dam. Such a large data set should provide a very useful baseline against which to measure future efforts to improve fish passage at the Project. But a large hydropower project is not a laboratory and each passage season and year is unique in terms of fish populations, passage conditions, dam operations, and sampling methods. In the past three years there has been one year (2000) that involved evaluation of a prototype surface collector, one year of severe drought and unusually high power generation demand (2001) and one year with episodes of unusually high spillway discharge superimposed on experimental spillway discharge manipulation (2002). In 2000, B1 had generation priority whereas in the subsequent two years priority went to B2. In the drought year, 2001, a greater than usual proportion of juvenile fish were captured for transport. In 2002, there was an unusually large crop of naturally produced sockeye $(O$. nerka) smolts. Over the three years of sampling we have improved our range of coverage. In light of these and other considerations, generalizations should be made cautiously. 


\subsubsection{Project and Powerhouse FPE}

Fish passage efficiency (FPE) is the primary fish passage metric. To the extent that turbine passage is more injurious or stressful to fish than are the other routes (spillway, juvenile bypass system, and sluiceway), and not considering delay, it is an index of the success with which fish pass a structure or a project. Since FPE can pertain to either a whole project or to a portion of the project we have presented 2002 spring and summer FPE data in several combinations of structures (Figure 3.8 in Results). Data on the horizontal distribution of discharge and estimated fish passage are presented in the Results section (Section 3.5.1) but for easy reference to the discussion of Project and partial FPEs we present proportions of project discharge and estimated fish passage in Figure 4.2.

The most immediately noticeable thing about Figure 4.2 is that the B1 sluiceway passed a very large proportion of the estimated total project fish passage (just over $6 \%$ in spring and nearly $11 \%$ in summer) with remarkably little water (less than three tenths of one percent of the entire project discharge in each season). Even that discharge is an overestimate of the sluiceway discharge that was actually attracting and passing fish. Since our split-beam data indicated that there was little or no net passage into the overflow weir at Intake 10C, these estimates are only of fish passage at the weir at Intake 7A, which passed a great many fish in very little water. Estimated proportions of fish and water passed through the spillway were similar in spring and summer. The turbines at B1 passed a higher proportion of fish than of water but at B2 the proportion of water was higher than the proportion of fish.
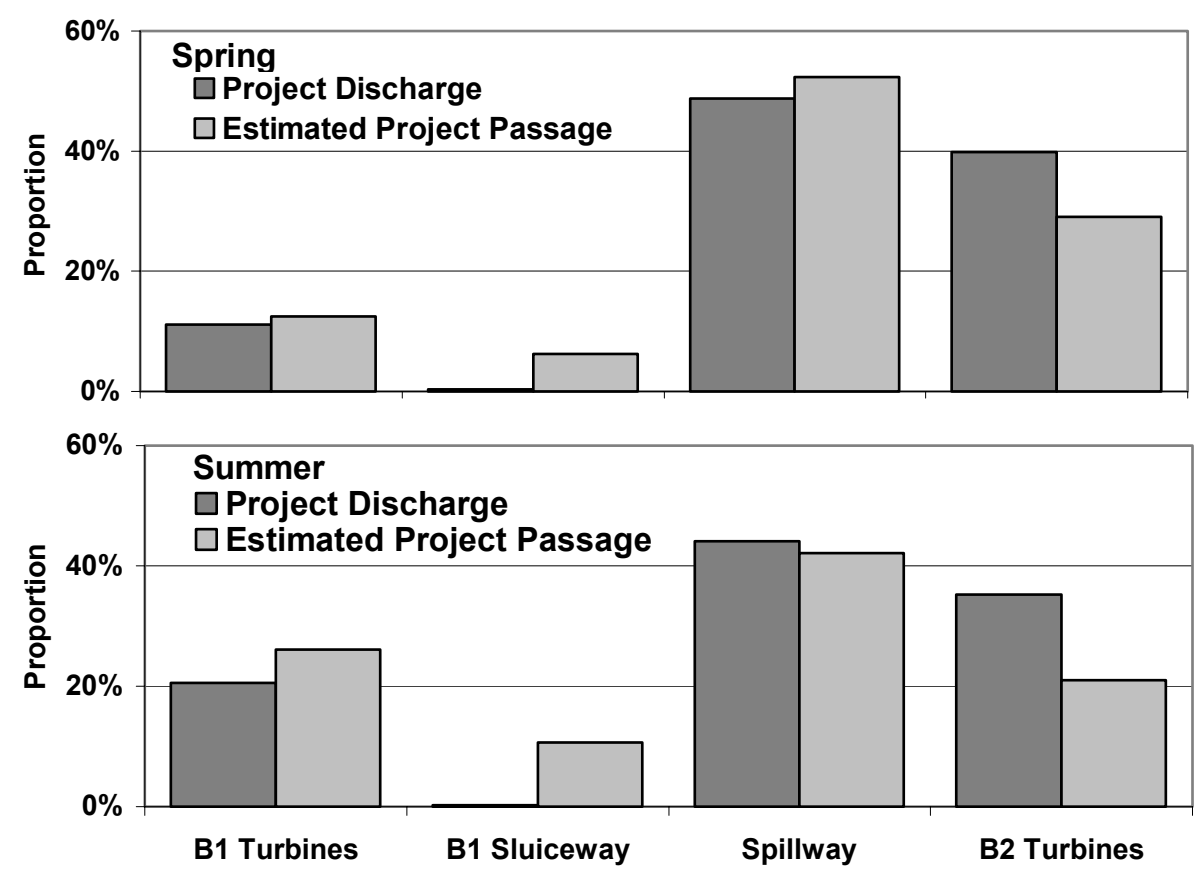

Figure 4.2. Distribution of Project Discharge and Estimated Fish Passage through Different Structures at Bonneville Dam in Spring and Summer of 2002

Although B1 turbines had considerably lower FGEs than did B2 turbines, the B1 FPE was $8 \%$ higher in spring and $15 \%$ higher in summer than was B2 FGE because of the very effective passage at sluiceway entrance 7A. However, as in 2001, B1 turbines ran so little and so sporadically that conclusions from the 
data should be made cautiously. Units at B1 ran only $30 \%$ of all possible unit hours in spring and $65 \%$ in summer. Caution also is required in comparing B1 metrics in 2001 and 2002, because units toward the center of B1 ran more than units toward the ends in spring 2002 (Figure 3.16), whereas the opposite was true in spring 2001.

We also calculated Project-wide metrics based solely upon data from B2 and the spillway (ignoring fish passage at B1), but we uncomfortable trying to infer an effect of a B1 shut done from those data because B1 units ran $30 \%$ of all possible unit hours in spring and $65 \%$ of all hours in summer. This is quite different than no B1 operation. If B1 were truly off or most fish traveling down the Oregon side of the river were somehow kept from entering the B1 forebay, Project FPE and spill efficiency might be higher than what we can calculate by ignoring B1 fish passage. Our calculations cannot account for fish densities in the river, the effect of density on fish behavior, or the closer proximity of fish passing down the Oregon side of the river to the spillway than to B2. The density of fish passage at B1 was higher than it was at the spillway or B2, so eliminating or reducing passage at B1 could greatly increase Project FPE and spill efficiency. Our exercise in computing FPE for only the spillway and B2 inevitably produces estimates considerably higher than those that are computed for the entire project, but the same result occurs if only B1 and the spillway are used in calculations. Of course the turbine units at B2 were off only about $18 \%$ of all possible unit hours in spring and $11 \%$ in summer, so it is less logical to ignore B2. Given the narrow entrance to the B1 forebay and the high density of fish passage at B1, we recommend that managers experiment with behavioral ways to shunt fish to the spillway, e.g., turbulence producing propellers.

\subsubsection{Spill Efficiency and Spill Effectiveness}

There may be reasons for given generation priority to one powerhouse over the other (e.g., differences in survival), but the decision should not be made solely based upon FPE estimates made from ignoring one or the other powerhouse for reasons described in the previous paragraph. Of course, actually operating the project with only one powerhouse could have important consequences for generation and water quality as well as fish passage. As is the case with the FPE estimates, computing spill efficiency and effectiveness for just one powerhouse and the spillway, regardless of which powerhouse is chosen, results in substantially higher estimates because the spill passage estimate becomes a greater proportion of total passage estimate. In this case, ignoring B2 increases the spill efficiency a great deal $(22 \%)$ in spring and substantially in summer (12\%) but ignoring B1 had a similar effect in the opposite seasons, raising spill efficiency $12 \%$ in spring and $25 \%$ in summer. For spill effectiveness, the result of ignoring either powerhouse was consistent across seasons. Just B1 and the spillway had lower spill effectiveness estimates than did the whole project ( 0.91 in spring and 0.80 in summer, 0.16 lower in both seasons) whereas just B2 and the spillway had higher spill effectiveness estimates (1.17 or 0.10 higher in spring and 1.20 or 0.24 higher in summer).

\subsubsection{Effects of Spillway Discharge on Spillway Fish Passage}

Results suggest that there may be an optimal spillway discharge rate above which not many more or even fewer fish are passed by spill, which is consistent with our previous findings, see Ploskey et al. 2001b on The Dalles Dam and 2002b and 2002c on Bonneville Dam. Figure 3.10 shows the linear regressions of hourly estimated spillway passage against hourly spillway discharge in spring and summer of 2002 at Bonneville Dam. There is often very high variability in spillway fish passage among hours 
with the same discharge. This is the case even when spillway passage is normalized for fish availability by dividing by total project estimated passage. In spring of 2002, there was a positive association between hourly spillway discharge and hourly estimated spillway passage, but by far the highest estimated spillway passage occurred at around $150 \mathrm{kcfs}$.

Higher spill events were fairly rare in spring and so sample bias may be important. However, hourly spillway discharge over 160,000 cfs was never associated with estimated spillway passage of more than 15 thousand fish. In contrast, there were many hours with spillway discharge of 145,000-160,000 cfs that passed between 20 thousand and almost 50 thousand fish. In summer, the hourly discharge explained $30 \%$ more of the variation in spillway passage than it did in spring (Figure 3.10), probably because of inclusion of a much higher range in discharge than in spring. Most of the exceptionally high spillway discharge hours occurred early in the summer and at those levels could include an increased proportion of fallback of American shad as well as juvenile salmonids. By the start of summer over 380 thousand upmigrating adult American shad had passed upstream of Bonneville Dam. Figure 4.3 also shows that while spillway passage very loosely tracks spillway discharge there are many cases where high spill does not result in high estimated spillway passage. In contrast, on the $23^{\text {rd }}$ of April there was a very high spillway passage event that occurred when spill was high but no higher than at many other times with much lower estimated passage.

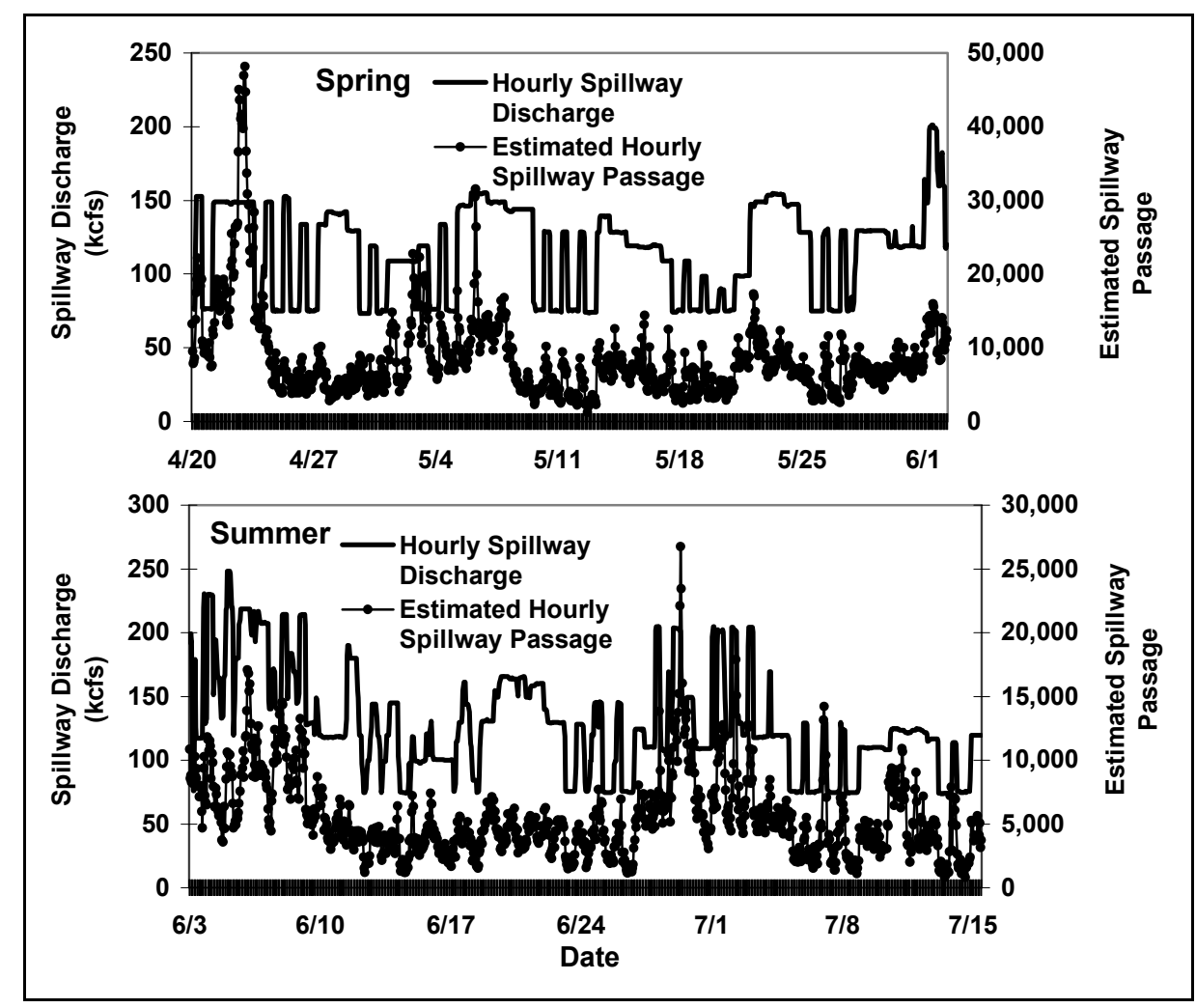

Figure 4.3. Time Histories of Spillway Discharge and Estimated Spillway Passage at Bonneville Dam in Spring and Summer of 2002. The horizontal axis is marked in weekly increments. Data are hourly hydroacoustic estimates and operational data from the Bonneville Project. 


\subsubsection{Effects of Spill Percent and Discharge on Spill Efficiency and Project FPE}

Relations of spill efficiency and FPE as a function of percent spill and spill discharge suggest that percent spill is more important than is the amount of spill for achieving benefits. Relations to percent spill are equally well fit by linear or quadratic relations, but relations to spill discharge are often better fit with quadratic equations. Therefore, the amount of control available to operators is critical and that is a function of the annual hydrograph and the need for generation.

The regression of hourly spill efficiency and Project FPE against percent spill (Figures 3.11 and 3.12) reveals close linear relationships in both spring and summer. The spill efficiency relation is always more significant than is the FPE relation because FPE depends upon other factors like turbine FGE and sluice efficiency. Spill efficiency is the spillway passage normalized for fish availability for passage and this explains why relations of efficiencies with spill percent or discharge are usually better than are relations of fish passage to the same spill variables. The relatively poor fit between hourly spill and spillway passage is to some extent due to high spill discharge hours when relatively few fish were available for passage at the project. Hourly spill efficiency tracks hourly spill discharge better than hourly FPE does (compare Figures 4.4 and 4.5).

Little operational control and lower turbine FGEs at B2 may explain why the relation between Project FPE and percent spill was much more significant in spring than in summer (Figure 3.12). When the hydrograph was below saturation in spring, operators were able to achieve very high spill proportions and FPE by shutting down turbine units, but this level of control was much less in summer when high river flow had to be more evenly distributed among turbines and the spillway (Figure 4.5). Turbine FGEs usually are lower in summer than they are in spring and this was true at B2 in 2002. If operators had been able to exercise more control over the distribution of flow in summer, there would have been more FGE estimates at high percent spill that could have strengthened the relation in summer. 

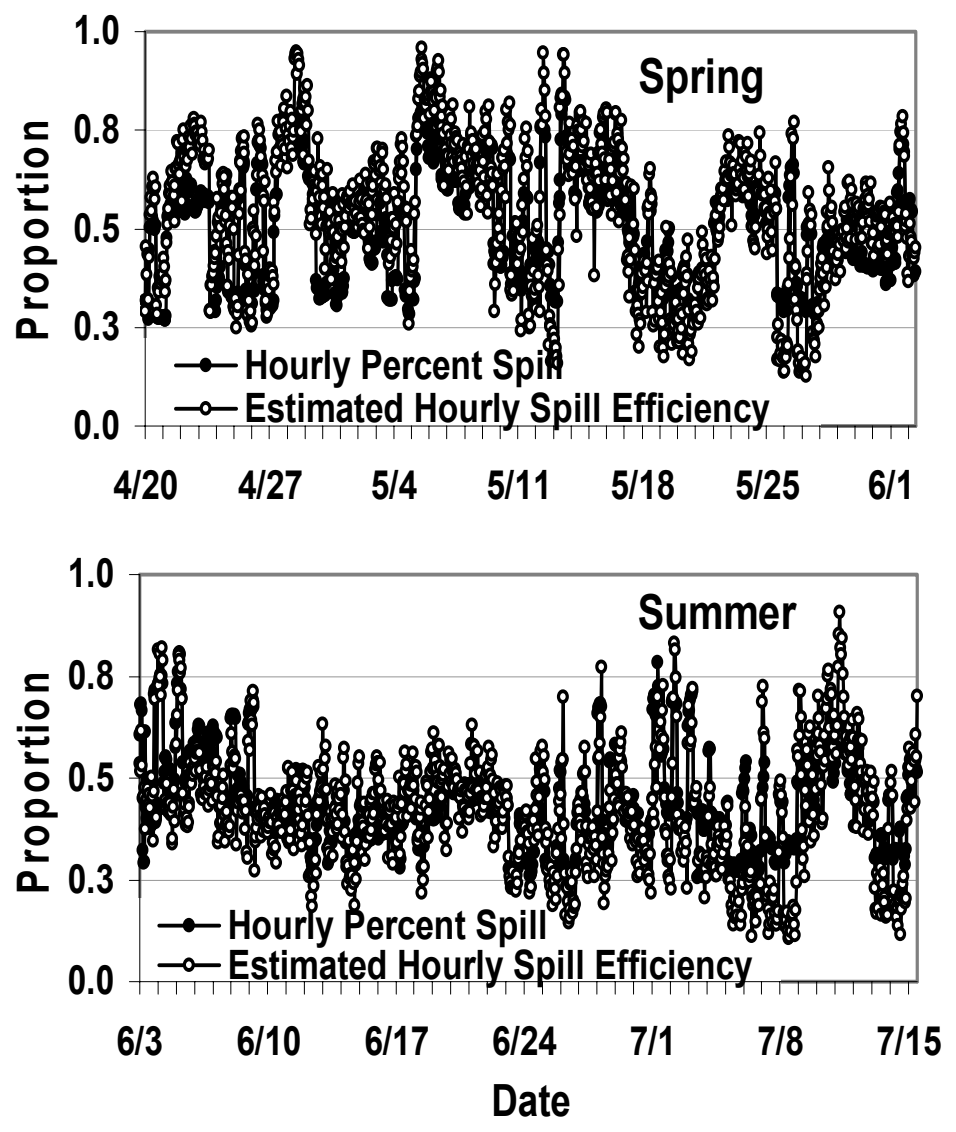

Figure 4.4. Time Histories of Hourly Percent Spill and Estimated Spill Efficiency at Bonneville Dam in Spring and Summer of 2002. The horizontal axis is marked in weekly increments. 

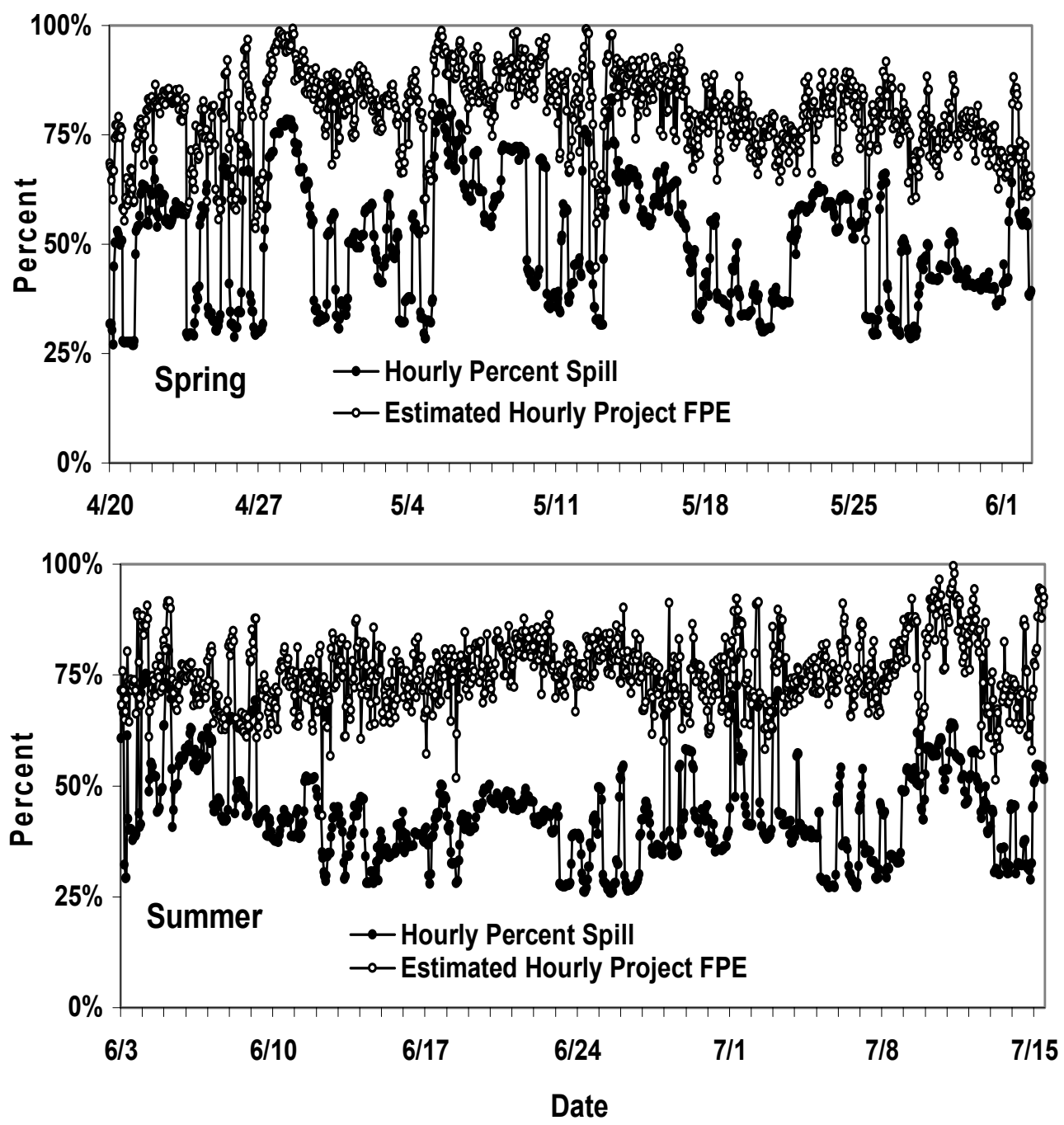

Figure 4.5. Time Histories of Hourly Percent Spill and Estimated Project Fish Passage Efficiency at Bonneville Dam in Spring and Summer of 2002. The horizontal axis is marked in weekly increments.

Although there is a lot of variability in estimated spill efficiency and FPE with discharge, there may be a threshold (perhaps $160 \mathrm{kcfs}$ in spring and somewhat higher in summer) above which the return for increased spill in improved spill efficiency or FPE may be very small or nonexistent. Of course this interpretation relies on the assumption of equal detectability of fish at all discharge rates (see Detectability Modeling Section 4.1 above). Figures 3.13 and 3.14 show spill efficiency and FPE as a function of spill discharge. Using spill efficiency normalizes spillway passage for fish availability, which is certainly the source of much of the variation in fish passage versus spill relations (Figure 3.10). Since spill over 200,000 cfs is unusual, we also examined the relations after the 107 hours with over $200 \mathrm{kcfs}$ spillway discharge had been deleted from the data sets. We found (Figure 3.15) that the quadratic fit of the summer spill efficiency data was improved substantially (over $25 \%, \mathrm{R}^{2}=0.20$ with spill over $200 \mathrm{kcfs}$ hours; $\mathrm{R}^{2}=0.45$ without). The change in the summer Project FPE vs. spill data was not significant. It is not surprising that FPE data is not as well correlated with spillway discharge as is spill efficiency since 
Project FPE includes guided passage at both powerhouses and at the B1 sluiceway. But the regression analysis of spill efficiency vs. spill especially, and of Project FPE to a lesser extent, provide support for the view that very high spill discharge, besides potentially harming fish in other ways, may not particularly increase or might even reduce spillway passage.

\subsubsection{Comparison with Radio Telemetry}

We start our spring season before our colleagues at the Cook, WA USGS laboratory, and they continue later into the summer than we do. They also take a short break between seasons. Therefore, in order for our passage estimates to be compared we must delete our early spring (before May 2) data and move our summer data from before June 9 into spring. The USGS workers cooperate closely with us and delete their data from after July 15 (our end date) for the comparison. This is the second year in which we have carried out this exercise.

For two radically different methods of estimating fish-passage metrics, most of the estimates were reasonably similar. All but one of the 18 pairs of estimates (98\%) were within 20\% of each other, $78 \%$ were within $15 \%, 65 \%$ were within $10 \%$, and $25 \%$ were within $5 \%$ (Table 3.1 ). Summer spill effectiveness estimates differed by $34 \%$, but as a ratio of ratios, effectiveness tends to amplify differences greatly. Summer spill efficiencies differed by only $14 \%$. We are thankful for the opportunity to compare estimates with those of our colleagues because it provides a better research product than results from either method alone. However, we were not surprised that the two methods provided different results. For example, radio telemetry estimates for two species in spring are averaged for comparison to hydroacoustic estimates, which are calculated from the passage of all species in the run at large.

The behavior and passage metrics for these two species often differ, which is the reason for obtaining separate estimates by tagging. However, the run at large includes both species in widely varying proportions over time, as well as other species such as coho $(O$. keta), sub-yearling chinook $(O$. tshawytscha), and sockeye salmon (Figure 3.22). In addition, the proportions of tagged yearling chinook and steelhead salmon are unlikely to match the proportions of those species in the run at large, given that the species composition of the smolt-index data ranged from $20-84 \%$ for yearling chinook, $0-60 \%$ for coho, and 2-25\% for steelhead salmon, and 0-68\% for sub-yearling chinook at (Figure 3.22). According to John Day Dam smolt-index data, juvenile sockeye salmon, which supposedly guide poorly at in-turbine screens, made up $25 \%$ of the spring run in 2002.

\subsection{Spatial Trends in Fish Passage}

\subsubsection{Horizontal Distributions}

Dam operations play an important role in the distribution of fish passage. In 2002, B2 had generation priority and B2 turbine units operated in about $82 \%$ of all possible turbine hours in spring and $89 \%$ in summer, whereas B1 turbine units ran in only about $30 \%$ of the possible turbine hours in spring and $65 \%$ in summer. The spill volume at the spillway was about evenly distributed across all 18 Bays in spring and summer (Figure 3.17). 
The proportion of discharge through the primary passage routes was generally a poor indicator of the relative proportion of fish passage among those same routes except on the scale of entire structures (Figure 4.2). For example, about $12 \%$ of the estimated fish passage and $11 \%$ of the discharge that passed the Project passed through B1 turbines and $52 \%$ of the fish and $49 \%$ of the discharge passed through the spillway in spring. In summer, an estimated $26 \%$ of total Project passage passed through B1 turbines in $21 \%$ of the Project discharge, and an estimated $42 \%$ passed the spillway in $44 \%$ of the discharge. The B1 sluiceway, which was very effective at passing juvenile salmon, was the reason that the percent of fish passage at B1 exceeded the proportion of flow to B1.

The B1 sluiceway entrance over Intake 7A clearly attracted and passed juvenile salmonids more effectively than any other route at the dam. Attraction is indicated by the density of fish passing there (Figures 3.18 and 3.21). The density of fish passing into Sluice Entrance 7A at B1 was 15,000 / M m3 in spring and 21,000 / M m3 in summer, and this would be about 12 and 29 times higher than the density of fish that passed through the most effective spill bay. It also would be about 21 and 27 times higher than the highest density passing into the average turbine.

If the District ever considers testing a removable spillway weir, we recommend locating it somewhere on the south half of the spillway to take advantage of the slight southerly skew in fish passage. The distribution of fish passage at the spillway was slightly skewed toward the south end in both seasons and did not correspond to the distribution of flow, which was fairly evenly distributed among bays, although slightly higher at end bays than at interior bays in both seasons. The southern half of the spillway (spill bays 10 through 18) passed 13 and 14\% more fish in spring and summer, respectively, than did the nine northern bays, largely due to low fish passage at bays 1 and 5. The southerly skew in passage distribution was even more apparent in spring and summer of 2000 (Ploskey et al. 2002b) and spring 2001 (Ploskey et al. 2002c) than it was in 2002.

A southern skew in the distribution of fish passage at B2 again suggests that the corner surface collector scheduled to come on line in 2004 will be highly successful. Southern units passed about 64 and $71 \%$ of the fish going through B2 in spring and summer, respectively, and units 11 and 12 accounted for 45.3 and $49 \%$ of the total each season. Estimated fish passage was especially low at Unit 18 (at the north end of B2), which discharged as much water as any other turbine unit at the project. Both Unit 11 and Unit 18 ran almost 100\% of the sampled hours in spring and summer. A mobile survey in 1996 showed high fish densities in the eddy upstream of the southern end of B2 (Units 11, 12, and 13) in both seasons (Ploskey et al. 1998). In 1998 when the sluice chute ran as a prototype surface collector, the combined FGE of unit 11-13 and sluice chute was 35\% higher in spring and 60\% higher in summer than the FGE of units 11-13 when the sluice chute was closed (Ploskey et al. 2001). In 2001, we also reported a southern skew in the distribution of fish passage at B2 (Ploskey et al. 2002c). 


\subsection{Temporal Trends in Fish Passage}

\subsubsection{Seasonal Trends}

\subsubsection{Run Timing}

Run timing estimated by hydroacoustics compared favorably with the smolt passage index by the Pacific States Marine Fisheries Commission, except for a peak around 23 April and two peaks around 3 June that were present in the hydroacoustic count (Figure 3.22). Interestingly, of the major peak detected by hydroacoustics on 23 April, 73\% passed at the spillway, 17\% passed as unguided at either powerhouse, and only $10 \%$ were guided by screens, which may explain why it was not apparent in the smolt index. This peak consisted of detections of some of the $3+\mathrm{M}$ hatchery fish released into the Bonneville pool a week earlier. The hatchery fish consisted of $1.45 \mathrm{M}$ yearling chinook salmon released from Carson Hatchery on 4/16, 1.00 M yearling chinook salmon released from Little White Salmon Hatchery on 4/18, and $0.97 \mathrm{M}$ coho salmon released from the Willard Hatchery on 4/18. Other peaks in hydroacoustic and JBS trends either coincided or the hydroacoustic peaks occurred on the day before the JBS peaks, which is plausible given smolt delays in orifice and JBS channels. The peaks in hydroacoustic counts between 2 and 8 June that were absent from the smolt index may be explained by hatchery releases from Prosser (1.7 M on 5/20 to 6/01 2002) and Umatilla (0.6 M from 5/20 to 5/31) adding numbers to the run at large. Of the $6 / 2$ peak in hydroacoustic data, $53 \%$ were spilled, $5 \%$ went through Sluice $7 \mathrm{~A}$, and $28 \%$ were unguided, leaving just $14 \%$ guided by screens.

\subsubsection{Major Fish Passage Metrics}

There was a slight downward trend in Project FPE and spill efficiency (Figure 3.24) and spill effectiveness (Figure 3.27) from spring through summer but all metrics varied nearly as much among days as over the seasons in 2002, as did percent spill through the project. Sluiceway 7A at B1 made a significant contribution to B1 FPE, as the former explained about $84 \%$ of the variation in the latter (Figure 3.25), and we observed more day-to-day variability than strong seasonal trends in B1 FPE (including sluiceway passage). Except for a couple of days, B2 FPE was significantly lower from about 28 May until 4 July than it was earlier in spring or later in summer (Figure 3.25). The increase in hydroacoustic estimates after 4 July may have been the result of contamination of samples by American shad because we would have expected B2 FPE to decline from spring to summer and not increase again based upon historical patterns. Numbers of adult American shad counted at fish ladders have increased significantly over the last 3 years of Project FPE studies at Bonneville Dam (Figure 3.28).

The daily estimates of FPE and spill efficiency were highly correlated with daily estimates of percent spill although the slope was less pronounced for Project FPE than for spill efficiency. The slope for Project FPE was less than that for spill efficiency because Project FPE includes other non-spill guided routes, which decrease in efficiency as percent spill increases, i.e., B1 sluiceway efficiency and B2 FPE. According to the regression line for Project FPE vs. percent spill, Project FPE would be about $60 \%$ if there were no spill, and this estimate is similar to an estimate of about 55\% in spring 2001 when there was no spill. 


\subsubsection{Guidance Efficiency at Modified Intake 17}

The FGE of modified Intake 17B had a typical spring-to-summer decline (Figure 3.27) that we expect for most Intakes at B2, but the decreasing trend at adjacent Intake 17C (same figure) was not as steep, for some unknown reason. Given that Intake 15B in 2001 (Figure 3.28 in Ploskey et al. 2002c) showed a spring-to-summer decrease similar to that at 17B in 2002 (Figure 3.27), we suspected that the trends may be more abrupt for Intakes between TIES than for those behind TIES. However, plotting seasonal trends in Intake FGE for every intake that ran all spring and summer suggests that the trends are more related to location along B2 than to the presence or absence of TIES (Figure 4.6). What might be contamination of late summer samples by American shad is most apparent at units 11-13, just downstream of the large eddy in the south part of the forebay. Most fish passed B2 at units 11 and 12 in both seasons, and this may explain why the seasonal pattern observed at those units was also apparent in the plot of B2 FPE by date (Figure 3.25).

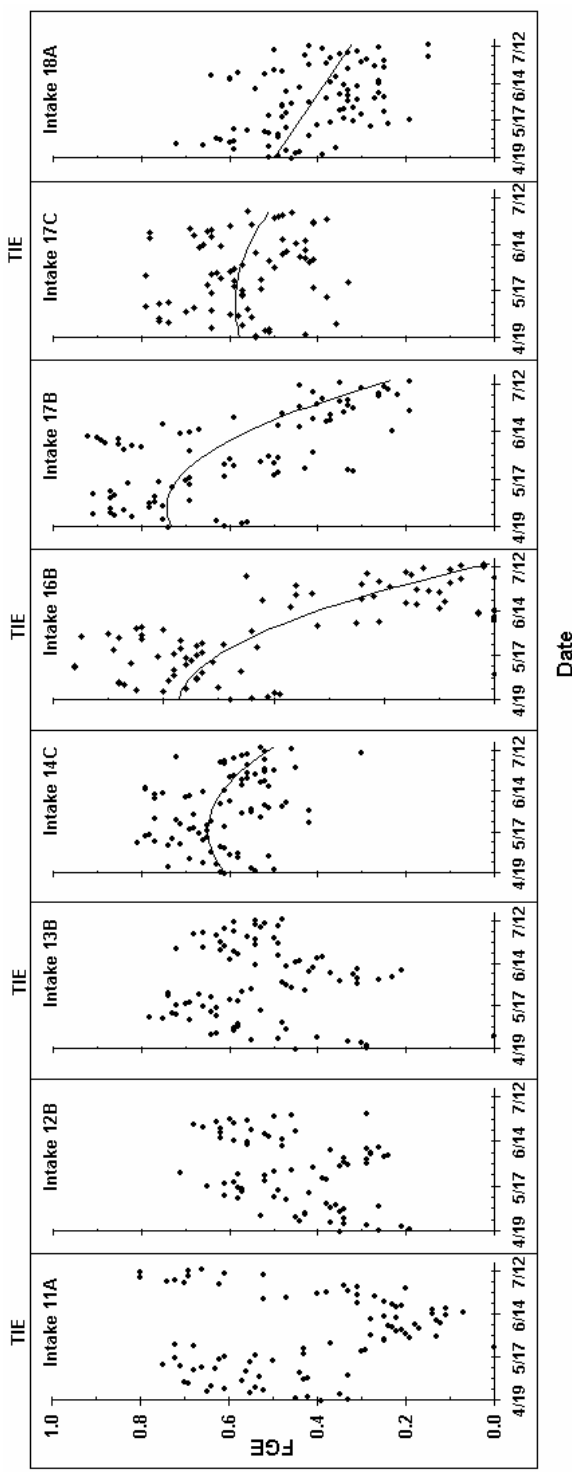

Figure 4.6. Plots of Seasonal Trends of Intake-specific FGE for B2 in 2002, with Labels Indicating the Intakes that were Behind, as Opposed to Between TIES. Intake 15B only ran during the spring and therefore was not plotted. 


\subsubsection{Diel Trends}

\subsubsection{Project-Wide Estimates and Spill}

Project FPE and spill efficiency estimates were both highest in the evenings and through the night, and this typical diel pattern is driven partly by fish behavior and partly by many nights having high spill and most days having low spill (Figure 3.29). In 2001, we saw a similar pattern for FPE in spring and summer and for spill efficiency in spring even though spill was constant 24-h per day, so we know that part of the pattern is the result of fish behavior. The day-night difference was less in summer than in spring, and summer estimated FPE, although always lower than in the same hour in spring, remained relatively higher after daylight (until about $0800 \mathrm{~h}$ ) and dropped relatively lower in the late afternoon and early evening. We suspect that sub-yearling smolts may have more difficulty holding in forebay areas during the day than yearling smolts. The straightforward diel trends were much simpler than the diel Project FPE data in 2000, when estimated Project FPE went up and down throughout the diel cycle in both seasons without a clear difference between day and night. It may be that high daytime guided passage by the PSC and high night passage at the spillway moderated the day-night difference in 2000.

The 2002 diel trends are most likely the most representative of a year of normal water availability and generation demand of the three years without the benefit of surface collection at B1 (see Ploskey et al. $2002 \mathrm{~b}$ and d), although conditions and operations always vary between seasons and among years. The diel trend in estimated Project FPE in 2001 was less consistent than in 2002. The drought and very high power demand in 2001 constrained the duration and level of spill in both seasons and spill, when it occurred at all, varied little day to night. It is also true that our sampling of the spillway was much more complete in 2002 than in either of the other years, especially 2001. Of course, Project FPE will probably be quite different and at B2 after the advent of the corner collector and bypass system in 2004 .

The diel peak in total fish passage in spring and summer is probably due to fish behavior and daytime delay of some individuals in the forebay areas until they lose visual cues and pass at twilight. For the whole project there was an evening peak in estimated project passage that coincided with twilight and with the hour of highest Project discharge (the 2100 hour in spring and the 2200 hour in summer). This has long been known to be typical of juvenile salmonid passage at northwestern dams. In general, surface passage, such as sluiceways and surface collectors have higher passage during daylight hours whereas turbine units and deep-passage spillways have higher passage at night (Thorne and Johnson 1993; Johnson and Giorgi 1999; Johnson and Carlson 2000; Ploskey et al. 2001a, 2001b; Ploskey et al. 2002a, $2002 \mathrm{~b}$, and 2002c). In the 2001 drought season, we found a strong diel trend in spillway passage (with higher passage at night) even with very nearly constant spillway discharge (Ploskey et al. 2002c).

Estimated spill passage peaked within an hour after sunset coincidental with the usual ramping up of spill discharge, but then began to a decline through 0400 hours, although discharge remained high until 0400 hours, and this pattern (Figure 3.31) may have implications for effective spill management. This may be because the preponderance of fish available in the spillway forebay passes in the evening peak and only fish that are newly arrived are available for passage thereafter. We had the same result, a reduction in estimated spillway passage as the night progressed, from The Dalles Dam in 1999 (Ploskey et al. 2001b) and at Bonneville Dam in 2000 (Ploskey et al. 2002b), although several studies have found other trends at The Dalles Dam (reviewed in Ploskey et al. 2001c). If the combination of higher spill and fish behavior predictably result in a reduction in spillway passage later in the night, then under low water 
availability or high dissolved gas constraints, the spillway operations might be modified to mitigate either problem. The night could start with high spillway discharge in the evening followed by lower spillway discharge later in the night to either conserve water or reduce gas entrainment, thereby rapidly passing the available juvenile fish in the spillway forebay. After midnight in spring and after 0200 in summer the spill discharge level might be somewhat reduced, if needed, with benefits to either water conservation or dissolved gas level reduction or both. These operations could be tested with a series of controlled experiments.

\subsubsection{Fish Guidance Efficiency and Passage at Turbines and the B1 Sluiceway}

The diel pattern in B1 fish passage is largely influenced by sluiceway passage, which is higher during the day than at night. The FPE of B1 FPE relatively constant throughout the diel cycle in both passage seasons, while fish passage undergoes rather large diel excursions with generally higher passage during the day than at night in both seasons (Figure 3.32). Total B1 passage estimates range from about 50,000 in the predawn (0200 and 0300) hours to over 200,000 in the early afternoon (1400 hour) in spring and from about 150,000 in the 0300 hour to over 250,000 around twilight (2100) hour in summer. Figure 3.33 presents the same data but without the sluiceway's contribution to either estimated passage or powerhouse FPE. Comparing the two graphs is instructive. Without the sluiceway's contribution, the diel record of spring estimated passage for turbines is much lower (never over 200,000) and much less varying throughout the day-night cycle than is the record for the turbines and the sluiceway. That is quite reasonable since our estimates of sluiceway passage in spring were about half of our estimates for B1 turbines only. The contour of spring passage with the sluiceway is especially higher during daytime, which is when surface passage is thought to predominate. The summer diel contour for FPE is fairly flat across the diel cycle both with and without the sluiceway but it is much higher with the sluiceway (from about $60-65 \%$ ) than without (from about 40-50\%). Contours of estimated fish passage with and without the sluiceway contribution in summer are almost identical, but paired optical camera and hydroacoustic data indicated that our hydroacoustic estimates of daytime sluiceway passage in summer are sometimes badly underestimated by insufficient range resolution of tightly schooled fish (Figures 3.36 and 3.37).

The relatively flat diel pattern of sluiceway passage in summer, which differed from the daytimedominated spring pattern by having slightly higher hourly rates at night, probably resulted from underestimates of sub-yearling fish passage when densities were highest during the day. Regression data comparing video and hydroacoustic estimates for the same daytime hours in spring and summer indicated that hydroacoustic counts kept up with camera counts in spring but fell very short in summer when camera densities were highest during the day. The spring data fit reasonably well $\left(\mathrm{r}^{2}=0.56\right)$ to a straight line, whereas the summer data was best described by a quadratic equation $\left(\mathrm{R}^{2}=0.52\right)$. Sub-yearling smolts passing over the weir in summer were often more tightly schooled than spring fish, which often passed as individuals. The hydroacoustic equipment and settings, especially the $200 \mu \mathrm{sec}$ pulse duration, were unable to resolve individual fish less than about 6-inches apart. Inter-fish distances in fish schools are typically a function of the length of individuals (Parris and Turchin 1997). The spring curve, in black, indicates a diel passage distribution that is typical of surface passage at northwestern dams (Thorne and Johnson 1993, Johnson and Carlson 2000, Ploskey et al. 2001a and $2002 \mathrm{a}$ and b). 


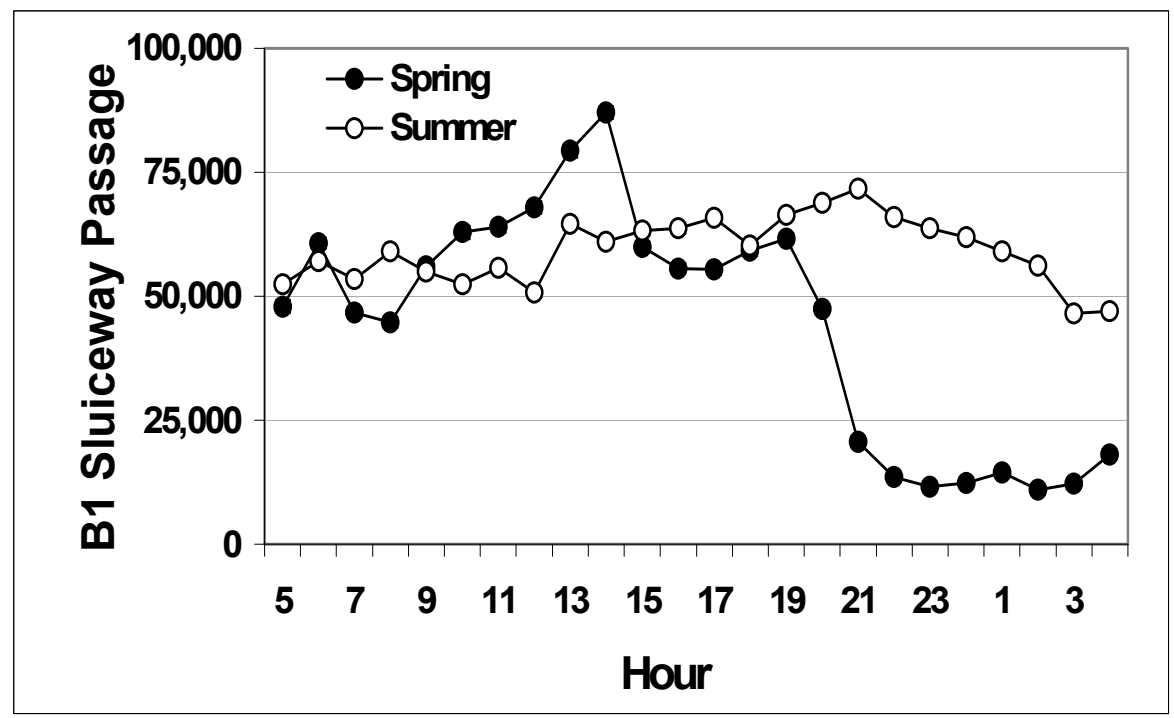

Figure 4.7. Diel Trends in Hydroacoustic Estimate of Fish Passage through B1 Sluiceway 7A. The spring curve shows a strong diel trend with much higher estimated sluiceway passage during daytime and lower estimates sluiceway passage at night. The summer curve shows much less variation among hours and lower estimated sluiceway passage during daytime (see text).

The $10 \%$ to $15 \%$ drop in B2 FPE at night from daytime (Figure 3.34) was consistent with what we observed in 1998 for units 11-13 (Ploskey et al. 2001) but different than what we observed in 2001, for unknown reasons. The patterns in 1998 and 2002 are easier to explain because more fish tend to be deep in the water column at night than they are during the day, as we observed during B2 forebay sampling in 2000 (Ploskey et al. 2002b). In 2001, the diel trend at B2 FPE was weak in spring when FPE was slightly lower from 1200 to 1500 than during other hours including the night, and summer FPE was higher from about 1800 through 0400 hours than from 0500 through 1700 hours.

We could not explain the difference among years, except that B2 operations were more sporadic in 2001 during the drought than they were in 1998 or 2002, when the powerhouse was more evenly loaded. The diel pattern in FGE may be more of curiosity than something with management implications, and more sampling will add consistency and clarity to the issue. At least the trend of higher nighttime passage of fish at B2 was consistent with what we observed in 2000 (Ploskey et al. 2002b) and 2001 (Ploskey et al. 2002c). If the lower nighttime FGE were the norm, that would be yet another reason to avoid using end units with the lowest FGEs at night. If units 11 and 12, and especially Unit 11, are operated in part to provide adult attraction flow for upstream passage adults it might be well to consider reducing their operations at night when adult salmonids do not enter ladders and many juveniles do pass through turbines. 


\subsection{Fish Guidance Efficiencies}

\subsubsection{Comparing Performance of Fish-Guidance Structures}

In 2002, the most important factors affecting FGE appeared to be related to modifications of units, including the presence of an ESBS instead of an STS at Unit 8, modified gatewells to increase flow up the slots of units 15 and 17, and unit location at B2. Factors that may result in differences in FGE among intakes include intake dimensions and depth, screen type, gatewell dimensions and flow, and the location of an intake among powerhouses, units, and within units (slot A, B, or C). Location at a powerhouse can determine proximity to structure (forebay sides, walls, or TIEs) or to forebay eddies. Unit 8 at B1 had the highest FGE of any unit at the Project in both spring and summer. It was followed by two units with modified gatewell slots and STSs (Unit 15 and 17) and one unmodified unit (14) near the center of B2 in spring and two unmodified units (10 and 14) in summer. It is important to note that FGE estimates for different units were not always computed for exactly the same days because units ran at different times. Therefore, time of day and day-to-day variation in FGE are a part of these estimates and comparisons.

Unlike results in 2000 and 2001, the FGE of the ESBS in Unit 8 in 2002 was as high in summer as it was in spring. In 2000 and 2001, Unit 8 FGE was significantly higher in spring than in summer, although the estimate in 2001 was based upon only 5 hours of operation for the entire summer season. A plot of Unit 8 FGE by sample date in 2002 indicates that FGE did fall off in summer, just not until early July instead of early June as it did in 2000 (Figure 4.8). In 2002, the late falloff in Unit 8 FGE, which began in the beginning of July, coincides with the major peak in run timing for sub-yearling chinook salmon on 30 June (Figure 3.22).

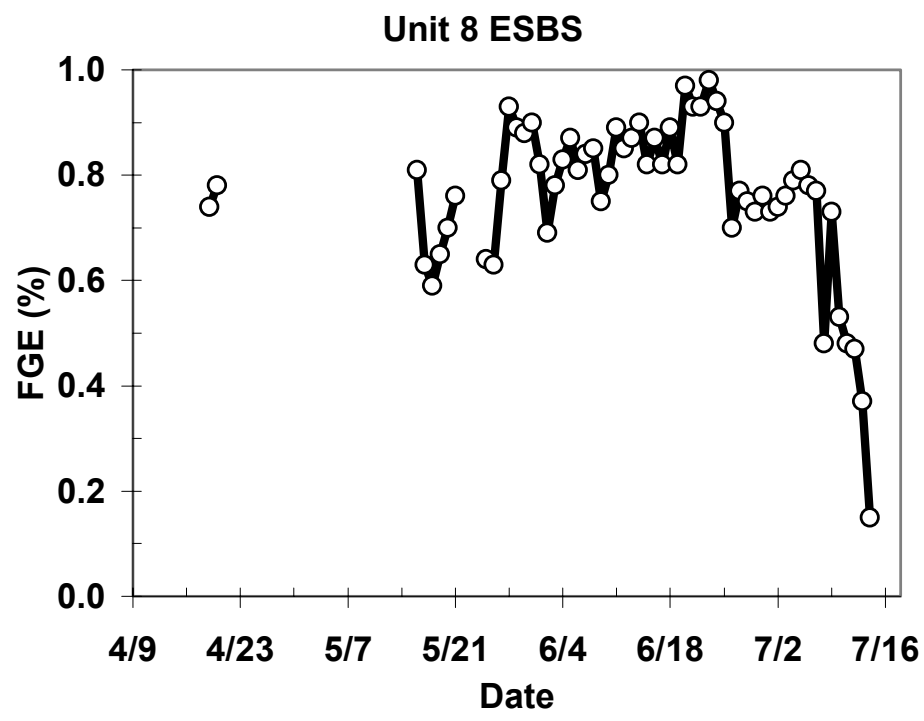

Figure 4.8. Seasonal Trend in the FGE of Unit 8 with an Extended Submerged Bar Screen

The reason for differences in Unit 8 performance was not related to the operation of adjacent units, although operations were quite different in the three summers. In 2000, managers gave the priority for generation to B1 to facilitate testing of the prototype surface collector. During about $74 \%$ of the hours that Unit 8 ran in summer 2000, units 7, 8, and 9 ran together, whereas simultaneous operation of the 
three units only occurred $41 \%$ of the time in 2002 . About $59 \%$ of the time that Unit 8 ran in summer 2002, units 7 and 8 ran without Unit 9. Nevertheless, in summer 2002, the mean FGE when only units 7 and 8 ran was $81 \%$ compared with $78 \%$ for times when all three units ran.

The $\mathrm{B}$ and $\mathrm{C}$ slots of $\mathrm{B} 2$ units and those intakes between TIES at B2 had significantly higher FGEs than did A slots or intakes behind TIES, respectively, probably because A slots have the highest flow, and TIEs create vortices that funnel fish down the face of the dam where they enter high in the intake and are easily guided. We found that intakes between TIES had 7-9 \% higher FGEs than do intakes behind TIES, a trend observed before (Gessel et al. 1991; Ploskey et al. 2002c), and B and C slots tended to have higher FGEs (10-17 \%) than A slots. The significance of an interaction term between slot and TIE treatments in a two-way ANOVA suggests that the relations are complex. In 2002, the B slot of Unit 17 had a higher FGE than did the $\mathrm{C}$ slot, and this likely was because the B slot was between two TIES. We observed a similar trend in 2001, when we sampled the B and C intakes of modified unit 15.

The operational priority of units at B2 results in a decrease in B2 FPE when percent spill increases because the end units, which have among the lowest FGEs at B2, keep running while center units with lower FGEs are shut down. Giving operational priority to end units makes sense for attracting adult salmonids to fish ladders during the day, but we recommend giving priority to center units at night when adult passage is minimal and juvenile passage is high. Our data suggest that B2 FPE could be increased by as much as $20 \%$ by shutting down the end units first at night. This is only critical when operational control is possible and required high spill levels dictate that some units must be taken off line. For example, operational control was good in spring 2002, and operators were able to achieve very high spill treatments by shunting water from the Powerhouses, but in early summer when river flow peaked, operators had less control over proportions of water in spill and turbines.

Provision of a B2 priority in spring was a good management tactic because B2 units tended to provide higher FGE than did those at B1, and the sluiceway at B1 was more efficient than it would have been if B1 had been fully loaded. Unit 8 with the ESBS ran more in 2002 than in 2001 and that also was good because of its high FGE. Unit 8 should be given a high priority in the future.

\subsubsection{Comparing FGE Estimates by Different Sampling Methods}

\subsubsection{Hydroacoustic and Camera Estimates of Sluice Passage}

Sampling Sluice Entrance 7A with optical cameras provided an independent estimate of fish passage which was correlated with estimates from a new side-looking hydroacoustic deployment, and both methods revealed similar horizontal distributions in fish passage. Comparison of results also provided valuable feedback about fish spacing and resolution limitations of the hydroacoustic gear used in 2002. The $200 \mu$ s pulse duration of the transducers provided a range resolution of about 6 inches, and this apparently was adequate to resolve most yearling fish at densities up to $8,000 \mathrm{fish} / \mathrm{h}$ in spring but not to resolve all sub-yearling chinook salmon in summer when densities exceeded about 4,000/h (Figure 3.37). Cameras revealed that the smaller subyearling fish were more closely packed in schools than were the yearling fish. The side-looking deployment is promising for sampling shallow, wide sluiceway entrances like those at B1, but clearly the resolution needs to be increased by increasing the bandwidth and shortening the pulse width. At the end of the 2002 sampling season, we had one 
transceiver and transducer modified to provide a range resolution of several centimeters, and we will be experimenting with that system for sampling sluiceway entrances in the future.

\subsubsection{Hydroacoustic versus Netting and Radio Telemetry Estimates}

Our estimates of FGE compared favorably with netting estimates by NOAA Fisheries in both seasons, particularly when we estimated FGE from all nighttime hours sampled (Figure 3.39) instead of just hours of concurrent sampling or all day and night hours. Hydroacoustic estimates of FGE require longer sampling durations than the 1 to 2 hours that are commonly used to estimate FGE by netting. Hydroacoustic beams sample only about $5 \%$ of the cross-sectional area of an intake compared to near $100 \%$ coverage by netting. For example, Ploskey and Carlson (1999) observed that the precision of hydroacoustic estimates of FGE at John Day Dam increased by $50 \%$, and the $r^{2}$ of a correlation line between hydroacoustic and netting estimates increased by $19 \%$, when the hydroacoustic sampling duration was extended from the typical netting duration of 1-2 h to $4 \mathrm{~h}$. In 2002, we were able to sample throughout the night after the NMFS finished netting because the unit was not left idle as it often was in 2001.

In 2002, we were able to assign zero counts to 1-minute samples collected when turbines were off because Dam operators provided exact on and off times for every turbine, and these data undoubtedly improved the accuracy of the FGE estimates by eliminating counts of un-entrained fish. Hydroacoustic equipment samples continuously, so it is important to know exactly when units are off. We recommend that future operations data include exact on and off times for turbines sampled with hydroacoustic methods.

We noticed that differences in hydroacoustic and radio telemetry estimates tended to be smaller when the number of fish detected by radio telemetry was higher, so we plotted differences as a function of the number of tagged fish detected at each unit in spring and summer and fit an exponential-decay curve to the data (Figure 4.9). We could not account for the largest differences of 33-39\% in spring or 30-44\% in summer between telemetry and netting or hydroacoustic estimates at Unit 17 by acoustic camera estimates of gap losses, which were only $13-15 \%$ of all guided and unguided fish. The fitted equation explained about $45 \%$ of the variation in observed differences, and the greatest differences occurred when detections were $<30$ tagged fish per unit. The data suggest that with $>30$ detections differences of \pm $15 \%$ can be expected. Eighty percent of the 16 seasonal estimates of FGE for B2 units by telemetry and hydroacoustics were within $\pm 10 \%$ of each other.

The horizontal distribution of fish passage at B2 suggests that the corner collector scheduled for operation in 2004 will pass many fish. Both hydroacoustic sampling and radio telemetry detections indicated that the distribution of fish passage at B2 was strongly skewed to the south end of the powerhouse in spring, and hydroacoustic sampling also showed a similar southerly skew in summer. Similarities in the horizontal distribution of fish passage at B2 in spring and differences in summer (Figure 3.40) might be explained by a relatively greater effect of tagging on sub-yearling fish than on yearlings. If tagged sub-yearlings were more fatigued than there untagged counterparts in summer then they might be more likely to pass at whatever unit they first contact. Water entering the B2 forebay approaches center units first because large eddies occur on the north and south sides. The southerly skew in the hydroacoustic distribution in summer would require fish to avoid passing through center units and to move laterally toward the south. The probability of avoiding entrainment and moving south may be 
higher for untagged than for tagged sub-yearling fish, and tagged and untagged yearlings may behave similarly because the effects of tagging are less with the larger fish.

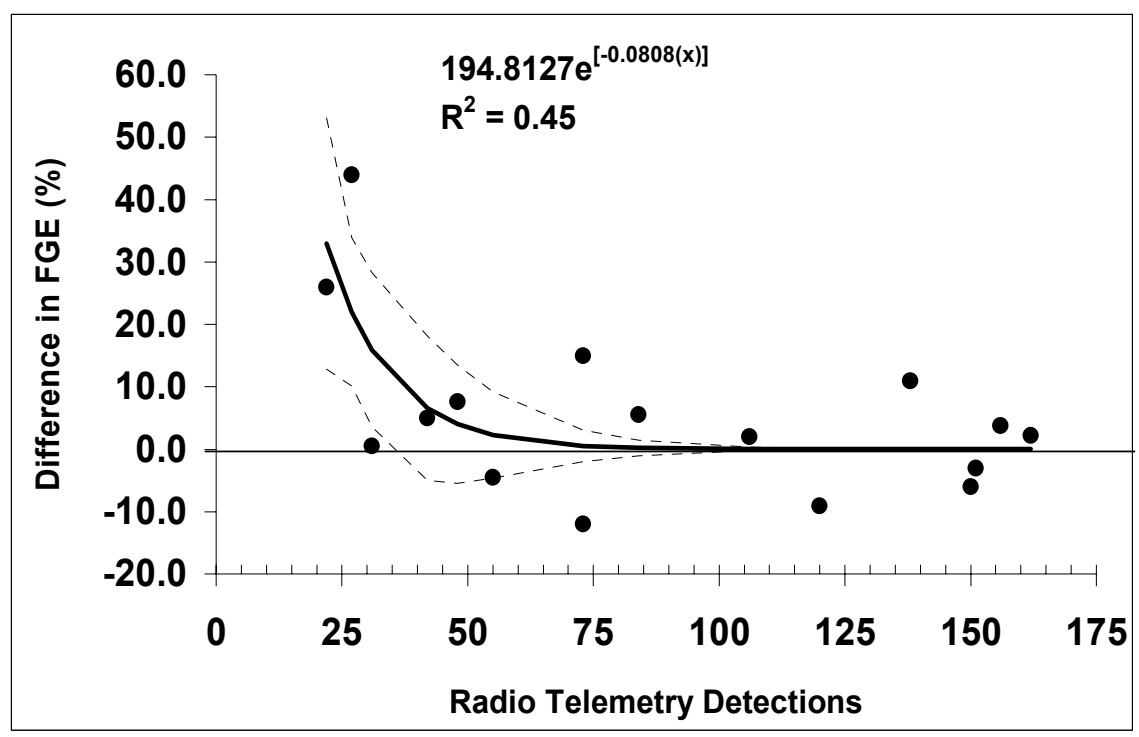

Figure 4.9. Plot of the Difference (Hydroacoustic - Radio Telemetry) in Estimates of FGE as a Function of the Total Number of Radio-tagged Fish Detected at a Turbine Unit. Dotted lines represent upper and lower $95 \%$ confidence limits on the regression line.

\subsection{Implications of Gap Losses}

There appears to be a disparity between gap loss estimates by netting and those made by imaging devices. According to gap sampling by NOAA Fisheries using a gap net, losses of fish typically range from $1-2 \%$, and the highest reported netting estimate was about $12 \%$ for a STS lowered $1.2 \mathrm{~m}$ below the normal position (Gessel et al. 1991). In 2002, the STSs in unmodified units of B2 had a gap of about 0.76 $\mathrm{m}$, and the gap should have been narrower in modified units with gap-closure devices. Our estimates of gap loss ranged from 13 to $15 \%$ of all guided and unguided fish, and this estimate is higher than that reported in netting studies, including the study by Bruce Monk (NMFS) at Unit 17 (gap loss $<2 \%$ ) this year. Using optical video cameras, Nestler and Davidson (1995), reported that 12 to $37 \%$ of the smolts initially guided by an ESBS at McNary Dam were lost to the gap between the VBS and the ESBS. We recommend additional evaluations of gap loss using the acoustic camera and optical cameras (for verification) in future years.

Losses of fish between the top of the STS and the bottom of the intake ceiling may explain some of the difference between FGE estimates by hydroacoustics, netting, and radio telemetry (Figure 3.41), provided that some gap lost fish are detected by radio telemetry antennas mounted on the downstream side of the STS. If gap losses are included in estimates by radio telemetry, partially included in netting estimates, and not included in hydroacoustic estimates, managers can view hydroacoustic and netting estimates as the potential FGE that could be achieved and telemetry estimates as the worst case including gap loss. We recommend an assessment of the potential for telemetry antennas to detect gap lost fish. Hydroacoustic estimates of guided fish in this report and previous reports have no correction for gap loss, 
but this year, using an acoustic camera, we estimated gap losses ranging from 26 to $41 \%$ of guided fish and $13-15 \%$ of all guided and unguided fish in intakes 13B, 17C, and 18A. The high gap loss at Intake $17 \mathrm{C}$ was a surprise, because we expected it to be like that of Intake $17 \mathrm{~B}$ ( $4 \%$ of guided and $2.7 \%$ of the total). Both $17 \mathrm{~B}$ and $17 \mathrm{C}$ had gap closure devices and turning vanes designed to increase flow up the slots, and these modifications presumably would reduce gap losses but did not in Intake 17C. There may be differences among slots in a unit based upon differences in the amount and direction of flow, and this potential needs to be investigated further.

Our effort to detect losses of fish through the side gap between the intake wall and the side of the STS with the acoustic camera were inconclusive because even the best aiming angle only allowed us to see about $3 \mathrm{ft}$ of the gap near the tip of the STS. An expanded estimate of side gap loss would only yield 1320 fish lost over a $24 \mathrm{~h}$ period, which is $<3 \%$ of the expanded estimates of numbers in the gatewell. Although the field of view of the acoustic camera was not ideal, and our expansion assumes that side-gap loss is uniform along the length of the STS, this preliminary estimate of side-gap loss does not seem to be significant, which agrees with previous netting studies (John Ferguson, NOAA Fisheries - Personal Communication).

\subsection{Comparison of Major Metrics from 2000 through 2002}

The three years of full Project FPE studies conducted in 2000-2002 yielded a baseline of metrics with a great deal of variability (Table 3.7) because operational strategies and river flow varied greatly among years. A goal of the multi-year effort was to establish a baseline for evaluating future management improvements. We found significant differences in most metrics in two or three of the years studied. For example, Project FPE and spill efficiency were lower in 2001 than in 2000 or 2002, because of drought that limited the duration and amount of spill. Spill effectiveness was lower in spring 2001 than it was in spring of 2000 or 2002, but it was higher in summer 2001 than it was in summer of 2000 or 2002 . The FPE of B1 was higher in 2000 than it was in 2001 or 2002 because the B1 PSC was tested and it was highly efficient in both seasons.

About the only metric than did not vary a lot among years was B2 FPE, where estimates for all three years were within $4 \%$ of each other in spring and within $11 \%$ of each other in summer. The B2 FPE probably would have lower in 2000 if that had been a low-water year, because generation priority was given to B1 to facilitate PSC testing, and unit outages at B2 would have been the more efficient center units. However, 2000 was a normal water year and unit outages at B2 were not excessive. Unit outages at B2 certainly were nothing like those observed at B1 in 2001 and 2002, when managers switched the generation priority to B2 because fish survival through B1 was poor. We sampled shallow sluiceway entrances at B1 as part of the full-Project FPE study for the first time in 2002, and results clearly indicate that the contribution of even small surface bypass routes can be very significant and should not be ignored. Not sampling B1 sluice entrances in 2000 and 2001 was an oversight, but did not diminish the usefulness of comparisons of route-specific metrics among years, as previous sections of this Discussion illustrate.

\subsection{Effects of Spill Treatments or Conditions}

High spill (day or night) increased spill efficiency $>20 \%$ over low-day spill each season, but effects on Project FPE were modest in spring (+ 7.6 to $10 \%$ ) were not significant in summer. Modest gains in 
Project FPE likely result from significantly lower B1-sluice efficiency and B2 FPE during high day or night spill than during low-day spill. During high spill, many fish that might have otherwise passed through the B1 sluiceway or the JBS at either powerhouse were spilled instead, so the major increase in spill efficiency by spilling more may not directly translate into a meaningful benefit unless passage by spill is preferable to passage by other routes. In two-way ANOVAs examining effects of spill-treatment, 4-day treatment blocks, and the interaction between block and treatment in spring (Appendix G-2), 4-day treatment block usually was significant, indicating that metrics changed significantly during the season. The interaction of treatment block and spill treatment also was significant or nearly significant for many metrics, indicating that spill-treatment effects depend upon time-related variables, perhaps run-timing of various juvenile salmonids, hydrology, or water temperature.

There were eight days and nine nights of high spill in spring require shutdown of all B1 turbines and this unusual condition produced 100\% FPE at B1 as all fish passed through the sluiceway. The analysis of variance that showed a major increase in B1 FPE during high spill treatments is spurious because of the inclusion of these data. We would have expected no effect, as observed when those data were excluded (Figure 3.42) or even a decrease in B1 FPE with increased spill, as observed in summer. The annual hydrograph peaked in summer, and many B1 turbines ran even during the days and nights of highest spill so that there were observations with $100 \% \mathrm{~B} 1 \mathrm{FPE}$. 


\subsection{Recommendations}

1. If $\mathrm{B} 1$ priority is to be reduced even further, managers might want to consider effects on water quality (temperature and $\mathrm{O}_{2}$ ) and use mobile hydroacoustic monitoring in case a sizeable number of smolts enter the B1 arm of the Bonneville Dam forebay and delay there. We estimate that in 2002 some $19 \%$ of the total project fish passage went through B1 in only about $11 \%$ of the discharge in spring and about $37 \%$ passed there in summer in about $21 \%$ of the Project discharge.

2. B1 sluiceway passage opportunities should be increased because the entrance at Intake 7A was the most effective passage route at the dam in 2002. The density of fish passing there was many times higher than at any other route. The intake at 7A was especially effective at collecting fish because its entrance flow was not limited by channel capacity, and its proximity to the pier between units 6 and 7 may have helped. If the sluiceway channel can handle the discharge, gates toward the south end (e.g., unit 5 or 6 and perhaps at Unit 2) might be opened to provide additional surface-bypass flow. Existing hydroacoustic and radio telemetry data could inform that choice.

3. We recommend closing B1 Sluiceway Entrance 10C, because unlike entrances further south, 10C has very low entrance volume and velocity, and fish are milling there rather than entering the sluiceway. Data indicate that $10 \mathrm{C}$ passes relatively few fish and may be collecting smolts in that corner where they are subject to delay and predation. If a sluice entrance is needed toward the north end of B1, hydraulic modeling studies can determine the first entrance (from the north) that is not limited by channel capacity.

4. Future hydroacoustic studies at B1 must sample every sluiceway entrance where entrance flow is not limited by channel capacity because passage is too high to ignore in FPE calculations. We also recommend a side-looking deployment with transducers mounted on the chain gates because passage estimates were highly correlated with estimates from four optical cameras.

5. We recommend testing equipment in fall 2003 by sampling juvenile American shad at one sluiceway entrance with hydroacoustic gear and optical cameras. The testing will help us identify needed improvements and allow time to prepare all required systems and transducers for sampling sluiceway entrances in spring 2004. Sampling sluiceway entrances is very important and may become more important if additional B1 entrances are opened or when the B2 corner collector comes on line in 2004. We have a prototype system that features increased bandwidth, shorter pulse duration, and much higher resolution, but it needs to be tested before the outmigration of 2004.

6. Generation priority should be given to center units at B2 at night when adult passage is minimal and juvenile passage is high. Hydroacoustic data suggest that B2 FPE could be increased by as much as $20 \%$ by shutting down the end units first at night. At B2, the FGEs of turbine units 11 , 12, and 18 have been consistently lower than the others on the powerhouse. Units 11 and 12 also pass many more fish than do any of the other units. Of course unforeseen consequences, such as effects on adult lamprey migration or changes in tailrace egress, should be considered. Also, conditions at B2 may be very different after the operation of the new corner collector adjacent to units 11 and 12.

7. There may be reasons for giving generation priority to one powerhouse over the other (e.g., differences in survival), but the decision should not be made solely based upon FPE estimates 
made from ignoring one or the other powerhouse. The examination of metrics calculated for only B2 and the spillway (ignoring fish passage at B1) lacks valid statistical inference. Although units at B1 were off during $70 \%$ of all possible unit hours in spring and 35\% in summer, those operations are quite different from no B1 operation. If B1 were truly off or most fish traveling down the Oregon side of the river were somehow kept from entering the B1 forebay, Project FPE and spill efficiency might be higher than what we can calculate by ignoring B1 fish passage. Calculations cannot account for fish densities in the river, the effect of density on fish behavior, or the closer proximity of fish passing down the Oregon side of the river to the spillway than to B2. The density of fish passage at B1 was higher than it was at the spillway or B2, so eliminating or reducing passage at B1 could greatly increase Project FPE and spill efficiency. Our exercise in computing FPE for only the spillway and B2 inevitably produces estimates considerably higher than those that are computed for the entire project, but the same result occurs if only B1 and the spillway are used in calculations.

8. Given the narrow entrance to the B1 forebay and the high density of fish passage at B1, we recommend that managers experiment with behavioral ways to shunt fish to the spillway (e.g., turbulence producing propellers).

9. If $\mathrm{B} 1$ generation is given low priority in the future, Unit 8 should be given among the highest operational priority because it provided the highest FGE of any turbine at Bonneville Dam in 2002.

10. In case of the need to either conserve water or limit dissolved gasses downstream, there may be an opportunity to reduce spillway discharge after the high passage pulse that occurs between 2000 $\mathrm{h}$ and midnight in spring without much cost to spillway passage and FPE. The opportunity is probably less in summer but some savings in discharge and either generation or dissolved gas might be achieved then as well. We observed a pulse in spillway passage that coincides with the onset of higher nighttime spill in both spring and summer, but spillway passage estimates fall off considerably as the night progresses, although spill discharge stays high. This was especially so in spring 2002, when spillway passage estimates dropped off considerably after midnight.

11. If the District considers testing a removable spillway weir, we recommend locating it somewhere on the south half of the spillway to take advantage of the slight southerly skew in fish passage.

12. We recommend that future operations data include exact on and off times for turbines sampled with hydroacoustic methods, as they did in 2002 . We were able to assign zero counts to 1 -minute samples collected when turbines were off because Dam operators graciously provided exact on and off times for every turbine, and these data undoubtedly improved the accuracy of the FGE estimates by eliminating counts of un-entrained fish. Hydroacoustic equipment samples continuously, so it is critical to know exactly when units are off.

13. We recommend additional evaluations of gap loss using the acoustic camera and optical cameras (for verification). There appears to be a disparity between gap loss estimates by netting and those made by imaging devices. The highest estimates of gap loss from the acoustic camera ranged from $13 \%$ to $15 \%$ of all guided and unguided fish and $26 \%$ to $41 \%$ of the guided fraction, and these estimates were higher than those reported in netting studies.

14. We recommend an assessment of the potential for telemetry antennas to detect gap lost fish. Losses of fish between the top of the STS and the bottom of the intake ceiling may explain some of the difference between FGE estimates by hydroacoustics, netting, and radio telemetry, if some 
tagged fishes passing through the gap were detected by radio telemetry antennas mounted on the downstream side of the STS.

15. We recommend conducting additional studies to determine why gap losses at Intake $17 \mathrm{C}$ were so high, while those at Intake 17B were so low, even though both intakes had modified gatewell slots, turning vanes, and gap-closure devices. There may be differences in gap loss among slots in a unit based upon differences in the amount and direction of flow.

16. Managers should consider running a log boom from the north shore to the tip of Cascades Island to guide surface-oriented fish to the spillway, reduce timber loading in the B2 forebay, and increase boater safety after the large corner collector becomes functional in 2004. 
Hydroacoustic Evaluation of Fish Passage through Bonneville Dam in 2002 


\subsection{References}

BioSonics, Incorporated. 1998. Hydroacoustic Evaluation and Studies at Bonneville Dam, Spring/Summer 1997. Contract Report to the U.S. Army Corps of Engineers Portland District, Portland, Oregon.

Gessel, M. H., B. H. Monk, and J. G. Williams. 1988. Evaluation of the Juvenile Fish Collection and Bypass Systems at Bonneville Dam 1987. Annual Report by the U.S. Department. Commerce, National Oceanic and Atmospheric Administration, National Marine Fisheries Service, Coastal Zone and Estuarine Studies Division to the U.S. Army Engineers Portland District, Portland, Oregon.

Gessel, M. H., J. G. Williams, D. A. Brege, and R. F. Krcma. 1991. "Juvenile Salmonid Guidance at the Bonneville Dam Second Powerhouse, Columbia River, 1983-1989." North American Journal of Fisheries Management 11:400-412.

Hawkes, L. A., R. D. Martinson, R. F. Absolon, and S. Killins. 1991. Monitoring of Downstream Salmon and Steelhead at Federal Hydroelectric Facilities. Annual Report 1990 by the U.S. Department. Commerce, National Oceanic and Atmospheric Administration, National Marine Fisheries Service, ETSD, to the U.S. Department of Energy, Bonneville Power Administration, Portland, Oregon.

Johnson, G. E. and T. J. Carlson. 2000. Monitoring and Evaluation of the Prototype Surface Collector at Bonneville First Powerhouse in 2000: Synthesis of Information on PSC Performance. U. S. Army Corps of Engineers Draft Report prepared by BioAnalysts, Inc and Battelle.

Johnson, G. E. and A. E. Giorgi. 1999. Development of Surface Flow Bypasses at Bonneville Dam: A Synthesis of Data from 1995 to 1998 and a Draft M\&E Plan for 2000. Draft final report submitted October 8, 1999 to Portland District, U.S. Army Corps of Engineers, Portland, Oregon.

Krcma, R. F., D. DeHart, M. Gessel, C. Long, and C. W. Sims. 1982. Evaluation of Submersible Traveling Screens, Passage of Juvenile Salmonids through the Ice-Trash Sluiceway, and Cycling of Gatewell-Orifice Operations at the Bonneville First Powerhouse, 1981. Final Report by the U.S. Department Commerce, National Oceanic and Atmospheric Administration, National Marine Fisheries Service, Coastal Zone and Estuarine Studies Div. to the U.S. Army Engineer District, Portland, Oregon.

Love, R. H. 1977. "Target Strength of an Individual Fish at any Aspect." Journal of the Acoustical Society of America 62(6):1397-1403.

Magne, R. A., D. J. Rawding, and W. T. Nagy. 1986. Hydroacoustic Monitoring at the Bonneville Dam Second Powerhouse during 1986 Fish Guiding Efficiency Tests. Fishery Field Unit, U.S. Army Engineer District, Portland, Oregon.

Magne, R. A. 1987. Hydroacoustic Monitoring at the Bonneville Dam Project in 1987. Fishery Field Unit, U.S. Army Engineer District, Portland, Oregon.

Magne, R. A., R. J. Stansell, and W. T. Nagy. 1989. A Summary of Hydroacoustic Monitoring at the Bonneville Dam Second Powerhouse in 1988. Fishery Field Unit, U.S. Army Engineer District, Portland, Oregon. 
Muir, W. D., A. E. Giorgi, W. S. Zaugg, and B. R. Beckman. 1989. An Assessment of the Relationship between Smolt Development and Fish Guidance Efficiency at Bonneville Dam. Annual Report by the National Marine Fisheries Service, Coastal Zone and Estuarine Studies Division, Northwest Fisheries Center, Seattle, Washington.

Nestler, J. M. and R. A. Davidson. 1995. Imaging smolt behavior on bypass screens and a vertical barrier screen at McNary Dam in 1992. Technical Report EL-95-21, U.S. Army Corps of Engineer Waterways Experiment Station, Vicksburg, MS.

NMFS (National Marine Fisheries Service). 2000. Biological Opinion. Reinitiation of consultation of the Federal Columbia River Power System, including the juvenile fish transportation program and 19 Bureau of Reclamation projects in Columbia Basin.

Parrish, J.K. and P. Turchin. 1997. Individual decisions, traffic rules, and emergent pattern in schooling fish. In: Animal Groups in Three Dimensions. J.K. Parrish and W.M. Hamner (eds). Cambridge University Press, New York. 126-142.

Ploskey, G. R., P. N. Johnson, W. T. Nagy, M. G. Burczinski, and L. R. Lawrence. 1998. Hydroacoustic Evaluations of Smolt Passage at Bonneville Dam Including Surface Collection Simulations. USAE Waterway Experiment Station Technical Report EL-98-4 prepared for the U.S. Army Engineer District, Portland, Oregon.

Ploskey, G. R. and T. J. Carlson. 1999. "Comparison of Hydroacoustic and Net Estimates of Fish Guidance Efficiency of an Extended Submersible Bar Screen at John Day Dam.” North American Journal of Fisheries Management 19:1066-1079.

Ploskey, G. R., W. T. Nagy, L. R. Lawrence, D. S. Patterson, C. R. Schilt, P. N. Johnson, and J. R. Skalski. 2001a. Hydroacoustic Evaluation of Juvenile Salmonid Passage through Experimental Routes at Bonneville Dam in 1998. Technical Report ERDC/EL TR-01-2, U.S. Army Engineer Research and Development Center, Vicksburg, MS.

Ploskey, G. R., W.T. Nagy, L.R. Lawrence, M.E. Hanks, C.R. Schilt, P. N. Johnson, G. E. Johnson, D. S. Patterson, and J. R. Skalski. 2001b. Hydroacoustic Evaluation of Juvenile Salmon Passage at The Dalles Dam: 1999. Technical Report ERDC/EL TR-01-11, U.S. Army Engineer Research and Development Center, Vicksburg, MS.

Ploskey, G,. T. Poe, A. Giorgi, and G. Johnson. 2001c. Synthesis of Radio Telemetry, Hydroacoustic, and Survival Studies of Juvenile Salmon at The Dalles Dam (1982-2000). Final report Contract Number DACW57-00-D-0009, Task Order Case No. 3. Prepared for the U.S. Army Corps of Engineers, Portland, OR by Battelle Pacific Northwest National Laboratory and BioAnalysts, Inc.

Ploskey, G.R., C.R. Schilt, M.E. Han ks, J.R. Skalski, W.T. Nagy, P.N. Johnson, D.S. Patterson, J. Kim, and L. Lawrence. 2002a Hydroacoustic Evaluation of a Prototype Surface Collector and In-Turbine Screens at Bonneville Dam First Powerhouse in 2000. Technical Report ERDC/ELTR-02-15 of the U.S. Army Research and Development Center, Waterways Experiment Station, Vicksburg, Mississippi.

Ploskey, G.R., C.R. Schilt, M.E. Hanks, P.N. Johnson, J.R. Skalski, W.T. Nagy, P.N. Johnson, D.S. Patterson, J. Kim, and L. Lawrence. 2002b. Hydroacoustic Evaluation of Fish Passage through 
Bonneville Dam in 2000. Technical Report ERDC/ELTR-02-8 of the U.S. Army Engineer Research and Development Center, Waterways Experiment Station, Vicksburg, Mississippi.

Ploskey, G.R., C.R. Schilt, M.E. Hanks, P. N. Johnson, J. Kim, J.R. Skalski, D.S. Patterson, W.T. Nagy, and L.R. Lawrence. 2002c Hydroacoustic Evaluation of Fish-Passage Efficiency at Bonneville Dam in 2001. Final Report PNNL-14047. Pacific Northwest National Laboratory, Richland, WA.

Stansell R. J., R. A. Magne, W. T. Nagy, and L. M. Beck. 1990. Hydroacoustic Monitoring of Downstream Migrant Juvenile Salmonids at Bonneville Dam, 1989. Fishery Field Unit, U.S. Army Engineer District, Portland, Oregon.

Thorne, R. E. and E. S. Kuehl. 1989. Evaluation of Hydroacoustics Techniques for Assessment of Juvenile Fish Passage at Bonneville Powerhouse I. Final Report by BioSonics Inc., Seattle, WA for the U.S. Army Engineer District, Portland, Oregon.

Thorne, R.E. and G.E. Johnson. 1993. A review of hydroacoustic studies for estimation of salmonid downriver migration past hydroelectric facilities on the Columbia and Snake Rivers in the 1980s. Reviews in Fisheries Science 1 (1) 27-56.

Uremovich, B. L., S. P. Cramer, C. F. Willis, and C. O. Junge. 1980. Passage of Juvenile Salmonids through the Ice-Trash Sluiceway and Sqawfish Predation at Bonneville Dam, 1980. Oregon Department of Fish and Wildlife Annual progress report prepared for the U.S. Army Engineer District, Portland, Oregon.

Willis, C. F. and B. L. Uremovich. 1981. Evaluation of the Ice and Trash Sluiceway at Bonneville Dam as a Bypass System for Juvenile Salmonids, 1981. Oregon Department of Fish and Wildlife Annual progress report prepared for the U.S. Army Engineer District, Portland, Oregon.

Wood, L. A., R. D. Martinson, R. J. Graves, D. R. Carroll, S. D. Killins. 1994. Monitoring of Downstream Salmon and Steelhead at Federal Hydroelectric Facilities. Annual Report 1993 by the U.S. Department. Commerce, National Oceanic and Atmospheric Administration, National Marine Fisheries Service, ETSD to the U.S. Dep. Energy, Bonneville Power Administration, Portland, Oregon. 
Hydroacoustic Evaluation of Fish Passage through Bonneville Dam in 2002 